\title{
Bismuth Surfactant Effects for GaAsN and Beryllium Doping of GaAsN Grown by Molecular Beam Epitaxy
}

Ting Liu

West Virginia University

Follow this and additional works at: https://researchrepository.wvu.edu/etd

Part of the Electrical and Computer Engineering Commons

\section{Recommended Citation}

Liu, Ting, "Bismuth Surfactant Effects for GaAsN and Beryllium Doping of GaAsN Grown by Molecular Beam Epitaxy" (2007). Graduate Theses, Dissertations, and Problem Reports. 4128.

https://researchrepository.wvu.edu/etd/4128

This Dissertation is protected by copyright and/or related rights. It has been brought to you by the The Research Repository @ WVU with permission from the rights-holder(s). You are free to use this Dissertation in any way that is permitted by the copyright and related rights legislation that applies to your use. For other uses you must obtain permission from the rights-holder(s) directly, unless additional rights are indicated by a Creative Commons license in the record and/ or on the work itself. This Dissertation has been accepted for inclusion in WVU Graduate Theses, Dissertations, and Problem Reports collection by an authorized administrator of The Research Repository @ WVU.

For more information, please contact researchrepository@mail.wvu.edu. 


\section{Bismuth Surfactant Effects for GaAsN and Beryllium Doping of GaAsN Grown by Molecular Beam Epitaxy}

Ting Liu

Dissertation Submitted to the College of Engineering and Mineral Resources

at

West Virginia University

In Partial Fulfillment of the Requirements for the Degree of

Doctor of Philosophy

In

Electrical Engineering

Dimitris Korakakis, Ph.D., Chair

Thomas H. Myers, Ph.D.

Lawrence A. Hornak, Ph.D.

Charter D. Stinespring, Ph.D.

Xian-an Cao, Ph.D.

Lane Department of Computer Science and Electrical Engineering

Morgantown, West Virginia

2007

Keywords:

GaAsN, Molecular Beam Epitaxy, Bismuth Surfactant, Beryllium Doping

Copyright 2007 Ting Liu 
UMI Number: 3300906

\section{$\mathrm{UMI}$}

UMI Microform 3300906

Copyright 2008 by ProQuest Information and Learning Company. All rights reserved. This microform edition is protected against unauthorized copying under Title 17, United States Code.

ProQuest Information and Learning Company 300 North Zeeb Road

P.O. Box 1346

Ann Arbor, MI 48106-1346 


\section{Abstract \\ Bismuth Surfactant Effects for GaAsN and Beryllium Doping of GaAsN Grown by Molecular Beam Epitaxy}

\section{Ting Liu}

Bi was investigated as a possible surfactant for growth of $\mathrm{GaAs}_{1-\mathrm{x}} \mathrm{N}_{\mathrm{x}}$ layers on (100) GaAs substrates by molecular beam epitaxy using an RF plasma nitrogen source. Bi extends the useable growth conditions producing smoother surfaces to a significantly higher $\mathrm{N}$ content than without $\mathrm{Bi}$. The conductivity of Be-doped GaAsN decreased significantly with increasing $\mathrm{N}$ concentration. Temperature dependent Hall measurement suggests possible compensation and increased activation energy. SIMS and Raman measurements indicate that the $\mathrm{N}$ composition increased by introducing $\mathrm{Be}$, and for low $[\mathrm{N}]$, Bi. The addition of $\mathrm{Bi}$ during growth of Be-doped GaAsN only produced semi-insulating layers.

$\operatorname{GaAs}_{1-\mathrm{x}} \mathrm{N}_{\mathrm{x}}$ layers and quantum dot-like structures were grown on (100) GaAs substrates by molecular beam epitaxy. The dependence of photoluminescence emission spectra on annealing temperature is consistent with literature at lower temperatures but after annealing at $750{ }^{\circ} \mathrm{C}$ a net red-shift is consistently observed. X-ray photoelectron spectroscopy measurements indicate that for different annealing times and temperatures, the nitrogen and arsenic surface concentrations changed compared to that of as-grown samples, specifically arsenic is lost from the material. Raman measurements are consistent with the trends in photoluminescence and also suggest the loss of arsenic occurs at higher annealing temperatures in both samples capped with GaAs and uncapped samples. 
The real substrate temperature preliminarily estimated by pyrometer measurement was further verified and determined by RHEED pattern transition. RHEED was also employed to observe the surface reconstruction. To optimize growth conditions, surface phase diagrams of $\mathrm{As}_{4} / \mathrm{Ga}$ BEP flux vs. the real substrate temperature under fixed $\mathrm{As}_{4}$ BEP $\sim 4.5 \times 10^{-6}$ Torr and fixed growth rate $0.46 \mu \mathrm{m} / \mathrm{hr}(0.45 \mathrm{ML} / \mathrm{s})$ were obtained.

Different aperture plates of RF-plasma nitrogen discharge tube were used. Only the one with $10 \times \varnothing 0.2 \mathrm{~mm}$ holes is able to produce streaky RHEED patterns under some growth circumstances, and was eventually selected to lead nitrogen species through for all growths in this work. Ga flux, $\mathrm{N}$ flow rate, and RF power were all found to be critical factors affecting the resultant $\mathrm{N}$ concentrations. 


\section{Acknowledgements}

I would like to express the deepest appreciation to my advisor and committee chair, Dr. Dimitris Korakakis, whose understanding and encouraging have been of great value to me, and without whose continuous guidance and tremendous support, this dissertation would not have been possible. His wide knowledge and his logical way of thinking have made a deep impression on me. Also being a mentor to his students, his support is not only academically but also mentally.

I thank Dr. Tom Myers, who continually and convincingly conveyed a spirit of adventure in regard to research and scholarship, for helping me developing a right attitude toward research and for the persistent and constructive help I received.

I would like to thank my committee members, Dr. Lawrence Hornak, Dr. Xian-an Cao, and Dr. Charter Stinespring for their time and effort.

I would like to express my gratitude to Dr. Aaron Ptak for all discussions and for sharing the experimental results. Sincere thanks to Sandeep Shandril and Eric Schires for their assistance in photoluminescence, Raman spectroscopy and Hall effect measurements. I would also like to acknowledge all helps from Dr. Kolin Brown. In addition, a thank you to Brenda VanMil for her suggestions during the system set up.

I want to thank Phil Tucker and Kirk Pirlo for making electric power connections for the MBE system. Also, thanks to Dr. Nianqiang Wu and Xinqi Chen for the XPS measurement.

I am grateful to Dr. Jianhua Gu for teaching me using AFM and for all the other help.

And then, over all those years, there are all the other people who have made me feel working in the lab is really fun: Craig, Luke, Huicheng, Chunchuan, Randy, Kyoungnae, Cameron, Odille, Miyeon, Lee, Sridhar, Kalyan. 
Financial support was provided by the National Science Foundation Grant DMR 0102753 and by NSF through the State of WV EPSCoR program. Work at NREL was completed under DOE Contract No. DE-AC36-99GO10337. 


\section{Table of Contents}

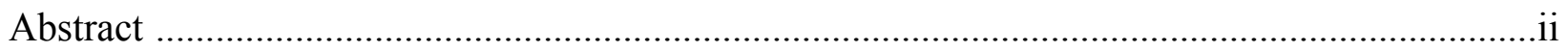

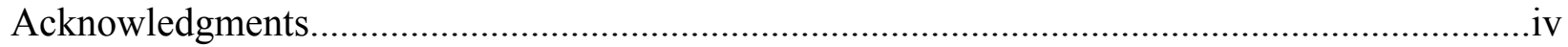

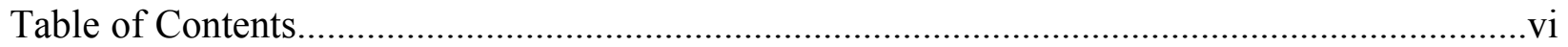

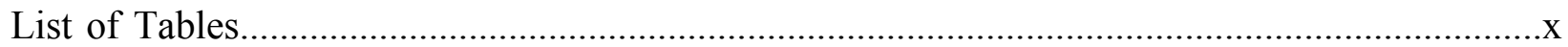

List of Figures ................................................................................................................

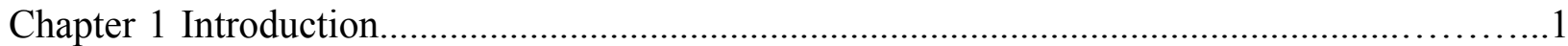

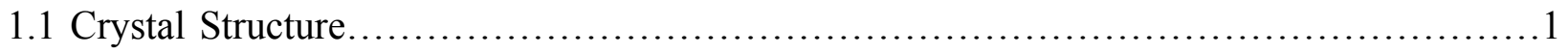

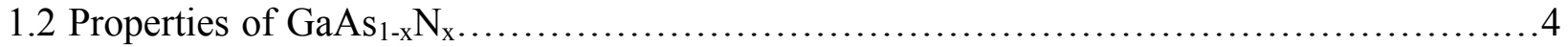

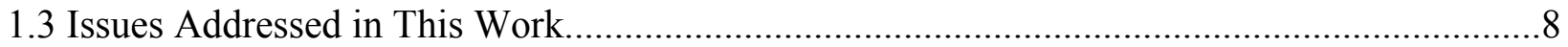

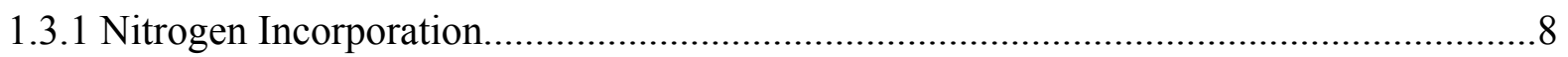

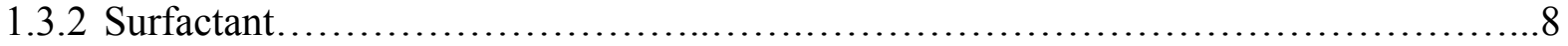

1.3.3 Postgrowth Annealing.............................................................

1.3.4 Beryllium Doping....................................................... 9

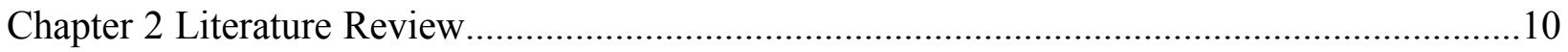

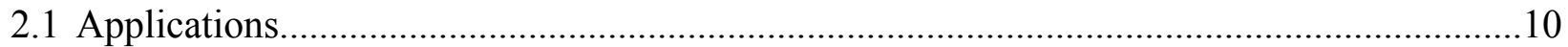

2.1.1 High-speed Optical Data Communications ..........................................................10

2.1.2 Potential Advantages over Current Technology......................................11

2.1.3 Applications in Devices.......................................................... 17

2.1.3.1 Laser Diodes...........................................................17

2.1.3.2 Photodiodes, and Photo Detectors.........................................17

2.1.3.3 Heterojunction Bipolar Transistors (HBTs).................................19

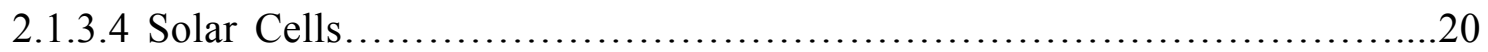

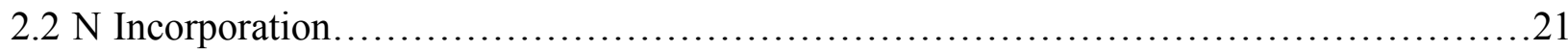

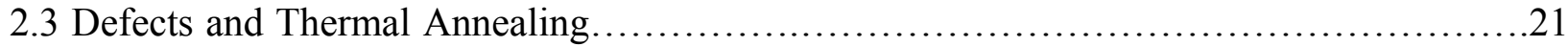

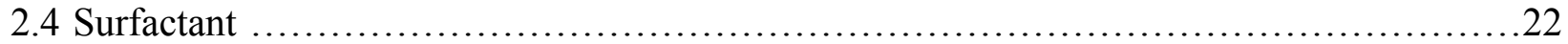

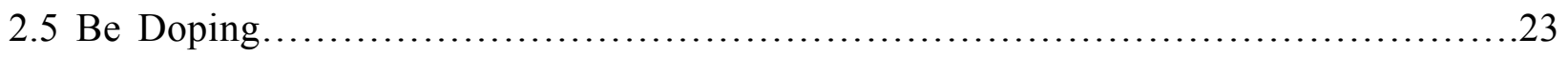

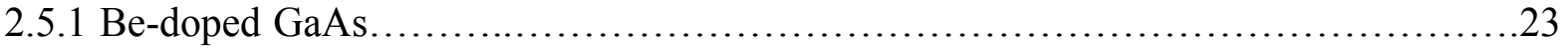

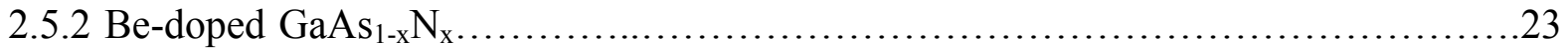

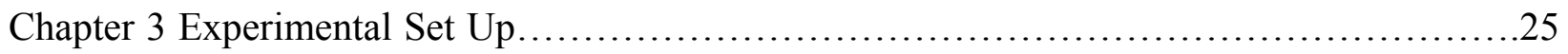




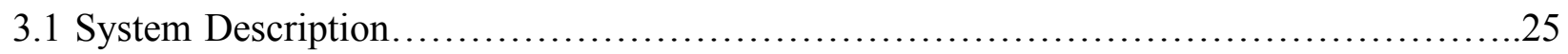

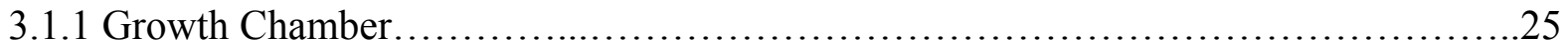

3.1.2 Buffer Chamber.................................................................. 30

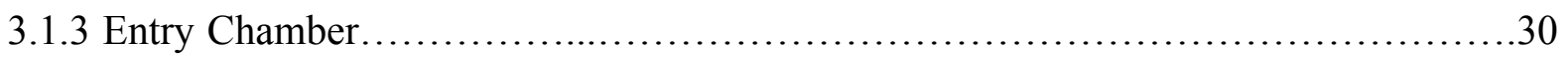

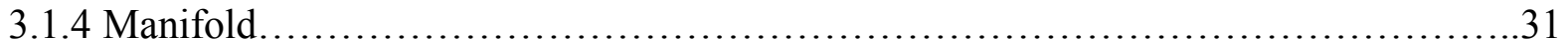

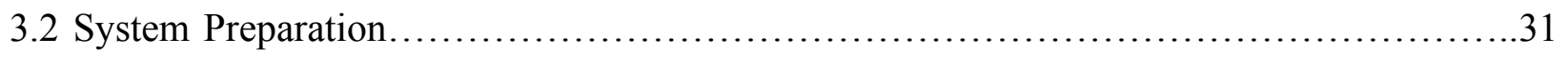

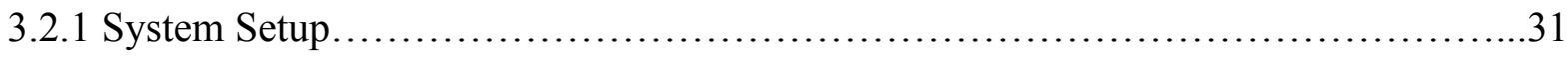

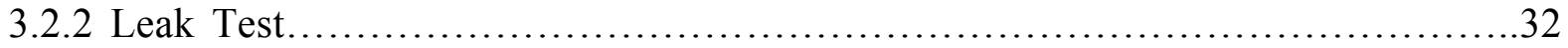

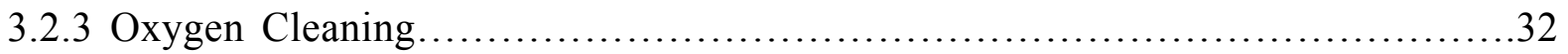

3.2.4 Loading sSource Materials and Outgassing .......................................33

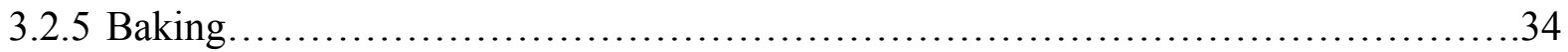

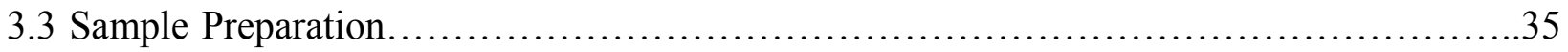

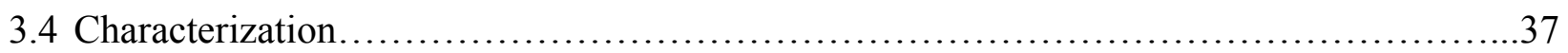

3.4.1 Reflection High Energy Electron Diffraction (RHEED)............................ 37

3.4.2 Mass Spectrometer.......................................................... 41

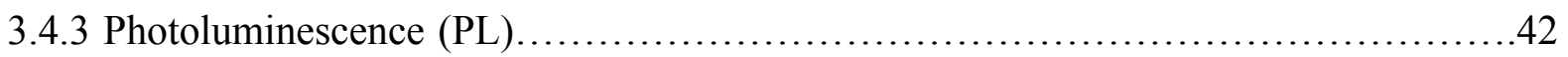

3.4.4 Atomic Force Microscopy (AFM) ................................................43

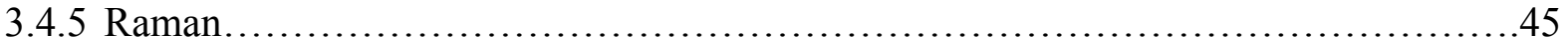

3.4.6 Hall Effect Measurement........................................................ 46

3.4.7 X-ray Photoelectron Spectroscopy (XPS) ...................................... 46

Chapter 4 Substrate Temperature Calibration............................................ 47

4.1 Introduction to Pyrometer........................................................ 47

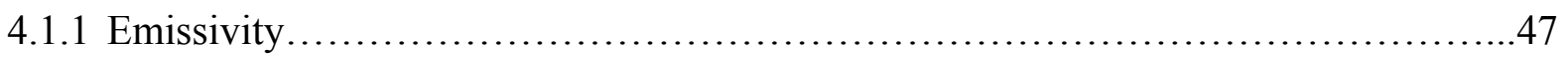

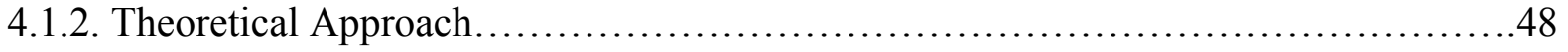

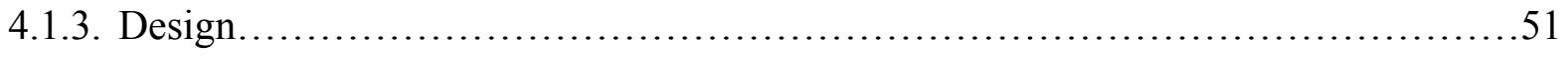

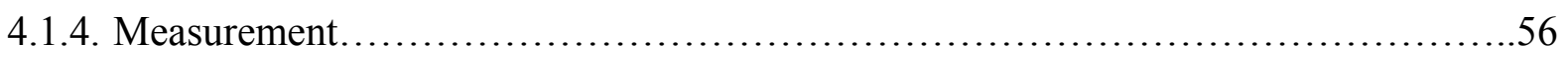

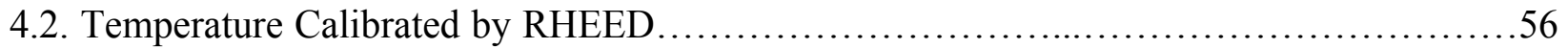

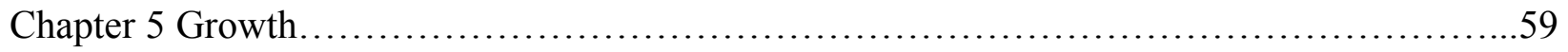

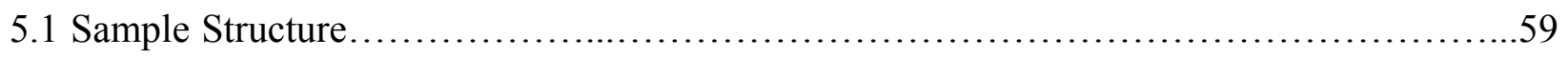

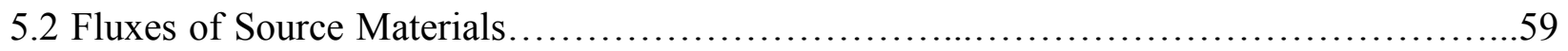

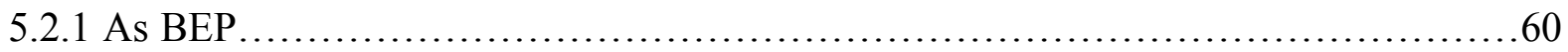




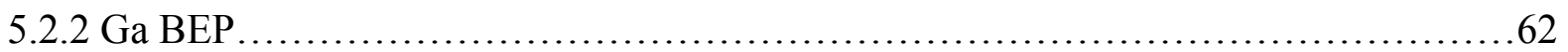

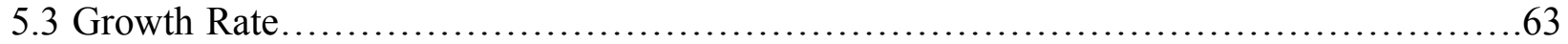

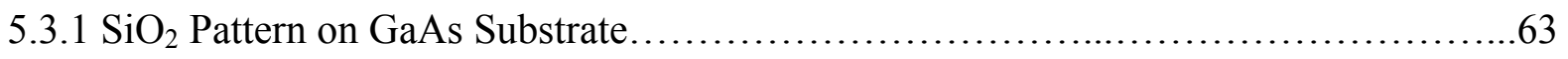

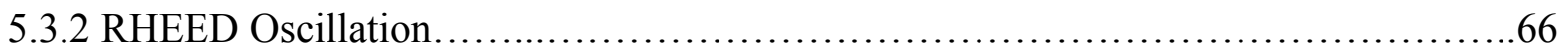

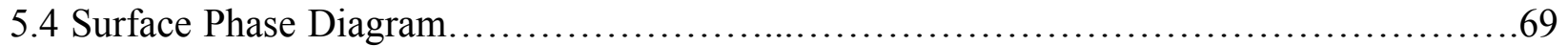

5.5 Factors Affecting N Concentration................................................... 73

5.5.1 Aperture Plate of the RF-plasma Discharge Tube.................................73

5.5.2 N Concentration vs. Ga Flux................................................. 74

5.5.3 N Concentration vs. N Flow Rate............................................. 75

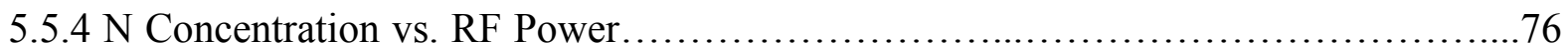

Chapter 6 Changes in Optical Properties of $\mathrm{GaAs}_{1-\mathrm{x}} \mathrm{N}_{\mathrm{x}}$ During Annealing...................... 80

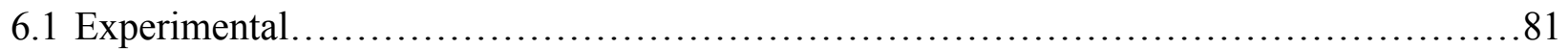

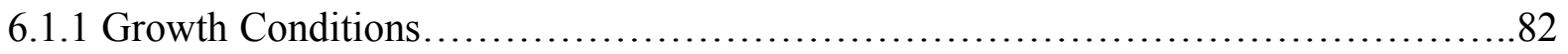

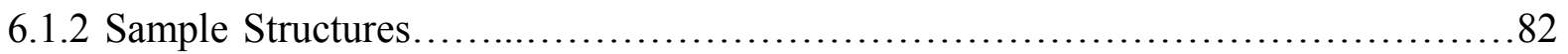

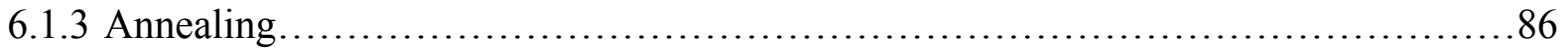

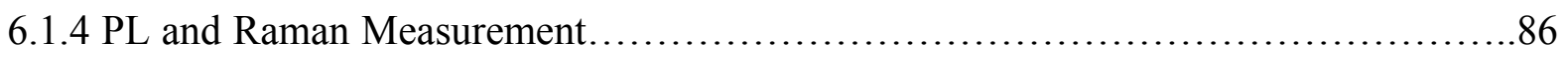

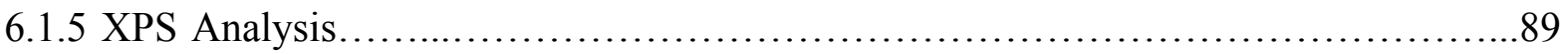

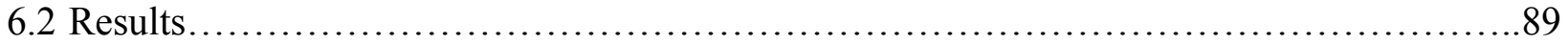

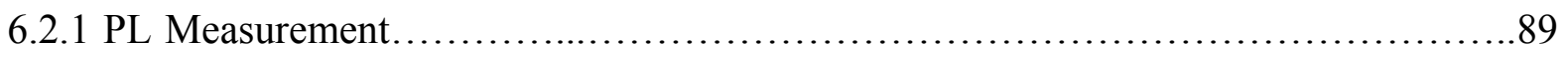

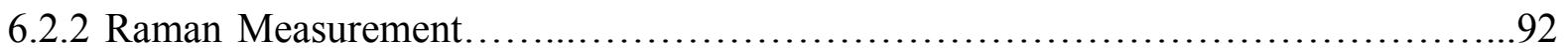

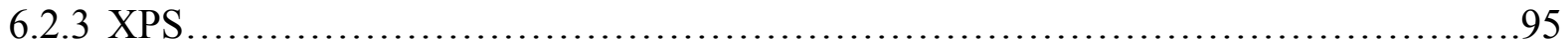

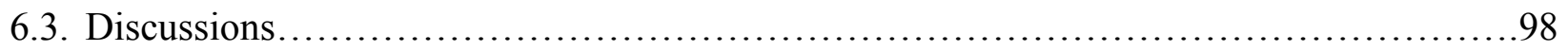

Chapter 7 Bismuth Surfactant Effects and Beryllium Doping...............................100

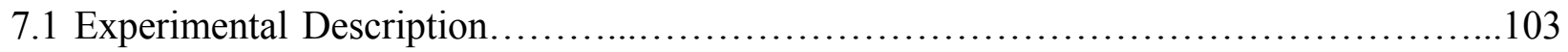

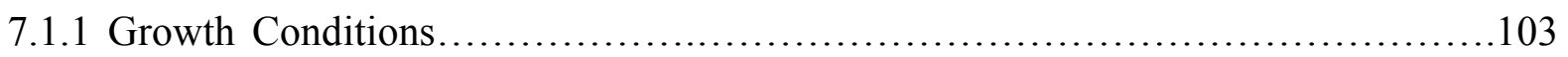

7.1.2 Sample Structures........................................................... 105

7.1.3 Beryllium Incorporation.................................................. 105

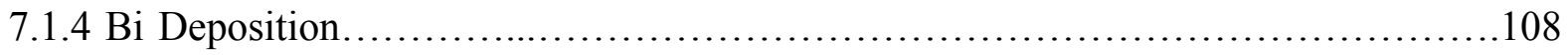

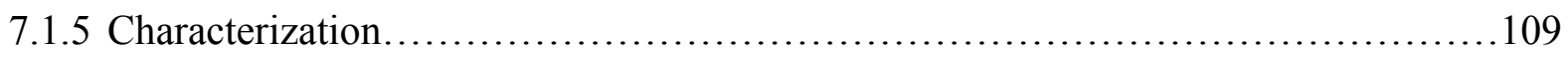

7.2 N Concentration Determined by Raman Measurement....................................109

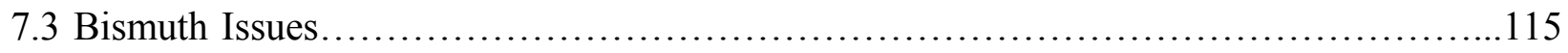


7.3.1 Effect on Growth Conditions............................................. 115

7.3.2 Effect on Surface Morphology ............................................ 115

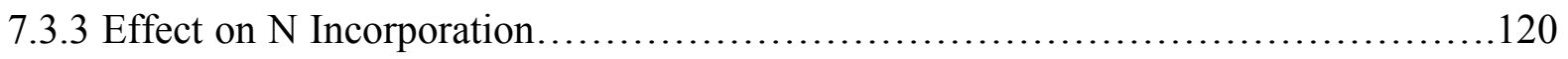

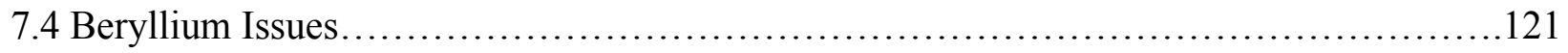

7.4.1 Effects on $\mathrm{N}$ Incorporation................................................ 121

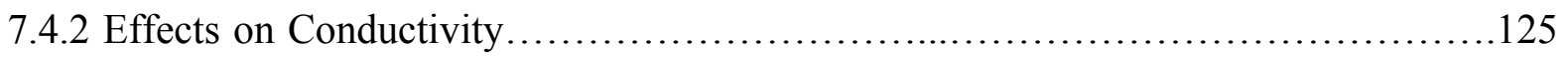

7.4.3 Photoluminescence of Be-doped Samples......................................131

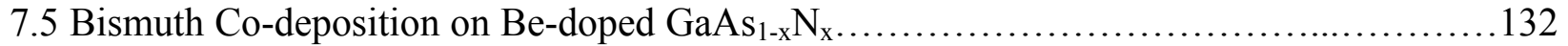

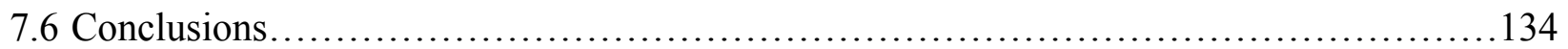

Chapter 8 Conclusions and Proposed Future Studies.................................... 135

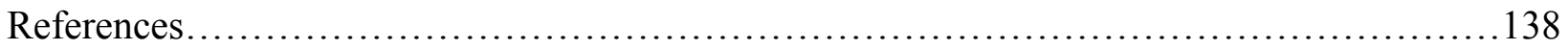




\section{List of Tables}

Chapter 1

Table 1.1 Basic properties of Zinc Blende GaAs and GaN at room temperature

Chapter 2

Table 2.1 Basic properties of Zinc Blende GaAs, InP and GaInP at room temperature. .13

Chapter 3

Table 3.1 Operating and outgassing temperatures applied for source materials loaded in VGV80H MBE system 33

\section{Chapter 7}

Table 7.1 $\mathrm{N}$ concentrations obtained from the multi-layer-sample .104

Table $7.2[\mathrm{~N}]$ measured by SIMS compared to [N] derived by Raman using Eq. (7.2). .112

Table $7.3[\mathrm{~N}]$ measured by XRD compared to [N] derived by Raman using Eq. (7.2) 114

Table 7.4 Comparison of nitrogen concentration and surface roughness for GaAsN samples grown with and without Bi flux at WVU 118

Table 7.5 N concentrations and conductivities of 3 series of Be-doped samples...............123

Table 7.6 Be doped $\mathrm{GaAs}_{1-\mathrm{x}} \mathrm{N}_{\mathrm{x}}$ with and w/o Bi (Target $\mathrm{N}$ concentration is $0.8 \%$ ). 


\section{List of Figures}

\section{Chapter 1}

Fig 1.1 (a) GaAs crystal structure. [Shockley, 1950] (b) Arsenic atoms (white) are replaced by nitrogen atoms (red), which form bonds with four Ga atoms surrounded. If indium is involved, In atoms (grey) take positions used to belong to Ga (black)......................... 2

Fig 1.2 Lattice constant of GaAsN vs. N concentration................................ 3

Fig 1.3 Band gap energy versus lattice constant of GaAsN, GaInAs, and $\mathrm{Ga}_{0.47} \operatorname{In}_{0.53} \mathrm{As}_{1-\mathrm{y}} \mathrm{N}_{\mathrm{y}} \ldots \ldots .4$

Fig 1.4 Band gap energy of GaAsN as a function of $\mathrm{N}$ composition at room temperature. (a) The theoretical calculation. [Bellaiche, 1996] (b) Experimental results from references of [Bi,

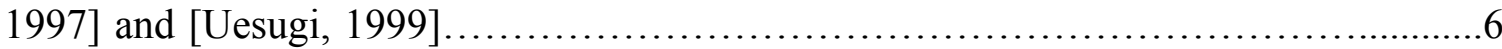

\section{Chapter 2}

Fig 2.1 Typical plot of attenuation coefficient vs. wavelength for an optical fiber.....................11

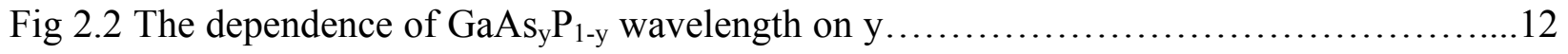

Fig 2.3 Schematic diagram of threshold currents dependent on the temperature of an InGaAsN/GaAsN laser with laser wavelength of $1.295 \mathrm{~nm}$. (a) Output power vs. current;

(b) Threshold current vs. temperature......................................... 16

Fig 2.4 Conduction band of GaAsN QWIP at $25 \mathrm{~K} . \mathrm{E}_{1}$ and $\mathrm{E}_{2}$ are interbands within the conduction band.

Fig 2.5 A HBT device with GaAsN based material as the base layer.........................20

Fig 2.6 GaAs Hole mobility vs. hole concentration at room temperature......................24

Chapter 3

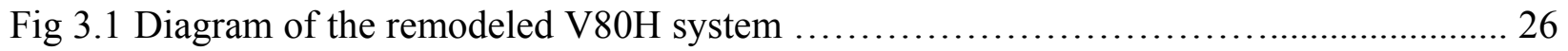

Fig 3.2 The outlook and schematic drawing of the growth chamber.......................27

Fig 3.3 A schematic diagram of source locations in our MBE system......................29

Fig 3.4 Pressure of the growth chamber vs. baking time................................. 34

Fig 3.5 The assembly procedure of installing the substrate (1/4 of one 2" GaAs wafer) in the In-

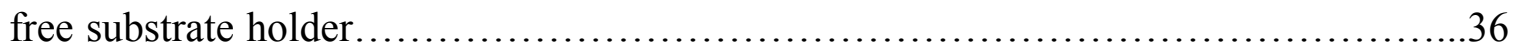

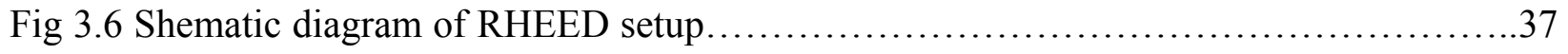


Fig 3.7 The diffraction satisfying the Laue condition in reciprocal space with the assist of Ewald sphere. $\vec{K}_{a}, \vec{K}_{b}$ and $\vec{K}_{c}$ are all vectors of the diffracted wave..........................

Fig 3.8 RHEED patterns of two $\mathrm{GaAs}_{1-\mathrm{x}} \mathrm{N}_{\mathrm{x}}$ samples with smooth surfaces. (a) The diffraction pattern of Laue rings. (b) RHEED pattern of streaky lines............................40

Fig 3.9 Partial pressure of species with different atomic mass units in the growth chamber were

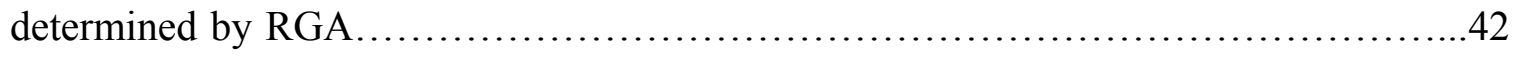

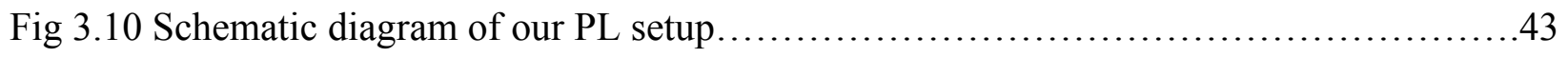

Fig 3.11 Photoluminescence of a GaAs (100) substrate obtained at the temperature of $77 \mathrm{~K} \ldots . . .44$

Fig 3.12 AFM image a GaAs sample.................................................. 44

Fig 3.13 Typical Raman shift of a GaAs sample...........................................45

Chapter 4

Fig 4.1 Plot of Planck's law at different temperatures assuming blackbody case................49

Fig 4.2 Illustration of infrared temperature measurement.................................5

Fig 4.3 Illustration of configuration of a modern infrared pyrometer.........................53

Fig 4.4 Total energy radiation of a blackbody over the wavelength range of 2.1 and $2.3 \mu \mathrm{m}$ vs. its temperature. The minimum temperature this pyrometer can detect is $400^{\circ} \mathrm{C}$, i.e. $\sim 663 \mathrm{~K}$ as mentioned in the manual. The inset demonstrates the energy absorbed corresponding to substrate temperatures normally used for our GaAsN growth $\left(400^{\circ} \mathrm{C}-650^{\circ} \mathrm{C}\right) \ldots \ldots \ldots . . .55$

Fig 4.5 Substrate temperature calibration by pyrometer or surface reconstruction monitored by

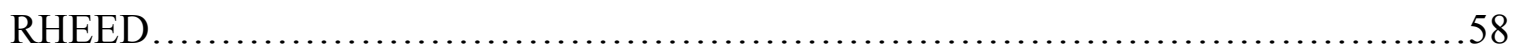

\section{Chapter 5}

Fig 5.1 The dependence of $\mathrm{As}_{4} \mathrm{BEP}$ on the valve position of the cracker.....................61

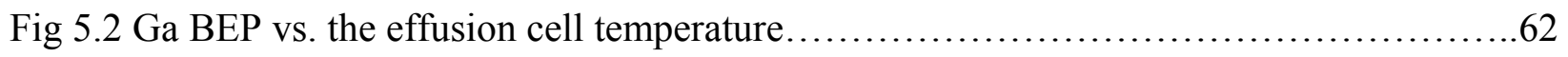

Fig $5.3 \mathrm{SiO}_{2}$ strip patterns on GaAs substrate used for measuring the growth rate................64

Fig 5.4 Growth rate vs. Ga BEP by patterned $\mathrm{SiO}_{2}$ or RHEED oscillation....................65

Fig 5.5 Schematic diagram explaining the RHEED intensity oscillation.......................67

Fig 5.6 RHEED intensity oscillations of two growths with different Ga BEPs...................68

Fig 5.7 Surface phase diagram of (100) GaAs with the growth rate of $0.71 \mu \mathrm{m} / \mathrm{hr} \ldots \ldots \ldots \ldots \ldots . .71$ 
Fig 5.8 Surface phase diagram of GaAs (100). (a) Growth rate $0.17-0.46 \mu \mathrm{m} / \mathrm{hr}(0.17-$ $0.45 \mathrm{ML} / \mathrm{s}$ ), As 4 BEP $\sim 4.5 \times 10^{-6}$ Torr and $\mathrm{Ts}<575^{\circ} \mathrm{C}$; (b) Growth rate $0.46 \mu \mathrm{m} / \mathrm{hr}$

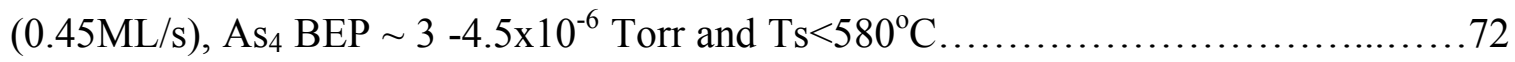

Fig 5.9 The dependence of $\mathrm{N}$ content on Ga BEP flux. $\mathrm{N}$ partial pressure $1 \times 10^{-7}$ Torr $(\sim 0.01$ sccm), RF power $100 \mathrm{~W}, \mathrm{As}_{4} \mathrm{BEP} \sim 6 \times 10^{-6}$ Torr, and $\mathrm{Ts} \sim 430^{\circ} \mathrm{C}$ .75

Fig 5.10 The dependence of $\mathrm{N}$ content on $\mathrm{N}$ flux. RF power $100 \mathrm{~W}, \mathrm{As}_{4} \mathrm{BEP} \sim 6 \times 10^{-6}$ Torr, and Ts $\sim 430^{\circ} \mathrm{C}$ .77

Fig 5.11 The dependence of $\mathrm{N}$ content on RF power. $\mathrm{As}_{4} \mathrm{BEP} \sim 6 \times 10^{-6}$ Torr, and $\mathrm{Ts} \sim 430^{\circ} \mathrm{C} \ldots . .78$

Fig 5.12 The dependence of $\mathrm{N}$ content on As flux. $\mathrm{N}$ partial pressure $1 \times 10^{-6}$ Torr $(\sim 0.1 \mathrm{sccm})$, RF power $100 \mathrm{~W}$, Ga BEP $\sim 3.5 \times 10^{-7}$ Torr, and $\mathrm{Ts} \sim 430^{\circ} \mathrm{C}$. 79

\section{Chapter 6}

Fig 6.1 Sample structures of (a) type A and (b) type B. .83

Fig 6.2 RHEED pattern transition from (a) 2D (prior to GaAsN growth) to (b) 3D (after initiating GaAsN growth) .84

Fig 6.3 AFM images of two GaAsN samples. (a) Type A: QD-like structure. (b) Type B: Thin layer structure. .85

Fig 6.4 Bandgap energy (obtained by PL measurement) dependent on $\mathrm{N}$ content $\mathrm{x}$ in $\operatorname{GaAs}_{1-\mathrm{x}} \mathrm{N}_{\mathrm{x}}$. Solid and dashed lines represent experimental and theoretical (calibrated without strain) results, respectively.

Fig 6.5 Relationship between Raman $\mathrm{LO}_{1}$ shift of GaAs-type phonons and $\mathrm{N}$ content $\mathrm{x}$ in $\mathrm{GaAs}_{1 \text { - }}$

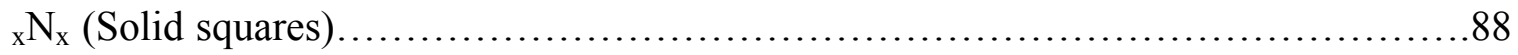

Fig 6.6 Type A sample PL measurement. (a) PL spectra at different annealing temperatures; (b)

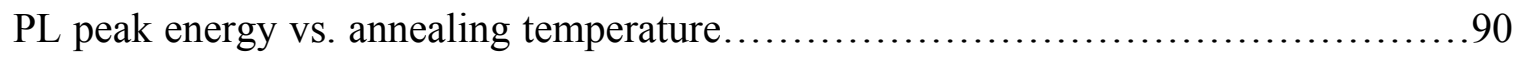

Fig 6.7 Type B sample PL measurement. (a) PL spectra at different annealing temperatures; (b) PL peak energy vs. annealing temperature.

Fig 6.8 Type A sample Raman measurement. (a) Spectra of GaAs-like $\mathrm{LO}_{1}$ Raman measurement; (b) Raman shift of $\mathrm{LO}_{1}$ vs. Annealing Temperature.

Fig 6.9 Type B sample Raman measurement. (a) Spectra of GaAs-like $\mathrm{LO}_{1}$ Raman measurement; (b) Raman shift of $\mathrm{LO}_{1}$ vs. Annealing Temperature. .94 
Fig 6.10 Type B Sample XPS spectra before and after $750^{\circ} \mathrm{C}$ annealing. (a) Ga2P peak; (b) As3d peak. ....

Fig 6.11 Type B Sample XPS measured N1s peak before and after $750^{\circ} \mathrm{C}$ annealing comparing to literature. (a) N1s peak in this study; (b) N1s peak obtained by Spruytte et al.[Spruytte, 2001] after $1 \mathrm{~min}, 760^{\circ} \mathrm{C}$ anneal.

\section{Chapter 7}

Fig 7.1 SIMS measurement of the multi-layer-sample under different growth conditions.......104

Fig 7.2 Sample structures for (a) undoped material, and (b) Be-doped material.... .106

Fig 7.3 The concentration of incorporated Be vs. the temperature of Be effusion cell at growth temperature $427^{\circ} \mathrm{C}$

Fig 7.4 Surface phase diagram on GaAs (100) depending on substrate temperature and Bi cell temperature, observed by Pillai et al. in their MBE system.

Fig 7.5 Bi stabilized $1 \mathrm{x} 3$ surface reconstruction at $\mathrm{T}_{\mathrm{s}} \sim 427^{\circ} \mathrm{C}$. The top is the $1 \mathrm{x}$ pattern, and the bottom is the $3 \mathrm{x}$ pattern .108

Fig 7.6 Composition dependence of the GaN-like $\mathrm{LO}_{2}$ phonon frequency on $\mathrm{N}$ composition of GaAsN.

Fig 7.7 SIMS and Raman measurements to determine $\mathrm{N}$ contents of GaAsN samples. (a) $\mathrm{N}$ contents measured by SIMS. (b) Raman shift of the GaN-like $\mathrm{LO}_{2}$ phonon frequency..111

Fig 7.8 Raman shift of the $\mathrm{LO}_{2}$ phonon frequency vs. $\mathrm{N}$ content measured by SIMS and XRD. Also shown are comparisons to the relationship reported in Ref. [Prokofyeva, 1998] and [Wagner, 2000]. Results for a sample grown under Bi are shown, but were not included in obtaining the fit

Fig 7.9 X-ray rocking curves of two $\mathrm{GaAs}_{1-\mathrm{x}} \mathrm{N}_{\mathrm{x}}$ samples with $\mathrm{x}=1.0 \%$ and $6.0 \%$ separately $\ldots 114$

Fig 7.10 The extension of growth regime with the use of Bi determined by RHEED. (a) The dependence of $\mathrm{N}$ concentration on growth rate with changing the Ga beam flux only. Tsub $\sim 427^{\circ} \mathrm{C}$; N: $10^{-7}$ Torr, $100 \mathrm{~W}$; As $4 \sim 3 \times 10^{-6}$ Torr. (b) Comparison of RHEED pattern with and without $\mathrm{Bi}$ at the growth rate of $200 \mathrm{~nm} / \mathrm{hr}$.

Fig 7.11 AFM images of $\mathrm{GaAs}_{1-\mathrm{x}} \mathrm{N}_{\mathrm{x}}$ grown with and without $\mathrm{Bi}$. Target $\mathrm{x}$ is $0.8 \%, 1.9 \%$ and $6.5 \%$ respectively. .118 
Fig 7.12 RHEED patterns of $\mathrm{GaAs}_{1-\mathrm{x}} \mathrm{N}_{\mathrm{x}}$ grown with and without $\mathrm{Bi}$. Target $\mathrm{x}$ is $0.8 \%, 1.9 \%$ and $6.5 \%$ respectively.

Fig 7.13 Diagram taken from Ref. [Young, 2005] showing $\mathrm{N}$ concentrations effected by Bi

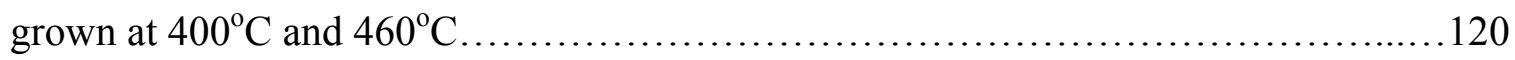

Fig 7.14 Be concentrations of Be-doped GaAs and GaAsN samples measured by SIMS measurement. For the GaAsN sample, [N] was determined to be $1.8 \%$

Fig 7.15 $\mathrm{N}$ concentrations of Be-doped $\mathrm{GaAs}_{1-\mathrm{x}} \mathrm{N}_{\mathrm{x}}$ compared to undoped samples determined by Raman measurement. Open circles, gray circles, and dark solid circles correspond to target $\mathrm{x}=0.8 \%, 1.9 \%$ and, $6.5 \%$ respectively. SIMS results are also shown as squares for those samples that had SIMS done on them

Fig 7.16 Dependence of room temperature carrier concentration on $\mathrm{N}$ content at different $\mathrm{Be}$ concentrations. Solid dots are GaAsN measured by Hall and open circles are GaInAsN measured by CV measurements.

Fig 7.17 RTA was applied on Be-doped $\mathrm{GaAs}_{1-\mathrm{x}} \mathrm{N}_{\mathrm{x}}(\mathrm{x}=1.8 \%)$, and SIMS measurement was done to compare $\mathrm{N}$ and $\mathrm{Be}$ concentrations with those of the as-grown sample. Dark lines represent [Be], and gray lines correspond to [N].

Fig 7.18 Temperature dependent Hall measurements. (a) Heavily doped $\operatorname{GaAs}_{1-\mathrm{x}} \mathrm{N}_{\mathrm{x}}$ with $\mathrm{x} \sim 0$, $0.8 \%$, and 1.8\% (b) Lower doped GaAsN and GaInAsN with varied N concentrations...129

Fig 7.19 Temperature dependent Hall measurements. (a) Heavily doped $\operatorname{GaAs}_{1-\mathrm{x}} \mathrm{N}_{\mathrm{x}}$ with $\mathrm{x} \sim 0$, $0.8 \%$, and $1.8 \%$. (b) Lower doped GaAsN and GaInAsN with varied $N$ concentrations

Fig 7.20 Photoluminescence of Be-doped GaAs or GaAsN samples with different carrier concentrations. [N] was also estimated by PL emission energy comparing to that measured by other methods. (a) $\mathrm{Be} \sim 2 \times 10^{19} \mathrm{~cm}^{-3}$; (b) $\mathrm{Be} \sim 2 \times 10^{18} \mathrm{~cm}^{-3}$; (c) $\mathrm{Be} \sim 10^{17} \mathrm{~cm}^{-3} . .131$ 


\section{Chapter 1}

\section{Introduction}

\subsection{Crystal Structure}

GaAs has Zinc Blende crystal structure, which consists two intermixing face centered cubic (fcc) sublattices with the displacement of one quarter of the cube diagonal from each other along the body diagonal as shown in Fig 1.1(a) [Shockley, 1950]. In the periodic table of the elements, Ga and As belong to group III and group V respectively. Each Ga atom is covalently bonded to four neighboring As atoms, and each As atom is also surrounded by four Ga atoms.

When $\mathrm{N}$, which is also group $\mathrm{V}$ element as As, is introduced into GaAs, one $\mathrm{N}$ replaces one As atom, occupying the location used to belong to As as shown in Fig. 1.1(b), in which some arsenic atoms are replaced by $\mathrm{N}$ atoms (highlighted with red color). Since the lattice constant of

cubic GaN is $4.52 \AA$ at room temperature, less than that of GaAs, $5.65 \AA$, the incorporation of $\mathrm{N}$ into a fully relaxed GaAs lattice structure could generate extended strain as the $\mathrm{N}$ atom draws neighboring $\mathrm{Ga}$ atoms toward it, resulting in the decrease of the lattice constant. The dependence of lattice constant on the N composition can be seen in Fig 1.2[Fan, 2004], which shows that more $\mathrm{N}$ leads to smaller lattice constant. 

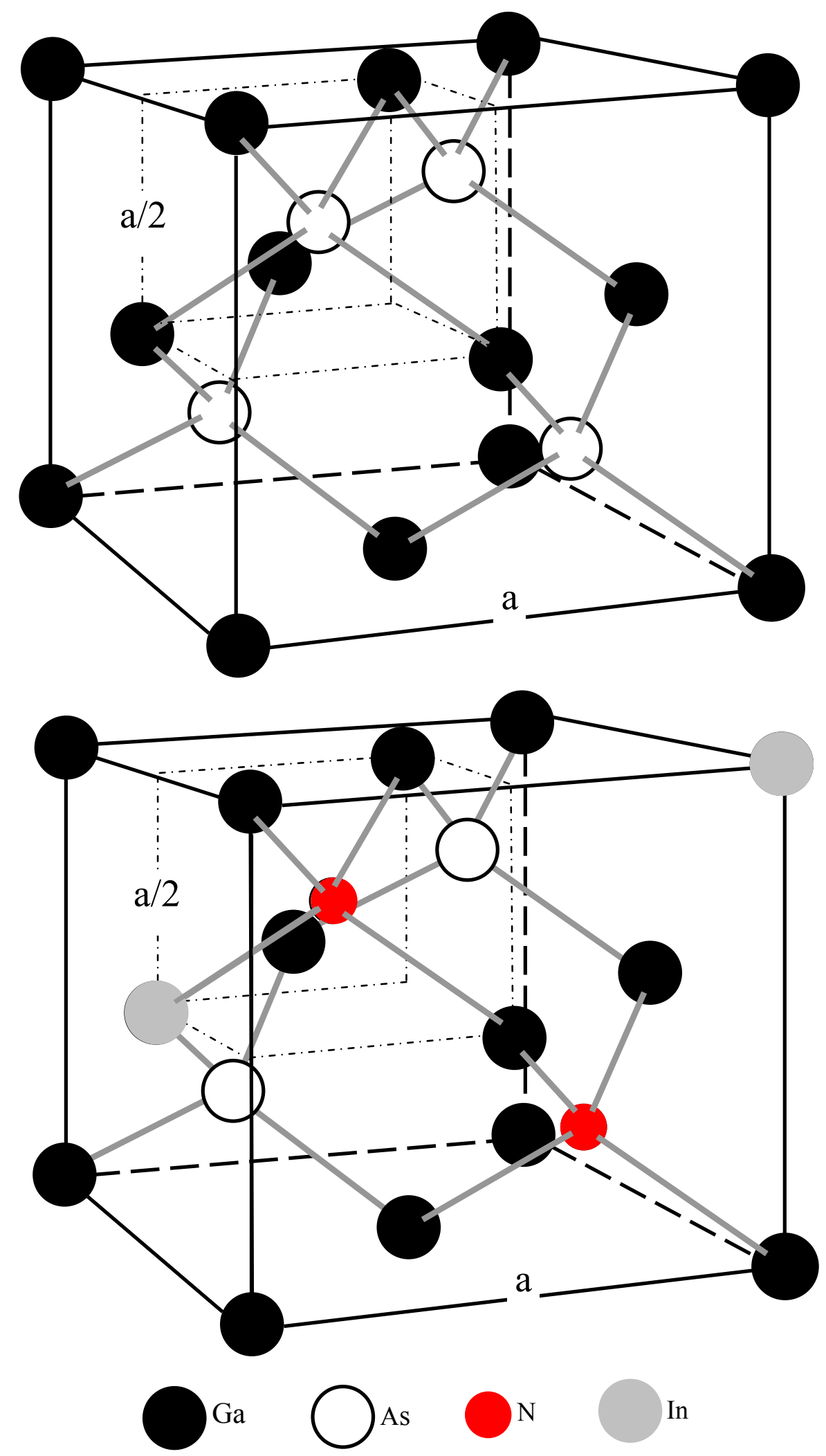

Fig 1.1 (a) GaAs crystal structure. [Shockley, 1950] (b) Arsenic atoms (white) are replaced by nitrogen atoms (red), which form bonds with four $\mathrm{Ga}$ atoms surrounded. If indium is involved, In atoms (grey) take positions used to belong to Ga (black). 
Sometimes indium is co-deposited to lessen the strain caused by N. As both In and Ga are group III elements, when $\mathrm{N}$ and In are introduced into GaAs, the same as $\mathrm{N}$ replacing As, some Ga atoms will be replaced by In (Fig 1.2). The lattice constant of InAs (6.06 $\AA$ at room temperature) is larger than that of GaAs, and thus the compressive strain originated by indium can offset the extended strain created by N. Fig 1.3 demonstrates how the lattice constant is altered by incorporating $\mathrm{N}$ and $\mathrm{In}$. The lattice parameter is increasing with increasing the In composition, so theoretically fully relaxed materials are achievable if $\mathrm{N}$ and In concentrations are carefully selected.

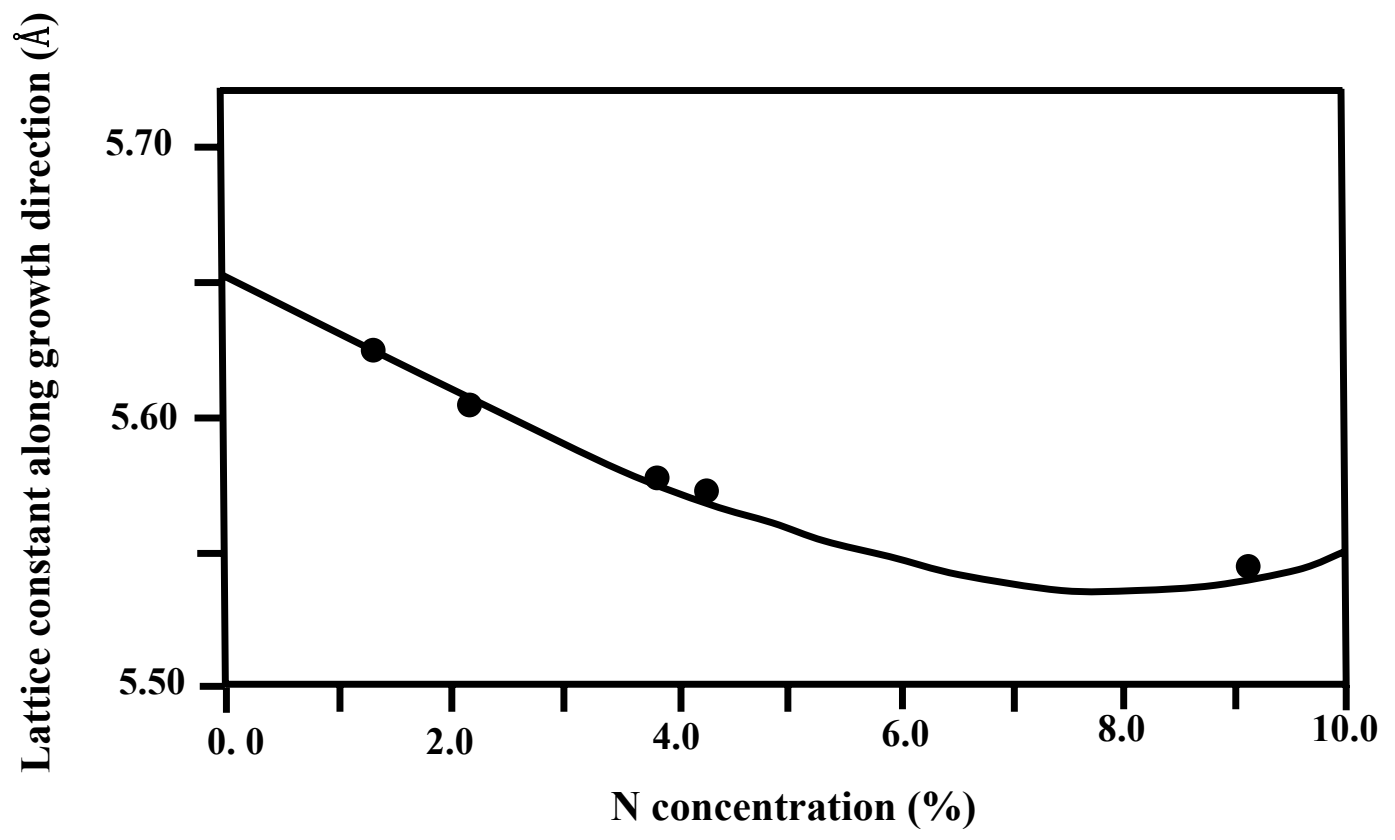

Fig 1.2 Lattice constant of GaAsN vs. $\mathrm{N}$ concentration.

[Fan, 2004] 


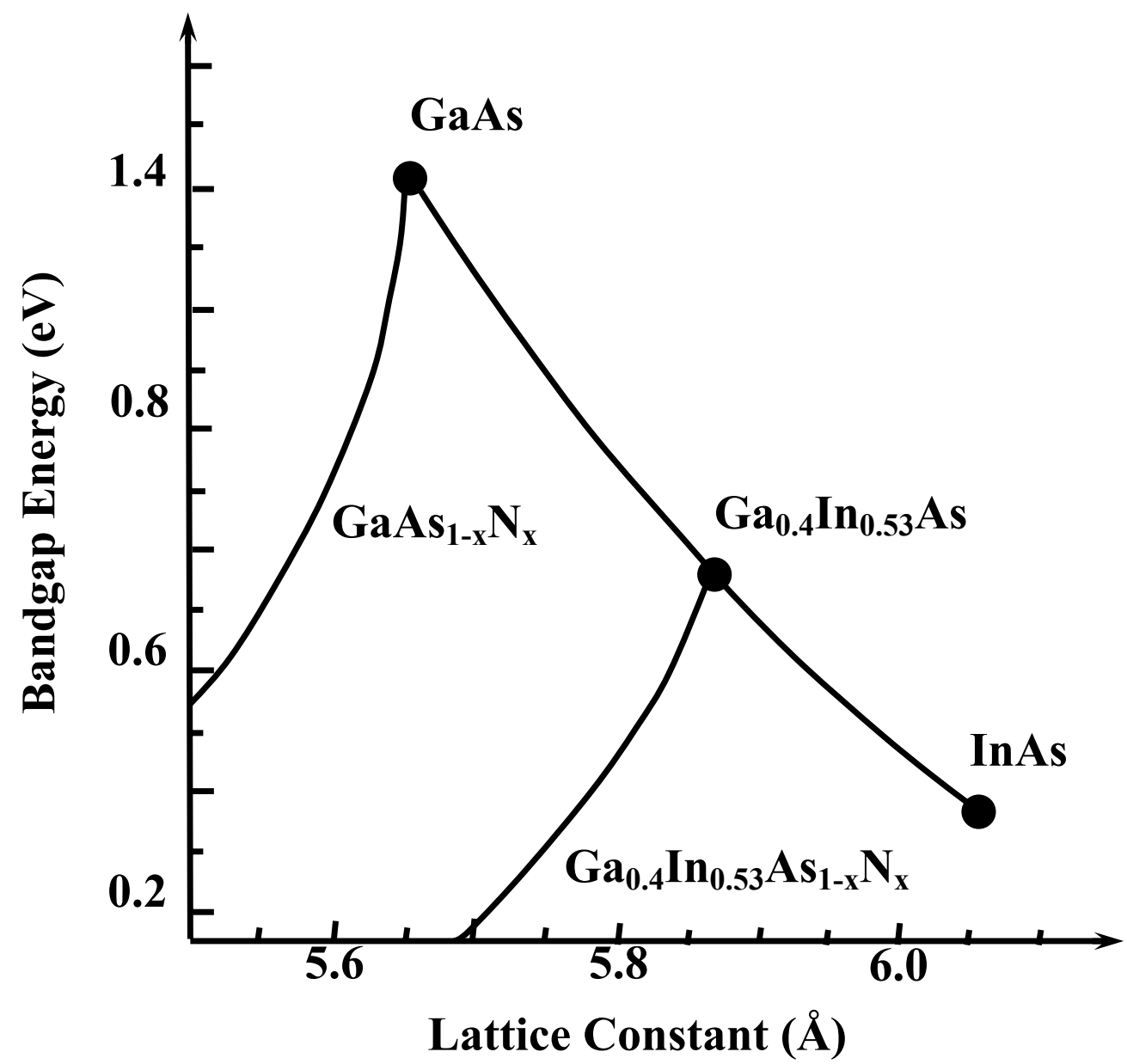

Fig 1.3 Band gap energy versus lattice constant of GaAsN, GaInAs, and $\mathrm{Ga}_{0.47} \operatorname{In}_{0.53} \mathrm{As}_{1-\mathrm{y}} \mathrm{N}_{\mathrm{y}}$. [Serries, 2002]

\subsection{Properties of $\mathrm{GaAs}_{1-\mathrm{x}} \mathrm{N}_{\mathrm{x}}$}

When nitrogen is added to GaAs, the nitrogen makes the band gap of $\mathrm{GaAs}_{1-\mathrm{x}} \mathrm{N}_{\mathrm{x}}$ decrease because of its highly nonlinear composition dependence, i.e., a large band gap bowing of III-Vdilute $\mathrm{N}$ materials, which was suggested to originate from large differences of atomic potentials and sizes between $\mathrm{N}$ and As being replaced. The large central-cell potential by introducing $\mathrm{N}$ (which is taken as the impurity in the alloy) supports the formation and persistence of spatially separated and deep localized band edge states. Unlike the case of alloys with small central-cell potential that impurity energy states overlap with band edges and thus the impurity has negligible effect on the band gap bowing parameter, the 'impurity-like' gap originated from the deep 
localization of band edge states contributes to the band gap variation and is highly dependent on $\mathrm{N}$ concentration $\mathrm{x}$. Therefore, the large bowing effect is observed for $\mathrm{GaAs}_{1-\mathrm{x}} \mathrm{N}_{\mathrm{x}}$ [Wei, 1996].

Theoretically, if enough $\mathrm{N}$ is incorporated into the material, the band gap energy could be very small, as low as $\sim 0.4 \mathrm{eV}$ as shown in Fig 1.4 (a) [Bellaiche, 1996]. However, due to the low solubility of $\mathrm{N}$ in GaAs, it is challenging to have large $\mathrm{N}$ incorporations, so the higher $[\mathrm{N}]$ regime in the curve of Fig. 1.4 (a) has not been experimentally verified yet. In practice to date $\sim 15 \%$ is the maximum $\mathrm{N}$ concentration reported and can be reached as shown in Fig 1.4 (b)[Bi, 1997], which also includes experimental results by another group [Uesugi, 1999]. Both of them indicate that increasing $\mathrm{N}$ concentration induces the decrease of band gap energy, which can be applied for the fabrication of devices operating in the infrared (IR) wavelength range as the band gap energy $<1.2 \mathrm{eV}$, i.e. wavelength $>1 \mu \mathrm{m}$ can be easily achieved by adding $\mathrm{N}$. The large bowing coefficient of $\operatorname{GaAs}_{1-\mathrm{x}} \mathrm{N}_{\mathrm{x}}$ makes small band gap energy achievable, and thus leading it to a promising material for potential long wavelength applications.

Besides the bowing effect of $\mathrm{GaAs}_{1-\mathrm{x}} \mathrm{N}_{\mathrm{x}}, \mathrm{N}$ content also has big influence on its other properties, which typically are closer to those of GaAs as the $\mathrm{N}$ incorporation is relatively low. Table 1.1 is a summary of basic parameters of cubic GaN and GaAs as a reference [Ioffe, 2001]. 

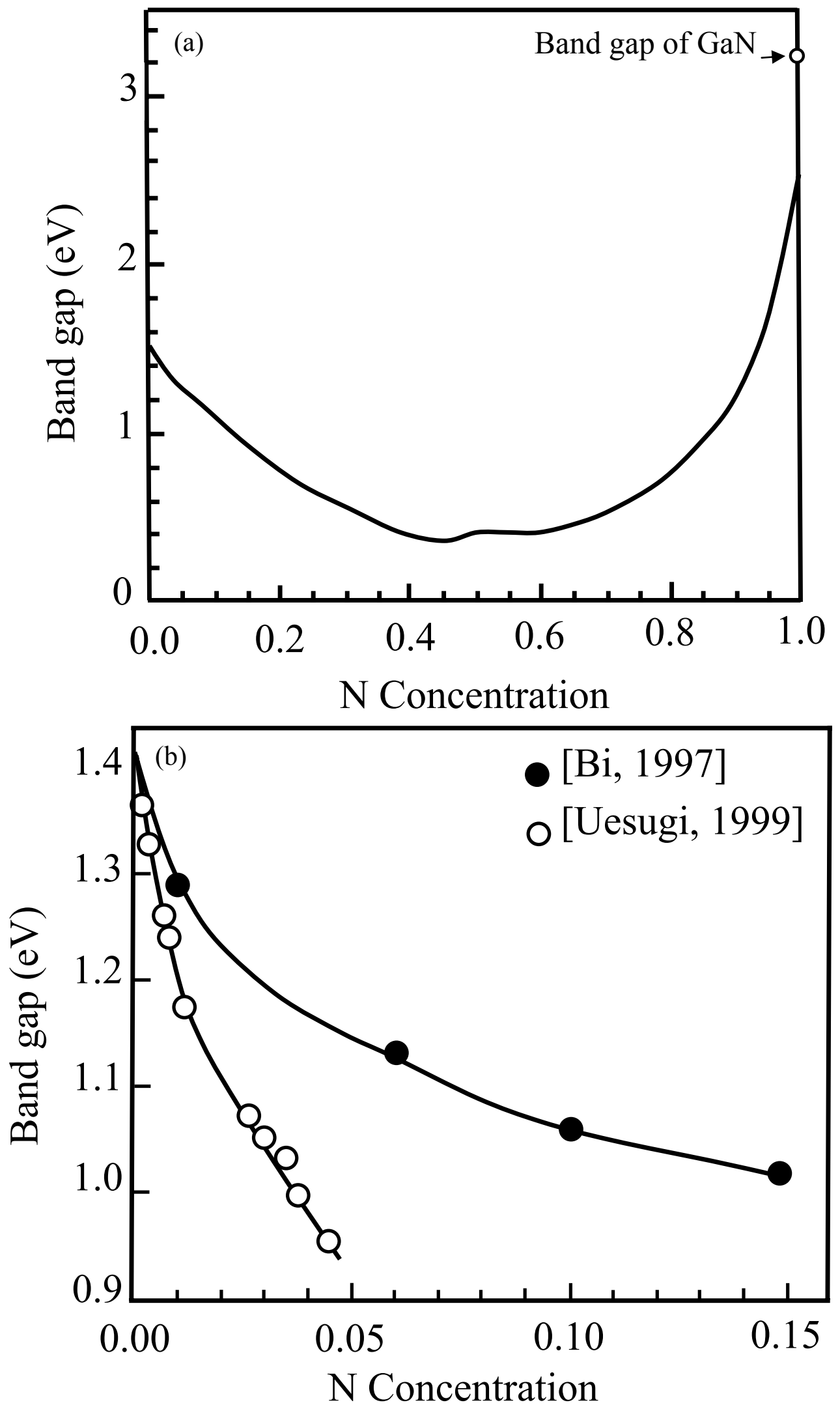

Fig 1.4 Band gap energy of GaAsN as a function of $\mathrm{N}$ composition at room temperature. (a) The theoretical calculation. [Bellaiche, 1996] (b) Experimental results from references of [Bi, 1997] and [Uesugi, 1999]. 
Table 1.1 Basic properties of Zinc Blende GaAs and GaN at room temperature [Ioffe, 2001].

\begin{tabular}{|c|c|c|}
\hline & GaAs & $\mathrm{GaN}$ \\
\hline Crystal structure & Zinc Blende & Zinc Blende \\
\hline Lattice constant & $5.65325 \AA$ & $4.52 \AA$ \\
\hline Energy gap & $1.424 \mathrm{eV}$ & $3.2 \mathrm{eV}$ \\
\hline Density & $5.32 \mathrm{~g} \cdot \mathrm{cm}^{-3}$ & $6.15 \mathrm{~g} \cdot \mathrm{cm}^{-3}$ \\
\hline Atomic density & $4.42 \cdot 10^{22} \mathrm{~cm}^{-3}$ & $8.9 \cdot 10^{22} \mathrm{~cm}^{-3}$ \\
\hline Molecular weight & 144.64 & 83.72 \\
\hline Effective electron mass $m_{e}$ & $0.063 \mathrm{~m}_{\mathrm{o}}$ & $0.13 \mathrm{~m}_{\mathrm{o}}$ \\
\hline Effective hole masses(heavy) $\mathrm{m}_{\mathrm{h}}$ & $0.51 \mathrm{~m}_{\mathrm{o}}$ & $\begin{array}{c}\mathrm{m}_{\mathrm{hh}}=1.3 \mathrm{~m}_{\mathrm{o}} \\
\mathrm{m}_{[100]}=0.8 \mathrm{~m}_{\mathrm{o}} \\
\mathrm{m}_{[111]}=1.7 \mathrm{~m}_{\mathrm{o}}\end{array}$ \\
\hline Effective hole masses(light) $\mathrm{m}_{l p}$ & $0.082 \mathrm{~m}_{\mathrm{o}}$ & $\begin{aligned} \mathrm{m}_{\mathrm{lh}} & =0.19 \mathrm{~m}_{\mathrm{o}} \\
\mathrm{m}_{[100]} & =0.21 \mathrm{~m}_{\mathrm{o}} \\
\mathrm{m}_{[111]} & =0.18 \mathrm{~m}_{\mathrm{o}}\end{aligned}$ \\
\hline Dielectric constant (static) & 12.9 & 9.7 \\
\hline Dielectric constant (high frequency) & 10.89 & 5.3 \\
\hline Melting point & $1238^{\circ} \mathrm{C}$ & $2500^{\circ} \mathrm{C}$ \\
\hline Electron mobility (undoped) & $\leq 8500 \mathrm{~cm}^{2} \cdot \mathrm{V}^{-1} \cdot \mathrm{s}^{-1}$ & $\leq 1000 \mathrm{~cm}^{2} \cdot \mathrm{V}^{-1} \cdot \mathrm{s}^{-1}$ \\
\hline Hole mobility (undoped) & $\leq 400 \mathrm{~cm}^{2} \cdot \mathrm{V}^{-1} \cdot \mathrm{s}^{-1}$ & $\leq 350 \mathrm{~cm}^{2} \cdot \mathrm{V}^{-1} \cdot \mathrm{s}^{-1}$ \\
\hline Debye temperature & $360 \mathrm{~K}$ & $600 \mathrm{~K}$ \\
\hline Optical phonon energy & $35 \mathrm{meV}$ & $87.3 \mathrm{meV}$ \\
\hline Electron affinity & $4.07 \mathrm{eV}$ & $4.1 \mathrm{eV}$ \\
\hline
\end{tabular}




\section{3 Issues Addressed in this work}

This dissertation addresses the Molecular Beam Epitaxy (MBE) growth of $\mathrm{GaAs}_{1-\mathrm{x}} \mathrm{N}_{\mathrm{x}}$ alloys regarding several aspects as listed below. Detailed background introduction to these issues will be discussed in Chapter 2.

\subsubsection{Nitrogen incorporation}

Nitrogen, which is related to the bandgap of the material, is a very critical factor on the characteristics of $\operatorname{GaAs}_{1-\mathrm{x}} \mathrm{N}_{\mathrm{x}}$. However, it is still challenging to improve its incorporation efficiency and get more nitrogen without degrading the optical and electronic quality of $\mathrm{GaAs}_{1-}$ ${ }_{x} \mathrm{~N}_{\mathrm{x}}$. Factors like quantities of active nitrogen (determined by $\mathrm{N}$ flux and plasma power), the Ga flux, the As fraction, V/III ration, and the growth temperature were all investigated to determine their effects on $\mathrm{N}$ incorporation, and thereby the optimal conditions can be deduced.

\subsubsection{Surfactant}

To overcome the deterioration due to the addition of more $\mathrm{N}$, one option is the use of surfactant, which relieves the strain caused by the lattice mismatch between the substrate and epilayer, lowers the surface free energy, and inhibits the formation of 3-D growth. Bi, which segregates to the surface and does not incorporate easily under normal growth conditions, was selected as the surfactant for our Surfactant-Mediated MBE growth of $\operatorname{GaAs}_{1-\mathrm{x}} \mathrm{N}_{\mathrm{x}}$. The surface roughness and RHEED pattern with and without $\mathrm{Bi}$ were compared to help understand the influence of bismuth on material's surface morphology. The effect of $\mathrm{Bi}$ on the $\mathrm{N}$ incorporation is also discussed. 


\subsubsection{Postgrowth annealing}

Post-growth thermal treatment effectively removes defects from as-grown material and significantly improves the luminescence efficiency at the cost of a blue-shift of the emission though. The identity of defects and the mechanism under the blue-shift effect remain unclear. To better understand the annealing mechanism, samples selected were annealed at different annealing conditions. With the assistance of characterization tools including photoluminescence (PL), X-ray Photoelectron Spectroscopy (XPS), and Raman spectroscopy, changes of their optical properties as well as compositions of incorporated species were observed compared to asgrown materials.

\subsubsection{Beryllium doping}

Beryllium doping of $\mathrm{GaAs}_{1-\mathrm{x}} \mathrm{N}_{\mathrm{x}}$ was studied to determine the carrier concentration drop of Be-doped $\mathrm{GaAs}_{1-\mathrm{x}} \mathrm{N}_{\mathrm{x}}$ with increasing $\mathrm{N}$ composition. Issues regarding both compensation and activation will be discussed. Experimental results about Bi co-deposition of Be-doped $\operatorname{GaAs}_{1-\mathrm{x}} \mathrm{N}_{\mathrm{x}}$ will also be demonstrated. 


\section{Chapter 2}

\section{Literature Review}

\subsection{Applications}

\subsubsection{High-speed optical data communications}

The rapid development of optical communication technology urges the widely use of glass optical fibers to transmit data. The transmission procedure is initiated as laser diodes converting the original electronic data to optical signals. Then light signals carrying the data information are waveguided within the fiber optic cable and received by optoelectronic detectors at the other end of the fiber and converted back to electronic data.

The increasing need for high-speed telecommunications has driven optical fiber to be equipped with optoelectronic devices that have better performance at longer wavelength. For example, with personal computers becoming more and more popular all over the world, it is important to get network access with higher reliability and speed. However, increasing the speed of optical networks comes at the expense of decreasing the transmission distance due to the fact that signal dispersion within fibers becomes an issue with increased bit rate [Dispersion, 2006]. In such a situation, short wavelength systems obviously can not meet the needs since the attenuation is large over the short wavelength range, causing a huge drop of signal intensity. This problem however can be overcome by employing devices operating within the wavelength between 1.3 and $1.55 \mu \mathrm{m}$ because this regime is associated with less attenuation as seen in Fig 2.1 [Schnelder, 2007]. Consequently, lasers working at longer wavelengths at $1.3 \mu \mathrm{m}$ and 1.55 $\mu \mathrm{m}$ like $\operatorname{GaAs}_{1-\mathrm{x}} \mathrm{N}_{\mathrm{x}}$-based materials are ideal light sources for fiber optic communication 
systems. At these wavelengths, the dispersion of light propagation in optical fibers is close to zero, and the attenuation is also largely minimized.

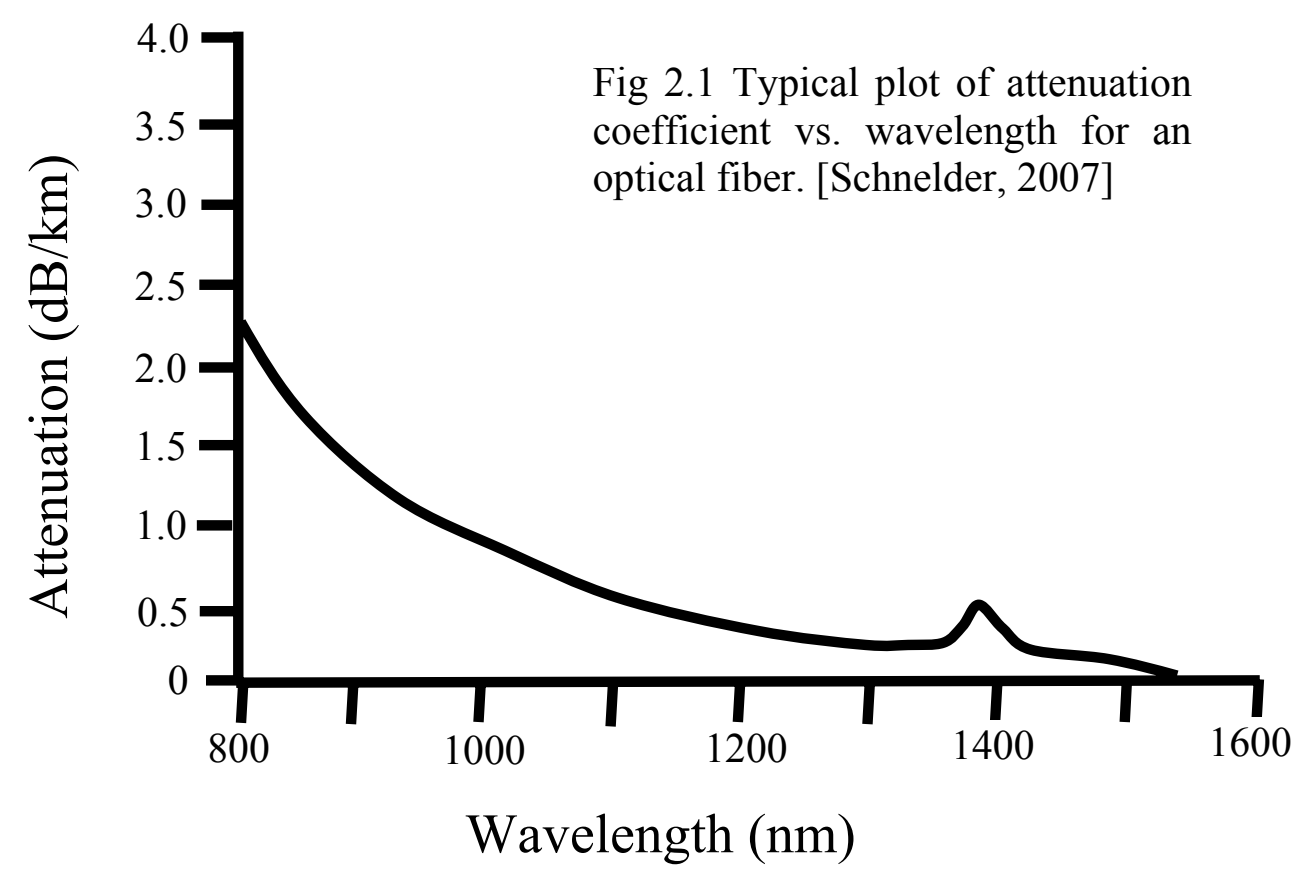

\subsubsection{Potential advantages over current technology}

Compared to InGaAs/GaAs, which is currently utilized for optoelectronic applications and only allows operation wavelengths up to around $1.2 \mu \mathrm{m}, \mathrm{GaAs}_{1-\mathrm{x}} \mathrm{N}_{\mathrm{x}}$ and $\operatorname{InGaAsN}$ can operate at longer wavelengths.

$\mathrm{Ga}_{\mathrm{x}} \mathrm{In}_{1-\mathrm{x}} \mathrm{As}_{\mathrm{y}} \mathrm{P}_{1-\mathrm{y}} / \mathrm{InP}$ is another popular option for long wavelength applications. The band gap energy of $\mathrm{Ga}_{\mathrm{x}} \mathrm{In}_{1-\mathrm{x}} \mathrm{As}_{\mathrm{y}} \mathrm{P}_{1-\mathrm{y}}$ can be expressed as

$$
E_{g}=1.35-0.72 y+0.12 y^{2}
$$


if it is lattice-matched to InP substrate by controlling element compositions to maintain $y=2.2 \mathrm{x}$. It is determined that $0.75 \mathrm{eV} \leq \mathrm{E}_{\mathrm{g}} \leq 1.35 \mathrm{eV}$ from Eq. (2.1), corresponding to the wavelength range of $0.92 \mu \mathrm{m} \leq \lambda \leq 1.65 \mu \mathrm{m}$ [Cai, 2007]. In contrast to $\mathrm{GaAs}_{1-\mathrm{x}} \mathrm{N}_{\mathrm{x}}, \mathrm{Ga}_{\mathrm{x}} \mathrm{In}_{1-\mathrm{x}} \mathrm{As}_{\mathrm{y}} \mathrm{P}_{1-\mathrm{y}}$ has a small bowing parameter. For example, the band gap energy of $\mathrm{GaAs}_{\mathrm{y}} \mathrm{P}_{1-\mathrm{y}}$ is nearly linearly decreasing when it is close to the GaAs side as shown in Fig 2.2 [Walukiewicz]. Fig 1.3 (section 1.1) also indicates an almost linear composition dependence of $\mathrm{Ga}_{\mathrm{x}} \mathrm{In}_{1-\mathrm{x}} \mathrm{As}$ with changing $\mathrm{x}$.

For comparison, Table 2.1 lists basic properties of GaAs, InP, and GaInP.

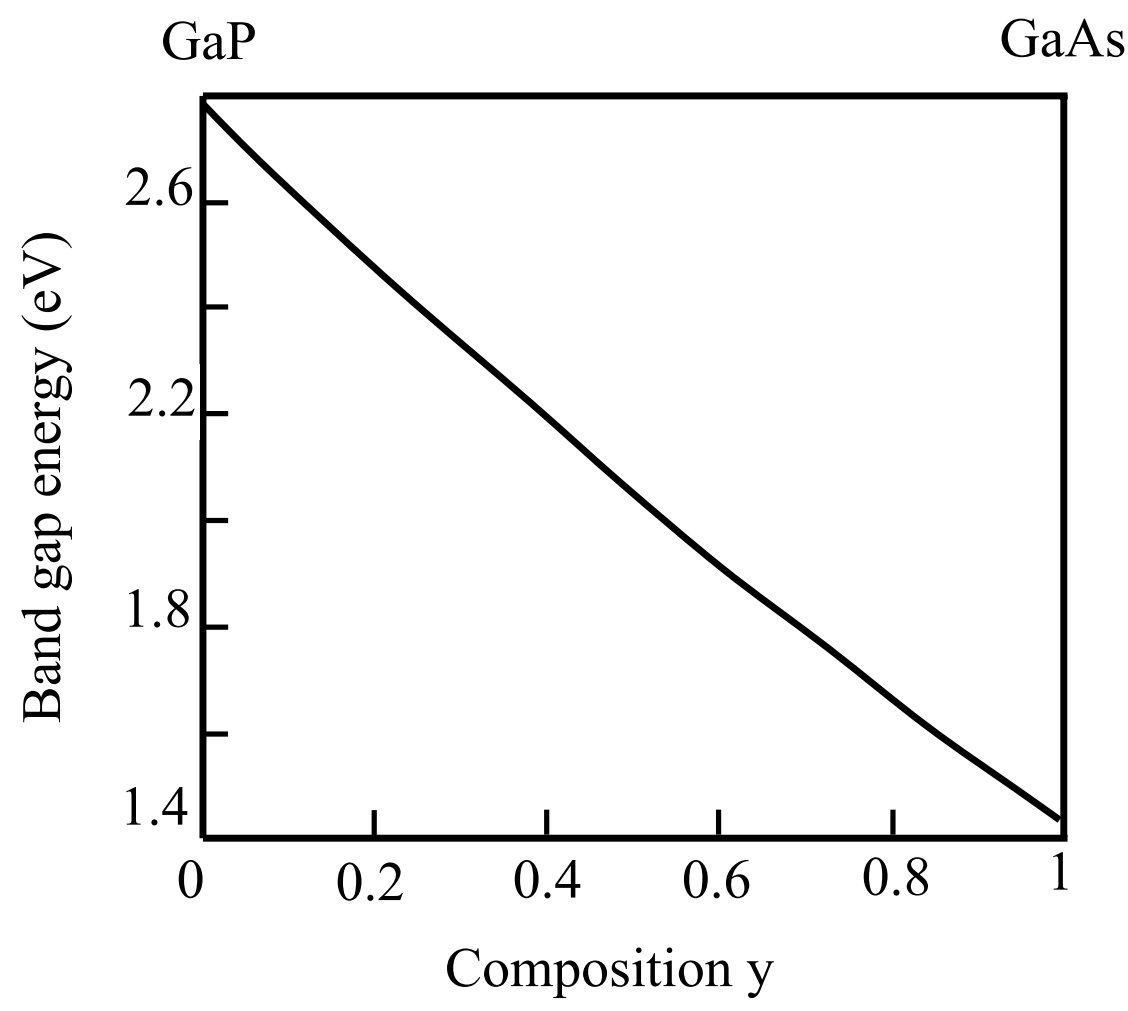

Fig 2.2 The dependence of $\mathrm{GaAs}_{\mathrm{y}} \mathrm{P}_{1-\mathrm{y}}$ wavelength on $\mathrm{y}$. [Walukiewicz] 
Table 2.1 Basic properties of Zinc Blende GaAs, InP and GaInP at room temperature.

[Ioffe, 2001]

\begin{tabular}{|c|c|c|c|}
\hline & GaAs & InP & $\mathrm{Ga}_{\mathrm{x}} \mathrm{In}_{1-\mathrm{x}} \mathrm{P}$ \\
\hline Crystal structure & Zinc Blende & Zinc Blende & Zinc Blende \\
\hline Group of symmetry & $\mathrm{T}_{\mathrm{d}}^{2}-\mathrm{F} 43 \mathrm{~m}$ & $\mathrm{~T}_{\mathrm{d}}^{2}-\mathrm{F} 43 \mathrm{~m}$ & $\mathrm{~T}_{\mathrm{d}}^{2}-\mathrm{F} 43 \mathrm{~m}$ \\
\hline Lattice constant & $5.65325 \AA$ & $5.8687 \AA$ & $5.8687-0.4182 \mathrm{x} \AA$ \\
\hline Energy gap & $1.424 \mathrm{eV}$ & $1.344 \mathrm{eV}$ & \\
\hline Density & $5.32 \mathrm{~g} \cdot \mathrm{cm}^{-3}$ & $4.81 \mathrm{~g} \cdot \mathrm{cm}^{-3}$ & $4.81-0.67 \times \mathrm{g} \cdot \mathrm{cm}^{-3}$ \\
\hline Atomic density & $4.42 \cdot 10^{22} \mathrm{~cm}^{-3}$ & $3.96 \cdot 10^{22} \mathrm{~cm}^{-3}$ & $(3.96+0.98 \mathrm{x}) \cdot 10^{22} \mathrm{~cm}^{-3}$ \\
\hline Molecular weight & 144.64 & 145.77 & 145.77 \\
\hline Effective electron mass $m_{e}$ & $0.063 \mathrm{~m}_{\mathrm{o}}$ & $0.08 \mathrm{~m}_{\mathrm{o}}$ & \\
\hline $\begin{array}{c}\text { Effective hole } \\
\text { masses(heavy) } \mathrm{m}_{\mathrm{h}}\end{array}$ & $0.51 \mathrm{~m}_{\mathrm{o}}$ & $0.6 \mathrm{~m}_{\mathrm{o}}$ & $0.6+0.19 \mathrm{x} \mathrm{m}_{\mathrm{o}}$ \\
\hline $\begin{array}{c}\text { Effective hole } \\
\text { masses(light)m } \mathrm{m}_{\mathrm{lp}}\end{array}$ & $0.082 \mathrm{~m}_{\mathrm{o}}$ & $0.089 \mathrm{~m}_{\mathrm{o}}$ & $0.09+0.05 \mathrm{x} \mathrm{m}_{\mathrm{o}}$ \\
\hline Dielectric constant (static) & 12.9 & 12.5 & $12.5-1.4 \mathrm{x}$ \\
\hline $\begin{array}{l}\text { Dielectric constant (high } \\
\text { frequency) }\end{array}$ & 10.89 & 9.61 & $9.61-0.5 x$ \\
\hline Melting point & $1238^{\circ} \mathrm{C}$ & $1060^{\circ} \mathrm{C}$ & \\
\hline $\begin{array}{l}\text { Electron mobility } \\
\quad \text { (undoped) }\end{array}$ & $\leq 8500 \mathrm{~cm}^{2} \cdot \mathrm{V}^{-1} \cdot \mathrm{s}^{-1}$ & $\leq 5400 \mathrm{~cm}^{2} \cdot \mathrm{V}^{-1} \cdot \mathrm{s}^{-1}$ & \\
\hline Hole mobility (undoped) & $\leq 400 \mathrm{~cm}^{2} \cdot \mathrm{V}^{-1} \cdot \mathrm{s}^{-1}$ & $\leq 200 \mathrm{~cm}^{2} \cdot \mathrm{V}^{-1} \cdot \mathrm{s}^{-1}$ & \\
\hline Debye temperature & $360 \mathrm{~K}$ & $425 \mathrm{~K}$ & \\
\hline Optical phonon energy & $35 \mathrm{meV}$ & $0.043 \mathrm{meV}$ & \\
\hline Electron affinity & $4.07 \mathrm{eV}$ & $4.38 \mathrm{eV}$ & $4.38-0.58 \mathrm{x} \mathrm{eV}$ \\
\hline
\end{tabular}


Although InP-based devices operate at long wavelengths, InP substrates are more expensive and less robust than GaAs substrate, which is mass producible. For example, for 2 inch (100) undoped InP and GaAs wafers with the same thickness and quality, the former may cost $\$ 400 /$ piece, while the latter costs about \$250/piece [Waferworld, 2007].

In order to reduce the energy waste, i.e. enhance the efficiency of optoelectronic devices, during the fabrication process, for applications like vertical-cavity surface-emitting lasers (VCSELs), the active region is typically sandwiched by cladding layers to confine carriers. Distributed Bragg reflectors (DBRs) grown around the active layers are often used for optical confinement and light amplification purpose. The low refractive index contrast in InP-based devices, however, limits the efficiency of the DBR. In this aspect, GaAs substrate is a much better option since AlAs/GaAs DBR mirrors have high reflectivity and mobility as well as low defect density [Kinsey, 2000a]. In addition, GaAs based devices can be compatible with monolithic GaAs integrated circuits [Kinsey, 2000b].

Poor thermal stability is another issue limiting the application of InP-based devices. Thermal stability can be quantitatively described using the concept of characteristic temperature $\mathrm{T}_{\mathrm{o}}$, which is defined as

$$
\mathbf{T}_{\mathrm{o}}\left(\mathbf{T}_{2}\right)=\frac{\mathbf{T}_{2}-\mathbf{T}_{1}}{\ln \left(\mathbf{I}_{\mathrm{th}}\left(\mathbf{T}_{2}\right) / \mathbf{I}_{\mathrm{th}}\left(\mathbf{T}_{1}\right)\right)} \quad\left(\mathrm{T}_{2}>\mathrm{T}_{1}\right)
$$

Where $T_{1}$ and $T_{2}$ denote two adjacent operation temperatures and $I_{\text {th }}$ is the threshold current. Fig 2.3 schematically illustrates the change of $\mathrm{I}_{\mathrm{th}}$ with changing the temperature as an example[Chang, 2005]. 
GaAs has a characteristic temperature $\sim 330 \mathrm{~K}$ [Dutta, 1982]. Ideally, if the threshold current of the device is immune from the influence of the temperature change, this value can be infinity meaning zero thermal sensitivity, but in practice, obtaining a high characteristic temperature is not that simple. $\operatorname{GaAs}_{1-\mathrm{x}} \mathrm{N}_{\mathrm{x}}$-based lasers are less sensitive to the temperature and thus have a higher characteristic temperature compared to InP-based devices. For instance, $\mathrm{T}_{\mathrm{o}}$ greater than 200K has been achieved [Miyamoto] [Gotthold, 2001]. The large bowing parameter by adding $\mathrm{N}$ has a much greater effect on the conduction band than on the valence band [Kitatani, 1999] [Shan, 1999], leading to the large conduction band offset greater than $200 \mathrm{meV}$ [Miyamoto] and forming strong electron confinement region hindering electrons from escaping. In comparison, InP-based devices do not possess large conduction band difference $(<100 \mathrm{meV}$ [Miyamoto]), so this small potential barrier is not able to effectively hold all electrons in the active region, especially for the high temperature situation that carriers are more thermally exciting and active. InP-based devices are therefore getting higher threshold currents with increasing their operating temperatures. As a result, a larger drive current might become a necessity to maintain devices' normal operation [Spruytte, 2002]. Typical $\mathrm{T}_{\mathrm{o}}$ of GaInAsP/InP is around $60 \mathrm{~K}$ [Li, 2002], and $90 \mathrm{~K}$ obtained by Postigo et al. is considered to be high for GaInAsP/InP [Postigo, 2002]. 

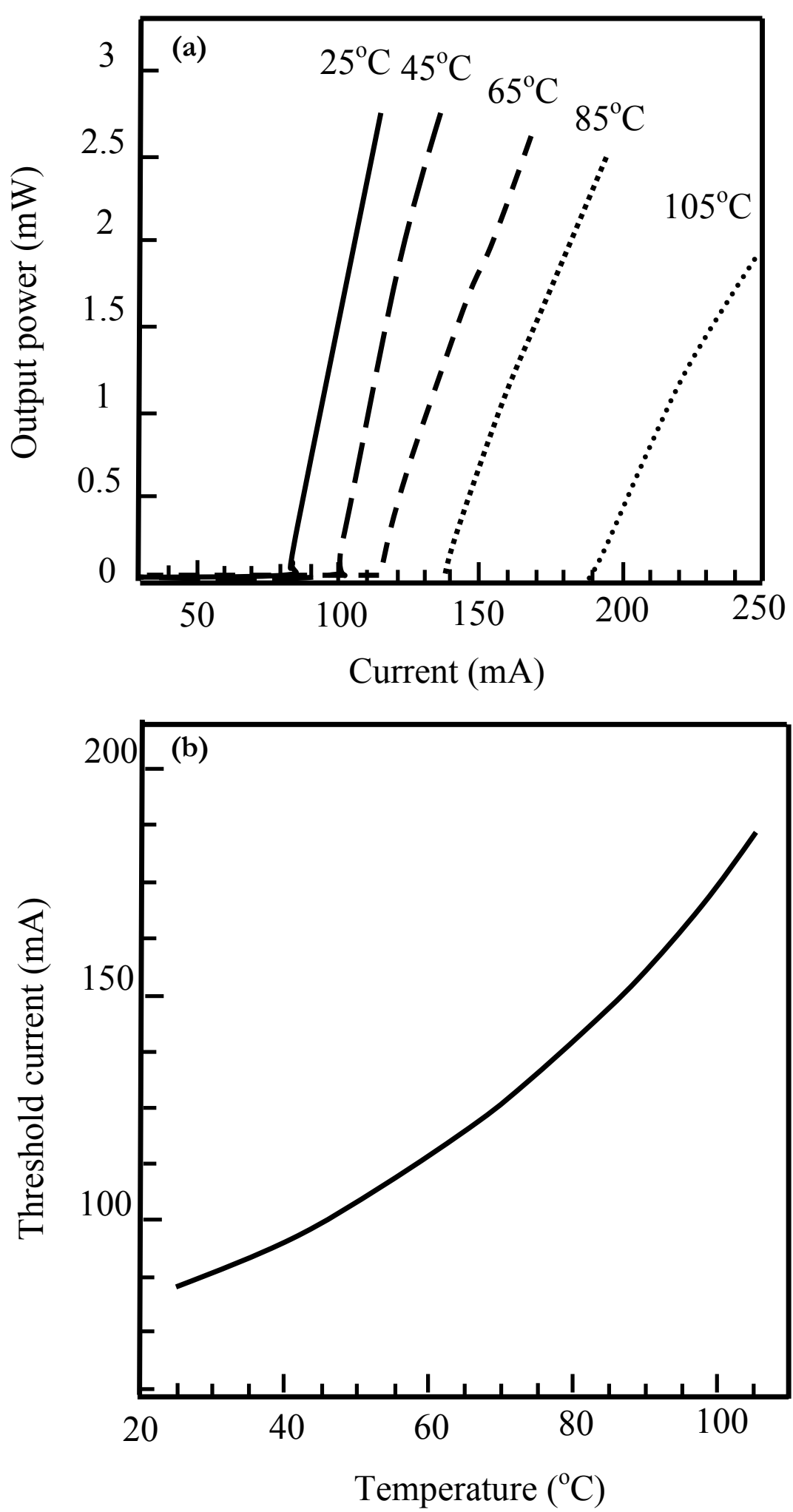

Fig 2.3 Schematic diagram of threshold currents dependent on the temperature of an InGaAsN/GaAsN laser with laser wavelength of $1.295 \mathrm{~nm}$. (a) Output power vs. current; (b) Threshold current vs. temperature. [Chang, 2005] 


\subsubsection{Applications in devices}

$\mathrm{GaAs}_{1-\mathrm{x}} \mathrm{N}_{\mathrm{x}}$-based materials can fabricate highly efficient, cost-effective, and lesstemperature-affected optoelectronic devices. Due to advantages described above, $\mathrm{GaAs}_{1-\mathrm{x}} \mathrm{N}_{\mathrm{x}^{-}}$ based materials are promising for a variety of applications in the optoelectronics field.

\subsubsection{Laser diodes}

The $\mathrm{GaAs}_{1-\mathrm{x}} \mathrm{N}_{\mathrm{x}}$ based broad-area edge-emitters and long wavelength VCSELs are advantageous in terms of cost, robustness and reproducibility (see section 2.1.2.1) due to the less expensive and less fragile GaAs wafer compared to InP as well as $\mathrm{GaAs}_{1-\mathrm{x}} \mathrm{N}_{\mathrm{x}}$ 's lower sensitivity to temperature. $\mathrm{GaAs}_{1-\mathrm{x}} \mathrm{N}_{\mathrm{x}}$-based systems can also have higher transmission speeds because of their larger differential gain than that of conventional long wavelength laser [Kondow, 2003]. The larger gain makes the intensity of optical signals higher, compensating the intensity loss caused by the long distance transmission. In addition, since $\mathrm{GaAs}_{1-\mathrm{x}} \mathrm{N}_{\mathrm{x}}$-based materials can be monolithically grown on a highly reflective AlAs/GaAs DBR mirror, highly quantum efficient VCSELs can be achieved. The VCSEL structure of devices with GaInAsN as the active region and $\mathrm{GaAs}_{1-\mathrm{x}} \mathrm{N}_{\mathrm{x}}$ grown as a barrier layer adjacent to GaInAsN was found correlated to better performance and higher thermal stability beyond a wavelength of $1.2 \mu \mathrm{m}$ [Spruytte, 2002].

\subsubsection{Photodiodes, and photo detectors}

$\mathrm{GaAs}_{1-\mathrm{x}} \mathrm{N}_{\mathrm{x}}$ can be also fabricated as detectors working over a broader light spectrum for high-speed data links and optical networks applications. A photo diode or detector, which senses and converts light signals to electric signals, has its sensitivity defined as the minimum optical power it is able to detect for a specified $\mathrm{S} / \mathrm{N}$ (signal-to-noise ratio) value [Das]. $\mathrm{dBm}$ is the unit 
commonly used for describing its sensitivity. The minimum power can be derived from the incident optical power $P_{\text {inc }}$ and the photo detector's efficiency $\eta$ as

$$
\mathrm{P}_{\text {min }}=\eta \mathrm{P}_{\text {inc }} / 2^{1 / 2}
$$

Conventionally silicon and InGaAs photo detectors are in use to accommodate long and short wavelengths requirements respectively. However, the low sensitivities of Si below 1.064 $\mu \mathrm{m}$ and of InGaAs over $0.94 \mu \mathrm{m}$ create a sensitivity valley imposing restrictions of applications within this wavelength range.

This problem was overcome by applying $\operatorname{GaAs}_{1-\mathrm{x}} \mathrm{N}_{\mathrm{x}}$, which besides working at $1.3 \mu \mathrm{m}$ and $1.5 \mu \mathrm{m}$, was used to fabricate resonant-cavity avalanche photodiodes (APDs) operating at 0.94 and $1.064 \mu \mathrm{m}$, by Kinsey et al. [Kinsey, 2000a] [Kinsey, 2000b] through controlling the $\mathrm{N}$ incorporation. In comparison to silicon detectors, which is a less efficient optical absorber within the wavenlength range above, these APDs have a higher efficiency as well as lower breakdown voltages due to the small band gap, and the growth process is not as complicated as the InGaAs structure growth.

Another group [Luna, 2003] fabricated quantum-well infrared photodetectors (QWIPs) with $\mathrm{GaAs}_{1-\mathrm{x}} \mathrm{N}_{\mathrm{x}}$ sandwiched into double-barrier structure as shown in Fig 2.4. The transitions between the intersubbands of $E_{2}$ and $E_{1}$ within the conduction band of the quantum wells correspond to the infrared wavelength of $1.64 \mu \mathrm{m}$ at $25 \mathrm{~K}$, and thus realizing the infrared light absorption. 


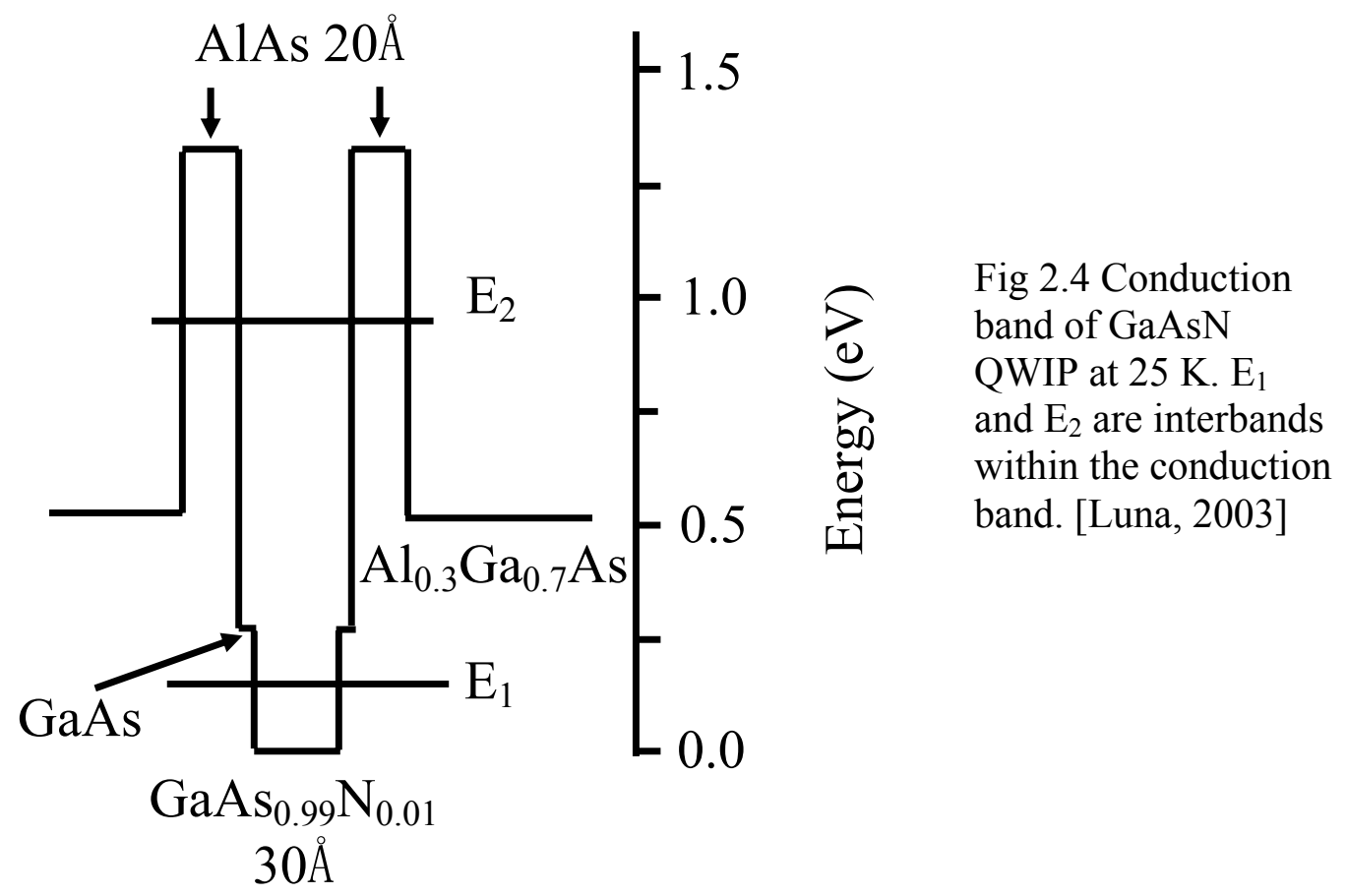

\subsubsection{Heterojunction bipolar transistors (HBTs)}

The large band gap bowing parameter in $\operatorname{GaAs}_{1-\mathrm{x}} \mathrm{N}_{\mathrm{x}}$ leads it to be very promising base layer candidate for low power HBT devices since the smaller band gap reduces the turn-on voltage required, and thus leads to less power dissipation and higher efficiency. Fig 2.5 is the schematic diagram of a typical GaAs $s_{1-x} \mathrm{~N}_{\mathrm{x}}$ based HBT device [Chang, 2000]. GaAs $\mathrm{s}_{1-\mathrm{x}} \mathrm{N}_{\mathrm{x}}-\mathrm{based}$ HBTs have many applications like power amplifiers for wireless handsets and high speed circuits for fiber optic communication systems [Welser, 2001]. 


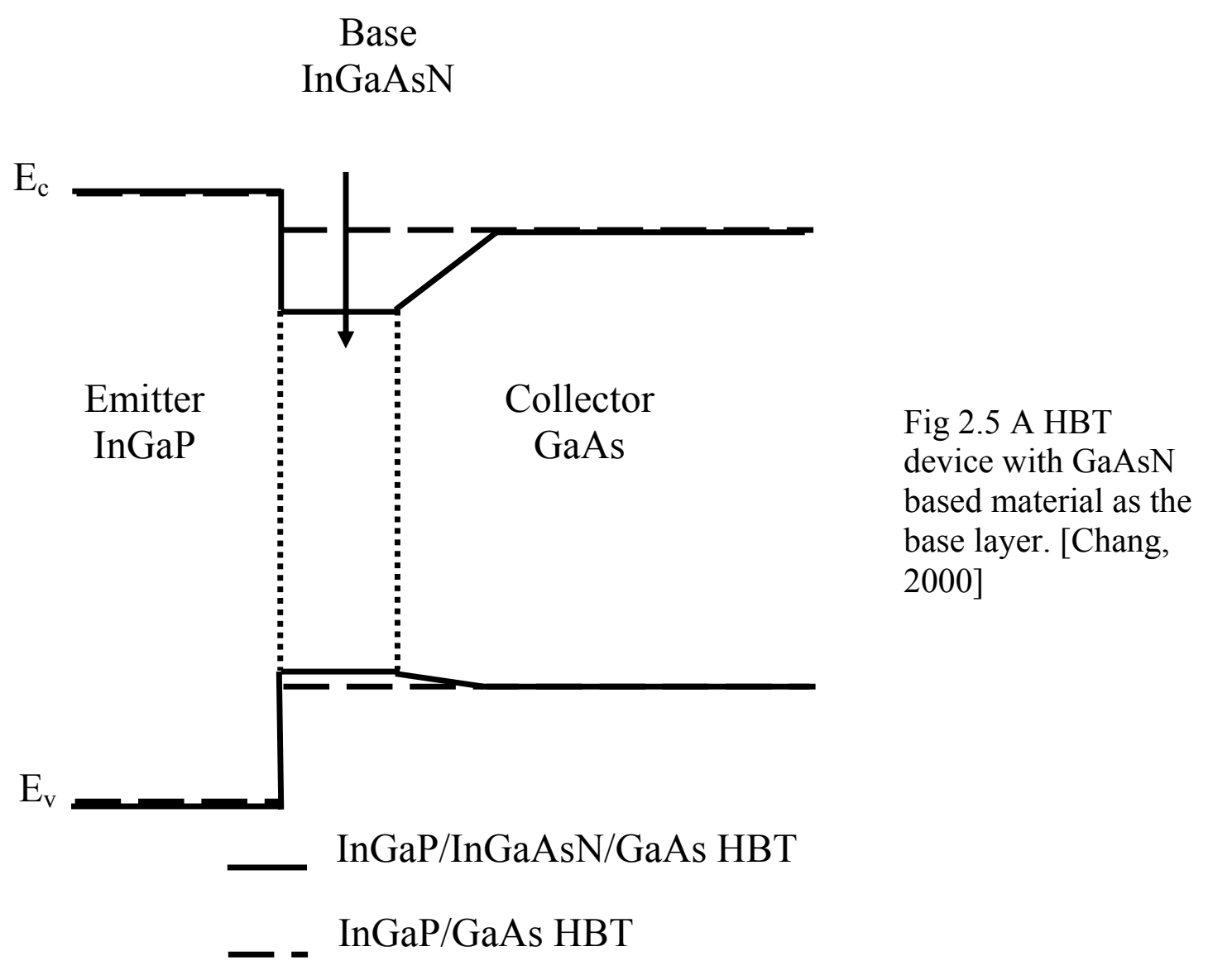

\subsubsection{Solar cells}

The bandgap and crystal structure (i.e., lattice constant) of $\mathrm{GaAs}_{1-\mathrm{x}} \mathrm{N}_{\mathrm{x}}$ also leads it to be a good material for solar cells in space power systems. Since the bandgap energy of $\mathrm{GaAs}_{1-\mathrm{x}} \mathrm{N}_{\mathrm{x}}$ is largely reduced by introducing nitrogen into GaAs, the energy required to create current by transferring an electron from valence band to conduction band will be less. Therefore, when used as an electricity-generating solar cell, $\mathrm{GaAs}_{1-\mathrm{x}} \mathrm{N}_{\mathrm{x}}$ can raise the overall cell efficiency and extract more power compared to traditionally used silicon. Due to its higher efficiency, $\operatorname{GaAs}_{1-\mathrm{x}} \mathrm{N}_{\mathrm{x}}$ makes the solar collecting package smaller and thus reduces satellite mass. Practical results 
demonstrate that it can have a much higher efficiency rate than that of a standard silicon solar cell [Allan, 2002].

\section{2 $\mathrm{N}$ incorporation}

The band gap decreases with increasing nitrogen compositions, but the nitrogen solubility in GaAs is not high (The equilibrium solubility of nitrogen is less than 2\% [Neugebauer, 1995]), and only a small amount of nitrogen can practically get incorporated. The heavily distorted bonds, which are caused by the much higher force constants (bond strength per unit length) and shorter bond lengths Ga-N bond owes compared to those of Ga-As bond, may eventually result in phase separation and limit further incorporation of $\mathrm{N}$ [Tite, 2004] [Bi, 1997]. Growing out of equilibrium, e.g. at low temperatures can partially overcome this but at the cost of degrading material quality.

The crystal quality of GaNAs deteriorates dramatically with increasing $\mathrm{N}$ concentration because of the large miscibility gap and phase separation due to the large size difference of $\mathrm{N}$ and As atoms [Buyanova, 2000].

\subsection{Defects and thermal annealing}

Due to the large difference in atomic sizes of $\mathrm{Ga}$, and As atoms compared to the $\mathrm{N}$ atom, and bombardment of energetic nitrogen ions during growth, as-grown GaNAs materials are relatively defective. Post-growth treatment is often used to remove defects and improve the alloy quality. On one hand, it largely increases the luminescence efficiency, but on the other hand, it could cause an undesired blue-shift of the emission. The mechanism of annealing has not been fully determined and still under study. 
It is speculated that the removal of non-radiative traps which are actually interstitial nitrogen less strongly bonded to Ga atoms is responsible for the improvement of luminescence efficiency after annealing [Spruytte, 2001]. Another report [Li, 2001b] attributes the low photoluminescence intensity of as-grown material to nitrogen interstitials and Ga vacancies. In addition to the reduction of the concentration of non-radiative defects, rapid thermal annealing (RTA) might also improve composition uniformity [Buyanova, 2000]. Another group [Loke, 2002] reports an intermediate redshift while with an overall blueshift of PL spectra when RTA was applied at $525-850^{\circ} \mathrm{C}$ suggesting an intermediate substitutional-interstitial diffusion.

\subsection{Surfactant}

During $\operatorname{GaAs}_{1-\mathrm{x}} \mathrm{N}_{\mathrm{x}}$ growth the surface becomes rougher with increasing $\mathrm{N}$ content. The increased strain results in the relaxation of the layer, yielding 3-D islands and deteriorating the quality of the film. Surfactants are widely used as a way to suppress the roughness. Sb [Sun, 2005], In [Morooka, 1999], and Te [Massies, 1992] are all candidates for this purpose. However, residual Te may get incorporated acting as a donor [Pillai, 2000]. In and Sb also have the same effect, incorporating into the material under typical growth conditions [Young, 2005]. Lately, bismuth started to attract more attention due to the advantage that normally it does not incorporate easily [Sakamoto, 1993]. Since it is isoelectronic with group-V atoms, trace amounts of incorporation would not change background doping levels and electrical properties of $\mathrm{GaAs}_{1-}$ ${ }_{x} \mathrm{~N}_{\mathrm{x}}$ [Pillai, 2000] [Young, 2005]. In addition, it might help increase the $\mathrm{N}$ incorporation as reported by Young et al. [Young, 2005], who observed an increase of nitrogen incorporation as much as $50 \%$ (from $\mathrm{x} \sim 0.4 \%$ to $\sim 0.6 \%$, and from $\mathrm{x} \sim 0.6 \%$ to $\sim 0.9 \%$ ) under Bi during their $\operatorname{GaAs}_{1-\mathrm{x}} \mathrm{N}_{\mathrm{x}}$ growth. 


\subsection{Be doping}

Doped $\mathrm{GaAs}_{1-\mathrm{x}} \mathrm{N}_{\mathrm{x}}$ can be employed in devices such as photo diodes, photo detectors, HBTs, etc. Due to its lower band gap, p-type $\mathrm{GaAs}_{1-\mathrm{x}} \mathrm{N}_{\mathrm{x}}$ potentially can be used as the base layer of n-p-n heterojunction bipolar transistors as discussed in section 2.1.3.3 since it yields less power dissipation. Be is a very common dopant for p-type GaAs.

\subsubsection{Be-doped GaAs}

For shallow acceptors, the ionization energy is $\sim 28 \mathrm{meV}$ [Binggeli, 1991] [Kressel, 1969]. Its mobility is less than $400 \mathrm{~cm}^{2} \mathrm{~V}^{-1} \mathrm{~s}^{-1}$ [Ioffe, 2001]. Fig. 2.6 is dependence of the hole hall mobility on carrier concentration. The mobility drops with increasing the doping level [Wiley, 1975]. It was found that if the doping level exceeds a critical concentration of $2.6 \times 10^{19} \mathrm{~cm}^{-3}$, the shrinkage of the lattice constant of the epilayer as well as the substitutional and interstitial Be outdiffusion into the substrate would take place [Liu, 1992].

\subsubsection{Be-doped GaAs $s_{1-\mathrm{x}} \mathrm{N}_{\mathrm{x}}$}

The addition of $\mathrm{N}$ reduces hole mobilities [ $\mathrm{Li}, 2001$ ] [Matsuura, 2004], which is commonly explained by the alloy scattering. But Matsuura et al. proposed another possibility, i.e. ionic scattering caused by the large electron negativity of nitrogen since even if with only $0.78 \% \mathrm{~N}$ incorporated, they observed a very significant drop of mobility, $\sim 33 \%$ relative to that of GaAs [Matsuura, 2004].

More important, it was found that the conductivity of Be-doped GaAsInN dropped significantly if more nitrogen is incorporated. For the growth by gas source molecular beam epitaxy (GSMBE) [Xin, 2000] [Li, 2001], hydrogen was thought to be the factor passivating the acceptors in GaInNAs by forming H-N-Be complexes, and which could be reduced by RTA as they claimed. However, Matsuura et al. [Matsuura, 2004], who also observed the drop of carrier 
concentrations of GaNAs and GaInNAs by solid source molecular beam epitaxy (SSMBE) growth which is free from hydrogen of the source materials, did not see any obvious change of carrier concentrations after RTA.

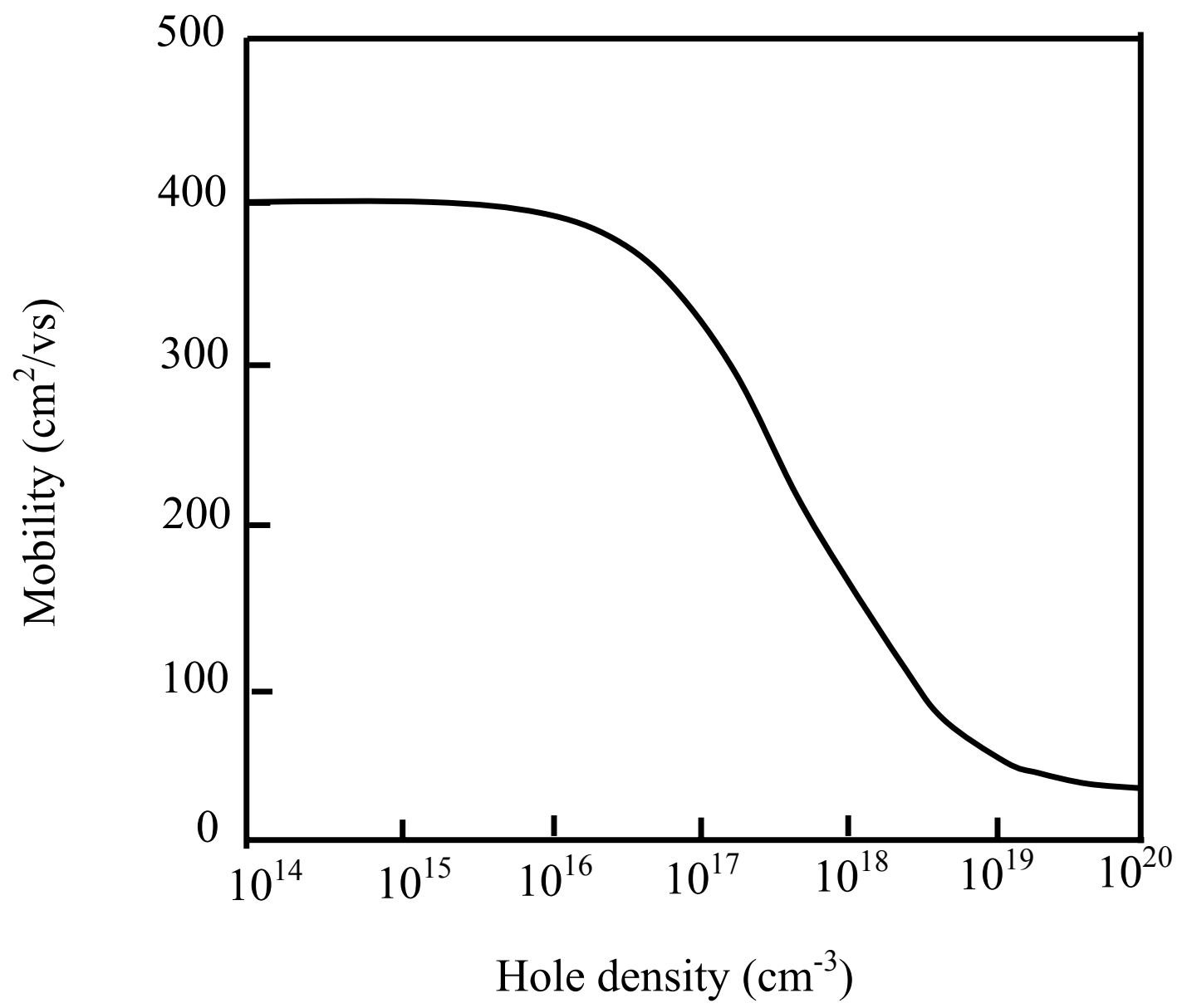

Fig 2.6 GaAs Hole mobility vs. hole concentration at room temperature. [Wiley, 1975] 


\section{Chapter 3}

\section{Experimental Set up}

\subsection{System Description}

All growths were carried out in a remodeled VG V80H MBE, which consists of three chambers, entry chamber, buffer chamber, and growth chamber. There is also a manifold connecting all these three chambers to each other as well as pumping chambers and purging connection lines. All components of the MBE system are constructed of stainless steel. The block diagram of the system is shown in Fig 3.1.

\subsubsection{Growth chamber}

The growth chamber (Fig 3.2) holds an ultra high vacuum environment for the material growth. It is separated from the buffer chamber by a gate valve, and pumped with a Cryo-Torr 10 cryopump,

Solid sources, Ga, In, Bi, and Be, loaded in Knudsen effusion cells separately, hooked up to individual temperature controllers, and heated up independently, are all equipped with pneumatic beam shutters which are manipulated by shutter controllers either manually or through a remote computer, to interrupt the flux between the source and the substrate.

Active nitrogen is generated through an Oxford Applied Research HD25 RF - plasma nitrogen source. A MDC Ultra-High Vacuum Precision Leak Valve ULV-150 was added between the plasma source and the gas tank to control the flow of the gas. For safety purposes, a Thomas 1600 series flow switch allowing a minimum flow rate of 0.25 gallon per minute (GPM) 
was equipped to ensure enough cooling water running through and prevent the source from overheating. An Omega DP461-V process indicator was hooked up to the RFX600 RF power supply to serve as an interlock shutting off the power when the reflected power is beyond the allowable range.

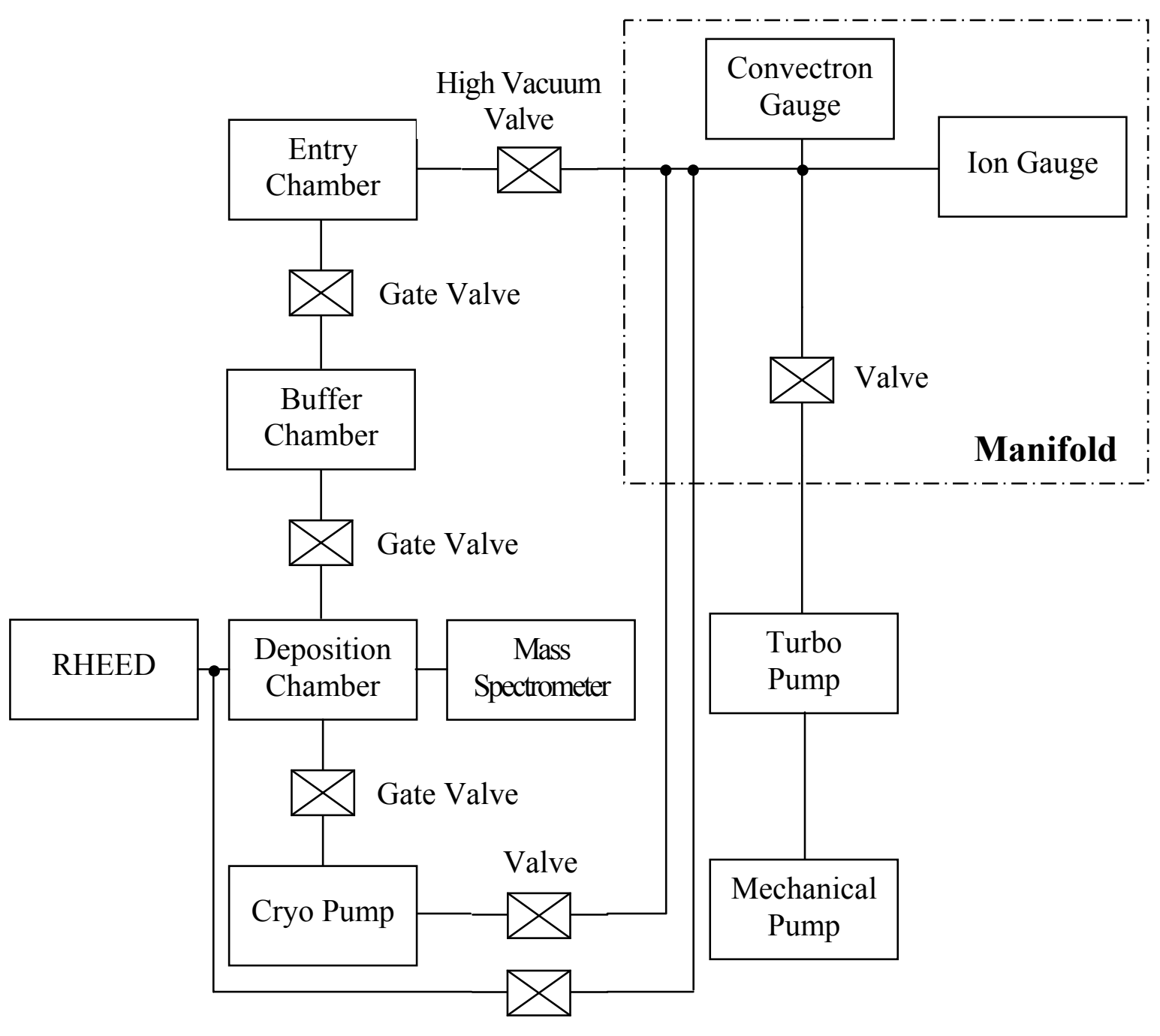

High Vacuum Valve

Fig 3.1 Diagram of the remodeled V80H system. 


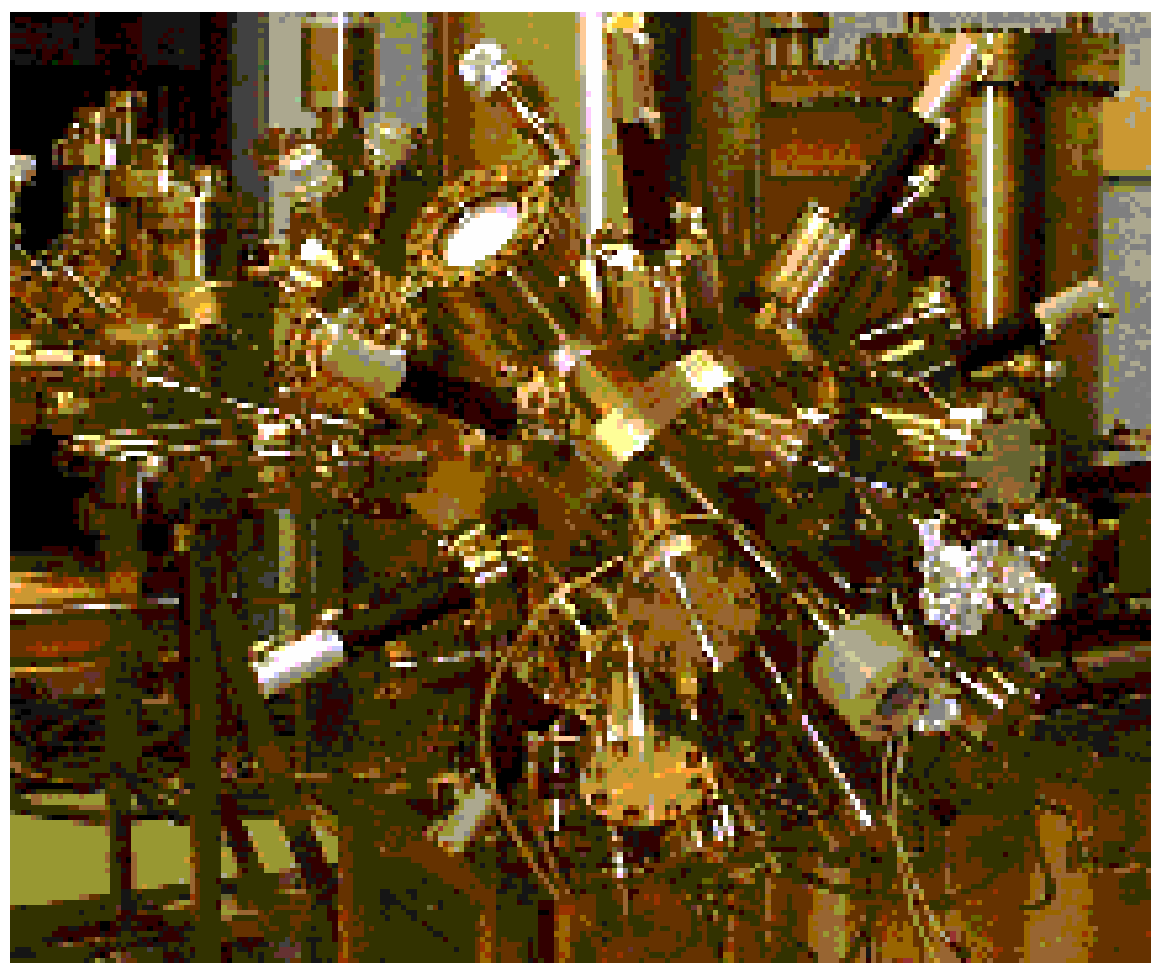

Fluorescent screen for RHEED

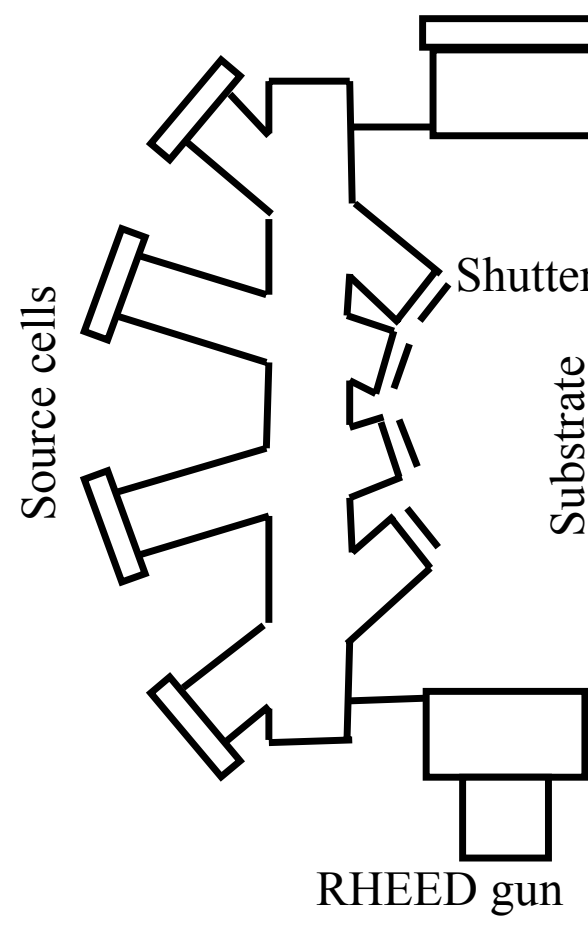

Fig 3.2 The outlook and schematic drawing of the growth chamber. 
Instead of a conventional effusion cell, a cracker cell is used to generate arsenic species, $\mathrm{As}_{4}$ or $\mathrm{As}_{2}$, depending on the temperature applied in the cracking zone, where the originally evaporated tetramer $\mathrm{As}_{4}$ passes through and is "cracked" into As2 or remain As 4 , prior to reaching the substrate. In this study, $900^{\circ} \mathrm{C}$ was applied to crack $\mathrm{As}_{2}$ and $550^{\circ} \mathrm{C}$ was used for $\mathrm{As}_{4}$. At a certain bulk zone temperature, the arsenic flux is determined by the position of a valve located in the bulk zone as the valve can be moved to any position (from close to fully open) by operating a valve positioner.

Source positions were carefully chosen to ascertain fluxes would not change appreciably with the depletion of the source materials. The position of As is not very important since it sublimes instead of melting. Ga, which melts at $30^{\circ} \mathrm{C}$, was placed in a low position to avoid the metal running out of the crucible, as was the In and $\mathrm{Bi}$. Be, which also sublimes, was placed in the top positions where the cell is almost horizontal. Fig 3.3 is a schematic diagram of source locations in our MBE system. All solid sources except bismuth have an idle temperature of $200^{\circ} \mathrm{C}$. Bismuth, which melts at $271.3{ }^{\circ} \mathrm{C}$ and expands $3.3 \%$ of volume on changing from liquid back to solid, is left at $300^{\circ} \mathrm{C}$ while not growing,

To keep the uniformity of the film being grown, a stepper motor is used to drive the substrate rotating during the growth. Indium-free molybdenum UNI-Block substrate holder ensures quick and clean mount of substrate. For each growth, one quarter of a 2" GaAs (100) wafer was used as the substrate. A beam flux monitor (BFM) attached to substrate manipulator calibrates the molecular beam intensities of different species.

To precisely control the thickness of the film, highly stable Eurotherm 825 proportionalintegral-derivative (PID) temperature controllers and type C Tungsten-Rhenium thermocouples are equipped to provide stable temperatures for the substrate and source cells. 


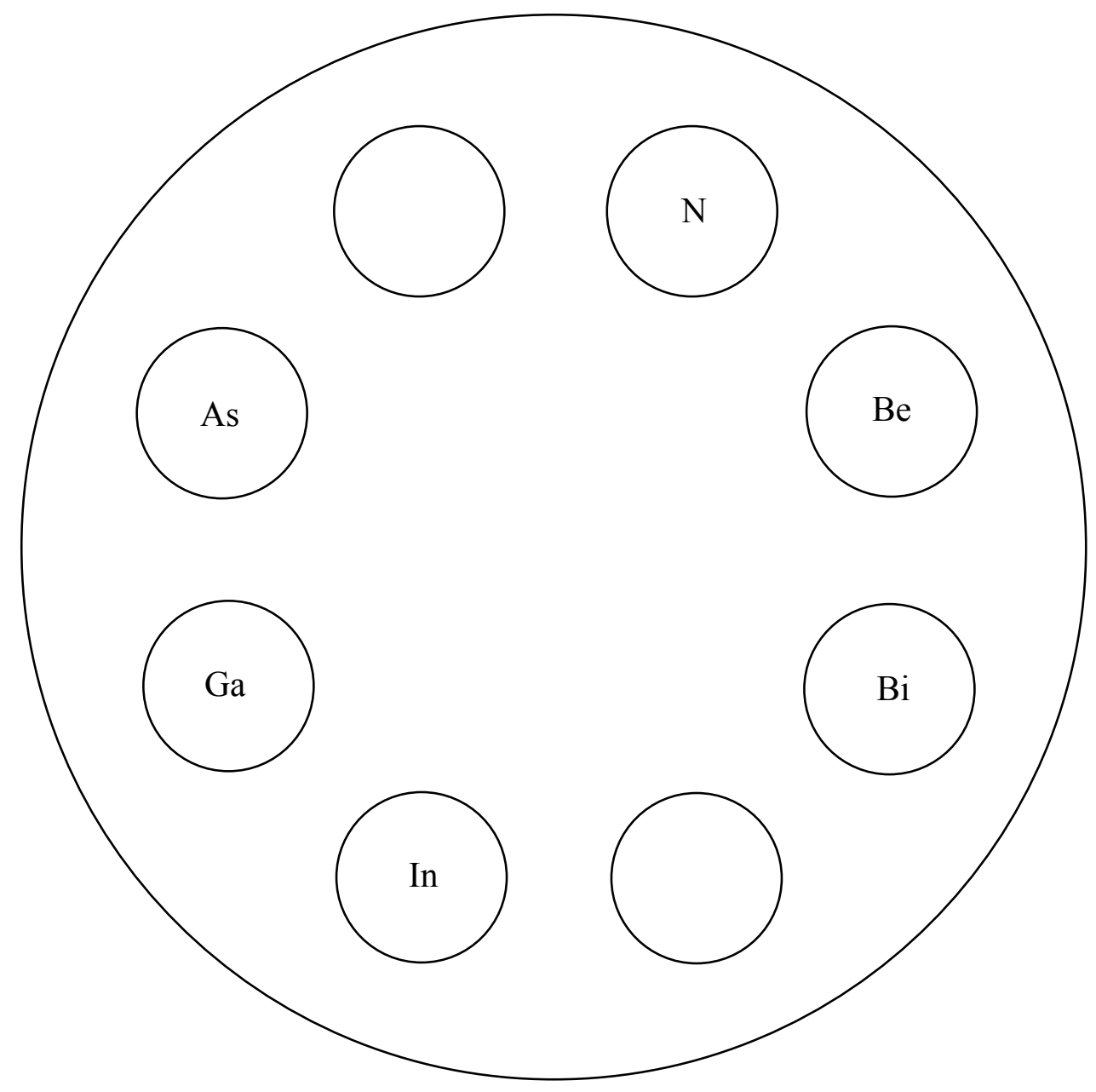

Fig 3.3 A schematic diagram of source locations in our MBE system.

A cryopanel surrounds the substrate and sources, providing a cold wall environment while growing. Instead of liquid nitrogen which is a typical cooling source for filling the cryopanel, cooling water lines was hooked up to this system to reduce the cost and to avoid the complications caused by transporting and transferring liquid $\mathrm{N}_{2}$. The re-circulated water, normally running at the temperature of $9^{\circ} \mathrm{C}$, cools down the growth chamber, minimizing the outgassing of impurities from walls of the chamber, preventing contaminants from incorporating 
into the film, eliminating cross contamination and crosstalk between adjacent sources and furnaces, and avoiding the high vacuum environment being broken due to overheating portions of the chamber.

A mass spectrometer, which can quantitatively diagnose species of molecules in the vacuum system, and a Reflection High Energy Electron Diffraction(RHEED) gun for in-situ monitoring the growth are also installed in the growth chamber.

\subsubsection{Buffer chamber}

The buffer chamber protects growth chamber from being contaminated by high pressure difference while venting. It also functions as a place to prepare and store samples, and to transfer samples through a transition tube to the growth chamber. The transfer system, including a substrate holder trolley on a track, driven by a rotary manipulator, guiding the sample to any chosen position, builds connections between three stages in the buffer, the cassette entry position, the sample storage stage, and the outgas station, each with a $100 \mathrm{~nm}$ I. D. viewport and a transfer fork allowing visually manipulating the sample onto and off the trolley.

The storage stage can hold at most 10 samples. A temperature controller and a power supply are also equipped for substrate outgassing up to $850^{\circ} \mathrm{C}$. An ion pump is used for the buffer chamber and typically keeps the pressure at about $10^{-9} \mathrm{mbar}$.

\subsubsection{Entry chamber}

The entry chamber is designed with a low volume for quick $\mathrm{N}_{2}$-purged vent and pump out while loading and unloading samples. It is equipped with a cassette rapid entry lock using the cassette lifting mechanism and can contain a cassette substrate holder with 10 positions for 
holding up to 10 samples. An isolation valve is separating the entry chamber from the buffer chamber.

\subsubsection{Manifold}

The manifold was re-designed to make connections from the mechanical pump (acting as a backing pump) and the turbopump to the load lock, to the cryopump and to the growth chamber through a 4-way cross, and high vacuum valves were inserted to create or isolate connections between these units. The combination of the turbo pump and the mechanical pump pumps down the load lock after loading samples, or rough pumps the preparation chamber and the deposition chamber, and can also regenerate the cryopump.

\subsection{System Preparation}

\subsubsection{System setup}

The VG V80H MBE system was remodeled and upgraded. A new cyropump was installed in the growth chamber to substitute the old diffusion pump. The RHEED gun was replaced, and a mass spectrometer was also installed. Ion gauge filaments and the beam flux monitor were repaired. The stepper motor was also repaired to ensure the rotation of substrates during growth. For the rf-plasma source, a new discharge tube, leak valve, gas line and interlock connections were designed and equipped for generating and controlling $\mathrm{N}$ flux. Gas lines providing compressed air were hooked up to pneumatic shutters. Water cooling connections as well as power supplies for outgas station, source cells and substrate were made for cooling and

heating. The gate valve between the cryopump and the growth chamber was replaced as well to fix the leak there. 


\subsubsection{Leak test}

Keeping an ultra high vacuum environment is of importance for obtaining less- defectmaterials with desired characteristics. Even a small leak can bring water and other impurities into the growth and cause unwanted contamination. Leak check is necessary to inspect the intactness of the vacuum environment. After the system set up, leak test was conducted with an inert search gas, typically ultra-high purity (UHP) helium, which is neither destructive nor explosive, and as the lightest inert gas (with an Atomic Mass Unit (AMU) of 4), is superior to other gases in the aspect of sensitivity and Signal to Noise ratio because it does not typically present as a background atmospheric gas, and it is able to easily and quickly diffuses through small cracks. Fine helium stream coming out of a nozzle was sprayed onto the outer surface of the system targeting any suspicious place, especially junction areas of different flanges, which are usually with a higher leakage possibility. If a leak exists at the area exposed to helium, the helium gas can enter the system through that leak and be detected by the mass spectrometer, so a rise of helium content indicates the presence of the leakage.

\subsubsection{Oxygen cleaning}

Oxygen was chosen to do a plasma clean-up of the chamber prior to use as it removes organic impurities, such as carbon. Ions generated from ultra high purity oxygen can react with organics and form volatile oxides, which can be very easily pumped out from the growth chamber. An oxygen clean process totally lasting 8.5 hours was employed to clean the growth chamber with a plasma power of $400 \mathrm{~W}$ and oxygen partial pressure of $\sim 5 \times 10^{-6}$ Torr. Oxygen was supplied through the same setup (for generating nitrogen RF plasma) described in section 3.1.1 but with the liner and the aperture plate $(448 \times 0.2 \mathrm{~mm})$ different from those of $\mathrm{N}$ source. 


\subsubsection{Loading source materials and outgassing}

Solid source materials, Ga, In, As, Be and Bi were loaded into crucibles equipped for source cells by venting the growth chamber. Once the material was loaded, outgassing needs to be done for each source cell to minimize any potential contamination by impurities that may arise from venting and from other operations while loading. A temperature higher than the cell's normal operating temperature was used to outgas the cell. Table 3.1 shows source cell temperatures used for outgassing with their typical operating temperatures listed also. Some materials are furnished with dual filament source cells, which have two heaters, primary and tip heaters, with the former heating the major part of the crucible and the latter heating the mouth region of the crucible. The use of the additional tip heater prevents the clog of materials at the tip area of the crucible.

Tabe 3.1 Operating and outgassing temperatures applied for source materials loaded in VGV80H MBE system

\begin{tabular}{|c|c|c|c|c|c|c|c|c|c|}
\hline & \multicolumn{2}{|c|}{ Ga } & \multicolumn{2}{|c|}{ In } & \multicolumn{2}{|c|}{ As } & \multirow[t]{2}{*}{$\mathbf{B e}$} & \multicolumn{2}{|c|}{$\mathbf{B i}$} \\
\hline & Prime & Tip & Prime & Tip & $\begin{array}{l}\text { Bulk } \\
\text { Zone }\end{array}$ & $\begin{array}{l}\text { Crack } \\
\text { Zone }\end{array}$ & & Prime & Tip \\
\hline $\begin{array}{c}\text { Typical operating } \\
\text { temperature } \mathrm{T}_{\mathrm{T}} \\
\left({ }^{\circ} \mathrm{C}\right)\end{array}$ & $\begin{array}{c}1010 \\
- \\
1170\end{array}$ & $\begin{array}{c}1119 \\
- \\
1220\end{array}$ & 882 & 932 & $\begin{array}{c}312\left(\mathrm{As}_{4}\right) \\
\text { or } \\
337\left(\mathrm{As}_{2}\right)\end{array}$ & $\begin{array}{c}550\left(\mathrm{As}_{4}\right) \\
\text { or } \\
900\left(\mathrm{As}_{2}\right)\end{array}$ & $\begin{array}{c}698- \\
969\end{array}$ & 610 & 630 \\
\hline $\begin{array}{c}\text { BEP } \\
\text { Corresponding to } \\
\mathrm{T}_{\mathrm{T}} \text { (Torr) }\end{array}$ & \multicolumn{2}{|c|}{$\begin{array}{c}2.4 \times 10^{-7}- \\
3.2 \times 10^{-6}\end{array}$} & \multicolumn{2}{|c|}{$4.5 \times 10^{-7}$} & \multicolumn{2}{|c|}{$\begin{array}{c}4.5 \times 10^{-6}\left(\mathrm{As}_{4}\right) \text { or } \\
2.5 \times 10^{-6}\left(\mathrm{As}_{2}\right)\end{array}$} & & & \\
\hline $\begin{array}{c}\text { Outgassing } \\
\text { temperature } \mathrm{T}_{\mathrm{o}} \\
\left({ }^{\circ} \mathrm{C}\right)\end{array}$ & 1180 & 1230 & 900 & 950 & 320 & 905 & 1100 & 900 & 950 \\
\hline
\end{tabular}




\subsubsection{Baking}

Every time after the growth chamber was vented or exposed to atmosphere, the system has to be baked to get rid of impurities and water that may be brought into the system from outer environment. Prior to baking, components not bakeable had to be removed from the system, which was then wrapped by aluminum foil for confining heat and heated up by heaters. The baking temperature was ramped up very slowly to avoid dramatic increase of the chamber pressure or excessive thermal stress. For the purpose of expelling water, eventually the baking had to be carried out at a temperature higher than the water boiling point. For the MBE system in this work, that temperature is $\sim 130^{\circ} \mathrm{C}$, i.e. the system was maintained at $\sim 130^{\circ} \mathrm{C}$ to allow the cyropump pumping the chamber pressure down. The baking could be terminated once the pressure was almost stabilized. Growth chamber pressure was typically as low as $10^{-11}$ Torr after baking, and $\sim 10^{-9}$ Torr after growing due to As overpressure.

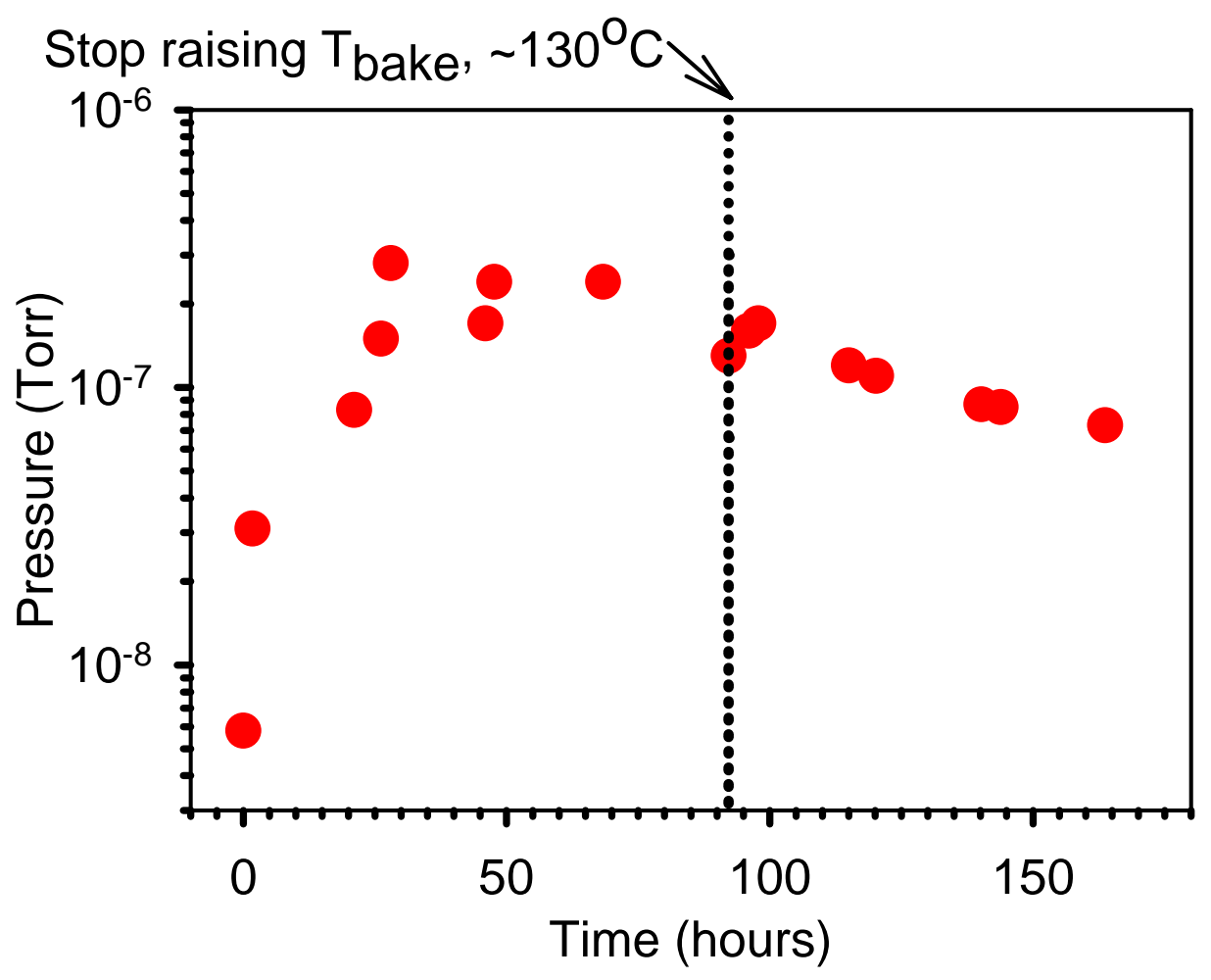

Fig 3.4 Pressure of the growth chamber vs. baking time. 
Fig 3.4 shows the variation of pressure vs. baking time, where the dotted line indicates that at this point the system was heated up to and stayed at $\sim 130^{\circ} \mathrm{C}$ afterward. Correspondingly, a small rise followed by a slow drop of pressure occurred. In the end of the baking the slope was almost flat meaning a stabilized pressure, so the baking could be stopped.

\subsection{Sample Preparation}

2-inch GaAs substrates were used in this work. No clean or degrease was done on them since all GaAs wafers used in this study came in separate package and sealed under clean environment. Prior to loading, each wafer was cut into four pieces and mounted to four indiumfree UNI-Block substrate holders, i.e. for each growth, one quarter of the wafer was used. Fig 3.5 demonstrates the mounting of a substrate. The bottom is the UNI-Block face down, followed by a spring plate sandwiching the substrate with a diffuser plate. The spring plate has several small

clamps extruded to fasten the substrate, which is placed face down and supported by the diffuser plate from behind. The whole assembly is secured by a tungsten snap ring on the top [Veeco, $2005]$.

Before the growth, the loaded substrate was transported to outgassing station by the cart and outgassed at $270^{\circ} \mathrm{C}$ for at least 6 hours. After that, it was transferred to the substrate holder in the growth chamber. 


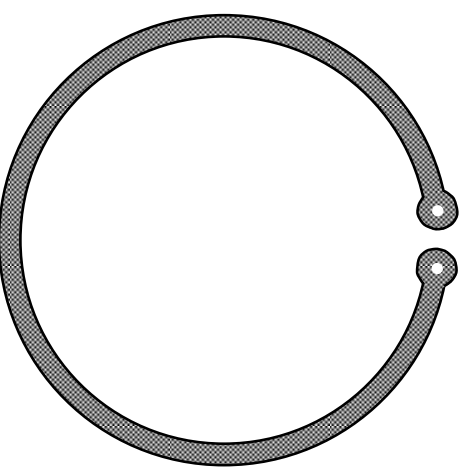

Tungsten retaining ring securing the stack

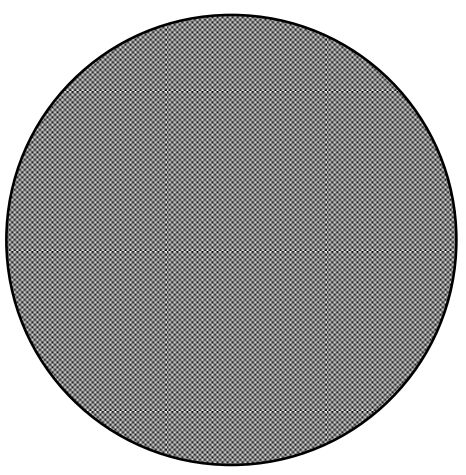

Diffuser Plate covering the substrate

Fig 3.5 The assembly procedure of installing the substrate $(1 / 4$ of one 2 " GaAs wafer) in the In-free substrate holder. [Veeco, 2005]
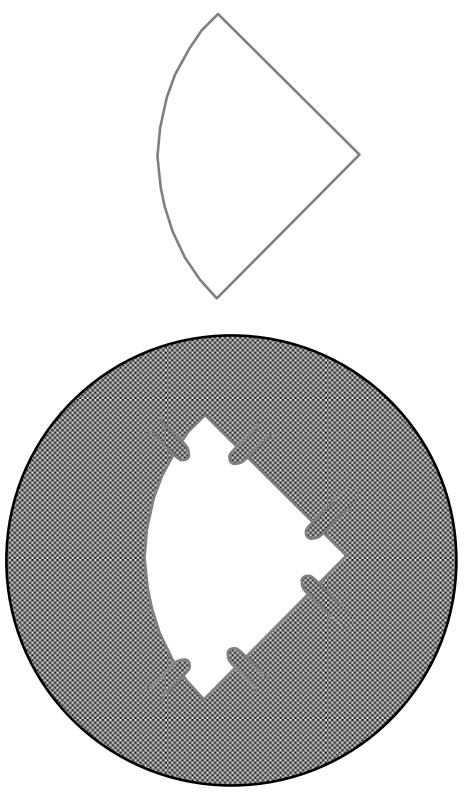

GaAs Substrate mounted on the spring plate

Spring plate on UNI-Block

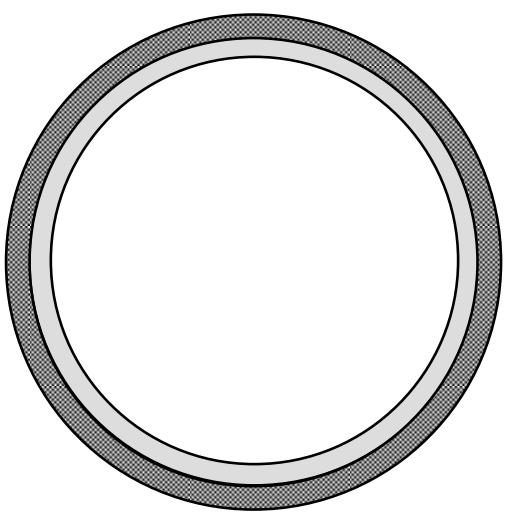

UNI-Block face down 


\subsection{Characterization}

Main techniques used for characterization are:

\subsubsection{Reflection High Energy Electron Diffraction (RHEED)}

RHEED is a very useful in-situ tool dynamically monitoring the growth and providing information of the surface smoothness, structure and phase transition etc. In ther MBE system, a Staib Instruments EK 150R3 RHEED gun (15 KeV) generates a high energy electron beam incident on the sample surface at a grazing angle normally less than 1 degree. Fig 3.6 is a schematic diagram of RHEED setup. Upon impinging on the surface, electrons are diffracted, directing onto a fluorescent screen on the other end, and forming a diffraction pattern, which reflects the surface smoothness and crystal structure. The pattern can also be captured by a CCD camera and monitored through a computer. The penetration depth limited to a few $\AA$ due to the glancing angle of incidence makes RHEED sensitive to just the top few monolayers, and ensures its effective characterization of the film surface.

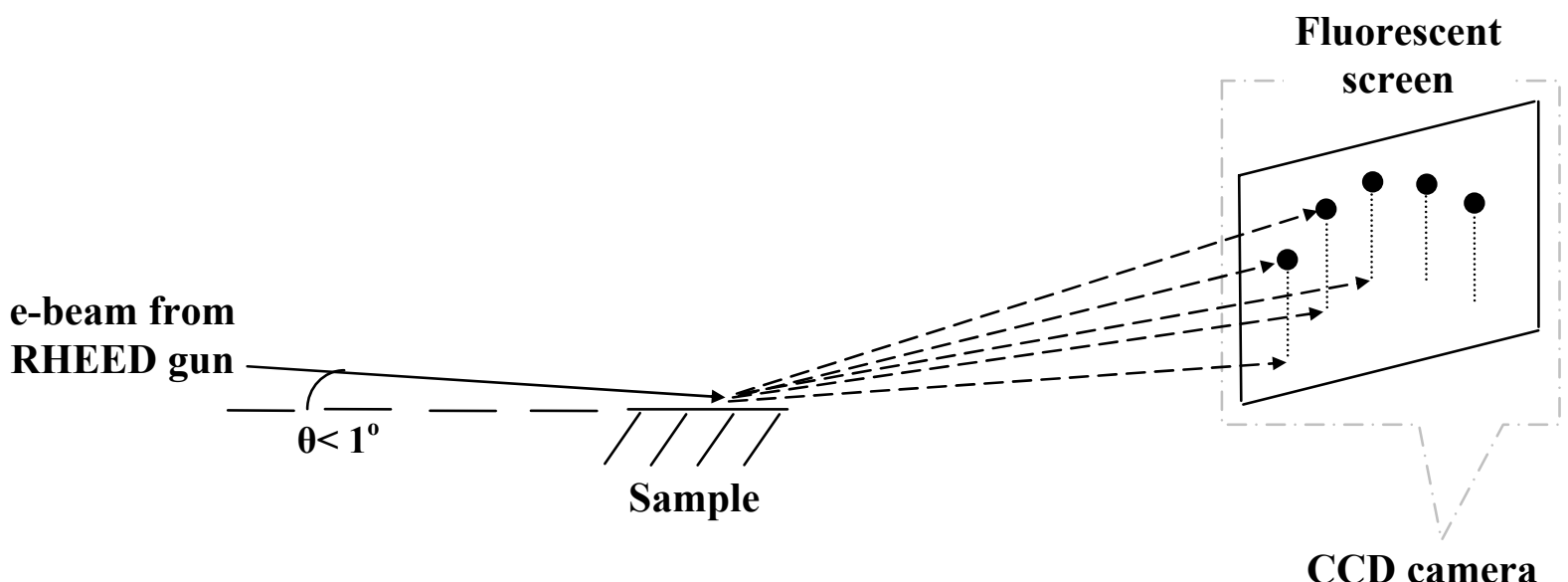

Fig 3.6 Shematic diagram of RHEED setup. 
Electrons diffraction follows the Laue condition, which is expressed as

$$
\vec{K}=\vec{K}_{o}+\vec{K}_{h}
$$

Where $\mathrm{K}$ and $\mathrm{K}_{0}$ are wave vectors of diffracted and incident beam respectively, $\mathrm{h}$ is the reciprocal lattice vector.

$$
\left|\vec{K}_{o}\right|=|\vec{K}|=\frac{2 \pi}{\lambda}
$$

and

$$
\lambda=\frac{h}{\sqrt{2 m_{0} V q+\left(\frac{V q}{c}\right)^{2}}}=\sqrt{\frac{150}{V\left(1+1.95 \times 10^{-6} V\right)}} \AA
$$

Where $\mathrm{m}_{0}$ is electron mass, $\mathrm{q}$ is electron charge, $\mathrm{V}$ is the accelerating potential in $\mathrm{eV}$, and $\mathrm{c}$ is the light speed.

The grazing angle of the electron beam striking the surface leads to a very short penetration depth, which results in the formation of reciprocal lattice rod along the direction nominal to the sample surface since the near-zero real lattice dimension at this direction corresponds to the infinite in the reciprocal lattice space. The diffracted direction can be determined by the intersection of the reciprocal lattice rod and the Ewald sphere, which is a sphere whose radius is $\left|\overrightarrow{K_{o}}\right|$ as shown in Fig 3.7. The center of the sphere is at the origin of $\overrightarrow{K_{o}}$, and the end of $\overrightarrow{K_{o}}$ points towards the substrate. 


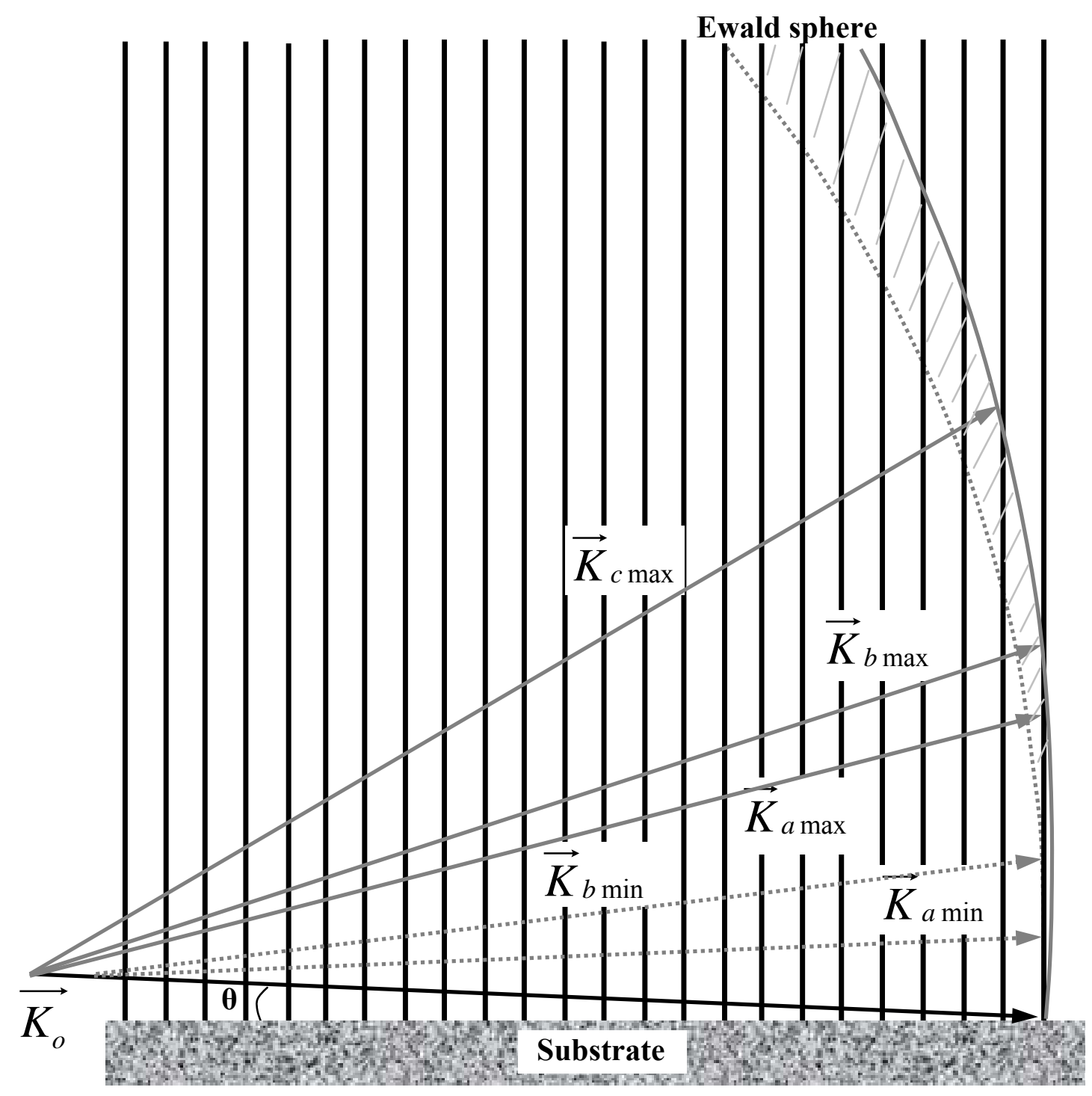

Fig 3.7 The diffraction satisfying the Laue condition in reciprocal space with the assist of Ewald sphere. $\vec{K}_{a}, \vec{K}_{b}$ and $\vec{K}_{c}$ are all vectors of the diffracted wave.

Theoretically, if the surface is smooth, diffraction pattern of Laue rings should be achieved (Fig 3.8 (a)), however, it is more common that streaks rather than Laue rings are obtained for flat surface(Fig 3.8 (b)) due to several reasons. One is the non-monochromaticity of the actual electron beam. Ideally, the incident electrons are monochromatic, i.e. with a single wavelength $\lambda$, attributing to the single Ewald sphere drawn in the reciprocal lattice space with a 
radius of $2 \pi / \lambda$ derived from Eq. (3.2). However actual electron beam generated by the RHEED gun normally contains continuous wavelengths falling in a small range of spectra. Therefore a series of Ewald spheres exist with respect to these wavelengths. As shown in Fig 3.7, Ewald spheres have radii ranging from $|\vec{K} \min |$ to $|\vec{K} \max |$ corresponding to the longest and shortest wavelengths respectively in that spectra range and form a shell (the shadow region in Fig 3.7) with some thickness. All lattice points located in this shell area contribute to the formation of the diffraction pattern, so the overall effect is the production of lines instead of rings.

Compared to the reciprocal lattice dimension of most crystals, which is usually less than $2 \AA^{-1}$, the radius of the Ewald sphere calculated from Eq. (3.2) and (3.3) is much larger, about $64 \AA^{-1}(\lambda \sim 0.099 \AA)$ with an accelerated potential of $15 \mathrm{keV}$ for instance. As a result, many reciprocal lattice rods will cross the Ewald sphere and producing streak diffraction pattern on the screen. Lattice vibrations of crystals, which spatially extend the size of reciprocal lattice rods and thus increase the chance of Ewald sphere intersecting with these reciprocal lattice rods, are also responsible for the formation of streaky patterns.

For the case of rough surface, the RHEED pattern is more diffused by transmission through the surface roughness, resulting in a spotty diffraction pattern.
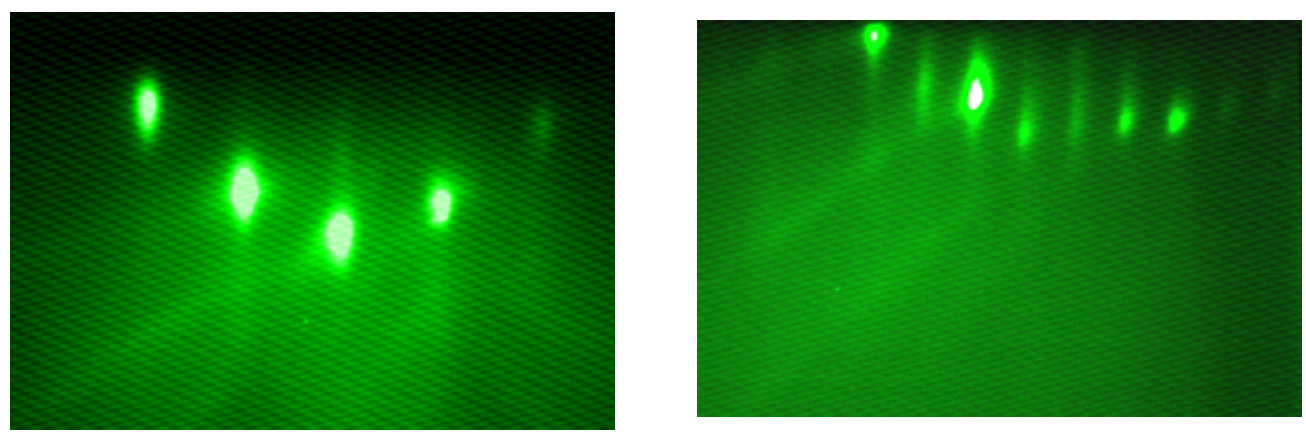

Fig 3.8 RHEED patterns of two $\mathrm{GaAs}_{1-\mathrm{x}} \mathrm{N}_{\mathrm{x}}$ samples with smooth surfaces. (a) The diffraction pattern of Laue rings. (b) RHEED pattern of streaky lines. 


\subsubsection{Mass spectrometer}

Stanford Research Systems (SRS) Residual Gas Analyzer (RGA) 200, which has a quadrupole probe protruded into the MBE system, is equipped to quantitatively identify the existence of all component species in the high vacuum chamber. Electrons emitted from the heated filament ionize residual gas molecules and generate positive ions when they collide through the ionizer. Those ions are transferred to the mass filter, a quadrupole, i.e. four cylindrical rods, with electric potentials applied to separate different mass species. Carefully choosing values for the combination of DC and RF voltages $U_{D}+U_{R}$ (where $U_{R}=U \cos (\omega t)$ ) applied to rods ensures only ions with specific mass/charge ratio having stable trajectories to be successfully directed to ion detector without being stopped by rods. Ions leaving from the filter pass through an exit aperture and are detected by a Faraday Cup. The faraday Cup directly tells ion currents, which is proportional to numbers of molecules to be measured. Therefore, it can tell partial pressure of component gases as well as the total pressure in a vacuum environment. Fig 3.9 is a RGA (Residual Gas Analysis) scan curve captured while doing the scan. Peaks at AMU of $2,14,28$, and 75 in the graph correspond to $\mathrm{H}_{2}, \mathrm{~N}, \mathrm{~N}_{2}$ and As respectively. 


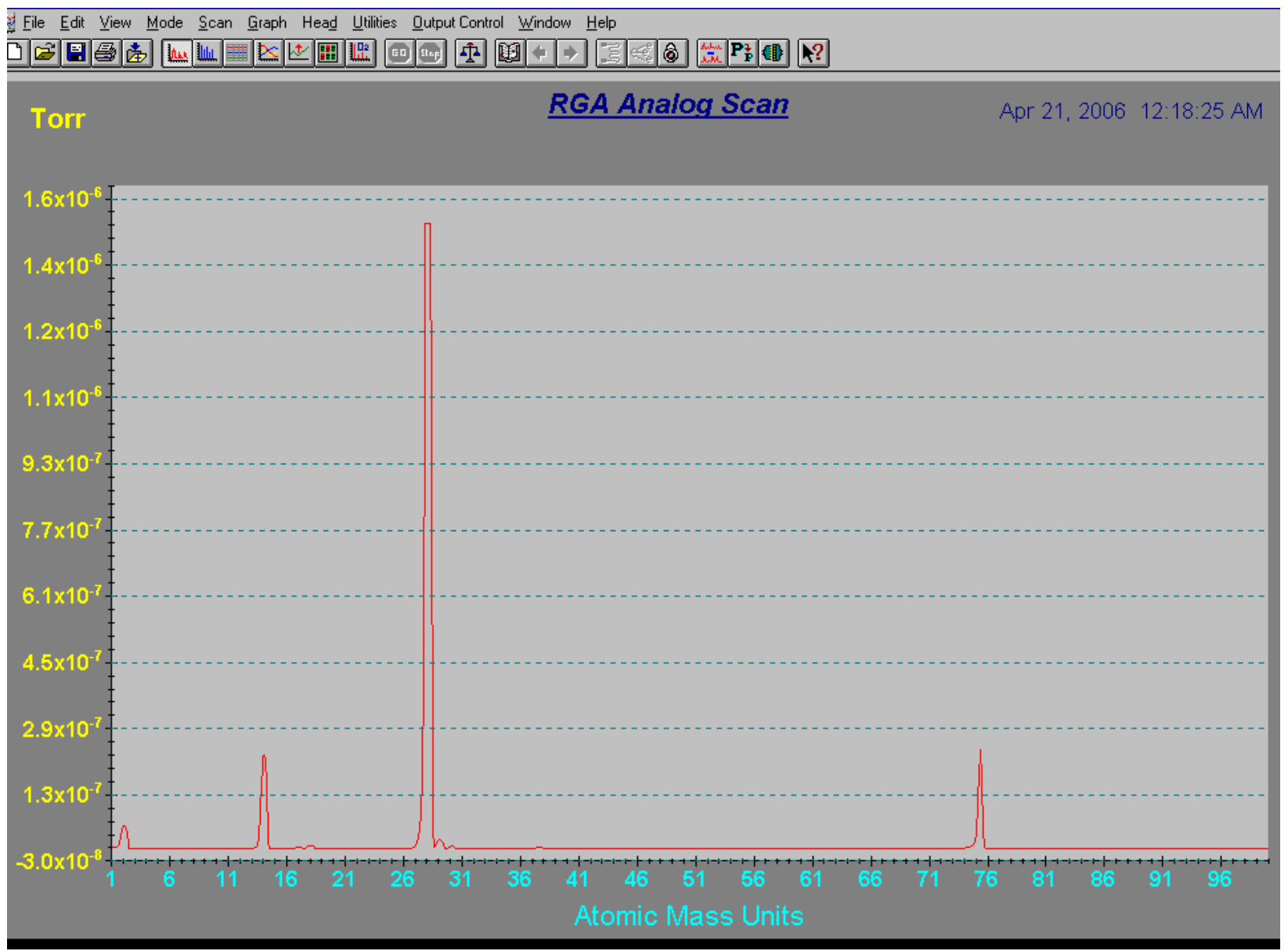

Fig 3.9 Partial pressure of species with different atomic mass units in the growth chamber were determined by RGA.

\subsubsection{Photoluminescence (PL)}

Photoluminescence is an effective method to test recombination properties of the material. It is a technique based on photo-excitation. When light hits onto the sample, electrons are excited and jumped to permissible higher energy levels. Light corresponding to the excess energy may be emitted when these electrons return back to their equilibrium states. The wavelength of the light is determined by a monochromator, and its intensity can be detected by a photodetector. Fig 3.10 is a schematic diagram of our PL setup. Electrical signals converted by a Ge photodetector are captured by the lock-in amplifier and ultimately the PL spectrum can be 
captured. This way, the band gap of the material, impurity and defect levels may be able to be determined.

Fig 3.11 shows the PL spectrum of a GaAs substrate measured at the temperature of $77 \mathrm{~K}$. The peak of the curve is due to the electron transition between the conduction band the valence band, so $1.4434 \mathrm{eV}$ derived from the peak corresponds to the band gap energy of the material.

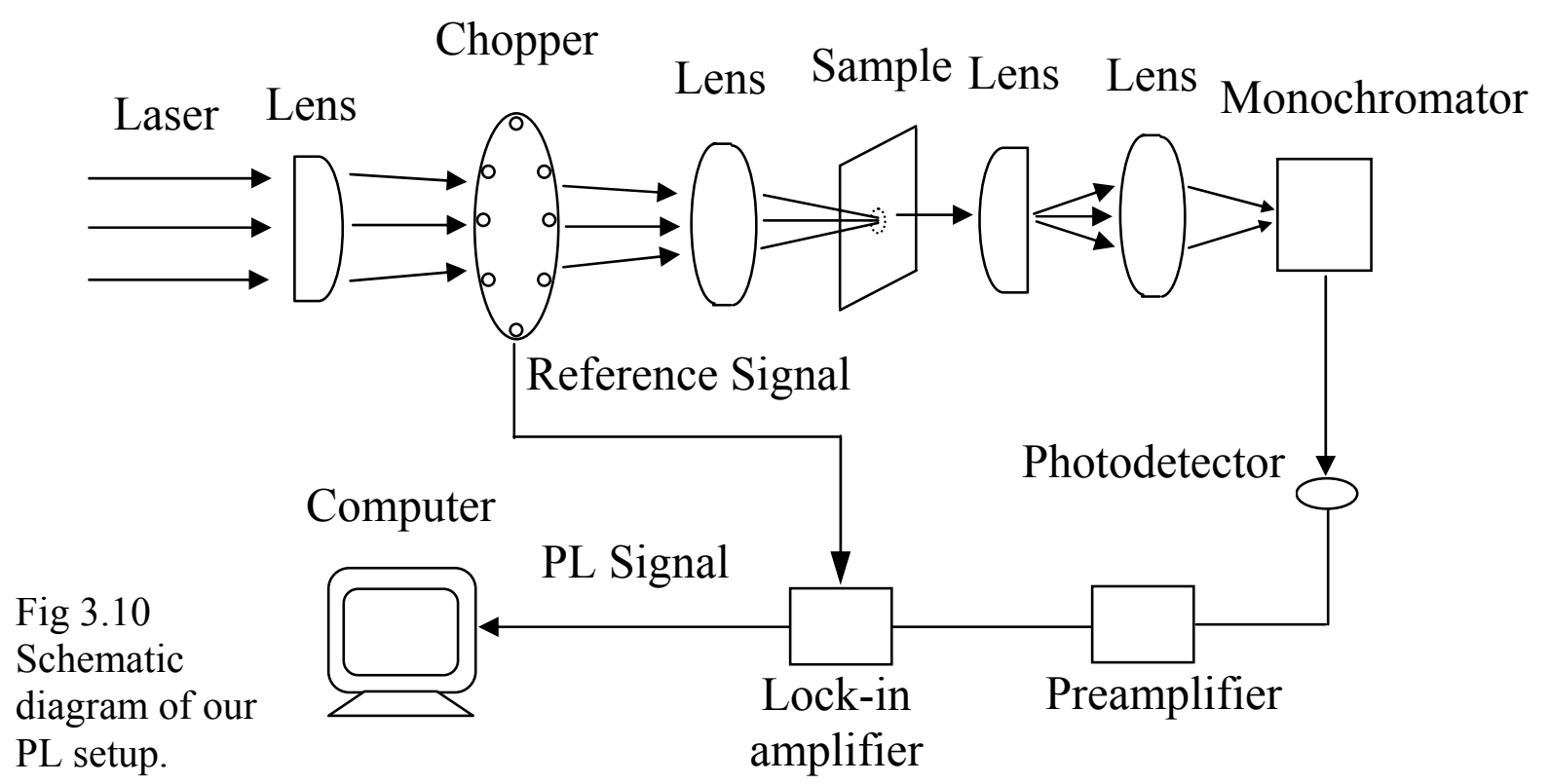

\subsubsection{Atomic Force Microscopy (AFM)}

AFM gives the topography, and tells the roughness of a sample. A tip attaching to a cantilever and staying very close to the surface of the sample acts as a probe. The attractive or repulsive force change between the tip and the sample reflects the height change of the point being measured. This force determines the vertical deflection of the cantilever, which could be converted to height. AFM image of a GaAs sample is shown in Fig 3.12 as an example. The 
different color in the figure means the different height of the surface. The lighter the color is, the higher the height is, so the color contrast stands for the depth between the low and high height.

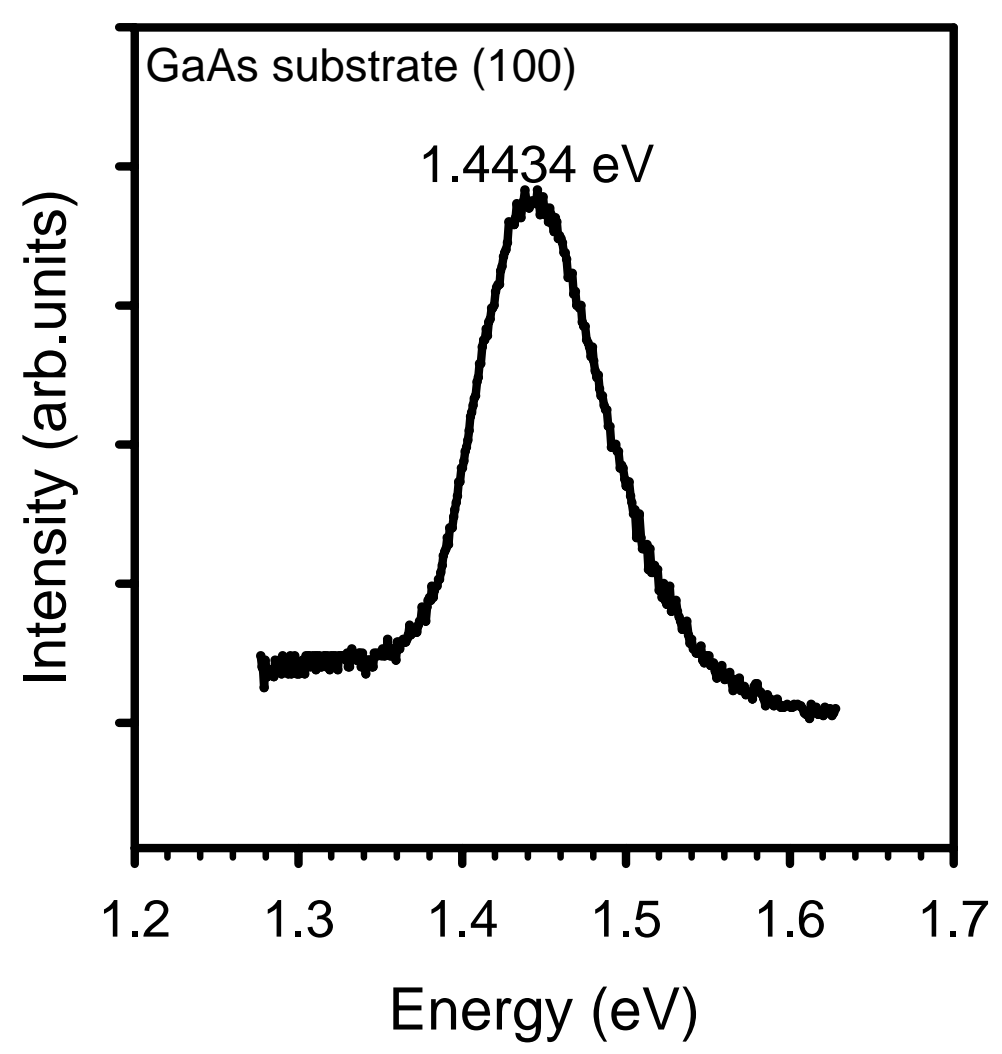

Fig 3.11

Photoluminescence of a GaAs (100) substrate obtained at the temperature of $77 \mathrm{~K}$.
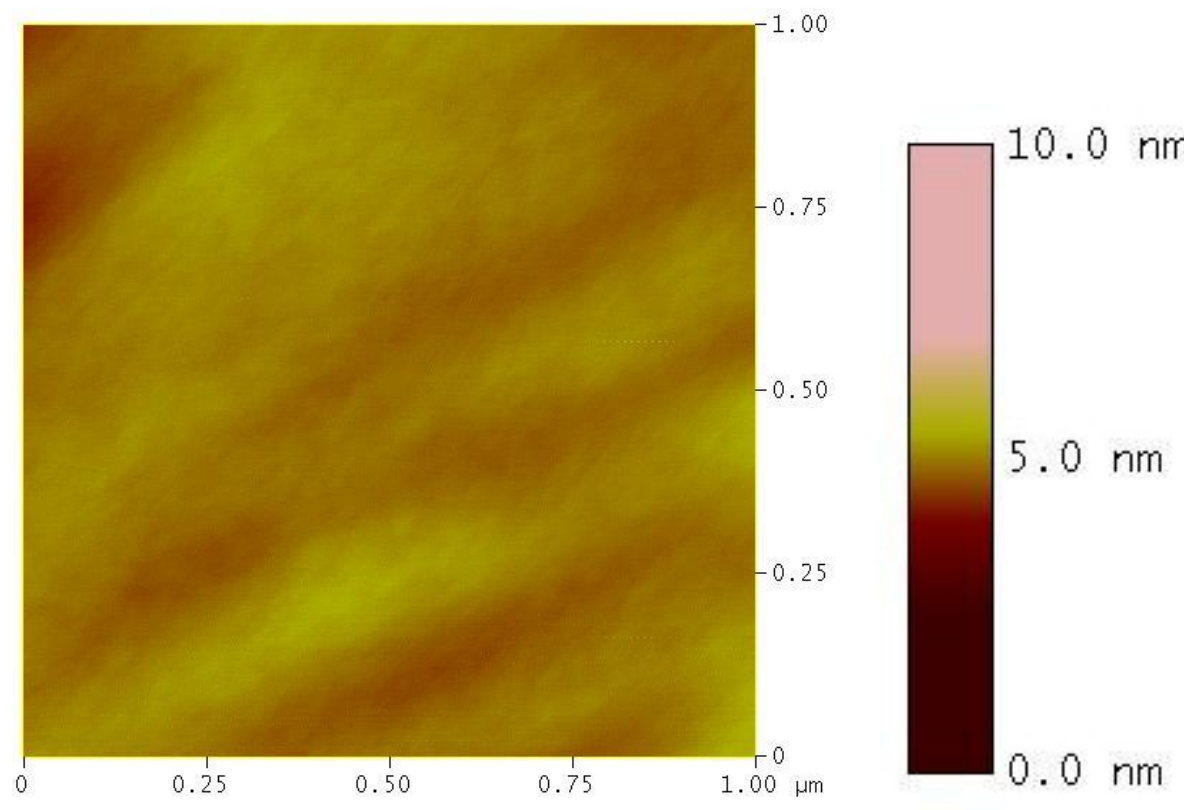

Fig 3.12 AFM image of a GaAs sample. 


\subsubsection{Raman}

Raman is a light scattering technique. When light hit on a molecule, although most scattered photons hold the same energy as incident ones, some of them get different energies from incident photons due to interaction with the electric dipole. This energy difference attributes to the vibration of the molecule, and is represented by the wave number change (usually known as Raman shift) compared to the initial vibrational level. The vibration energy depends on the particular molecule or compound, i.e. factors such as atomic mass, bond structures, lattice constant, stress and strain, etc. all have effects on the Raman shift. Raman therefore is a very informative tool. Fig 3.13 shows the room temperate Raman shift of a GaAs sample. A GaAs-like $\mathrm{TO}_{1}$ line, a $\mathrm{LO}_{1}$ line, and a $\mathrm{LO}_{1}+\mathrm{TO}_{1}$ line were observed at $~ 269,293$, $369 \mathrm{~cm}^{-1}$.

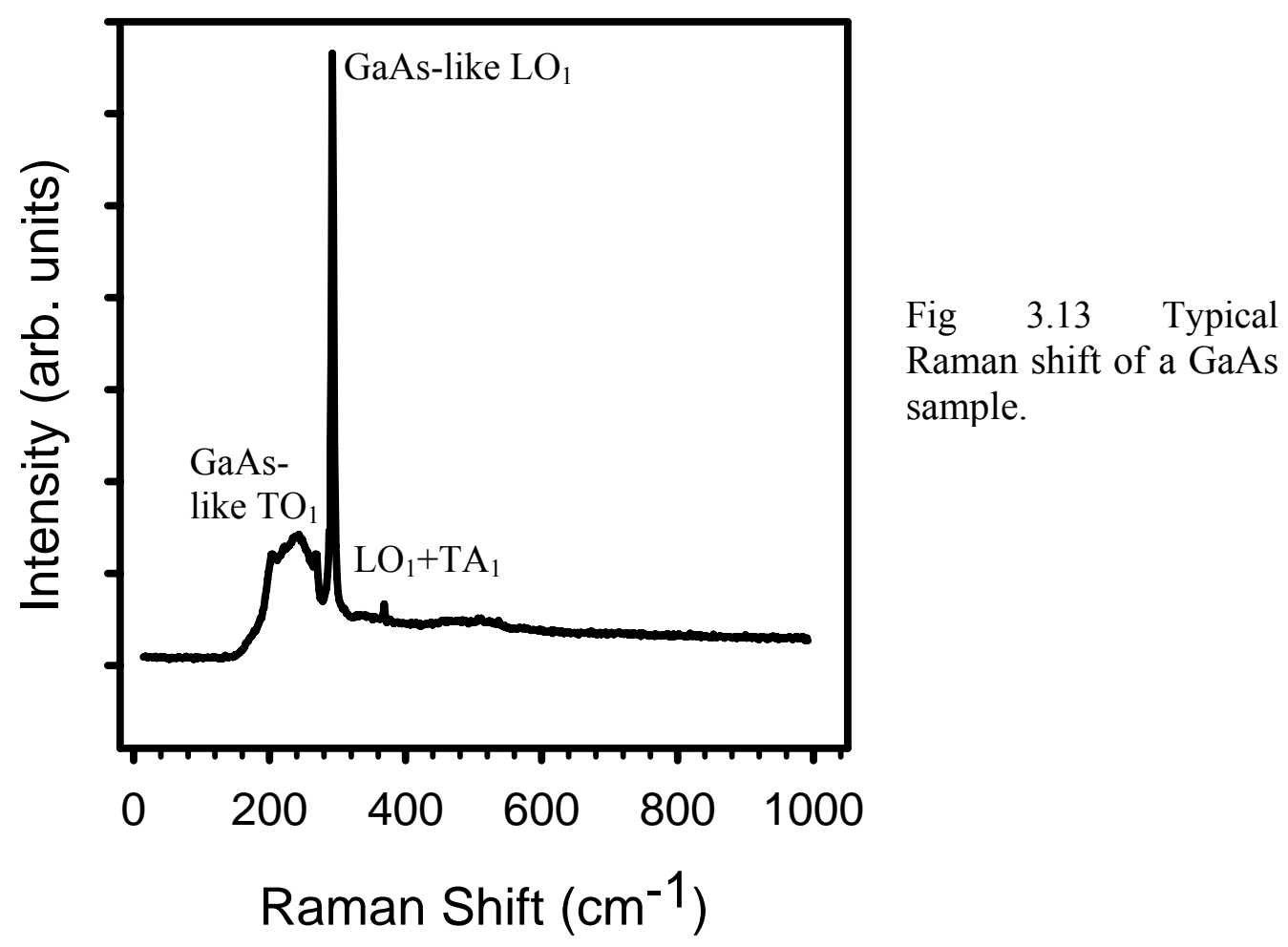




\subsubsection{Hall Effect measurement}

If putting a conductor with the electric current flowing through in a magnetic field whose direction is non-parallel to the current's direction, magnetic forces would push electrons moving toward one direction, leading to the accumulation of positive and negative charges on both side of a sample and forming an electric field whose effect on electrons oppose the magnetic force. Eventually the interaction between the magnetic and the electrical field created from the opposite type of charges reaches a balance, and their relationship under this state can be used to get carrier concentrations, mobility and conductivity.

\subsubsection{X-ray Photoelectron Spectroscopy (XPS)}

A photon is absorbed by an atom and gives rise to an ionized atom and the emission of core electron. For a specific element, the energy difference between the ionized and neutral atoms, i.e., binding energy, presents at particular energies, forming a characteristic set of peaks related to core atomic orbitals in the photoelectron spectrum, and the intensity of the peaks is associated with the concentration of that element. The composition of each constituent therefore is able to be determined by XPS. 


\section{Chapter 4}

\section{Substrate Temperature Calibration}

Substrate temperature is an important parameter requiring accurate control during the growth. Thermocouple attached to the back side of the substrate holder was equipped to give an exact value of the temperature, however, which is usually different from the real temperature and sometimes the difference can be big, as high as $150^{\circ} \mathrm{C}$ [Fernández, 1992]. It is always necessary to do calibration to have the measurement accurately reflect the actually substrate temperature.

For the calibration purpose, the real substrate temperature must be carefully measured and compared to the count value to determine a relationship between them. Pyrometry is often considered an option to measure temperatures.

\subsection{Introduction to pyrometry}

Pyrometry is an instrument measuring the surface temperature of an object without contact. All materials with temperatures above absolute zero absorb and radiate thermal energy. The EM (electromagnetic) radiation energy emitted by the material therefore can be detected, and the object temperature can be determined by the radiation intensity and wavelength.

\subsubsection{Emissivity}

As comparison to the perfect radiator, i.e. a blackbody, which absorbs all the radiation hitting on its surface, in reality the energy striking on the surface of an object can only be partially absorbed, and the rest will be reflected or transmitted. The difference between the real materials and blackbody referring to the radiation absorption is expressed as the ratio of the 
energy absorbed to the total energy, called emissivity. Therefore, blackbody has an emissivity of 1, while any common object has a value between 0 and 1 , and the sum of the emissivity, the transmissivity, and the reflectivity is always 1 . Since the emission intensities vary for different materials and can vary with wavelength, it is important to have the emissivity taken into account for calibrating the measurement. Otherwise, incorrect results may be obtained.

\subsubsection{Theoretical approach}

The operation of a pyrometer is based on the following:

One is the Kirchoff's Law. If an object is under a thermally stable state, the energy absorbed equals emitted:

$$
\mathrm{W}_{\mathrm{a}}=\mathrm{W}_{\mathrm{e}}
$$

Kirchoff's Law is the theoretical basic why the temperature can be determined by measuring the emission energy since the temperature at which the object reaches its thermal balance depends on the energy absorbed.

Planck's law, disclosing the relationship between the radiant energy and the source temperature $\mathrm{T}$, is universally applicable to all objects and express as

$$
W_{\lambda}=C_{1} \varepsilon_{\lambda}\left[\lambda^{5}\left(e^{C_{2} / \lambda T}-1\right)\right]^{-1}
$$

where $c_{1}=2 \pi c^{2} h$, and $c_{2}=h c / k$,

$W_{\lambda}$ is the radiation energy from an object at a given wavelength $\left(\mathrm{W} / \mathrm{m}^{3}\right)$,

$\varepsilon_{\lambda}$ is the emissivity of the material,

$\lambda$ is the wavelength (m),

$\mathrm{T}$ is the temperature of the object $(\mathrm{K})$,

$\mathrm{C}$ is the speed of light, $3 \times 10^{8} \mathrm{~m} / \mathrm{s}$, 
$h$ is Planck's constant, $6.626 \times 10^{-34} \mathrm{~J} \cdot \mathrm{s}$,

$\mathrm{k}$ is Boltzmann's constant, $1.38 \times 10^{-23} \mathrm{~J} / \mathrm{K}$.

The temperature $\mathrm{T}$ then can be derived at a specific wavelength $\lambda$ by measuring the radiation intensity $W_{\lambda}$. It is often employed for narrow-band pyrometers, where only one or a few specific wavelengths are targeted [Efunda, 2006].

The plot of Planck's law is shown in Fig 4.1 [Smith, 1999], which demonstrates the distribution of radiation energy at different temperatures.

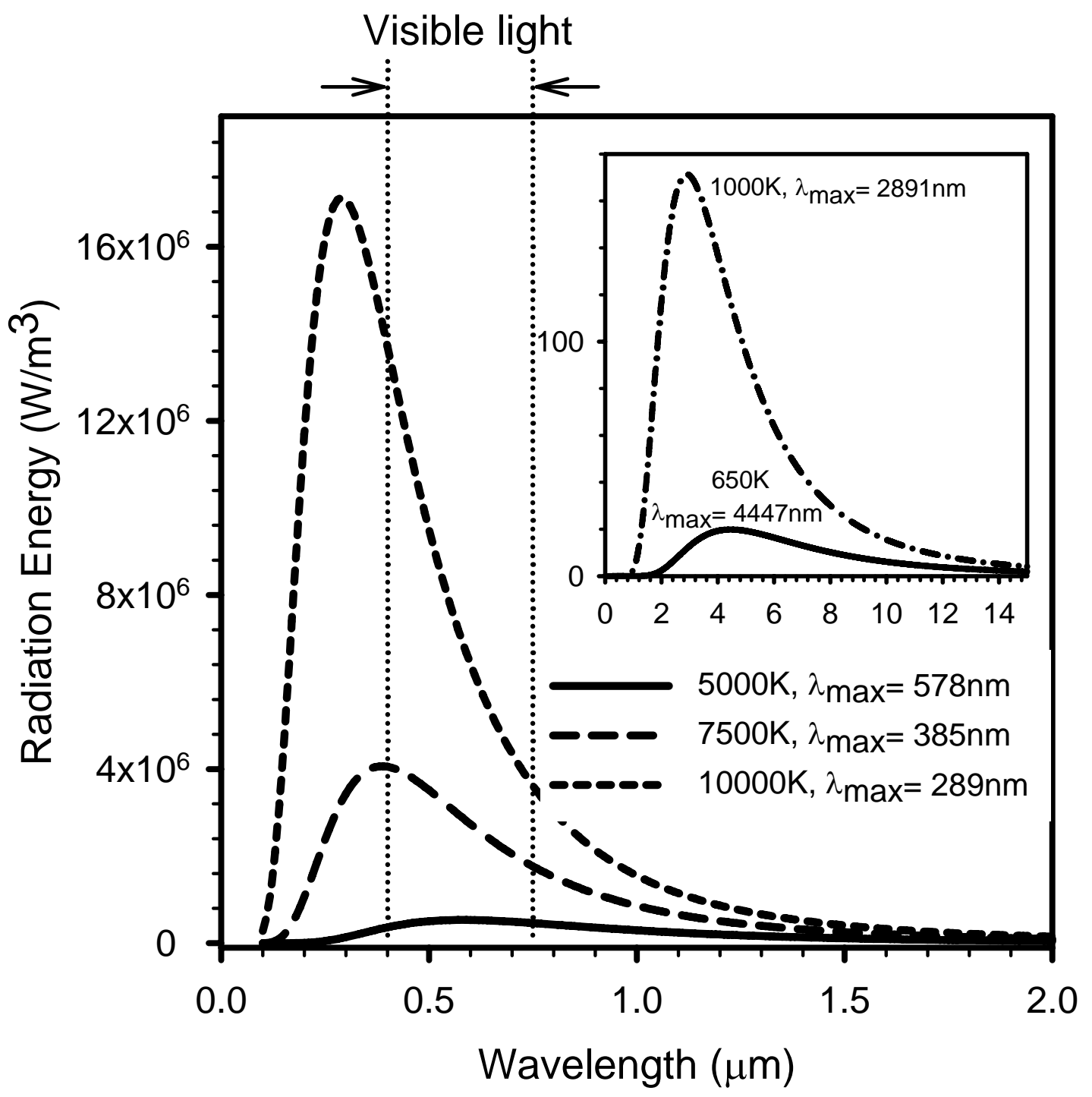

Fig 4.1 Plot of Planck's law at different temperatures assuming blackbody case. 
Fig 4.1 indicates that at any given temperature, there exists a $\lambda_{\max }$ that corresponds to the maximum intensity of the radiation energy. For a specified temperature, if the pyrometer is designed with its sensitive range around this wavelength, a maximized signal can be detected, making the measurement easy and precise. Therefore, if the approximate temperature range going to be measured was known, the appropriate pyrometer can be chosen prior to the measurement. $\lambda_{\max }$ deduced from Planck's law should fit the equation below:

$$
\lambda T\left(1-e^{-\frac{h c}{k \lambda T}}\right)=\frac{h c}{5 k}
$$

which comes with the solution

$$
\lambda_{\max } T=2891 \mu m \cdot K
$$

called Wein's displacement law and employed to determine $\lambda_{\max }$. It indicates that the wavelength associated with the maximum emission energy will be decreasing with increasing the temperate as illustrated in Fig 2.1. Eq. (2.4) equals

$$
e^{-\frac{h c}{k \lambda T}}=148>>1
$$

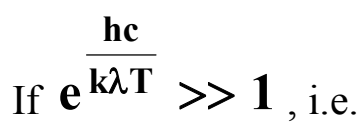

$$
2.5 \lambda T<\frac{h c}{k}\left(\lambda \mathrm{T}<5.76 \cdot 10^{3} \mu \mathrm{m} \cdot \mathrm{K}\right)
$$

Planck's law is simplified to Wein's radiation law as

$$
W_{\lambda}=C_{1} \varepsilon_{\lambda}\left[\lambda^{5} e^{C_{2} / \lambda T}\right]^{-1}
$$

where $c_{1}=2 \pi c^{2} h$, and $c_{2}=h c / k$. 
Eq. (24.4) and (4.6) narrows conditions related to the wavelength and temperature down to where one is actually interested in. At a certain temperature, they can help defining the spectrum range desired for the pyrometer to operate. For instance, if the temperature of the object is estimated to be $1000 \mathrm{~K}$, a pyrometer with the working range below $5.76 \mu \mathrm{m}$ and covering $\lambda_{\max } \sim 2.89 \mu \mathrm{m}$ is good for this measurement. Our growth of $\mathrm{GaAs}_{1-\mathrm{x}} \mathrm{N}_{\mathrm{x}}$ normally goes with substrate temperatures below $650^{\circ} \mathrm{C}$ and above $400^{\circ} \mathrm{C}$, therefore a pyrometer responding to wavelengths $<8.6 \mu \mathrm{m}$ works.

Stefan-Boltzmann law is another equation often applied in broad-band pyrometers, which collect the radial power intensity $W_{\lambda}$ over a wide range of wavelengths. Stefan-Boltzmann law is the integration of $W_{\lambda}$ across that wavelength range [Efunda, 2006]:

$$
W=\int_{\lambda} W_{\lambda} d \lambda
$$

and it becomes

$$
W=\sigma T^{4}
$$

if integrated over the entire spectral range. $\sigma$ is the Stefan-Boltzmann constant $5.6697 \times 10^{-8} \mathrm{~W} / \mathrm{m}^{2} \mathrm{k}$.

\subsubsection{Design}

One common type of optical pyrometers is Disappearing Filament Pyrometer (DFP), whose basic idea is to visually compare the brightness of a lamp filament inside the instrument with that of the target until the filament reaches the temperature of the target, and disappears into the targeted surface background as its color matches the color of the target when they have the same temperature. This use of this kind of pyrometer however is limited since usually it is not able to measure temperatures below $700^{\circ} \mathrm{C}$ because the object may not be hot enough to be 
incandescent, and in addition, the judgment of whether the filament having disappeared or not is dependent on human's eye, so the measurement couldn't be very accurate [Spectrodyne, 2006].

The pyrometer used in this work for substrate temperature calibration is infrared (IR) pyrometer. Compared to DFP, the infrared pyrometer is more precise, and has a higher and wider temperature measurement range, faster time response, and better error correction capability [Opyro, 2006]. Conventional IR pyrometer consists of a lens focusing the IR radiation from the object onto a detector which is responsible for converting the energy to an electrical signal. The signal is then compensated through an ambient temperature compensation circuit to eliminate the influence of the environmental variation and transferred to final displayable output of temperature reading after being adjusted with emissivity. This procedure is illustrated in Fig 2.2 [Merchant, 2006].

The IR pyrometer nowadays like the one used in this work is based on this concept but is more advanced with a greater variety of detectors, and selective filters limiting the IR spectrum reaching the detector, and hence avoiding error measurement that may otherwise be induced by the atmosphere or the interference in the sight path [Merchant, 2006] [Omega]. The IR part of the spectrum spans wavelengths from $0.7 \sim 1000 \mu \mathrm{m}$ [Merchant, 2006]. Fig 4.3 is a schematic configuration example of a modern IR pyrometer [Merchant, 2006]. 


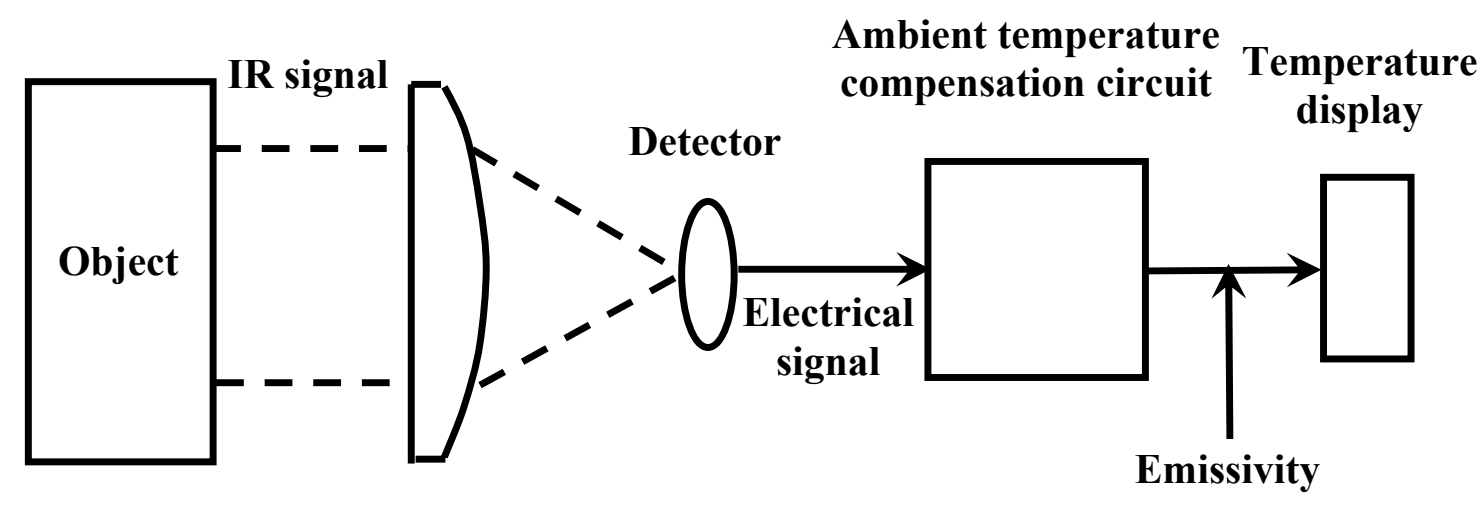

Fig 4.2 Illustration of infrared temperature measurement. [Merchant, 2006]

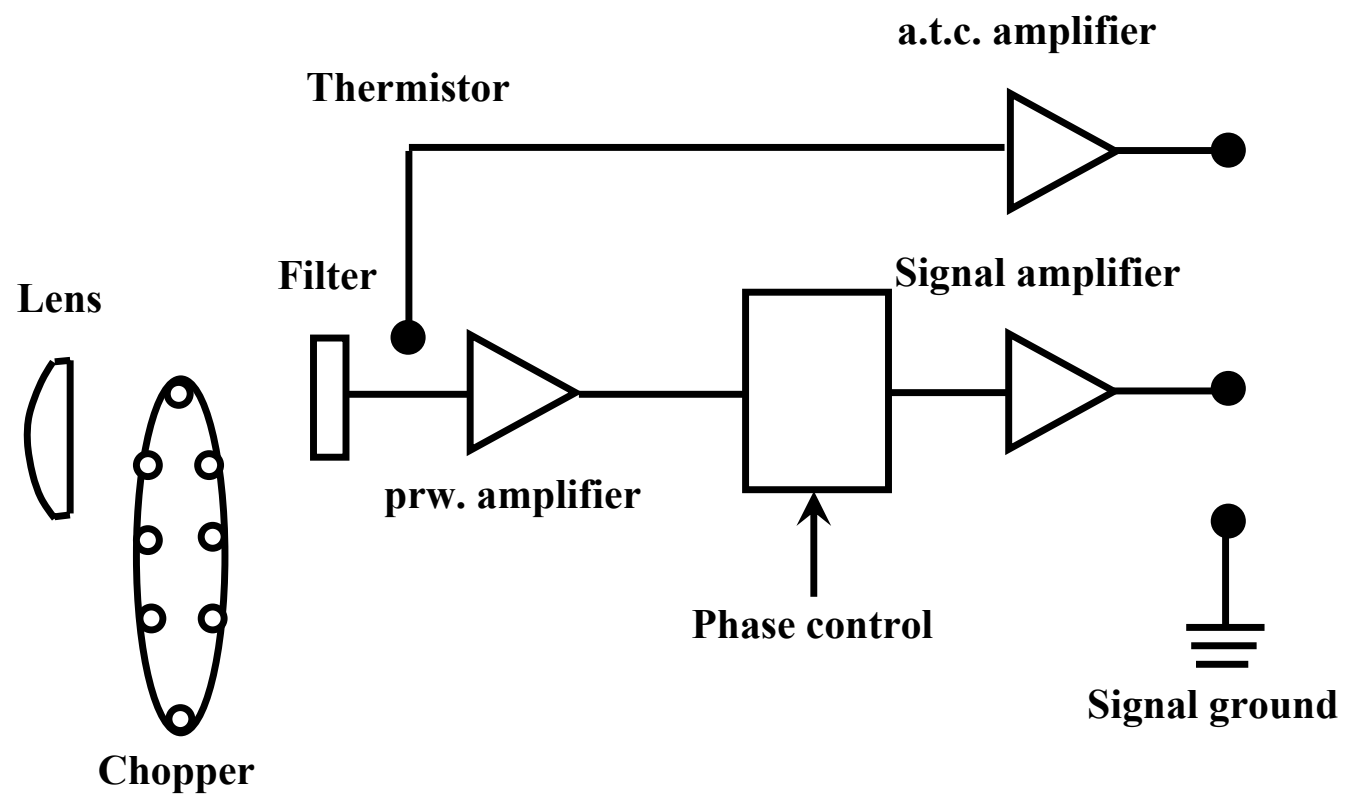

Fig 4.3 Illustration of configuration of a modern infrared pyrometer. [Merchant, 2006] 
The model employed in our experiments is Omegascope infrared pyrometer OS-3000 AS, which is equipped with a thermopile detector sensitive to the IR spectral band range between 2.1 and $2.3 \mu \mathrm{m}$. All radiation energies emitted from the target object are filtered by a filter, and only wavelengths within the detector's responding spectrum (2.1 to $2.3 \mu \mathrm{m})$ pass through and are absorbed by the detector. As indicated in Fig 4.1, the integrated radiated energy ranging over 2.1 to $2.3 \mu \mathrm{m}$, i.e. the total energy able to be absorbed by the detector is increasing with increasing the temperature. Their characteristic relationship is schematically demonstrated in Fig 4.4 assuming the case of a blackbody as an example. At any temperature the target holds, the corresponding integrated radiation energy over the detector's responding spectrum can be retrieved from Planck's law. Fig 4.4 is the assembly of these energies with respect to different temperatures. This figure reflects the dependence of energy absorbed by the detector on the blackbody's temperature. For any radiator really existing in natural, the curve still keeps exactly the same shape except shifting toward lower energy depending on the emissivity of that object.

The total absorbed energy, which is proportional to the object's temperature as indicated in Fig 4.4, heats the detector up until a thermal equilibrium is reached, and then the detector creates a signal relative to its temperature. This signal is amplified through an amplifier, converted to digital by the analog-to-digital converter, and calibrated by comparing to instrument-stored calibration values. Then the target temperature is finally calculated and obtained by the comparison results. 


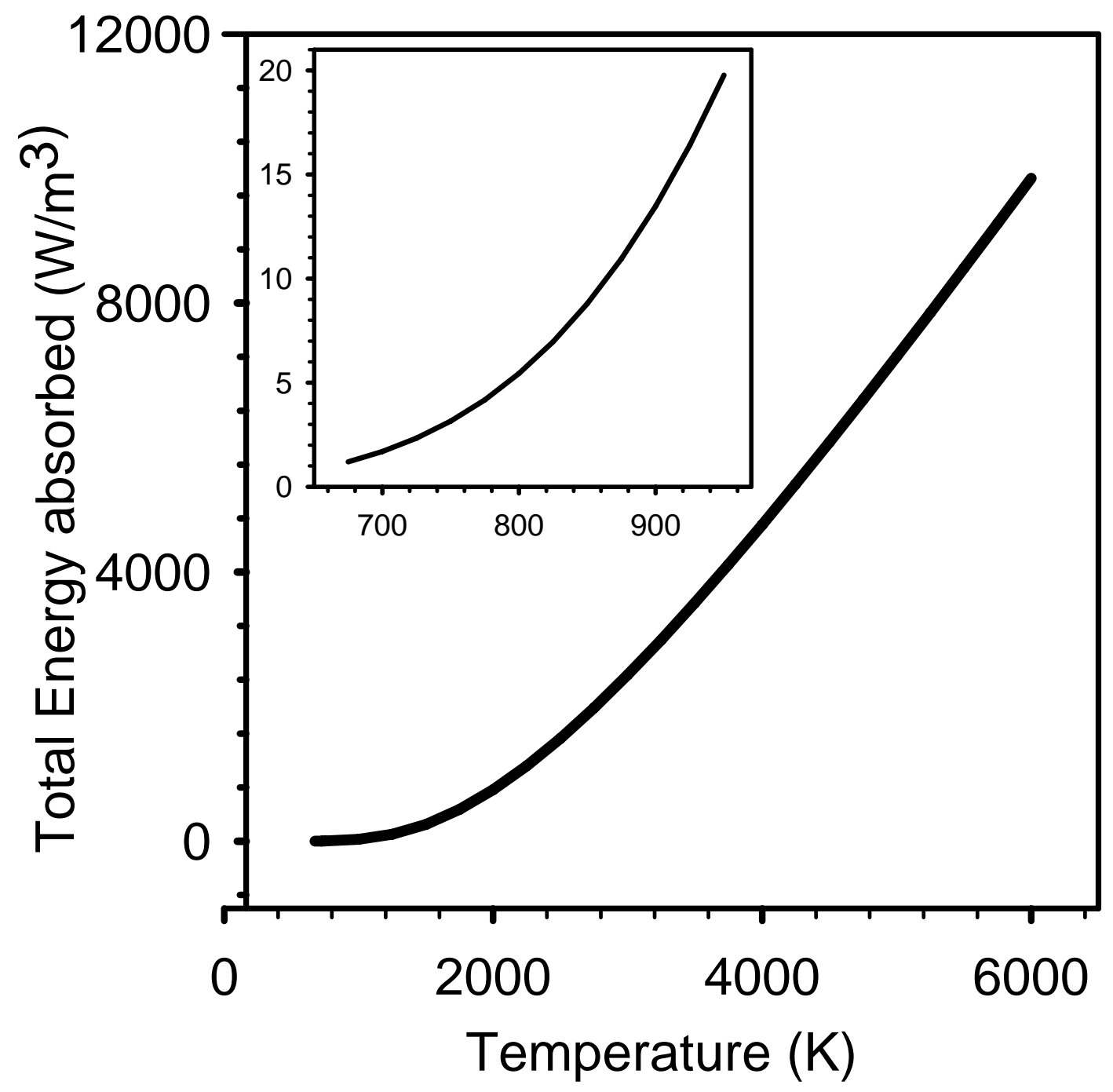

Fig 4.4 Total energy radiation of a blackbody over the wavelength range of 2.1 and $2.3 \mu \mathrm{m}$ vs. its temperature. The minimum temperature this pyrometer can detect is $400^{\circ} \mathrm{C}$, i.e. $\sim 663 \mathrm{~K}$ as mentioned in the manual. The inset demonstrates the energy absorbed corresponding to substrate temperatures normally used for our GaAsN growth $\left(400^{\circ} \mathrm{C}-650^{\circ} \mathrm{C}\right)$. 


\subsubsection{Measurement}

To determine the real temperature of one object, its emissivity must be taken into account as explained in section 4.1.1. The emissivity of GaAs obtained from literatures however came with discrepancies. Three values, $0.55,0.75$, and 0.36 were found from three different sources [Derby, 1986] [Sabhapathy, 1989] [Dupret, 1990]. Since it is not sure which one is closer to our case, all three above were tried for our pyrometer measurement to at least get a rough idea of how the real temperature related to the reading value. As mentioned in 4.1.3.3, a high temperature model Omega OS-3000 AS infared (IR) pyrometer was employed. It targeted the substrate through a transparent viewport and detected the energy radiated from the surface of the substrate. Depending on what emissivity applied, the energy signal received was converted to a temperature that can be read from the LCD screen of the pyrometer. Solid lines in Fig 4.7 are temperatures measured by pyrometer versus dial temperatures.

\subsection{Temperature calibrated by RHEED}

Pyrometer could be a good and effective tool to determine temperatures if the emissivity is known, however, in our experiment, the uncertainty of emissivity limited the accuracy of the measurement as seen in Fig 4.5, which at a certain dial temperature gave top and bottom boundaries that real temperatures might fall between, but an exact relationship between them could not be decided due to the existence of several possible emissivities. In addition, considering the radiation from open effusion cells that may perturb the reading of pyrometer, a more accurate method may be required for a better calibration. Reflection high energy electron diffraction (RHEED) is such an option since for GaAs growth, surface reconstruction occurs at several certain substrate temperatures, if monitoring the RHEED pattern change and marking 
down reading temperatures where pattern transitions happen, a relationship can be found since real temperatures associated with those transitions were already known.

When the GaAs substrate is initially mounted on the substrate holder, no clear RHEED pattern could be observed unless the oxide on the surface is removed. The oxide desorption can be done by heating the substrate up under an As4-rich environment until a bright bulk spot RHEED pattern appears, meaning the oxide is desorbed and corresponding to a oxide desorption temperature of $\sim 580^{\circ} \mathrm{C}$ [SpringThorpe, 1987] [Rumberg, 1995]. The dial temperature at this point was $800^{\circ} \mathrm{C}$ in our experiment, so along with this reading temperature, this pair of temperatures served as the first point in our calibration curve.

Next a buffer layer was deposited under a substrate temperature at which a 2x4 RHEED pattern could be observed, and then Ga cell shutter was closed to interrupt Ga flux but leaving the As valve open to remain a $\mathrm{As}_{4}$ beam equivalent pressure (BEP) of $4 \mu$ Torr. The experiment was started by cooling down the substrate $10^{\circ} \mathrm{C}$ each time while keeping an eye on the RHEED. A transition of RHEED pattern from $2 \mathrm{x} 4$ to $\mathrm{c}(4 \mathrm{x} 4)$ occurred when the reading became $675^{\circ} \mathrm{C}$. Then the substrate was heated up in $10^{\circ} \mathrm{C}$ increments and at some point the pattern was back to $2 \times 4$ again. The temperature was continually increased until a surface reconstruction of $2 \times 1$ appeared at the dial temperature of $839^{\circ} \mathrm{C}$. Under the $\mathrm{As}_{4} \mathrm{BEP}$ of $4 \mu \mathrm{Torr}$, the transition from $2 \times 4$ to $\mathrm{c}(4 \times 4)$ and $2 \times 1$ happen at real temperatures of $490^{\circ} \mathrm{C}$ and $605^{\circ} \mathrm{C}$ [LaBella, 2001], associated with dial $675^{\circ} \mathrm{C}$ and $839^{\circ} \mathrm{C}$ respectively. The addition of these two pairs of data formed the complete calibration curve shown in Fig 4.5 as the dotted line, suggesting a substrate thermocouple calibration relationship as

$$
\mathrm{T}_{\text {real }}=0.724 \times \mathrm{T}_{\text {dial }}
$$


All substrate temperatures shown in this work are real temperatures determined by this equation. One may also notice that this result fits the measurement made by pyrometer if an emissivity of 0.55 was applied, so it might imply that the substrate used here has an emissivity close to 0.55 .

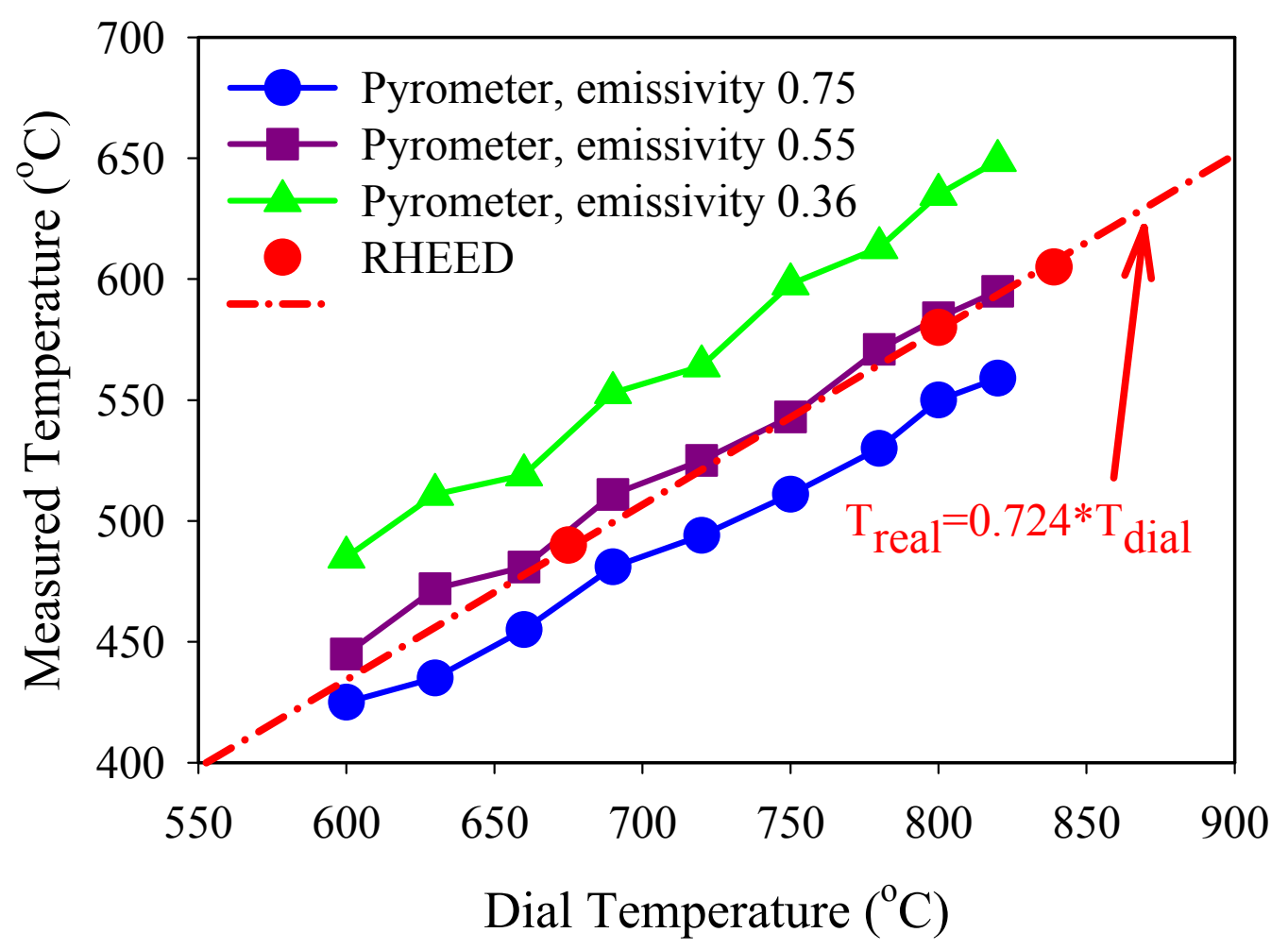

Fig 4.5 Substrate temperature calibration by pyrometer or surface reconstruction monitored by RHEED. 


\section{Chapter 5}

\section{Growth}

\subsection{Sample structure}

Samples in this work were grown on either semi-insulating or $\mathrm{n}^{+}(100) \mathrm{GaAs}$ substrate. A GaAs buffer layer is grown first, followed by $\operatorname{GaAs}_{1-x} \mathrm{~N}_{\mathrm{x}}$ layer or structures on the top. The buffer layer effectively suppresses background impurities and reduces the formation of dislocations in the top $\mathrm{GaAs}_{1-\mathrm{x}} \mathrm{N}_{\mathrm{x}}$ layer since it absorbs impurities and is lattice matched to the substrate. Also, potential surface contamination or damage associated with the process of preparing substrates would not affect active layers due to the isolation effect of the buffer layer. Therefore, samples with better quality and smoother surface can be obtained.

\subsection{Fluxes of source materials}

The quality of a crystal grown by MBE is determined by many factors, among which the beam flux of species applied during growth is of importance. The measurement and adjustment of beam fluxes every time before the growth are routine procedures ensuring desired conditions are employed, and growths are duplicable and comparable all the time. The beam flux $\mathrm{J}$ of any component species is determined and expressed as:

$$
J \propto \frac{P}{A} \sqrt{\frac{T}{M}}
$$

where $\mathrm{P}$ is the beam equivalent pressure (BEP), $\mathrm{A}$ is the area of the interface of the effusion cell orifice, $\mathrm{T}$ is the crucible temperature, and $\mathrm{M}$ is the molecular weight of the species. 
In a given MBE system, for a material loading in a Knudsen effusion cell, whose orifice area and distance to the substrate are fixed, the BEP read by the beam flux monitor is proportional to the amount of molecules arriving at the substrate surface during a unit time. BEPs can be read directly from the ionization gauge, avoiding the complicacy of taking the cross section area and temperature of the source cell into account, hence in practice it is more straightforward to use the BEP instead of the real beam flux.

\subsubsection{As BEP}

As mentioned in 3.1.1, arsenic species is generated from a cracker cell made by EPI. The temperature of the cracker zone determines what species $\left(\mathrm{As}_{2}\right.$ or $\left.\mathrm{As}_{4}\right)$ will be produced, and temperature of the bulk zone is related to its flux. At a given bulk zone temperature, a desired arsenic flux can be achieved by turning the valve to a position between 0 and 200 through a valve positioner with the reading $(0-200)$ shown on the LCD screen. The maximum flux it can reach as the valve is fully open (at position 200) is determined by the bulk zone temperature. Fig 5.1 is the $\mathrm{As}_{4} \mathrm{BEP}$ as a function of the valve position. $312^{\circ} \mathrm{C}$ and $320^{\circ} \mathrm{C}$ are bulk zone temperatures. It is obvious that the higher this temperature is, the higher the maximum flux it can get.

Different from most species like Ga and In, which always stick to the first surface they reach, arsenic has the sticking coefficient changing depending on the amount of arsenic atoms already exist there due to the volatility of As, causing atoms reflected from the surface possibly strike the ion gauge again and be re-counted for the BEP measurement. This inaccuracy can be avoided if the measurement is taken by sending As onto group III covered surface since almost all arsenic atoms reaching can stick under this condition. The following steps are applied to determine the As BEP. First the Ga shutter has to be opened to have Ga flux targeting the 
ionization gauge, and then close the shutter once Ga atoms are estimated to have covered the whole surface of the detector of the beam flux monitor, which may take about 1 minute. Right after that, open the As shutter, and the reading got by the ion gauge jumps to a value which represents the As BEP.

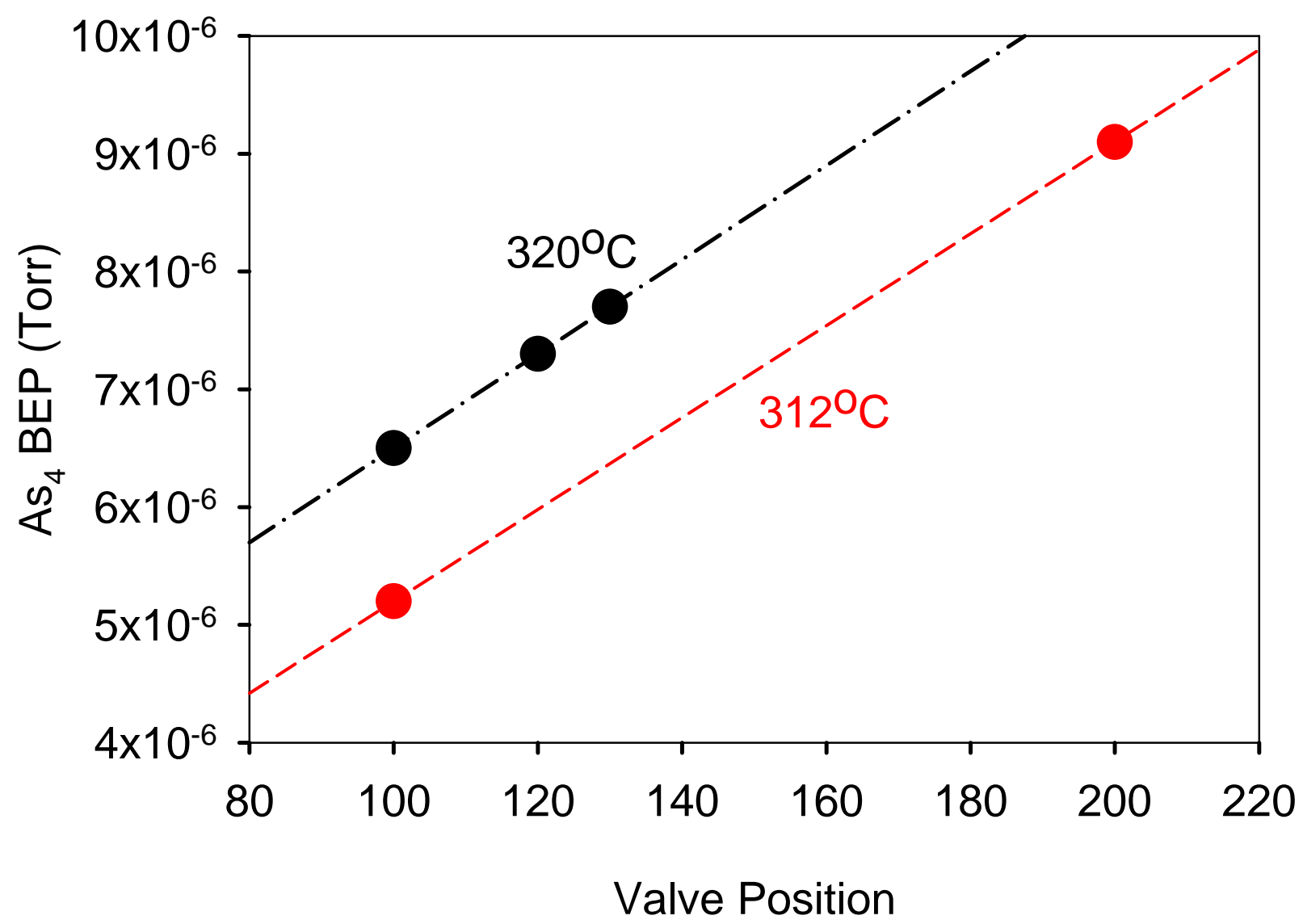

Fig 5.1 The dependence of $\mathrm{As}_{4} \mathrm{BEP}$ on the valve position of the cracker. 


\subsubsection{Ga BEP}

The desired Ga flux can be obtained by adjusting Ga effusion cell temperature. Compared to As, It is simple to measure Ga BEP since its sticking coefficient is close to a unity as mentioned in 5.2.1. Normally the Ga BEP at a certain evaporated temperature would not change too much from one growth to the next if there is enough Ga left in the crucible as seen in Fig 5.2. Ga BEP starts to drop at a given temperature if the source material is about to run out. In that case, the curve shown in Fig 5.2 will drop but keep the same rate as compared to previous measurements.

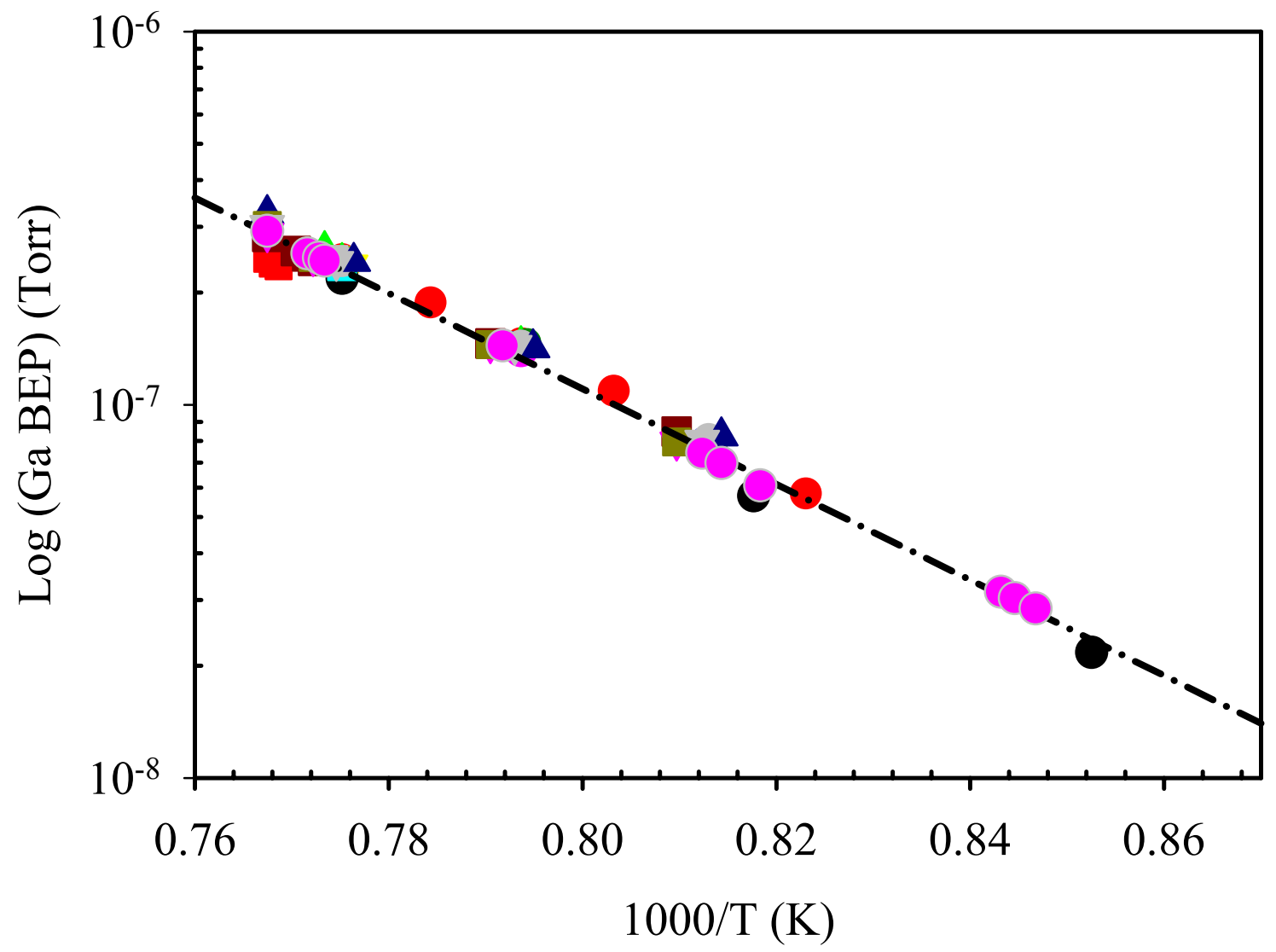

Fig 5.2 Ga BEP vs. the effusion cell temperature. 


\subsection{Growth Rate}

To fabricate a device, the thickness of each layer contained in the sample structure is often critical. Therefore, the growth rate must be known to determine the time needed for each growth. Two different methods were tried to get the growth rate.

\subsection{1 $\mathrm{SiO}_{2}$ pattern on $\mathrm{GaAs}$ substrate}

$\mathrm{SiO}_{2}$ was deposited and covered the GaAs substrate by Plasma Enhanced Chemical Vapor Deposition (PECVD). On top of the $\mathrm{SiO}_{2}$ layer, photolithography procedure was carried out to form photoresist stripes. The wafer was then put into buffered oxide etch (BOE) solution to etch off $\mathrm{SiO}_{2}$ areas where there are no photoresist protected. The etching stopped at GaAs since BOE is highly selective and does not attack GaAs. Finally the wafer was soaked into acetone which removed photoresist and had $\mathrm{SiO}_{2}$ stripe patterns left on the GaAs. This $\mathrm{SiO}_{2}$ patterned GaAs substrate was loaded into the growth chamber with GaAs film grown on it, and then had BOE etching conducted again after taken out of the system. GaAs grown on GaAs region remained but GaAs grown on $\mathrm{SiO}_{2}$ stripes was worn off since $\mathrm{BOE}$ attacked $\mathrm{SiO}_{2}$ underneath and hence peeled off the GaAs sitting on it. The thickness of GaAs stripes left was measured by Alfa step profilometer and divided by the growth time to get the growth rate. Fig 5.3 is a step by step flow demonstrating the whole process.

Growth rates measured at different Ga fluxes (Fig 5.4) were achieved employing the procedure above, indicating a linear relationship between growth rate and Ga flux as expected. 


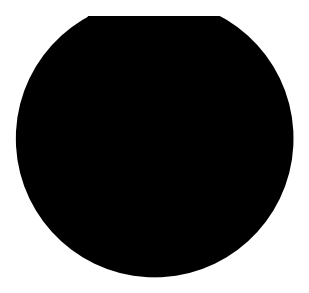

GaAs substrate

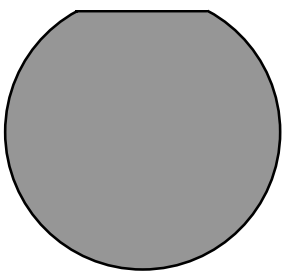

PECVD

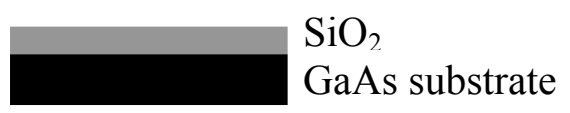

Photolithography
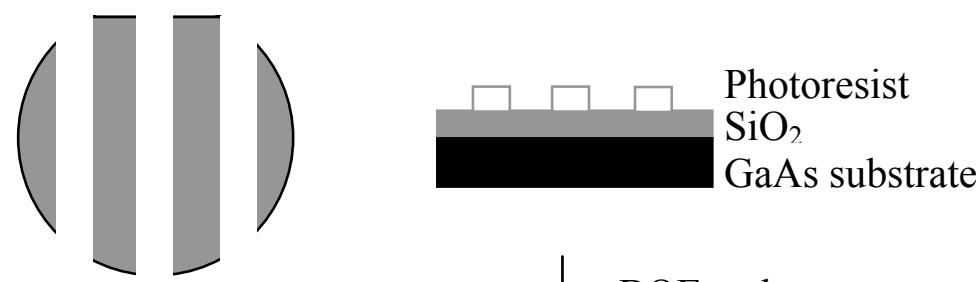

BOE etch
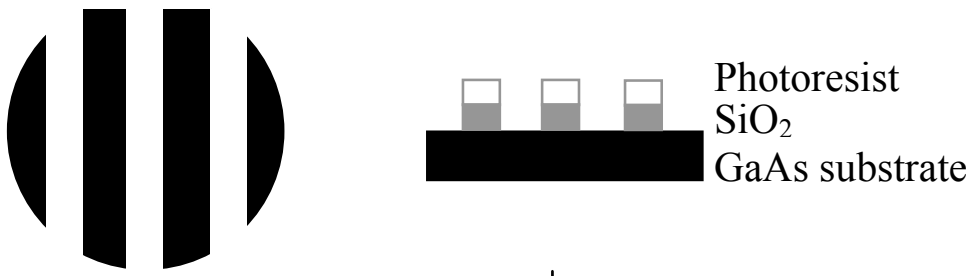

Acetone
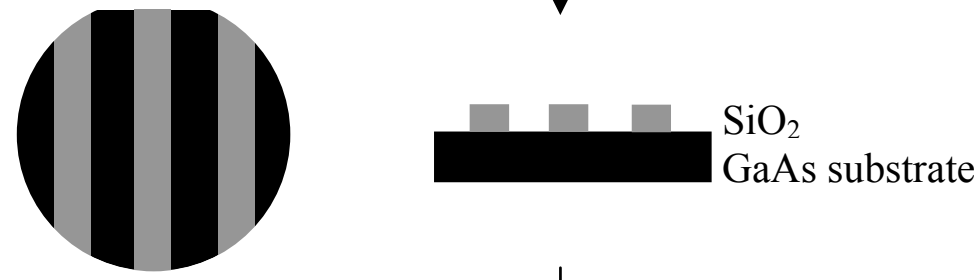

GaAs growth

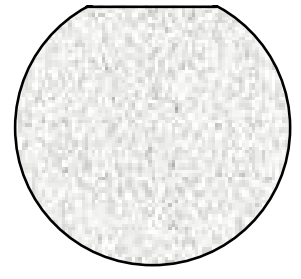

GaAs

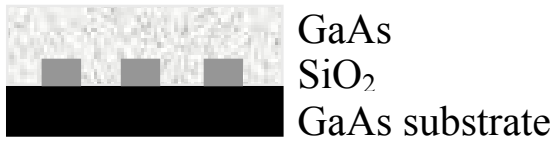

BOE etch

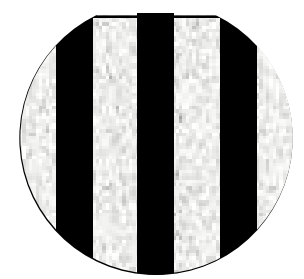

Fig 5.3 $\mathrm{SiO}_{2}$ strip patterns on GaAs substrate used for measuring the growth rate. 


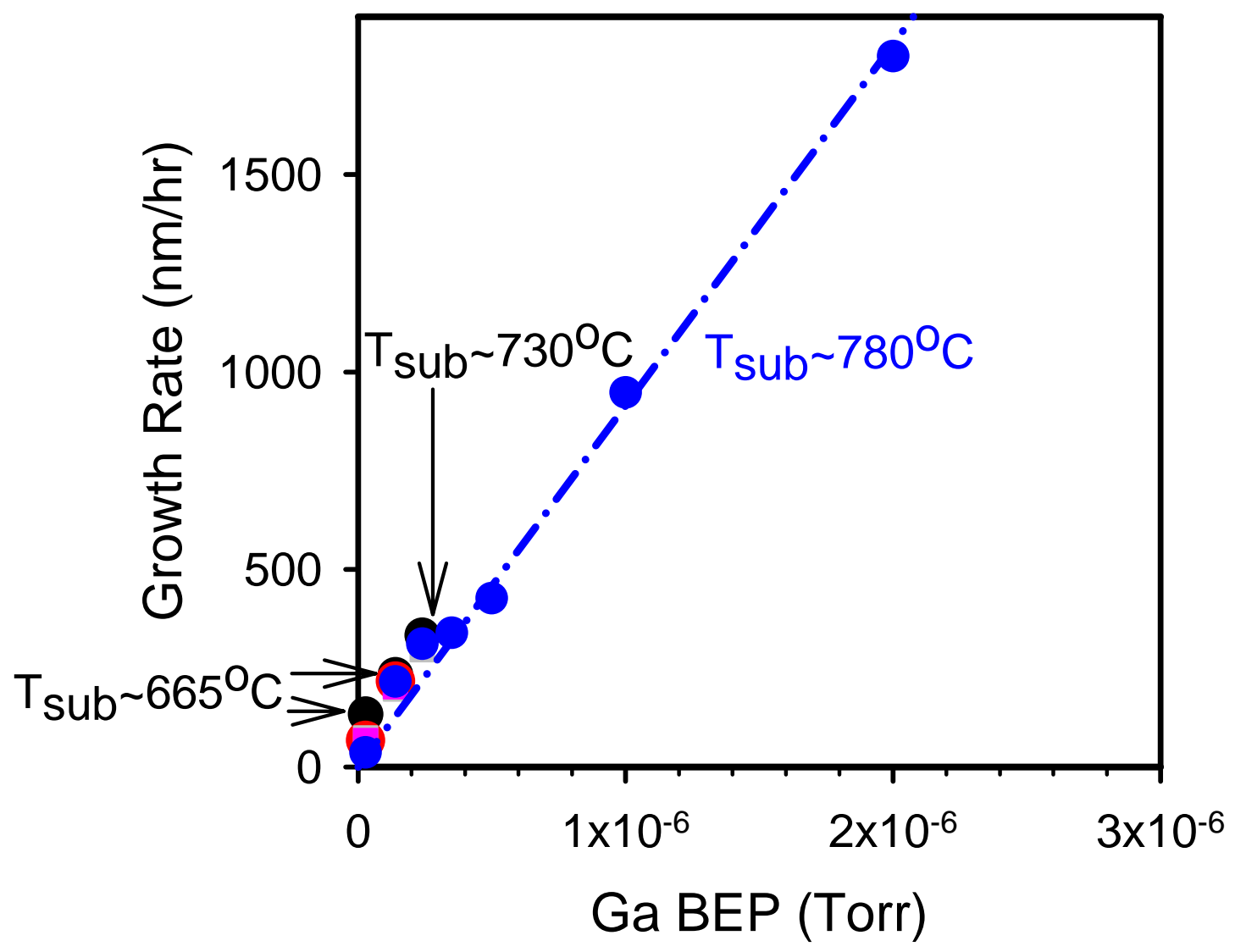

\begin{tabular}{|c|c|}
\hline $\begin{array}{c}0 \\
0 \\
\square \\
0 \\
-\cdot-\end{array}$ & $\begin{array}{l}\text { GaAs, As4, by patterned } \mathrm{SiO}_{2} \\
\text { GaAsN, As4, by patterned } \mathrm{SiO}_{2} \\
\text { GaAs, As2, by patterned } \mathrm{SiO}_{2} \\
\text { GaAsN, As2, by patterned } \mathrm{SiO}_{2} \\
\text { GaAs, As4, by RHEED oscillation } \\
\text { Tsub } \sim 780^{\circ} \mathrm{C}\end{array}$ \\
\hline
\end{tabular}

Fig 5.4 Growth rate vs. Ga $\mathrm{BEP}$ by patterned $\mathrm{SiO}_{2}$ or RHEED oscillation. 


\subsubsection{RHEED oscillation}

The specular intensity was found to oscillate right after starting the growth and its period corresponds to the time taken to grow one monolayer of crystal. Fig 5.5 [Ohring, 1992] schematically explains the mechanism of RHEED oscillation. The RHEED pattern of the specular spot is bright when the growth surface is flat, while becomes dim if the surface is rough

due to the increase of beam scattering. The very strong RHEED intensity normally observed prior to the growth reflects a smooth surface and corresponds to the peak position of the RHEED oscillation. When the growth is initiated, atoms reaching the surface at first do not possess enough energy to diffuse to a lattice step edge, so 2-D islands are formed. Electron interference effects stemming from the islanded surface cause the continuous drop of the RHEED intensity until most areas of the surface are covered by evaporated atoms and islands begin to annihilate. This annihilation of islands recovers the intensity back and when one monolayer is completely finished, the intensity reaches another peak. The time taken between two adjacent peaks, i.e. the period of the oscillation thus represents the time needed to grow one monolayer.

Fig 5.6 shows the intensity oscillation of the specular spot of two GaAs growths done with varied Ga BEP. The growth rate obtained this way is more accurate, and can be determined as

$$
G R=\frac{3600 d_{m l}(\stackrel{\circ}{A})}{t(s)}(\stackrel{\circ}{A} / h r)
$$

Where $d_{m l}$ is the thickness of one monolayer, which is $2.83 \AA$ for GaAs. $t$ is the period of oscillation in second. 


\section{E-Beam}
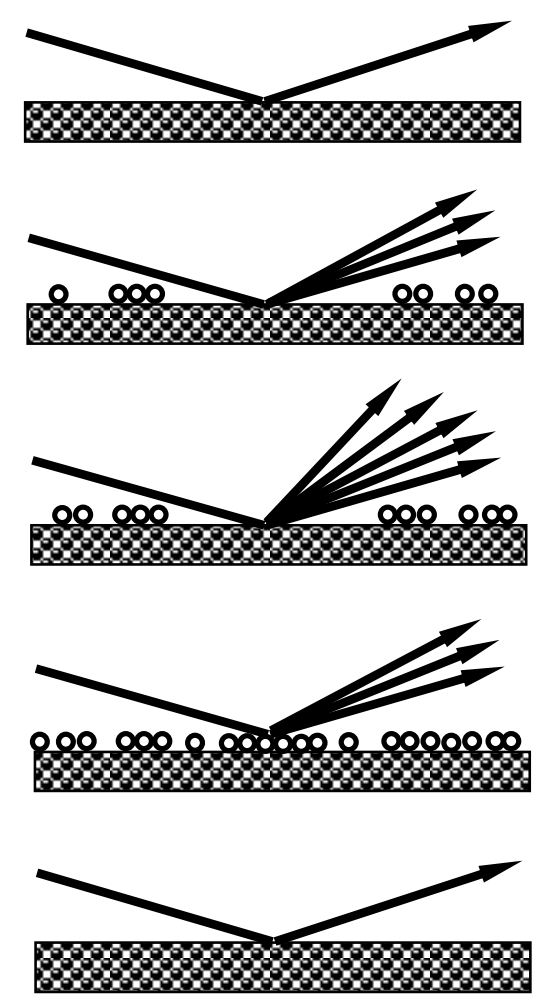

RHEED Intensity of

Specular Spot
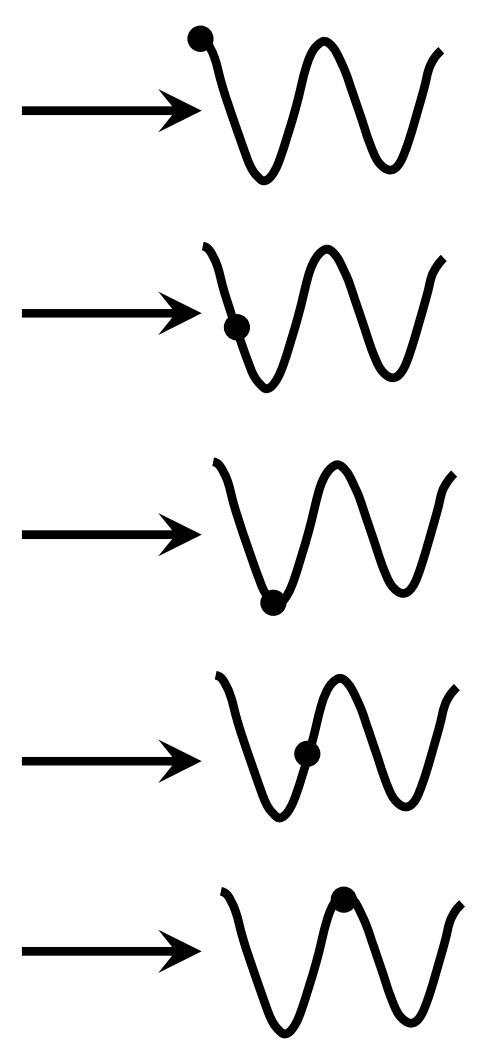

Fig 5.5 Schematic diagram explaining the RHEED intensity oscillation. [Ohring, 1992]

In Fig 5.6, a shorter period of oscillation representing a higher growth rate was observed for the higher Ga BEP case, while a lower growth rate was obtained for a lower Ga BEP. The decay of the intensity oscillation is partially attributed to the phase mismatch between different layers generated by the nucleation of the second or even more layers on the surface before its being fully buried by the first layer [Neave, 1981]. Another mechanism responsible for the damping of the RHEED oscillation is the possible transition of growth pattern from island growth to step propagation which takes place a while after initiating the growth when the growth becomes steady [Joyce, 1988], in which case, the smooth drift of lattice step edges is dominant as atoms obtain enough energy to diffuse to the lattice step edge, so the absence of timedependent electron interference effects maintains the RHEED intensity constant, and the oscillation decays and eventually disappears. 

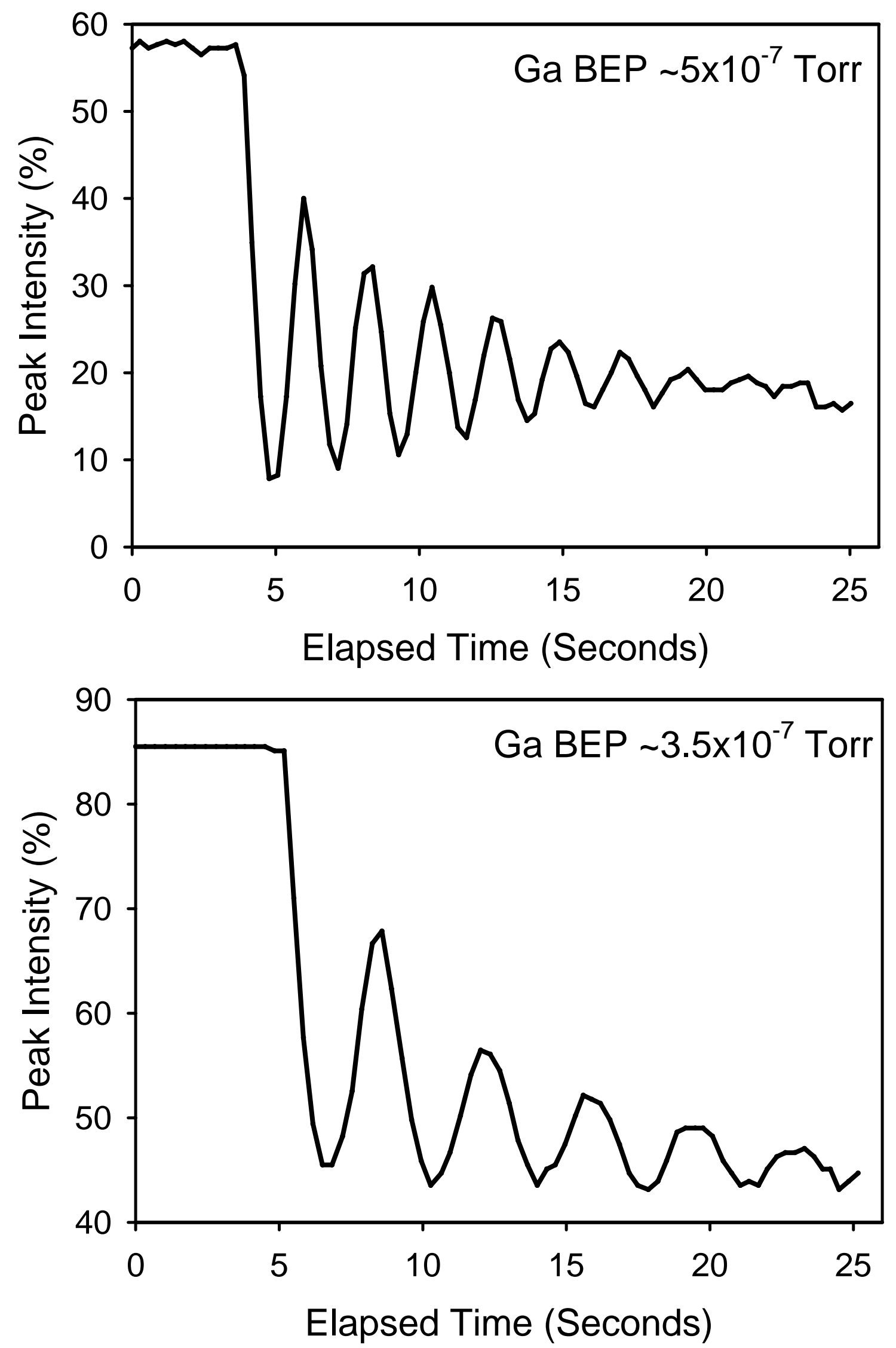

Fig 5.6 RHEED intensity oscillations of two growths with different Ga BEPs. 
Growth rates obtained by RHEED oscillations in Fig 5.4 agree with results got from growths on $\mathrm{SiO}_{2}$ patterned GaAs. As seen in the figure, the growth rate is linearly proportional to the $\mathrm{Ga}$ BEP, by varying which therefore can realize the control of growth rate. All growth rates used in this work are from the RHEED oscillation since it is more reliable, easier and applicable for real growths.

\subsection{Surface phase diagram}

RHEED is used to monitor the surface reconstruction, which is varied with the change of surface stoichiometry affected by factors like Ga BEP, As BEP, group V/III flux ratio and the substrate temperature. Fig 5.7 is an example of surface phase diagram of GaAs orientated along (100) direction with the growth rate at $\sim 0.71 \mu \mathrm{m} / \mathrm{hr}(0.7 \mathrm{ML} / \mathrm{s})$ [Farrow, 1995a]. Parameters related to growth should be chosen carefully to optimize crystal's quality. For example, relatively low substrate temperature is suitable for growing doping material because of less dopant diffusion corresponding to lower substrate temperature, while higher growth temperature can minimize impurities and defects, and thus is used if better optical properties are desired. As for V/III ratio, which influences the surface stiochiometry and growth kinetics, lower ratios can improve luminescence efficiency by minimizing impurities incorporated from As, and higher ratios are often employed for doping case since dopant diffusion can be suppressed with a higher V/III ratio. The same experiment reproduced was shown in Fig 5.7 by monitoring RHEED pattern change to get growth conditions translated into our MBE system. It helps to narrow growth conditions that can be used in our system since the change of surface reconstruction reflects the change of atoms incorporation and redistribution at the surface, and thus a rough range of growth conditions corresponding to the crystal structure and morphology desired can be approximately determined. 
Too low growth temperature induces more impurities and defects into the material, so usually the substrate temperature is limited to be no less than $420^{\circ} \mathrm{C}$. Too high V/III flux ratio also leads to the incorporation of impurities. If V/III ratio is too low however, the surface could be destructive because Ga has a near unity stick probability but no enough As atoms fit all neighboring positions adjacent to it, causing group $\mathrm{V}$ vacancies left and leading to a rough surface. The ratio generally is chosen to be no more than 20 and at least more than 1 . As seen in Fig 5.7, growth conditions meeting requirements for both growth temperature and V/III ratio primarily correspond to the surface reconstruction area of $2 \times 4$ and $2 \times 1$. Since $2 \times 4$ reconstruction occupies a wider range in the diagram, if the transition edge of $2 \times 4$ to $1 \times 1$ and $2 \times 4$ to $2 \times 1$ are able to be determined, growth conditions desired can be easily retrieved from the diagram.

Keeping As BEP at $4.5 \times 10^{-6}$ Torr and varying the V/III ratio by changing the Ga BEP, the $2 \times 4$ reconstruction range was determined, and the highest and lowest substrate temperatures that can hold a 2x4 RHEED reconstruction pattern under that ratio were also found. The result shown in Fig 5.8 (a), in which the blue line 'best' is where the brightest and clearest $2 \times 4$ pattern, which is associated with better controlled growth conditions maintaining a smooth surface, well organized atom arrangement, and optimized crystal structure, could be seen. Therefore, the 'best' line can be tracked to retrieve growth conditions for the growth, such as what growth temperature should be taken at a given $\mathrm{V} / \mathrm{III}$ ratio.

If the Ga BEP remained the same at $5 \times 10^{-7}$ Torr (corresponding to the growth rate of 0.46 $\mu \mathrm{m} / \mathrm{hr}$ ) and changing the As BEP, the similar result was got as shown in Fig 5.8 (b), which also gives the $2 \times 4$ surface reconstruction region and the 'best' line for determining the optimal growth parameters. 
Although the result shown in Fig 5.8 may vary a little bit per choosing different fixed BEPs for As (Fig 5.8 (a)) or Ga (Fig 5.8 (b)), it provides important information and is a very reliable reference for choosing parameters related to growths. For GaAs like buffer layer growth, conditions are set to remain a $2 \times 4$ RHEED pattern, while for $\mathrm{GaAs}_{1-\mathrm{x}} \mathrm{N}_{\mathrm{x}}$ growth, growth temperature and group V/III BEP ratio are altered to get the $2 \mathrm{x} 1$ reconstruction since Reason et al. [Reason, 2004] found under 2x1 reconstruction more $\mathrm{N}$ can be substitutionally incorporated probably because in this case more group $\mathrm{V}$ sites are available in a unit area.

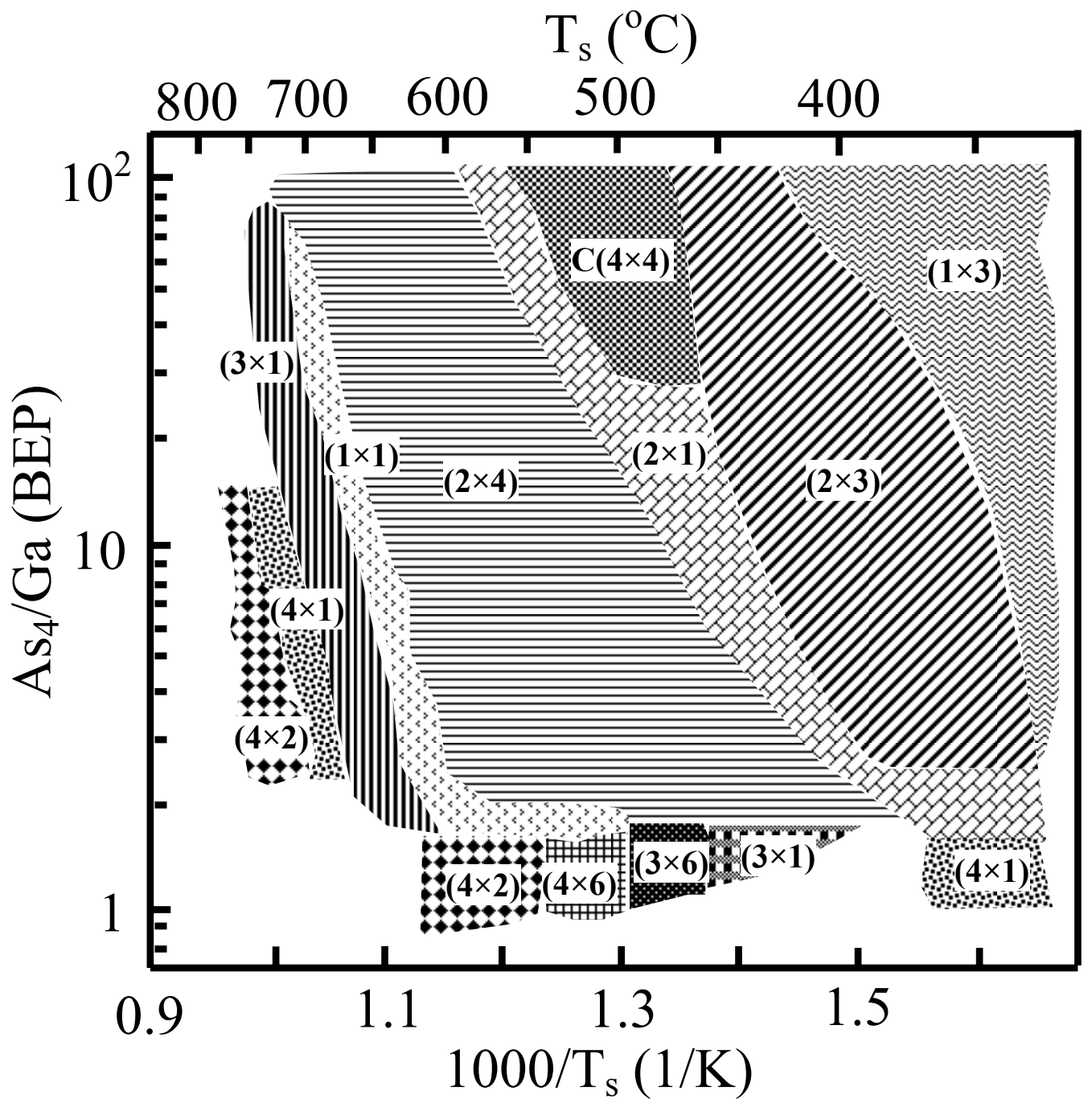

Fig 5.7 Surface phase diagram of (100) GaAs with the growth rate of $0.71 \mu \mathrm{m} / \mathrm{hr}$. [Farrow, 1995] 
$\mathrm{T}_{\mathrm{S}}\left({ }^{\mathrm{O}} \mathrm{C}\right)$
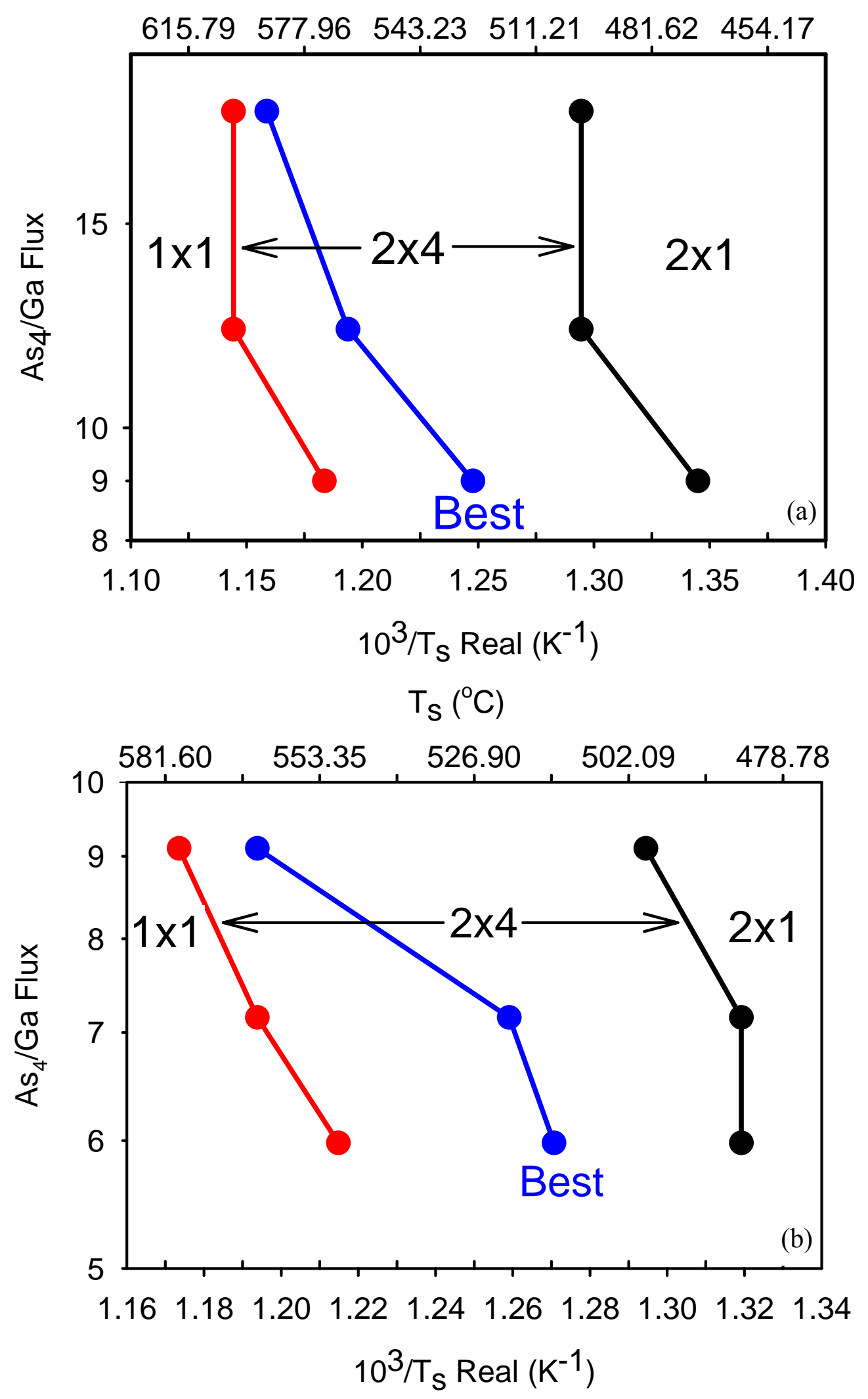

Fig 5.8 Surface phase diagram of GaAs (100). (a) Growth rate $0.17-0.46 \mu \mathrm{m} / \mathrm{hr}$ $(0.17-0.45 \mathrm{ML} / \mathrm{s}), \mathrm{As}_{4} \mathrm{BEP} \sim 4.5 \times 10^{-6}$ Torr and $\mathrm{Ts}<575^{\circ} \mathrm{C}$; (b) Growth rate 0.46 $\mu \mathrm{m} / \mathrm{hr}(0.45 \mathrm{ML} / \mathrm{s}), \mathrm{As}_{4} \mathrm{BEP} \sim 3-4.5 \times 10^{-6}$ Torr and $\mathrm{Ts}<580^{\circ} \mathrm{C}$. 


\subsection{Factors affecting $N$ concentration}

As mentioned in section 1.2 and 2.1, high $\mathrm{N}$ incorporation of $\mathrm{GaAs}_{1-\mathrm{x}} \mathrm{N}_{\mathrm{x}}$ corresponding to a narrow band gap is desired for long wavelength applications, however in practice $\mathrm{N}$ incorporation is limited by the low $\mathrm{N}$ solubility and large miscibility gap, and too much $\mathrm{N}$ can cause phase separate and hence deteriorates the material [Bi, 1997]. To accurately manipulate $\mathrm{N}$ incorporation, the first thing is to sort out all factors that may influence the $\mathrm{N}$ composition.

\subsubsection{Aperture plate of the RF-plasma discharge tube}

The tube for discharging RF-plasma nitrogen was originally equipped with an $Ø 30.8 \mathrm{~mm}$ PBN beam aperture plate having $488 \times \varnothing 0.2 \mathrm{~mm}$ holes uniformly distributed on the plate. The diameter of each hole and the total number of holes determine the amount of reactive $\mathrm{N}$ that go through holes reaching the substrate surface. This aperture plate always led to the $2 \mathrm{D}$ to $3 \mathrm{D}$ surface reconstruction by RHEED pattern transforming from streaky to spotty right after opening the $\mathrm{N}$ shutter to release ionized $\mathrm{N}$ to the substrate, even if with the lowest $\mathrm{N}$ partial pressure and RF power achievable, which are $10^{-7}$ Torr and $100 \mathrm{~W}$ respectively. $\mathrm{N}$ source in the MBE system for this work does not have a mass flow meter, but the flow rate can be estimated based on the formula below:

$$
\mathrm{Q}=\mathrm{SP}
$$

Where $\mathrm{Q}$ is the gas flow rate, $\mathrm{S}$ is the pumping speed, and $\mathrm{P}$ is the pressure at the intake of the pump. Our growth chamber is pumped by a CTI Cryo-Torr 8 cryopump with a pumping speed of $15001 / \mathrm{s}$, so $10^{-7}$ Torr was calculated to correspond to $0.01 \mathrm{sccm}$ based on the pumping speed and conductance of the system. 
Increasing the growth rate, increasing the As BEP, and reducing the growth temperature were all tried, but 3D spotty RHEED pattern kept coming out every time when $\mathrm{N}$ was introduced into the growth. To resolve this problem, the aperture plate was substituted with a $7 \times \varnothing 0.5 \mathrm{~mm}$ holes one since too much $\mathrm{N}$ is the most possible reason responsible for the surface deterioration as every other possibility was tried and eliminated. Although this appreciably blocked a great amount of active nitrogen species from passing through, the RHEED pattern still indicated the $3 \mathrm{D} \mathrm{GaAs} \mathrm{1-x}_{\mathrm{x}} \mathrm{N}_{\mathrm{x}}$ growth no matter how the other growth conditions were chosen.

To further reduce the effective area that $\mathrm{N}$ beam flux can leak through, a $10 \times \varnothing 0.2 \mathrm{~mm}$ holes aperture plate was mounted in to substitute the previous one, and streaky RHEED pattern representing the 2D growth was observed eventually under some growth conditions. All growths in this study were carried out with the $10 \times \varnothing 0.2 \mathrm{~mm}$ holes aperture plate.

\subsection{2 $\mathrm{N}$ concentration vs. Ga flux}

Ga flux changes $\mathrm{N}$ concentration (measured by SIMS) as shown in Fig 5.9 if the other growth conditions are fixed and within a normal and applicable regime. It is easy to understand that $\mathrm{N}$ incorporation would be suppressed with a higher $\mathrm{Ga}$ flux as the ratio of $\mathrm{Ga} / \mathrm{N}$ arriving at the growth surface becomes larger with increasing Ga flux while keeping the amount of active $\mathrm{N}$ still the same. For growth under As-stable growth conditions, arsenic atoms can accommodate increased Ga atoms by filling extra group V lattice positions produced due to the higher Ga flux. As a result, the fractional composition of nitrogen is reduced in comparison to the increase of As. Therefore, $\mathrm{N}$ composition is reversely proportional to Ga flux, which can be adjusted to vary the $\mathrm{N}$ concentration. 


\subsection{3 $\mathrm{N}$ concentration vs. $\mathrm{N}$ flow rate}

A leak valve inserted between the $\mathrm{N}$ source and the RF-plasma generator effectively alters the $\mathrm{N}$ flux rate. The $\mathrm{N}$ partial pressure is proportional to its flow rate and therefore the alternation of $\mathrm{N}$ flow rate for our growths is controlled by changing the partial pressure since our $\mathrm{N}$ source is not equipped with a mass flow meter.

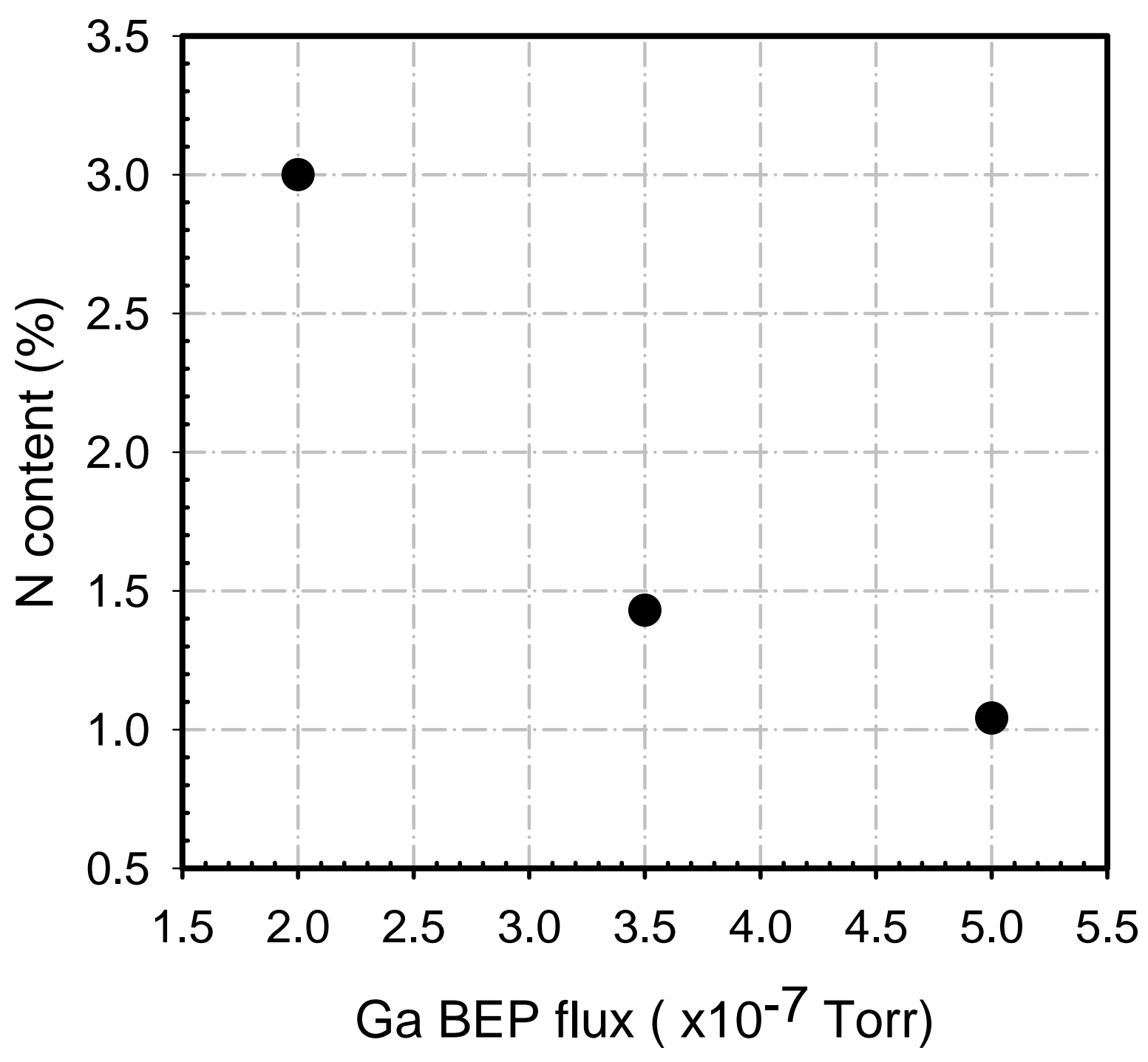

Fig 5.9 The dependence of $\mathrm{N}$ content on Ga BEP flux. $\mathrm{N}$ partial pressure $1 \times 10^{-7}$ Torr $(\sim 0.01 \mathrm{sccm})$, RF power $100 \mathrm{~W}, \mathrm{As}_{4} \mathrm{BEP} \sim 6 \times 10^{-6}$ Torr, and Ts $\sim 430^{\circ} \mathrm{C}$. 
Increasing $\mathrm{N}$ flow rate leads to the increase of $\mathrm{N}$ composition. Fig 5.10 is two series of growths with different Ga fluxes. For each of them, the higher $\mathrm{N}$ flow rate corresponded to a higher $\mathrm{N}$ content because more nitrogen was involved into the growth. The partial pressure change from $10^{-7}$ Torr to $10^{-6}$ Torr caused the rise of $[\mathrm{N}]$ approximately $0.5-0.8 \%$. The influence of Ga flux was also seen that the $\mathrm{N}$ concentration dropped with increasing the Ga flux.

\subsection{4 $\mathrm{N}$ concentration vs. RF power}

$R F$ power may be one more effective factor affecting the $\mathrm{N}$ concentration in $\mathrm{GaAs}_{1-\mathrm{x}} \mathrm{N}_{\mathrm{x}}$. Different from the mechanism of varying the $\mathrm{N}$ flow rate, which changes the total amount of nitrogen atoms existing in the RF-plasma generator, RF power alters the actual number of active $\mathrm{N}$ species generated by the generator while keeping the amount of $\mathrm{N}$ atoms the same for a given $\mathrm{N}$ flow rate, so more active $\mathrm{N}$ can be obtained if a higher RF power is applied. Fig 5.11 shows three sets of growths carried out under different $\mathrm{N}$ flow rate and Ga fluxes. For a certain $\mathrm{N}$ flow rate, adjusting the RF power directly altered the final $\mathrm{N}$ content. For example, with the $\mathrm{N}$ partial pressure $\sim 10^{-7}$ Torr and the Ga flux $\sim 5 \times 10^{-7}$ Torr (solid circles in Fig 5.11), [N] was $\sim 1 \%$ if the RF power was set at $100 \mathrm{~W}$, and became $\sim 3.7 \%$ if $300 \mathrm{~W}$ was used, so each $100 \mathrm{~W}$ increase in the $\mathrm{RF}$ power is responsible for the incorporation of $\sim 130 \%$ more N. The same trend was observed for the other two growth conditions (solid triangles and solid squares) in Fig 5.11.

Compared to other factors, even if the As flux has any influence on $\mathrm{N}$ incorporation, the effect is negligible. As shown in Fig 5.12, the drop of $[\mathrm{N}]$ is very small when raising As BEP flux from $\sim 3 \times 10^{-6}$ Torr to $\sim 6 \times 10^{-6}$ Torr. 


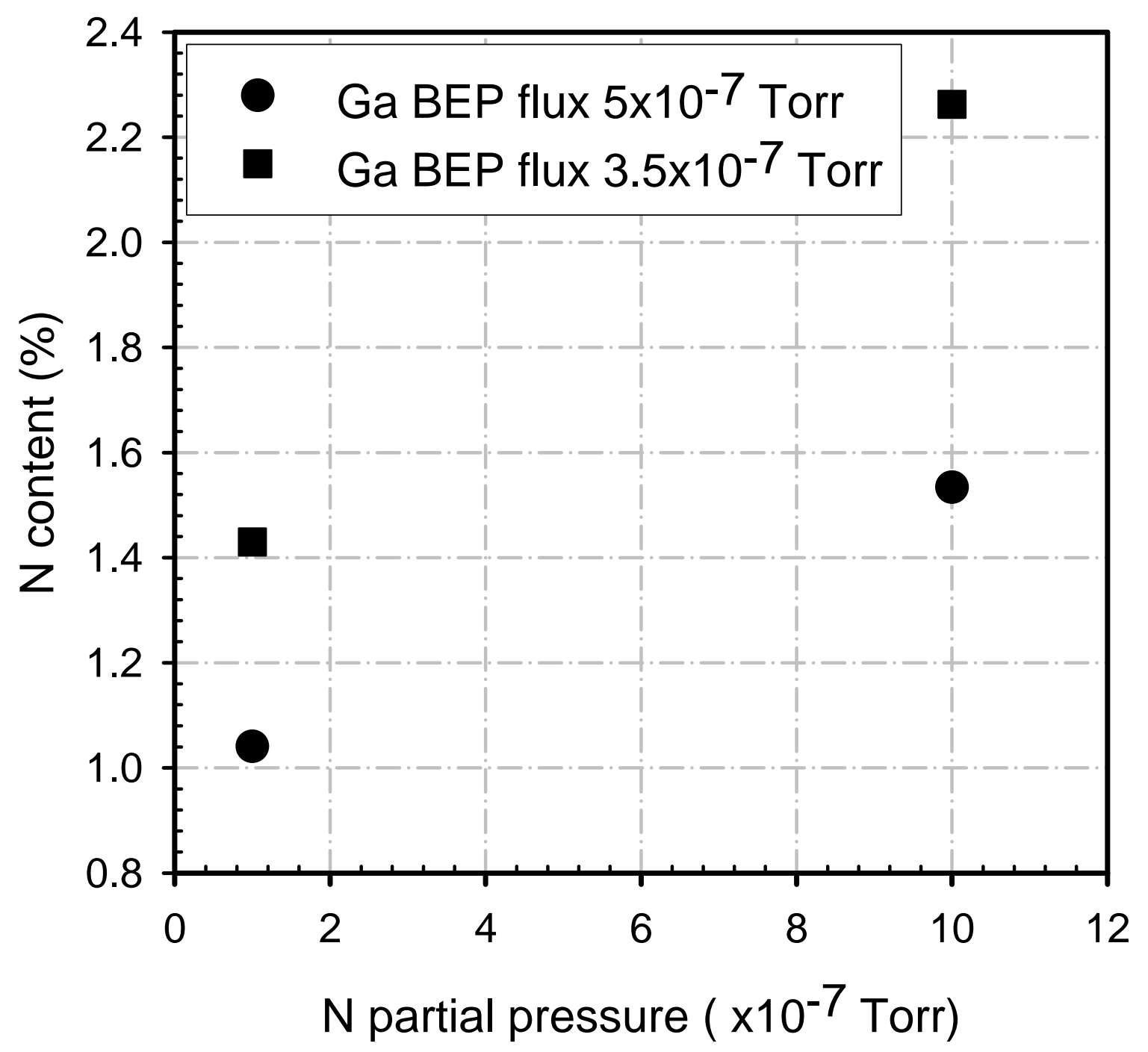

Fig 5.10 The dependence of $\mathrm{N}$ content on $\mathrm{N}$ flux. RF power $100 \mathrm{~W}, \mathrm{As}_{4}$ BEP $\sim 6 \times 10^{-6}$ Torr, and $\mathrm{Ts} \sim 430^{\circ} \mathrm{C}$. 


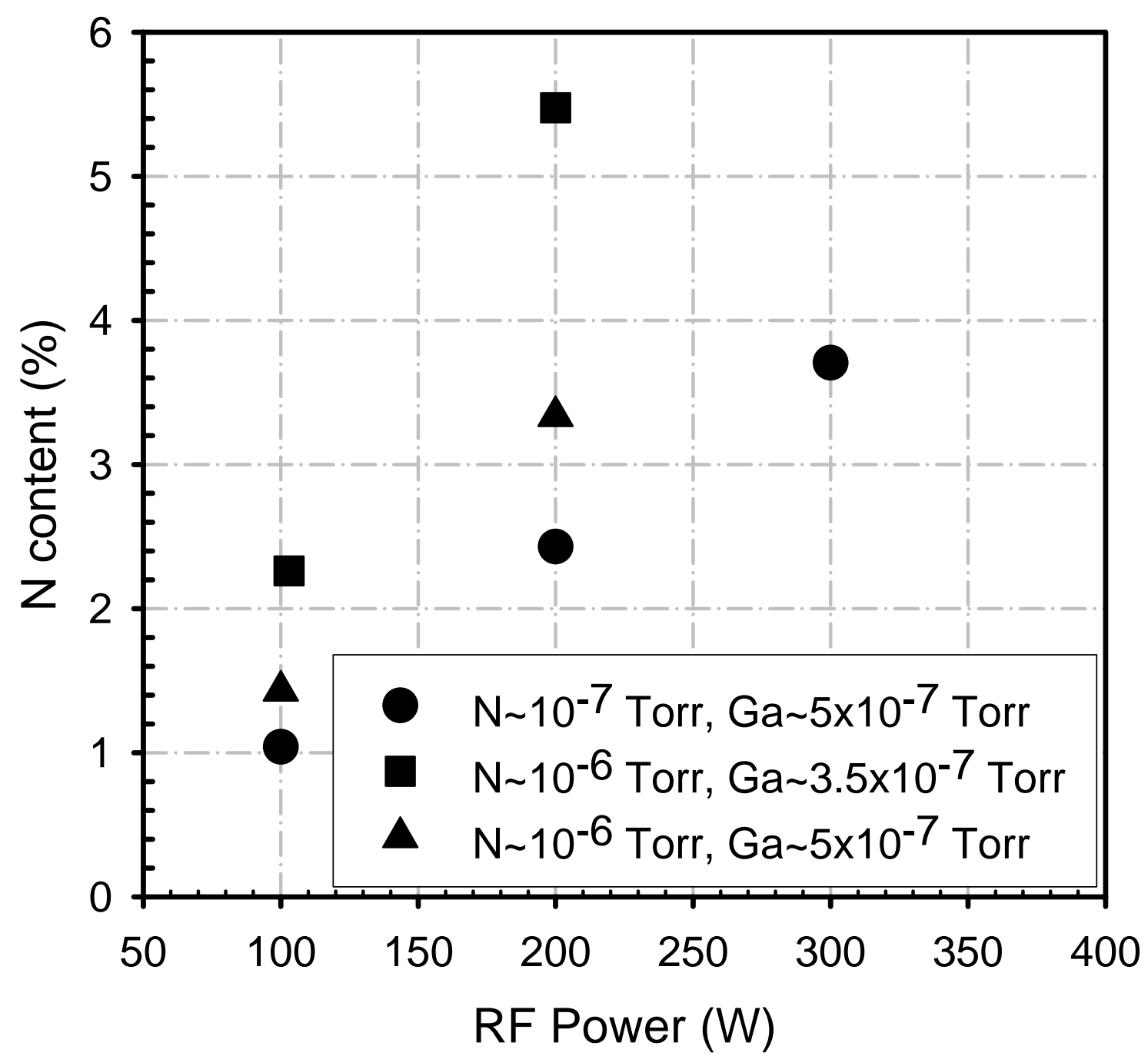

Fig 5.11 The dependence of $\mathrm{N}$ content on RF power. As 4 BEP $\sim 6 \times 10^{-6}$ Torr, and Ts $\sim 430^{\circ} \mathrm{C}$. 


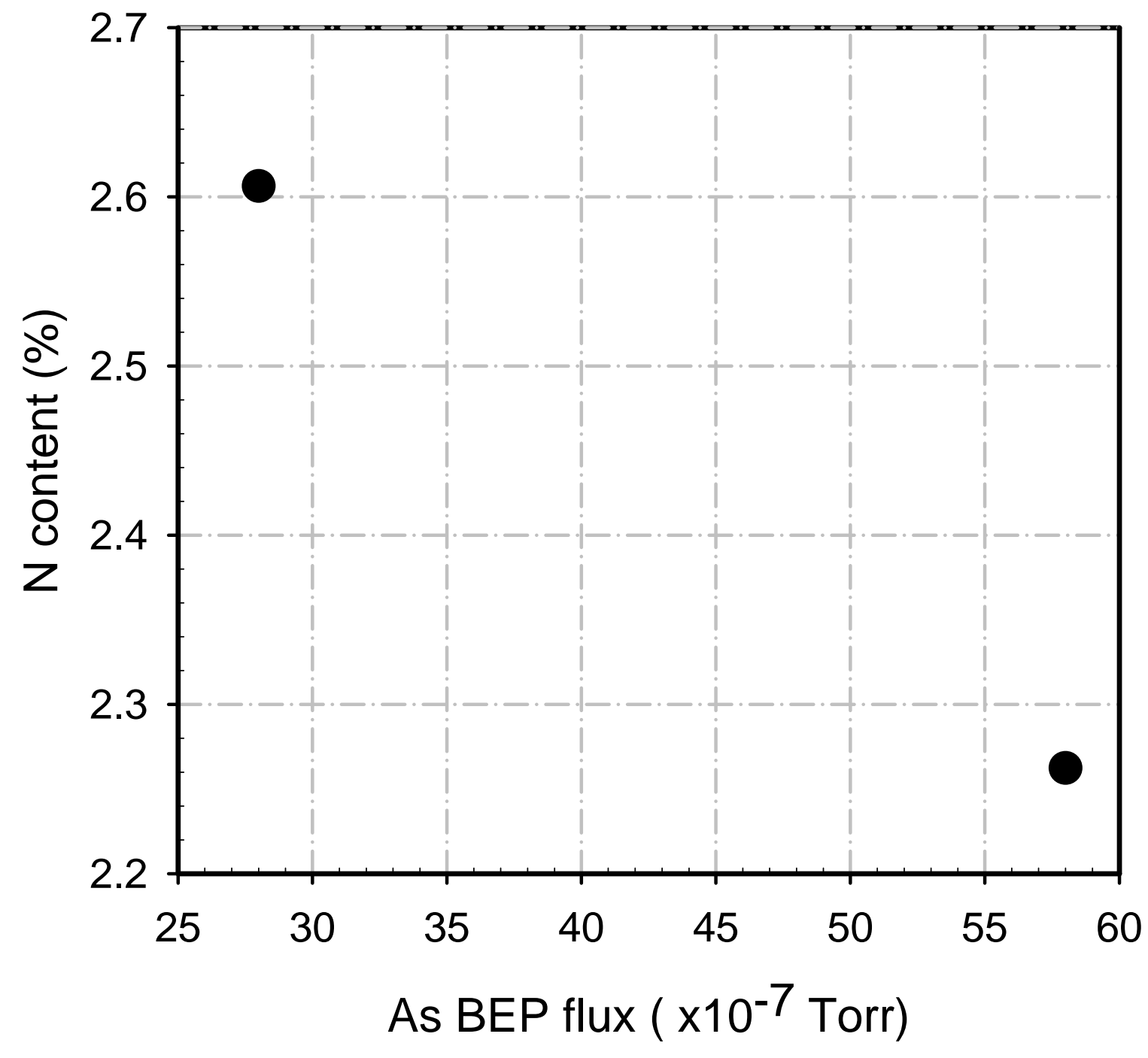

Fig 5.12 The dependence of $\mathrm{N}$ content on As flux. $\mathrm{N}$ partial pressure $1 \times 10^{-6}$ Torr $(\sim 0.1 \mathrm{sccm}), \mathrm{RF}$ power $100 \mathrm{~W}, \mathrm{Ga} \mathrm{BEP} \sim 3.5 \times 10^{-7}$ Torr, and Ts $\sim 430^{\circ} \mathrm{C}$. 


\section{Chapter 6}

\section{Changes in Optical Properties of GaAs$s_{1-x} \mathbf{N}_{x}$ During Annealing}

Increasing the $\mathrm{N}$ composition can help in realizing the long wavelength optoelectronic applications of $\mathrm{GaAs}_{1-\mathrm{x}} \mathrm{N}_{\mathrm{x}}$ related devices as the band gap energy is reduced, but on the down side, the incorporation of $\mathrm{N}$ leads to the formation of $\mathrm{N}$-associated defects. $\mathrm{N}$ interstitials caused by the large lattice mismatch between GaAs and $\mathrm{GaN}$ are considered to be a major source of defects [Spruytte, 2001] [Li, 2001]. Another origin of defects is from the comparatively low growth temperature applied during $\mathrm{GaAs}_{1-\mathrm{x}} \mathrm{N}_{\mathrm{x}}$ growth, which on one hand boosts $\mathrm{N}$ concentrations, while on the other hand results in the uptake of more impurities as the impurity desorption is slowed down with decreasing the substrate temperature. The existence of undesired defects weakens the quality of materials and alters their properties. Devices fabricated based on these as-grown crystals therefore are not able to perform as designed or expected if defects play an active role.

A common way to lessen the amount of defects is annealing, which for example can effectively remove non-radiative centers responsible for the deterioration of optical properties of materials as the photoluminescence intensity becomes higher upon annealing [Spruytte, 2001]. However, at the same time another issue comes up with respect to annealing, i.e. the blueshift of photoluminescence emission spectra [Spruytte, 2001] [Buyanova, 2000] [Loke, 2002], indicating the loss of $\mathrm{N}$ and limiting the alloy's applications over longer wavelengths. This effect can be attributed to several possibilities. One is the interdiffusion at the $\operatorname{GaAs}_{1-\mathrm{x}} \mathrm{N}_{\mathrm{x}} / \mathrm{GaAs}$ heterointerface, which may vary the depth of the potential difference along the interface. With increasing annealing temperature, the diffusion length becomes longer, thus causing the increase 
of blueshift [Li, 2000] [Buyanova, 2000]. Spruytte et al. suggested the outdiffusion of excess nitrogen to be responsible for the blueshift. Another origin of this effect may be the removal of $\mathrm{N}$ from substitutional to interstitional positions during annealing as proposed by Loke et al [Loke, 2002]. Besides the overall blue shift, it has been reported in the literature [Loke, 2002] that there is an intermediate redshift in the PL spectra upon annealed at $525-850^{\circ} \mathrm{C}$,

As discussed above, $\mathrm{GaAs}_{1-\mathrm{x}} \mathrm{N}_{\mathrm{x}}$ annealing has attracted a lot of interest. Much attention has been given to the mechanisms behind the improvement of luminescence efficiency or blueshift induced by $\mathrm{N}$ moving or loss. But it is still far from achieving definitive conclusions regarding the origin and characteristics of non-radiative channels and defects. All explanations addressing the phenomena of PL peak shift are more suggestive than conclusive. There is also no report found investigating the role arsenic plays during annealing. To improve the optical properties of $\mathrm{GaAs}_{1-\mathrm{x}} \mathrm{N}_{\mathrm{x}}$ for practical applications, it is necessary to get a deep understanding of the effects of annealing.

\subsection{Experimental}

To date, most research on $\mathrm{GaAs}_{1-\mathrm{x}} \mathrm{N}_{\mathrm{x}}$ is based on quantum well (QW) or thicker bulk-like structures with low nitrogen content, typically $2-3 \%$, and not more than $\sim 14.8 \%$ [Bi, 1997] [Buyanova, 2000]. In comparison, quantum dots (QDs) fabricated devices may be superior in the aspect of thermal stability and high-temperature-operation efficiency due to their 3-dimensional confinement effect [Kouklin, 2003]. However, the majority of the quantum dot (QD) studies involving GaAs $s_{1-x} N_{x}$ have involved InAs QDs with a GaAs $s_{1-x} N_{x}$ overlay to reduce strain, rather than real $\mathrm{GaAs}_{1-\mathrm{x}} \mathrm{N}_{\mathrm{x}}$ QDs [Zhang, 2003] [Gannapathy, 2003]. In the interest of presenting a 
comprehensive study, QD-like $\operatorname{GaAs}_{1-\mathrm{x}} \mathrm{N}_{\mathrm{x}}$ were grown to investigate the annealing effects on both $\mathrm{GaAs}_{1-\mathrm{x}} \mathrm{N}_{\mathrm{x}}$ thin layers and QD-like structures.

\subsubsection{Growth conditions}

$\mathrm{GaAs}_{1-\mathrm{x}} \mathrm{N}_{\mathrm{x}}$ samples for this study were grown in the VG V80H molecular beam epitaxy (MBE) system on $n^{+}(100)$ GaAs substrates. The Oxford Applied Research nitrogen source as described in chapter 3 was used for the RF nitrogen plasma. The nitrogen partial pressure was set around the $10^{-7}$ Torr with the RF power ranging between 100 to $500 \mathrm{~W}$ to target different nitrogen incorporations. Arsenic species were generated through the EPI cracker cell operating with a cracking temperature of $550^{\circ} \mathrm{C}$. For all samples in this study, a 1100 -nm thick GaAs buffer layer was grown at the growth temperature of $565^{\circ} \mathrm{C}$ before the deposition of active layers.

\subsubsection{Sample structures}

Two different types of samples were grown as shown in Fig 6.1. For type A, following the buffer layer growth, four periods of 4-nm thick $\mathrm{GaAs}_{1-\mathrm{x}} \mathrm{N}_{\mathrm{x}}$ layers with 10 -nm thick GaAs barrier layers were grown at $510^{\circ} \mathrm{C}$, and terminated with a 8-nm-thick cap layer. The reflection high energy electron diffraction (RHEED) pattern underwent a $2 \mathrm{D}$ to $3 \mathrm{D}$ transition during the growth of the $\mathrm{GaAs}_{1-\mathrm{x}} \mathrm{N}_{\mathrm{x}}$, indicating roughening typical of QD formation. Fig 6.2 is an example of RHEED pattern modification before and during $\mathrm{GaAs}_{1-\mathrm{x}} \mathrm{N}_{\mathrm{x}}$ layer growth. Atomic force microscopy (AFM) indicated formation of QD-like structures, with lateral dimensions of 50 to $100 \mathrm{~nm}$, depending on growth conditions. A VEECO multimode scanning probe microscope was used for ex-situ inspection of the surface morphology. Fig 6.3 (a) shows the surface morphology of one QD-assembled sample with dot mean diameter $\sim 62 \mathrm{~nm}$, mean height $\sim 5 \mathrm{~nm}$, and standard deviation $\sim 6 \mathrm{~nm}^{2}$. 

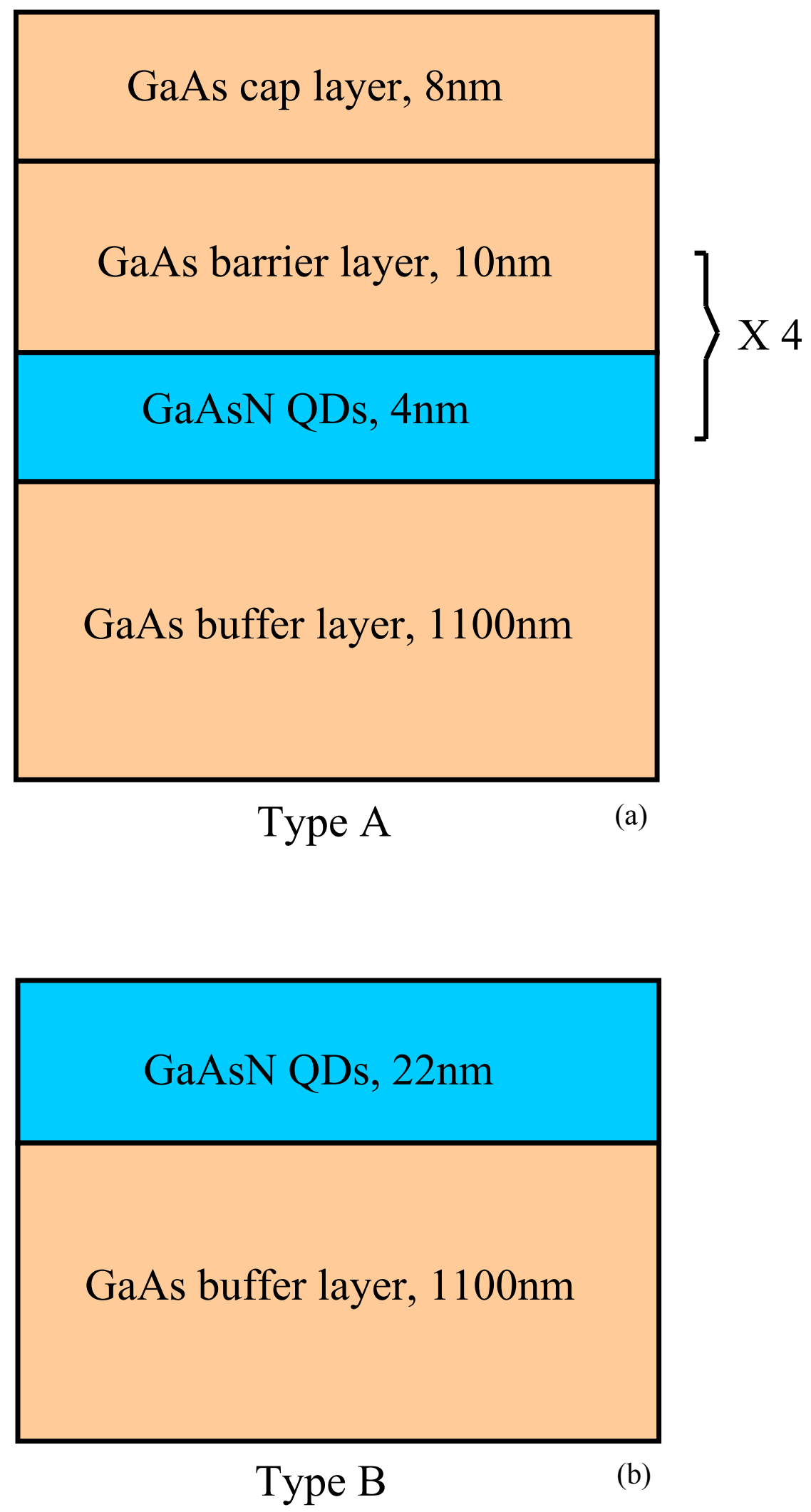

Fig 6.1 Sample structures of (a) type A and (b) type B. 


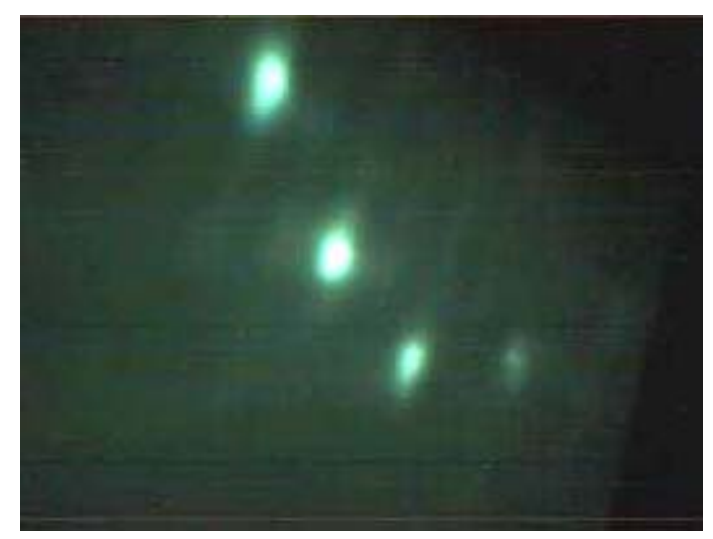

(a)

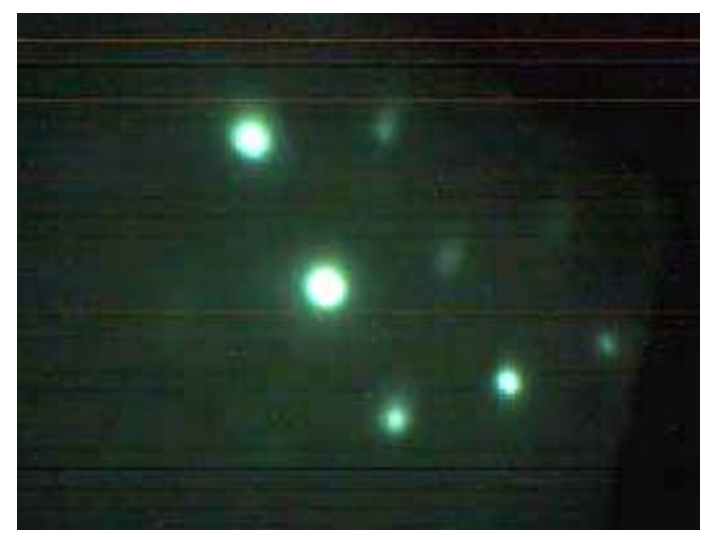

(b)

Fig 6.2 RHEED pattern transition from (a) 2D (prior to GaAsN growth) to (b) 3D (after initiating GaAsN growth). 


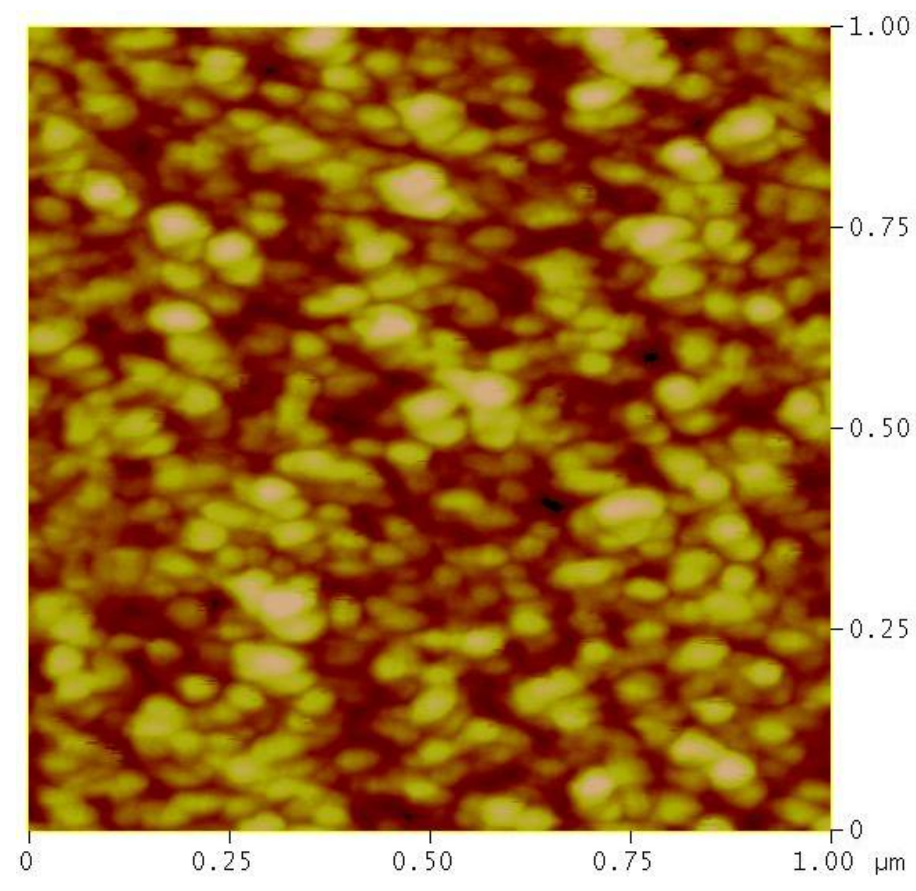

Image statistics

\begin{tabular}{|ll|}
\hline Img. Z range & $12.066 \mathrm{~nm}$ \\
Img. Mean & $-0.000000 \mathrm{~nm}$ \\
Img. Raw mean & $-138.00 \mathrm{~nm}$ \\
Img. Rms (Rq) & $1.772 \mathrm{~nm}$ \\
Img. Ra & $1.403 \mathrm{~nm}$ \\
Img. Rmax & $12.066 \mathrm{~nm}$ \\
Img. Srf. area & $1.015 \mathrm{\mu m}^{2}$ \\
Img. Prj. Srf. area & $999999 \mathrm{~nm}^{2}$ \\
Img. Srf. area diff & $1.490 \%$ \\
Img. SAE & 1.005 \\
\hline
\end{tabular}

Box Statistics

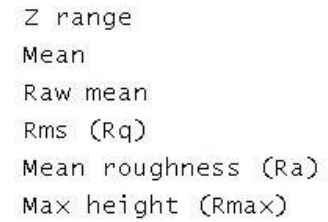

(a)

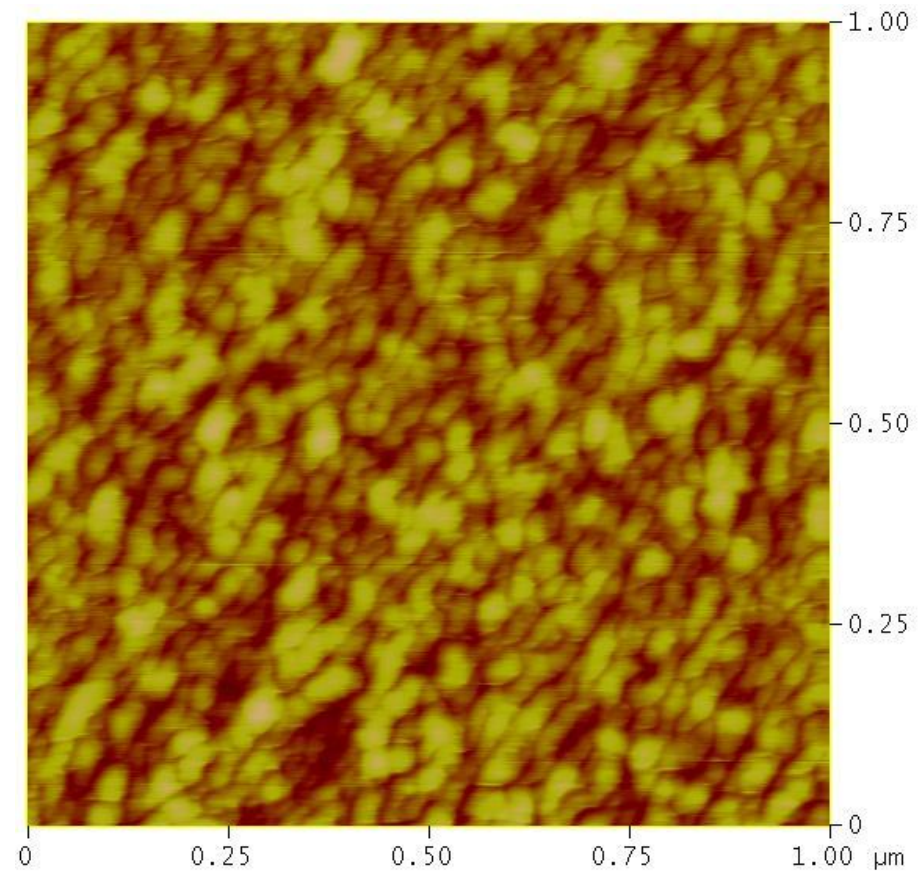

\begin{tabular}{|c|c|}
\hline Img. $z$ range & $8.744 \mathrm{~nm}$ \\
\hline Img. Mean & $0.000000 \mathrm{~nm}$ \\
\hline Img. Raw mean & $253.30 \mathrm{~nm}$ \\
\hline Img. Rms (Rq) & $1.217 \mathrm{~nm}$ \\
\hline Img. $\mathrm{Ra}$ & $0.980 \mathrm{~nm}$ \\
\hline Img. Rmax & $8.744 \mathrm{~nm}$ \\
\hline Img. Srf. area & $1.016 \mu \mathrm{m}^{2}$ \\
\hline Img. Prj. Srf. area & $999999 \mathrm{~nm}^{2}$ \\
\hline Img. Srf. area diff & $1.567 \%$ \\
\hline Img. SAE & 1.005 \\
\hline \multicolumn{2}{|c|}{ Box statistics } \\
\hline \multicolumn{2}{|l|}{$Z$ range } \\
\hline \multicolumn{2}{|l|}{ Mean } \\
\hline \multicolumn{2}{|l|}{ Raw mean } \\
\hline \multicolumn{2}{|l|}{$\operatorname{Rms}(R q)$} \\
\hline \multicolumn{2}{|l|}{ Mean roughness ( $R a)$} \\
\hline Max height $(\operatorname{Rma} \times)$ & \\
\hline
\end{tabular}

(b)

Fig 6.3 AFM images of two GaAsN samples. (a) Type A: QD-like structure. (b) Type B: Thin layer structure. 
Type B samples consisted of an uncapped 22-nm-thick GaAs ${ }_{1-\mathrm{x}} \mathrm{N}_{\mathrm{x}}$ layer grown at $510^{\circ} \mathrm{C}$ on top of the buffer layer. AFM measurements indicated a root mean square (RMS) roughness of about $1 \mathrm{~nm}$ on these samples as seen in Fig 6.3 (b).

\subsubsection{Annealing}

1 minute ex-situ annealing was operated in air with three different applied temperatures, $350^{\circ} \mathrm{C}, 550^{\circ} \mathrm{C}$ and $750^{\circ} \mathrm{C}$. Annealing conditions were chosen by referring to literature [Spruytte, 2001] [Buyanova, 2000]. Different pieces cleaved from the same sample were annealed at a range of temperatures, allowing the comparison of results obtained at different annealing temperatures for each sample. No sacrifice GaAs or $\mathrm{GaAs}_{1-\mathrm{x}} \mathrm{N}_{\mathrm{x}}$ wafer was used to cover the sample being annealed.

\subsubsection{PL and Raman measurement}

The PL experiments were conducted at $77 \mathrm{~K}$ with liquid nitrogen cooling the sample. The PL setup has the 514-nm line of an argon ion laser for excitation and 0.32 meter monochromator/Ge detector combination. A Renishaw Raman system was used for the Raman scattering study at room temperature with the same 514-nm laser.

Nitrogen contents of samples in this study were estimated by PL and Raman measurements. The dependence of PL emission energy on $[\mathrm{N}]$ of $\mathrm{GaAs}_{1-\mathrm{x}} \mathrm{N}_{\mathrm{x}}$ (Fig 6.4) was determined experimentally and theoretically by Kondow et al. [Kondow, 1994], who had GaAss. ${ }_{x} \mathrm{~N}_{\mathrm{x}}$ epi-layers grown on GaAs substrates. Their relationship experimentally achieved at $77 \mathrm{~K}$ was used to estimate the nitrogen content of our samples as shown below:

$$
[N]=8.11 \text { - } 5.41 \times \text { Bandgap energy }
$$

Where $[\mathrm{N}]$ is in \% and bandgap energy is in $\mathrm{eV}$. 


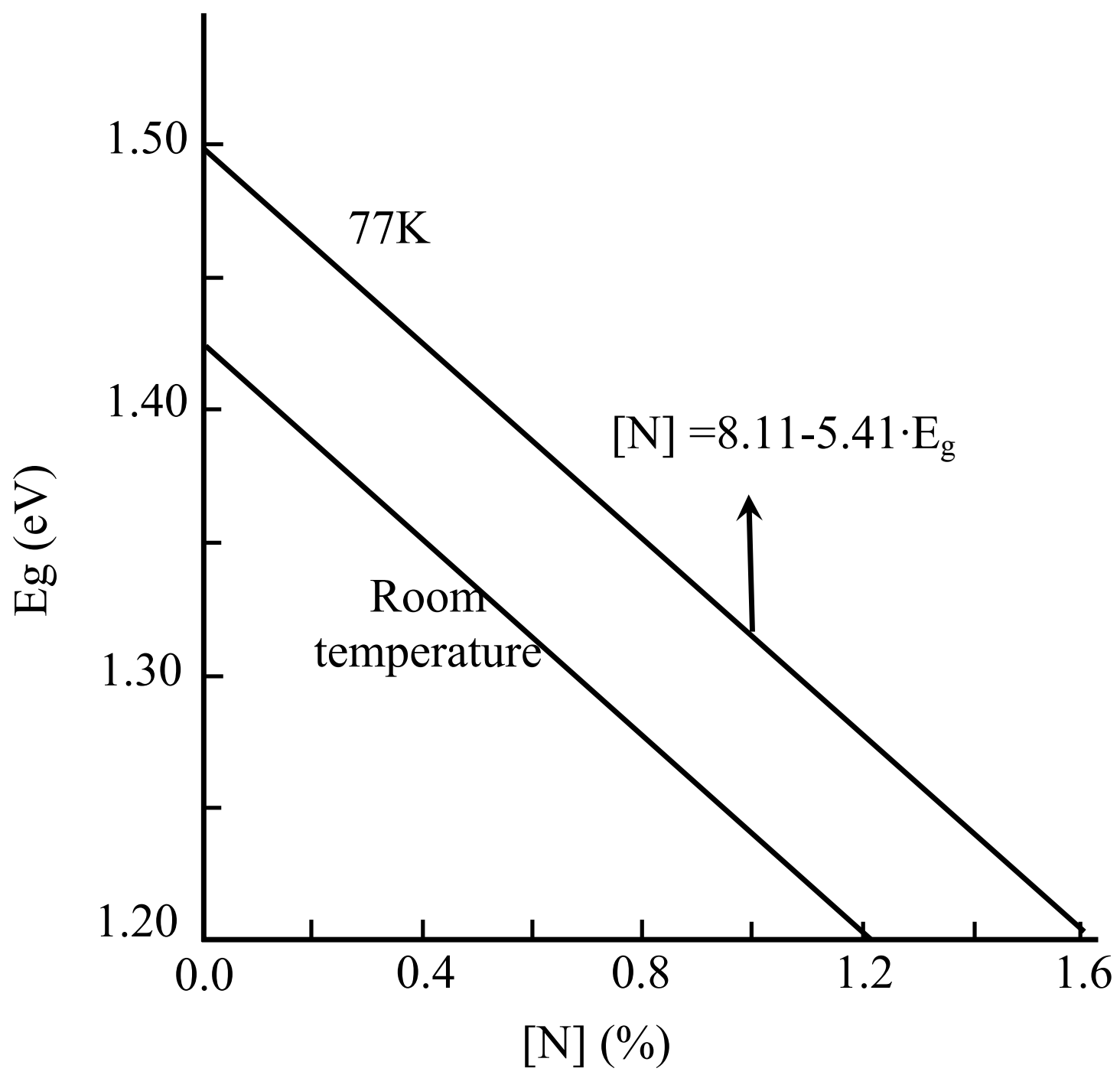

Fig 6.4 Bandgap energy (obtained by PL measurement) dependent on $\mathrm{N}$ content $\mathrm{x}$ in $\mathrm{GaAs}_{1-\mathrm{x}} \mathrm{N}_{\mathrm{x}}$. Solid and dashed lines represent experimental and theoretical (calibrated without strain) results, respectively.[Kondow, 1994] 
The Raman $\mathrm{LO}_{1}$ shift of GaAs-type phonons was found to be related to $\mathrm{N}$ content $\mathrm{x}$ in $\mathrm{GaAs}_{1-\mathrm{x}} \mathrm{N}_{\mathrm{x}}$ as well, and was expressed as

$$
[\mathrm{N}]=1.48+1.25 \times\left(290-\mathrm{LO}_{1} \text { Shift }\right)([\mathrm{N}] \text { is in } \%)
$$

as shown in Fig 6.5 [Mintairov, 1997]. The Raman measurement results therefore were also employed to roughly determine nitrogen composition. Samples reported in this study had a nitrogen content of about $1 \%$ to $4 \%$ as estimated by PL and Raman measurements.

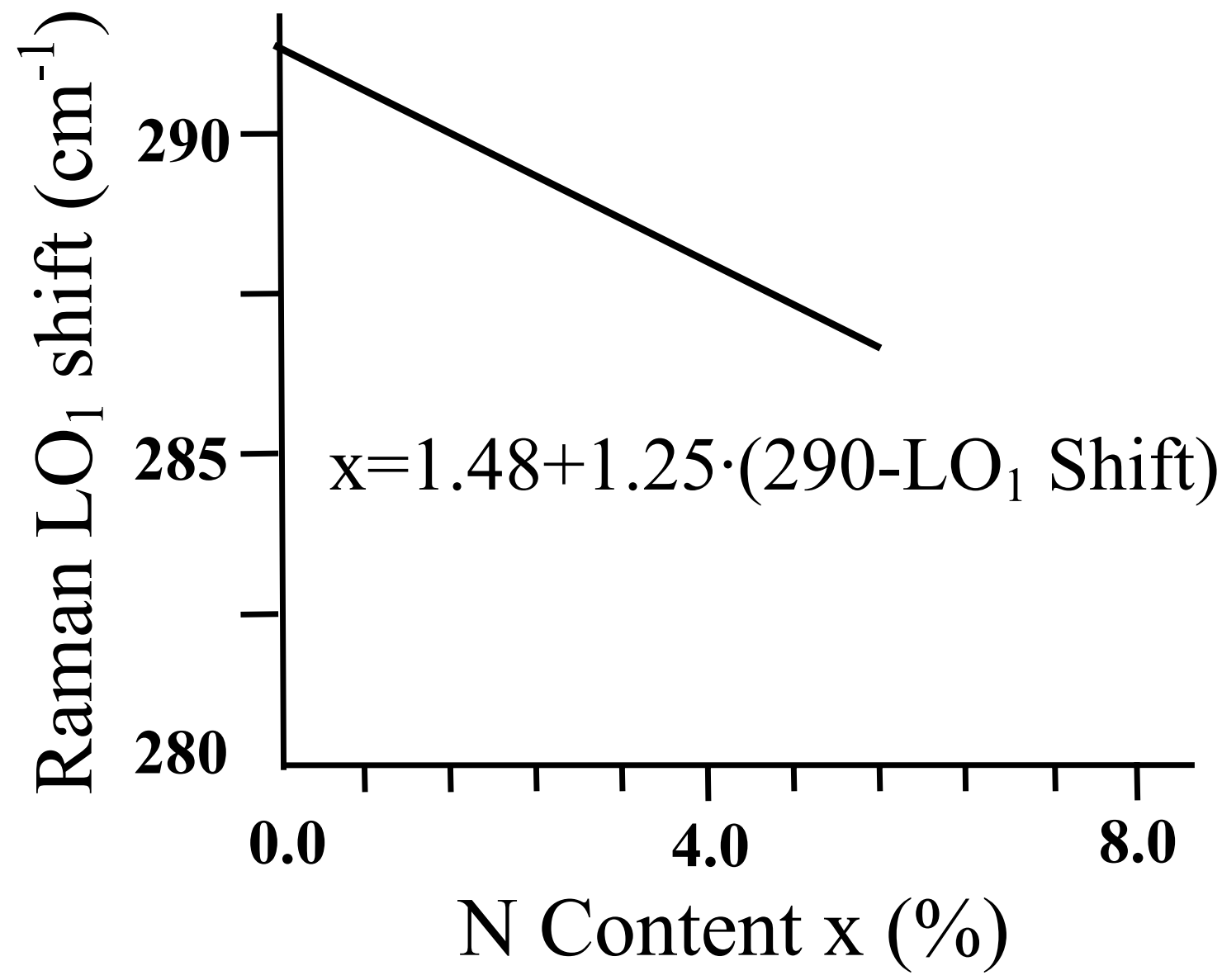

Fig 6.5 Relationship between Raman $\mathrm{LO}_{1}$ shift of GaAs-type phonons and $\mathrm{N}$ content $\mathrm{x}$ in $\mathrm{GaAs}_{1-\mathrm{x}} \mathrm{N}_{\mathrm{x}}$ (Solid squares).[Mintairov, 1997] 


\subsubsection{XPS analysis}

XPS analysis was performed at Northwestern with an Omicron ESCA probe, which was equipped with an EA125 energy analyzer. Photoemission was stimulated by monochromatic Al $\mathrm{K}$ radiation $(1486.6 \mathrm{eV})$ with the operating power of $300 \mathrm{~W}$. Survey and high-resolution scans were collected with the pass energies of $50 \mathrm{eV}$ and $24 \mathrm{eV}$, respectively. Binding energies of the spectra were referenced to the C $1 \mathrm{~s}$ binding energy set at $284.8 \mathrm{eV}$. Prior to XPS measurement, the samples were put into the entry-load chamber to pump for $4 \mathrm{hrs}$.

\subsection{Results}

\subsubsection{PL measurement}

In agreement with most reports [Spruytte, 2001] [Buyanova, 2000] [Toivonen, 2000], a blue-shift in the emission spectra of all the samples is observed for lower annealing temperatures. This is indicated by the PL results shown in Fig 6.6 and 6.7. The type B sample seen in Fig 6.7 exhibits emission energies consistent with a $\sim 1 \%$ nitrogen content derived from Eq. (6.1). The type A sample shown in Fig 6.6 applied the same growth conditions as the type B one in Fig 6.7 did, and the only difference is their structures as described in section 6.1.2. This type A sample exhibits higher energy emission than the type B sample due to quantum confinement, as expected, and emission energies are consistent with calculations for nitrogen content measured by Raman, as expressed in Eq. (6.2). Of interest for this study, for higher temperature annealing a significant red-shift with respect to the as-grown PL is observed for the

QD-like samples, while the spectra from annealed type B samples more resemble that previously reported [Loke, 2002]. The net red-shift of all the type A samples was consistently about 30 to $40 \mathrm{meV}$ after annealing at $750^{\circ} \mathrm{C}$. 


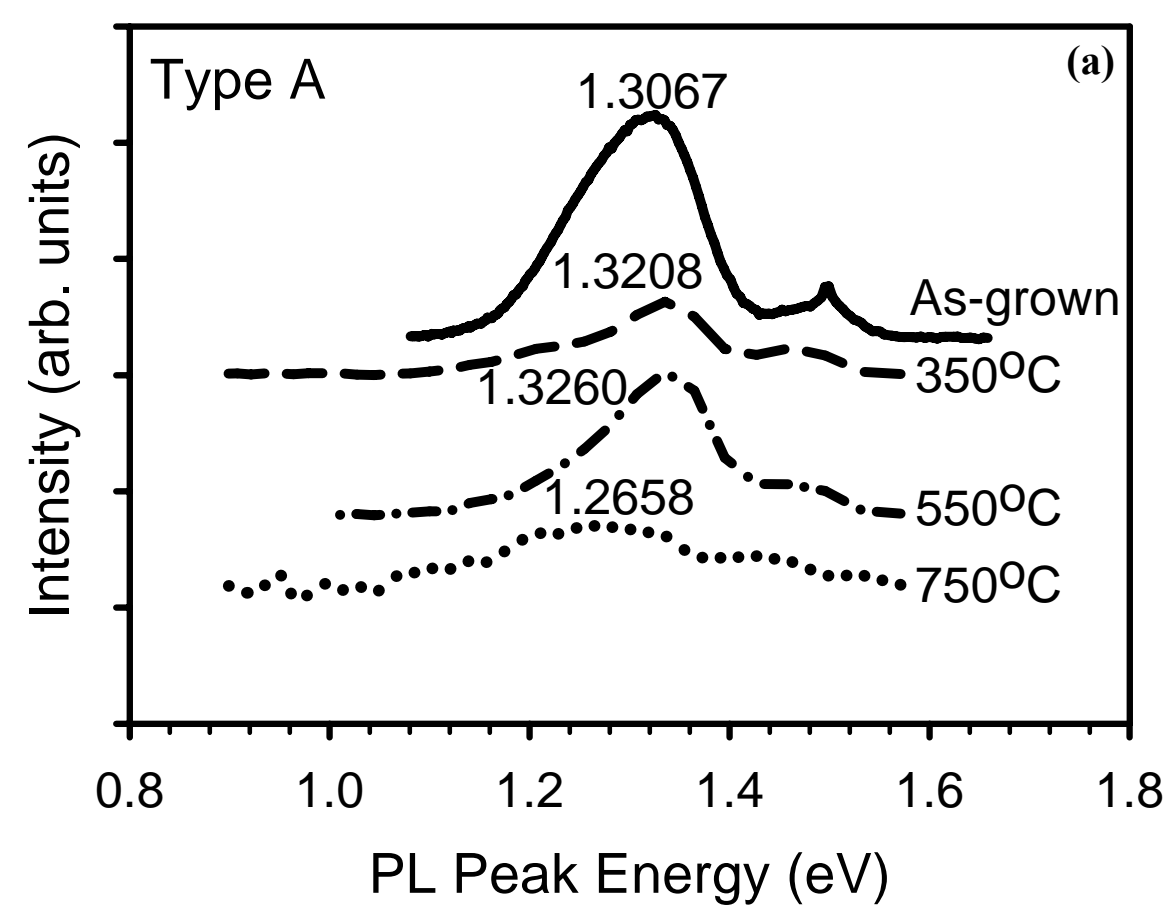

Fig 6.6 Type A sample PL measurement. (a) PL spectra at different annealing temperatures; (b) PL peak energy vs. annealing temperature.

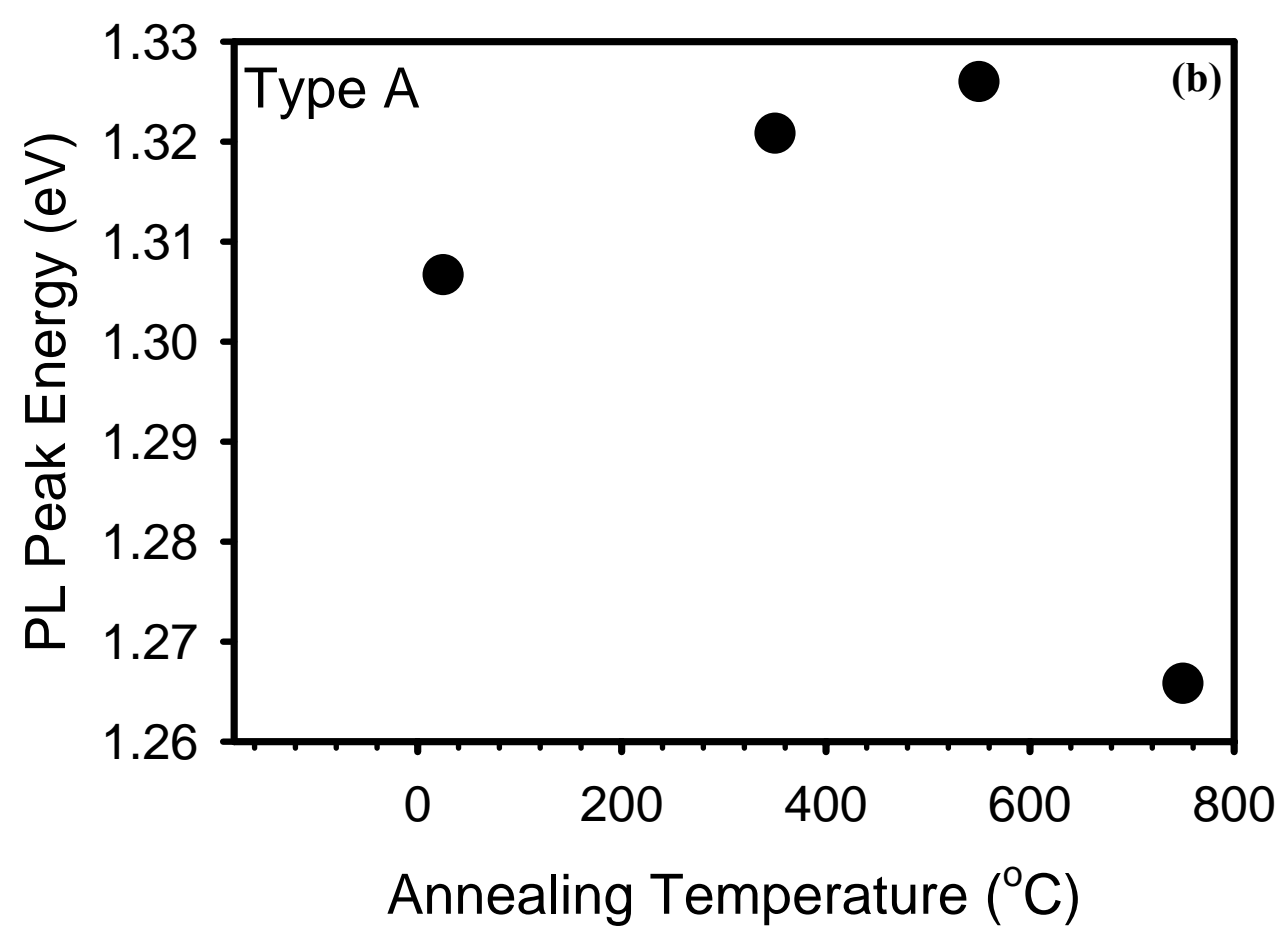




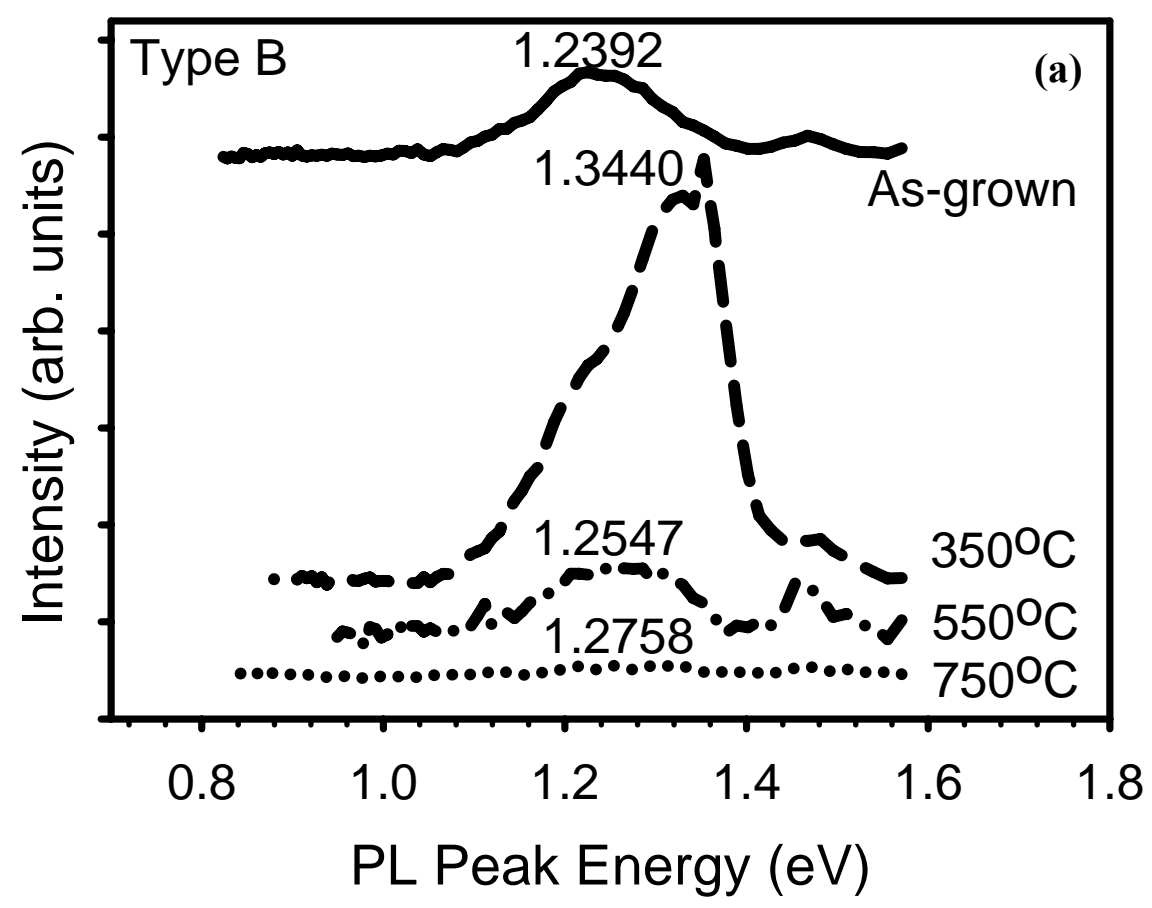

Fig 6.7 Type B sample PL measurement. (a) PL spectra at different annealing temperatures; (b) PL peak energy vs. annealing temperature.

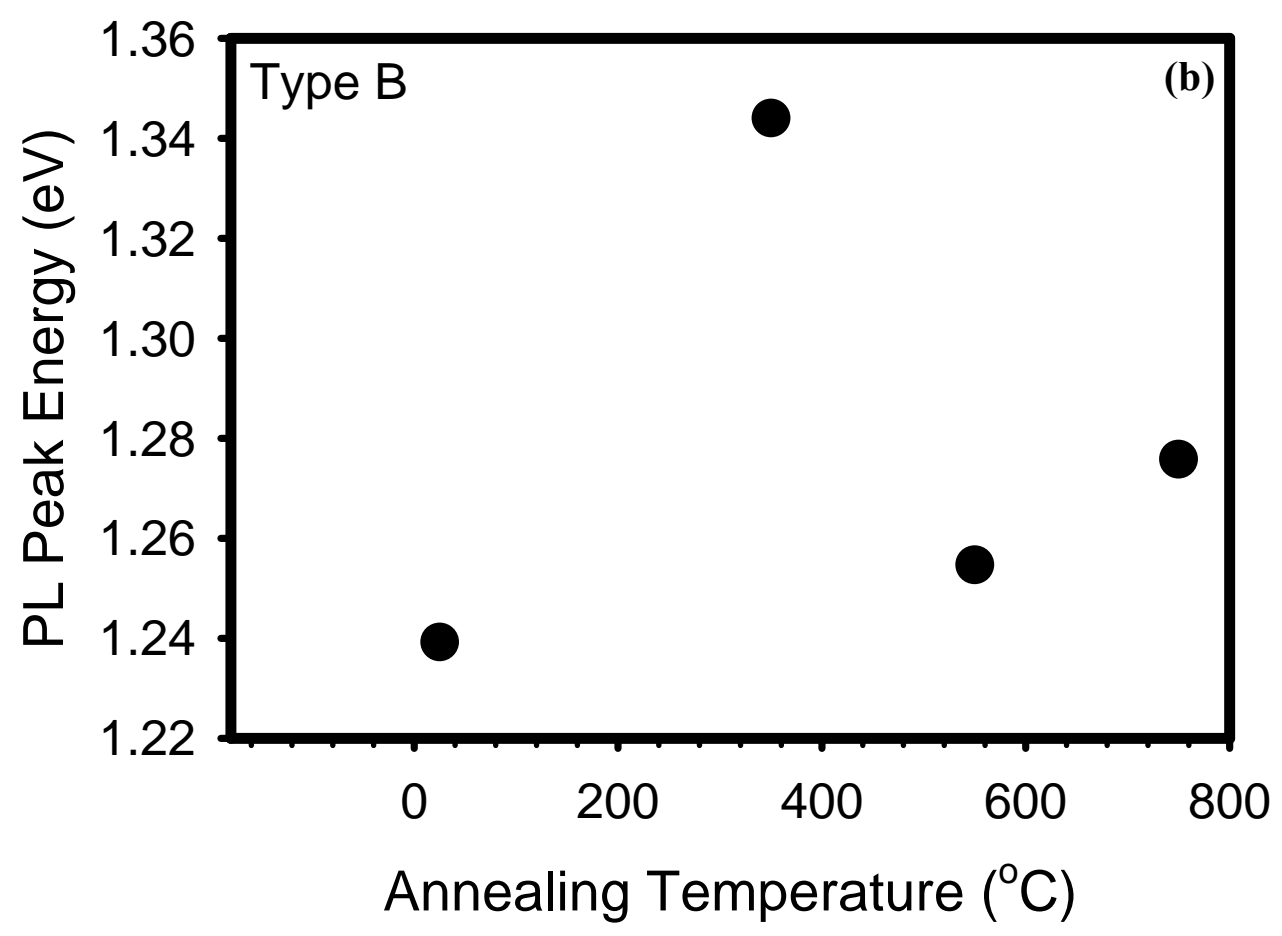




\subsubsection{Raman measurement}

Raman measurements were carried out for both type A and type B samples. Examples of Raman spectra of the GaAs-like $\mathrm{LO}_{1}$ peak during annealing of a type $\mathrm{A}$ and a type $\mathrm{B} \mathrm{GaAs}_{1-\mathrm{x}} \mathrm{N}_{\mathrm{x}}$ sample are shown in Fig 6.8 and 6.9. The phonon frequency of the $\mathrm{LO}_{1}$ is inversely proportional to the GaN content [Mintairov, 1997] in this composition range as quantitatively illustrated by Eq. (6.2). The observed $\mathrm{LO}_{1}$ for the type B sample indicates a nitrogen content of about $1 \%$, consistent with the PL emission. Annealing results in a Raman shift consistent with loss of nitrogen as suggested by many studies [Spruytte, 2001] [Gwo, 2001], while annealing at higher temperatures results in a shift suggesting nitrogen enrichment and $4 \%$ nitrogen content. Type A samples exhibited a much smaller shift, but had the same trend of initial N-depletion followed by N-enrichment. This is also shown in Figure 6.8 for a sample with an initial nitrogen concentration of about $4 \%$ as indicated by Raman measurement. The initial annealing results in nitrogen depletion, while after $750^{\circ} \mathrm{C}$ annealing, the Raman spectra suggests nitrogen enrichment. 


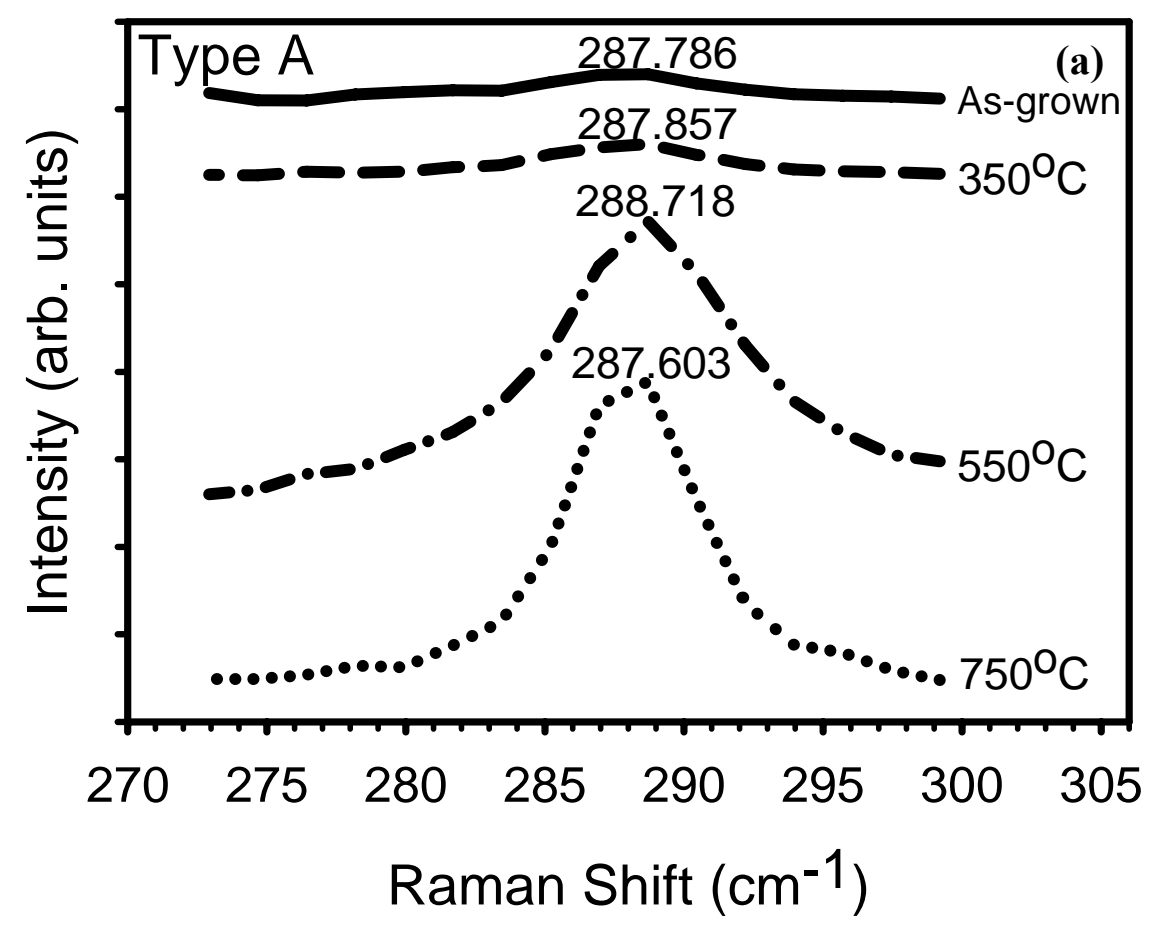

Fig 6.8 Type A sample Raman measurement. (a) Spectra of GaAs-like $\mathrm{LO}_{1}$ Raman measurement; (b) Raman shift of $\mathrm{LO}_{1}$ vs. Annealing Temperature.

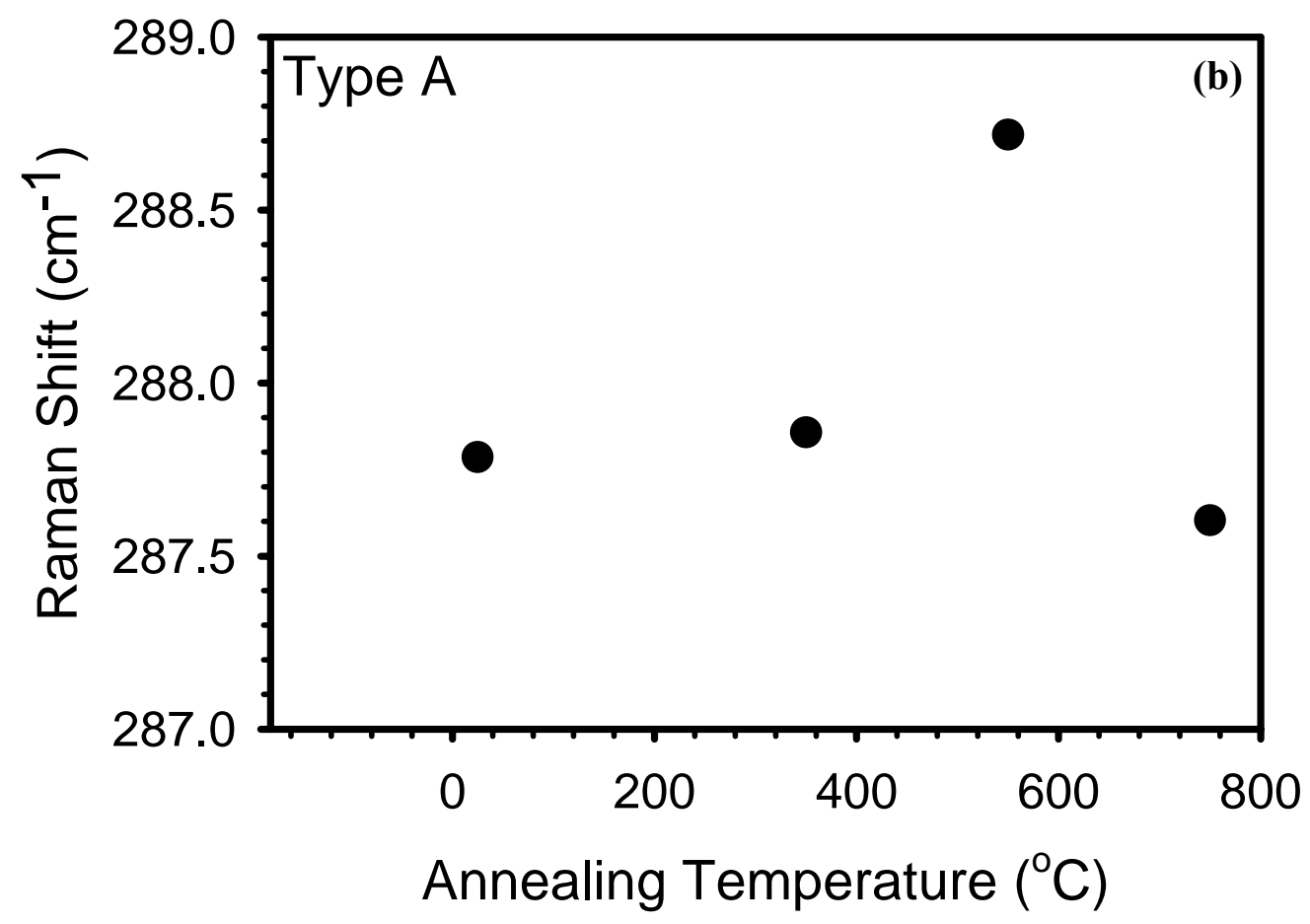




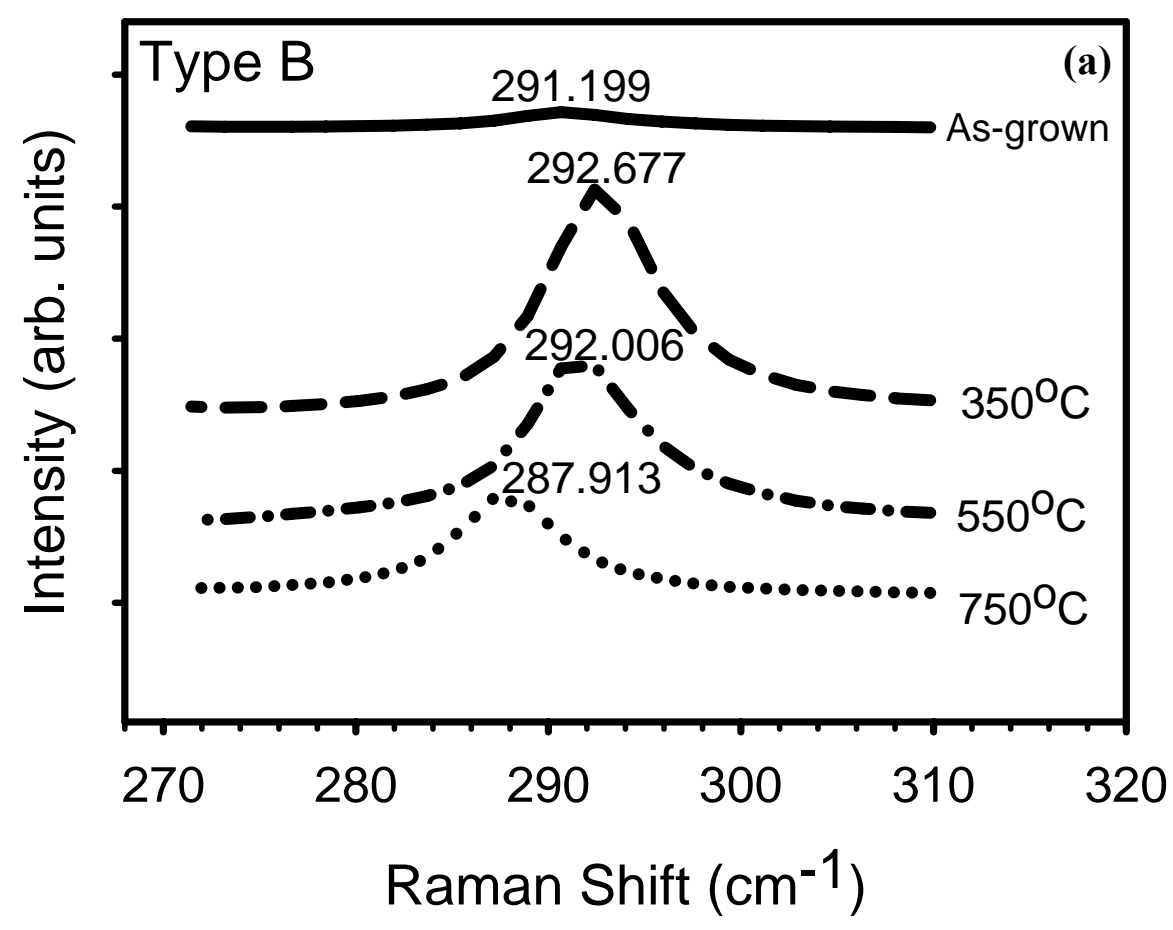

Fig 6.9 Type B sample Raman measurement. (a) Spectra of GaAs-like $\mathrm{LO}_{1}$ Raman measurement; (b) Raman shift of $\mathrm{LO}_{1}$ vs. Annealing Temperature.

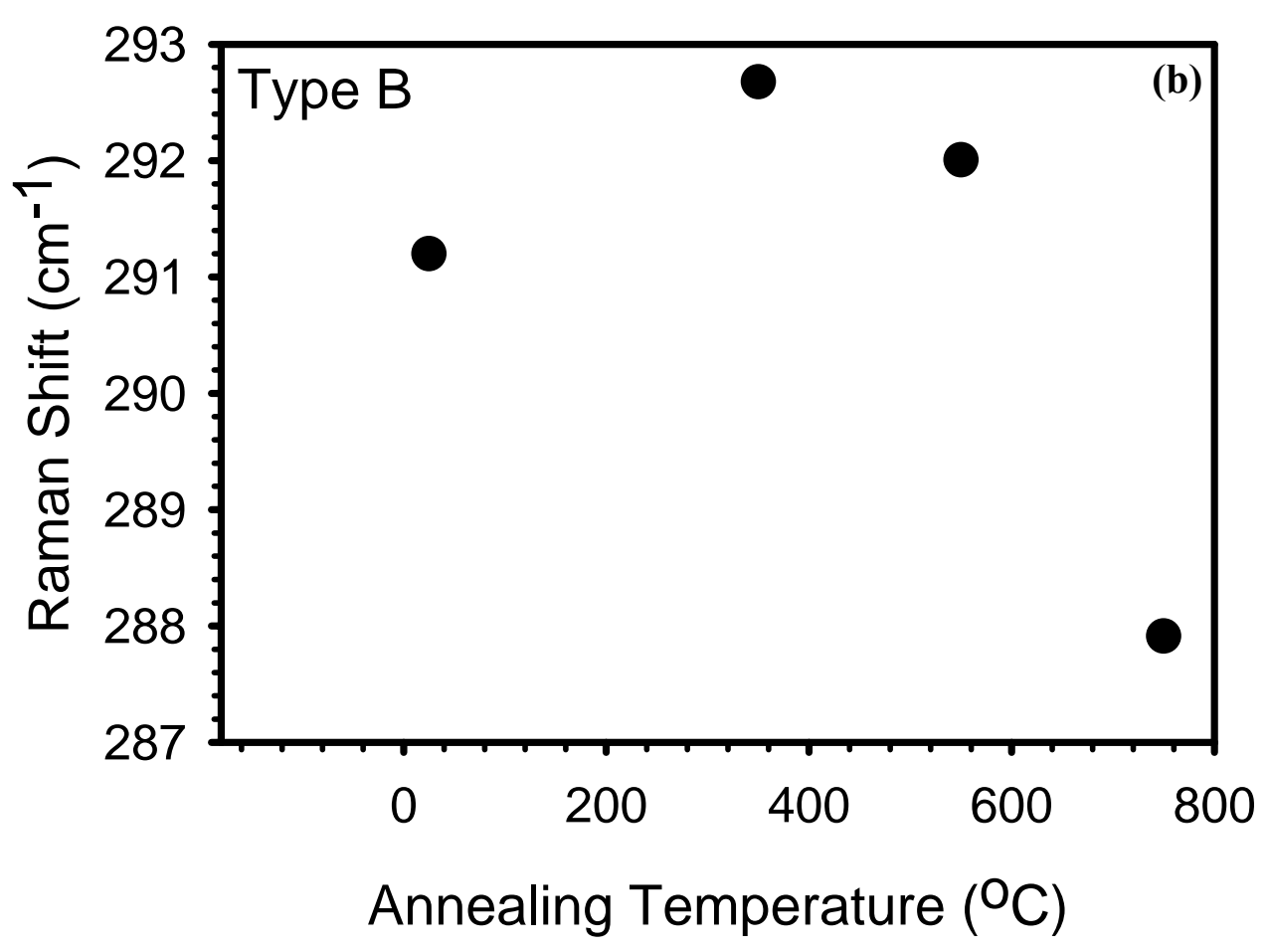




\subsubsection{XPS}

Fig 6.10 and 6.11 illustrate the XPS measurement results of a type B sample before and after annealing at $750^{\circ} \mathrm{C}$. All data shown was normalized to the GaLMM peak at $394 \mathrm{eV}$. The $\mathrm{Ga}(2 \mathrm{p})$ peak was easily observed at $\mathrm{E}_{\mathrm{b}} \sim 1119 \mathrm{eV}$ before and after annealing as shown in Fig 6.10 (a). The intensity did not have a large change upon annealing, indicating a relatively stable Ga composition since the peak intensity is proportional to the concentration of the corresponding element involved in the material as mentioned in section 3.3.7. Fig 6.11 (a) demonstrates XPS results regarding $\mathrm{N}(1 \mathrm{~s})$ and GaLMM peaks. The $\mathrm{N}(1 \mathrm{~s})$ peak appeared at $\mathrm{E}_{\mathrm{b}} \sim 398 \mathrm{eV}$ and is more pronounced after annealing as can be seen by comparing to the GaLMM peak at $394 \mathrm{eV}$. Concurrently, the $\operatorname{As}(3 \mathrm{~d})$ signal demonstrated in Fig 6.11 (b) disappears after annealing at $750^{\circ} \mathrm{C}$, while a strong peak was observed in the as-grown sample at $\mathrm{E}_{\mathrm{b}} \sim 41 \mathrm{eV}$. This result indicates that arsenic escapes from the samples during annealing, at least in the top $\sim 2$ to $3 \mathrm{~nm}$ probed by XPS, resulting in a GaN-like surface. This introduces the possibility of a non-uniform As concentration in the sample as well. Of interest, the XPS studies also suggest that the surface layers of the as-grown samples are nitrogen enriched, with an N-concentration of about 50\%. 


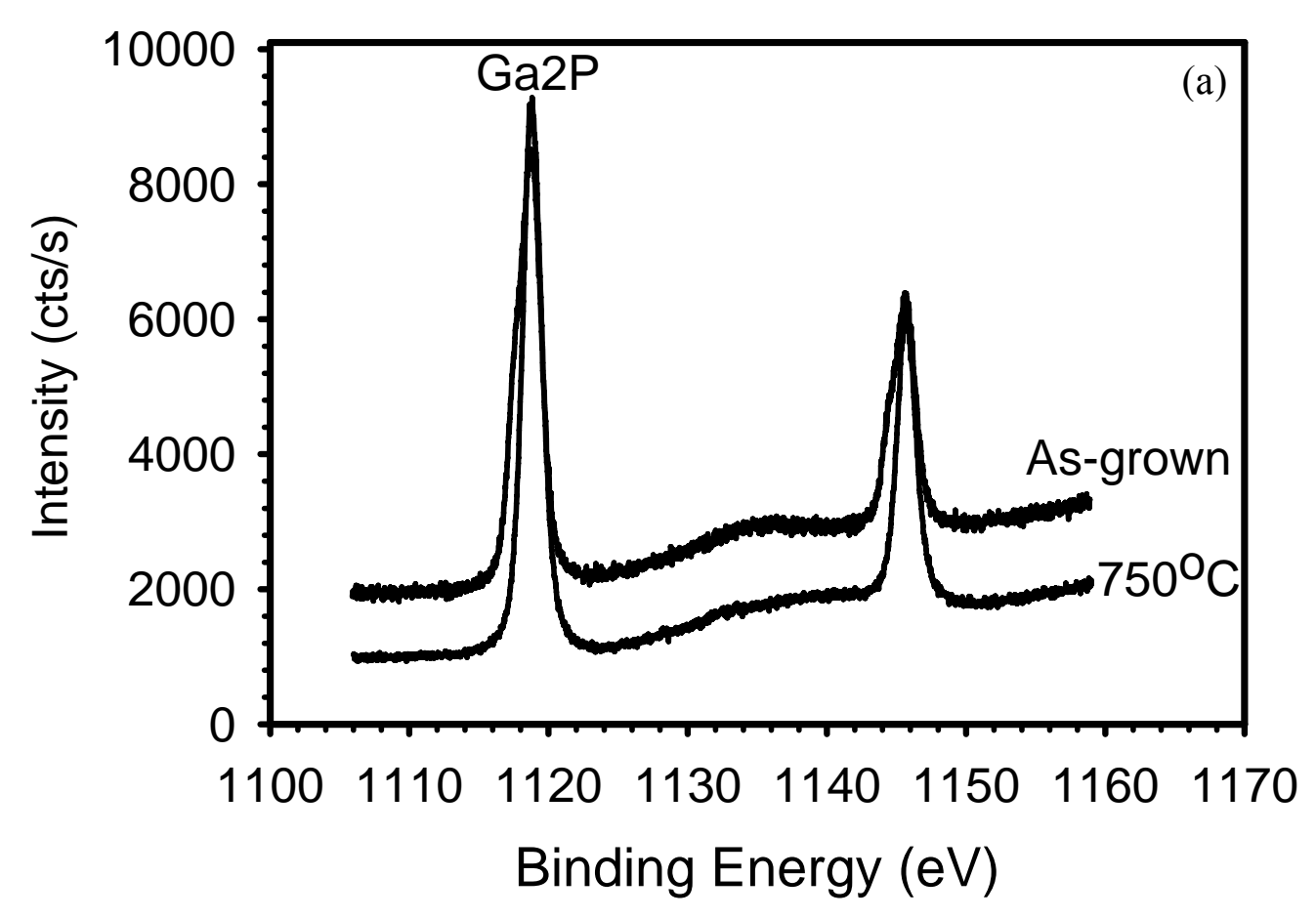

Fig 6.10 Type B Sample XPS spectra before and after $750^{\circ} \mathrm{C}$ annealing. (a) Ga2P peak; (b) As3d peak.

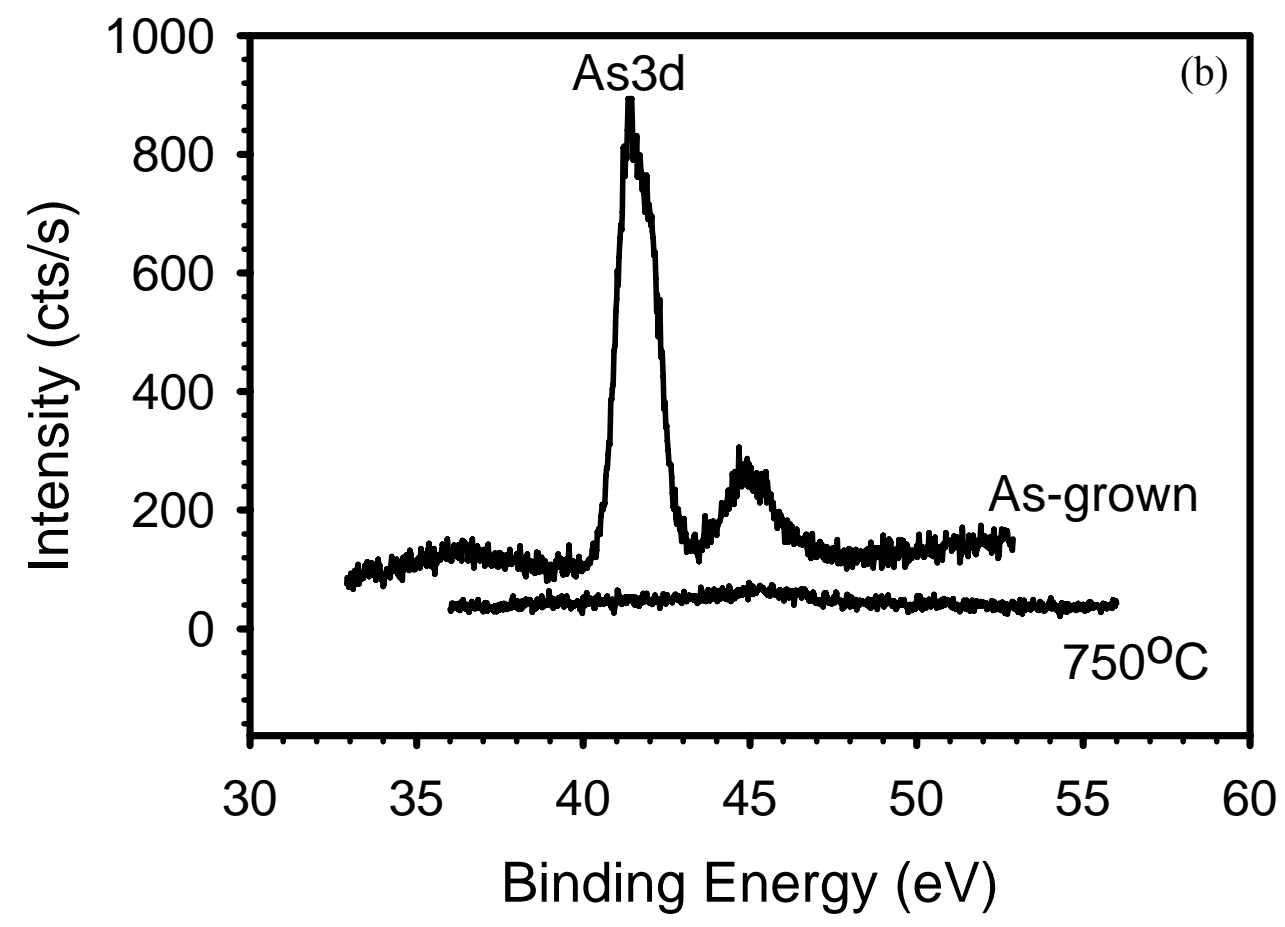




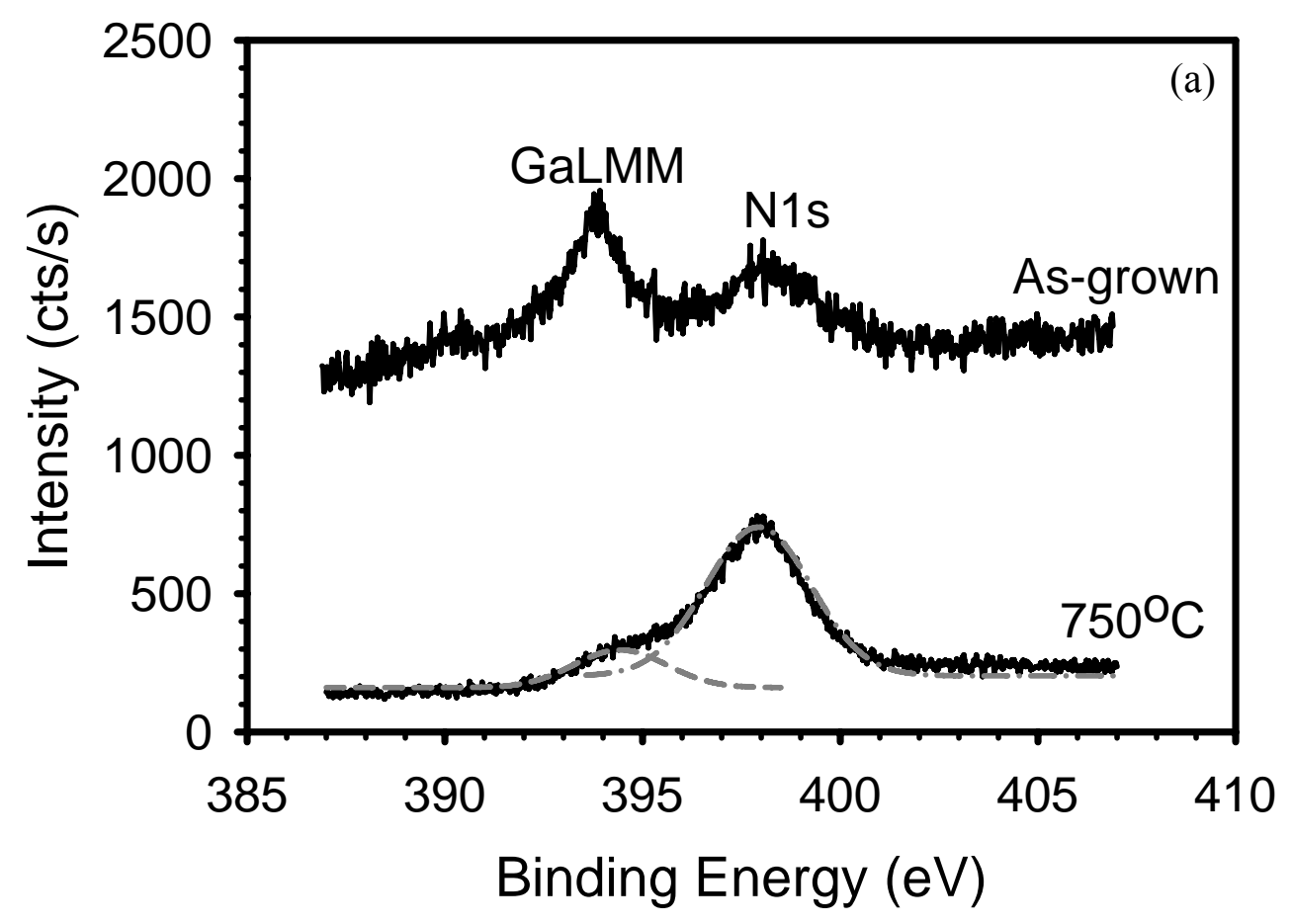

Fig 6.11 Type B Sample XPS measured N1s peak before and after $750^{\circ} \mathrm{C}$ annealing comparing to literature. (a) N1s peak in this study; (b) N1s peak obtained by Spruytte et al.[Spruytte, 2001] after $1 \mathrm{~min}, 760^{\circ} \mathrm{C}$ anneal.

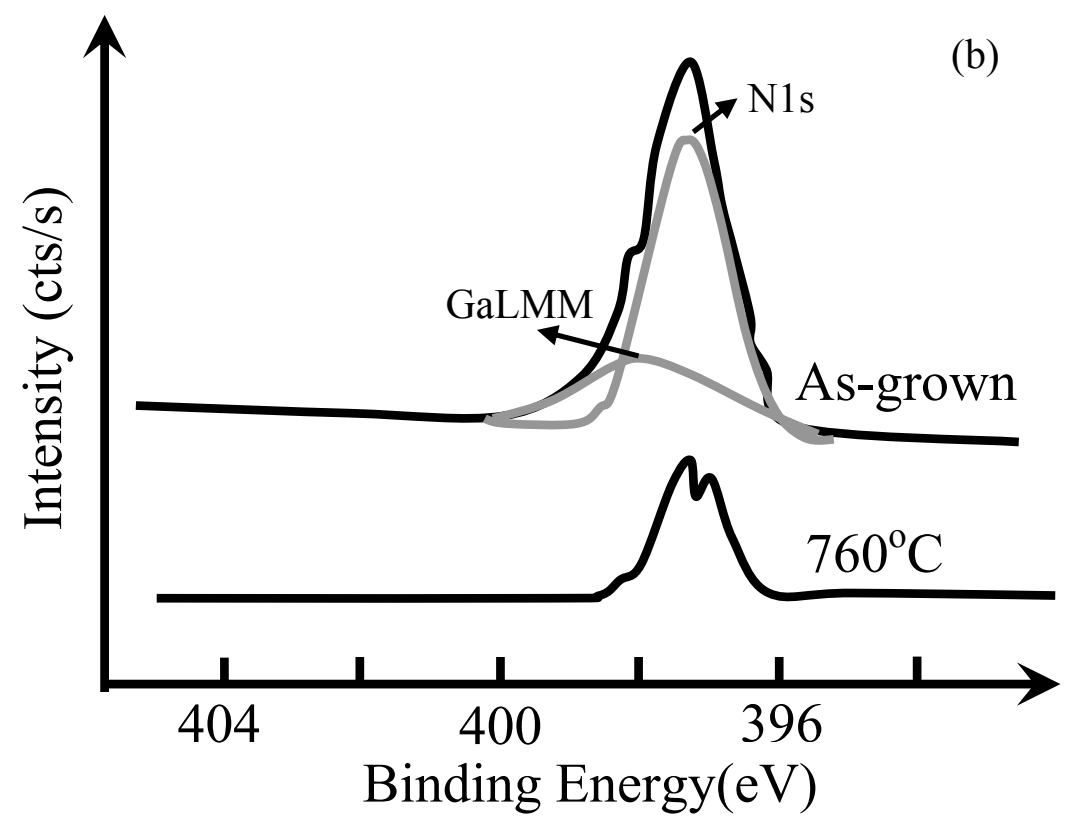




\subsection{Discussions}

The XPS results from this study for type B samples are different than the reported results shown in Fig 6.11 (b) by Spruytte et al. [Spruytte, 2001], who observed a reduction of N(1s) peak intensity corresponding to a reduced overall nitrogen concentration after 1 min annealing at $760^{\circ} \mathrm{C}$. Spruytte et al. [Spruytte, 2001] attributed this to the removal of the less strongly Gabonded nitrogen complex sitting on other locations than the group V lattice sites. This is likely due to the fact that the samples investigated by Spruytte et al. [Spruytte, 2001] were capped with GaAs while our type B samples were not. This result suggests that arsenic may also be lost after higher temperature thermal treatment, with a resultant increase in overall $\mathrm{N}$ concentration. Since our type A samples were capped with GaAs, and had a similar, if reduced, trend in the Raman measurements, this should be considered as a possibility for all samples.

The PL and Raman results reported here are consistent with previous reports that a number of mechanisms are present when the $\mathrm{GaAs}_{1-\mathrm{x}} \mathrm{N}_{\mathrm{x}}$ structures are annealed. For example, it has been reported in the literature [Loke, 2002] that nitrogen is removed from the substitutional site to the interstitial site, and therefore the spectra are blue-shifted. The removal of the interstitial nitrogen, the intermixing at the $\mathrm{GaAs}_{1-\mathrm{x}} \mathrm{N}_{\mathrm{x}} / \mathrm{GaAs}$ heterointerface [Buyanova, 2000], or the outdiffusion of excess nitrogen [Spruytte, 2001] have also been suggested as the origin of the blue-shift. However, at high annealing temperature, a net red-shift is observed from many of the samples in our study. From the presented results, in particular the XPS and Raman spectra, the samples clearly became more nitrogen rich, suggesting arsenic outdiffusion. Thus, the probable cause of the net red-shift at high annealing temperature appears to be the loss of arsenic from the lattice, increasing the $\mathrm{N}$ content and decreasing the bandgap due to the band bowing. 
Arsenic outdiffusion is another mechanism that complicates annealing studies of $\operatorname{GaAs}_{1-\mathrm{x}} \mathrm{N}_{\mathrm{x}}$ and suggests the resulting structures may also be non-uniform, which would also contribute to PL peak broadening.

Given the complexity of the $\mathrm{GaAs}_{1-\mathrm{x}} \mathrm{N}_{\mathrm{x}}$ material system further studies are needed to confirm the findings reported in this Chapter 6. In particular, one needs to do careful characterization of the layer and quantum dot structures themselves, typically with a technique such as transmission electron microscopy, to verify layer thicknesses and dot structure. Furthermore, the origin of the PL peak needs to be investigated in order to verify that it is the same optoelectronic transition as the one reported in the literature [Loke, 2002]. However, these studies were not undertaken because it was beyond the scope of this work. 


\section{Chapter 7}

\section{Bismuth Surfactant Effects and Beryllium Doping}

The large bandgap bowing effect of III-V-nitride alloys has made $\mathrm{GaAs}_{1-\mathrm{x}} \mathrm{N}_{\mathrm{x}}$ a promising material for use in long wavelength optoelectronic devices. However, the large lattice mismatch $(\sim 20 \%)$ and large miscibility gap between GaAs and GaN complicate the growth of high quality $\mathrm{GaAs}_{1-\mathrm{x}} \mathrm{N}_{\mathrm{x}}$, particularly for large $\mathrm{N}$ concentrations. In addition, the highly reactive nature of active nitrogen can lead to significant surface roughening for higher active nitrogen flux. The use of a surface active agent, i.e. surfactant, is one option for reducing surface roughness for higher concentrations of nitrogen.

As commonly known, epitaxial growths are categorized into three different modes: Frank-Van der Merwe (FM) mode [Frank, 1949], Volmer-Weber (VM) mode [Volmer, 1926], and Stranski-Krastanow (SK) mode [Stranski, 1938]. Among them, FM mode, which requires lower surface free energy on the overlayer than on the substrate and little lattice mismatch between interfaces, is the ideal $2 \mathrm{D}$ growth mode. VM mode corresponds to the $3 \mathrm{D}$ growth with island formation occurring during growth. This growth usually occurs if the deposit, rather than the substrate, has a higher surface free energy. SK mode, which normally takes place in III-V material growth such as in our $\mathrm{GaAs}_{1-\mathrm{x}} \mathrm{N}_{\mathrm{x}}$ growth, is initiated with a $2 \mathrm{D}$ growth but is followed by a growth transition from $2 \mathrm{D}$ to $3 \mathrm{D}$ due to highly mismatched lattice constants. Surfactant was thought to be effective in inhibiting the formation of islands by modifying the growth mode [Grandjean, 1992]. The major effect of surfactant on III-V semicondutors as Grandjean et al. suggested was to reduce the surface free energy by surfactant segregating on the surface, and thus alter the growth mode to 2D growth [Grandjean, 1992]. There was another point of view 
attributing 'the success of surfactants' to the reduction of surface diffusion, which is facilitated by introducing surfactant into the growth. The segregation of surfactant increases the energy barrier for thermal activation. The increase of this barrier helps overcome and suppress the diffusion of atoms under the surfactant once the deposited film becomes subsurface [Snyder, 1993].

Although details with regard to surfactant mechanism are still under discussion, the improvement of the quality of crystal surface morphology is unquestionable as proved by many reports [Sun, 2005] [Yuen, 2006] [Young, 2005] [Tixier, 2003] [Pillai, 2000]. Small solid solubility and low vapor pressure are the criteria for the selection of surfactants [Shurtleff, 2000]. The former ensures little or no incorporation, and the latter means most surfactant atoms could stay on the surface instead of evaporating away. If these two characteristics are satisfied, the surfactant can maintain a high rate of concentration on the growing surface and therefore play an active role of suppressing surface roughness. A variety of materials, including tellurium, indium, and antimony, have been tried as surfactants. However, as mentioned in Section 2.1.3, they all can be incorporated during growth and cause the properties of the film to change [Pillai, 2000] [Young, 2005]. For example, the self-incorporation of $\mathrm{Sb}$ for $\mathrm{Si} / \mathrm{Ge}$ superlattice MBE growth could be very appreciable, nearly $5 \times 10^{17} \mathrm{~cm}^{-3}$ [Fujita, 1990]. Compared to elements listed above, bismuth possesses some characteristics allowing it to be a closer to ideal surfactant. Both its segregation coefficient and solubility in solid are small, around $10^{-4}$ and $10^{17} \mathrm{~cm}^{-3}$ respectively [Trumbore, 1960], reducing the chance of being incorporated. Moreover, it is less harmful to the electrical properties of $\mathrm{GaAs}_{1-\mathrm{x}} \mathrm{N}_{\mathrm{x}}$ semiconductors even if self-incorporation happens, because $\mathrm{Bi}$ has the same number of valence electrons as the other group-V elements do and thus the background doping concentration would keep the same [Pillai, 2000] [Young, 2005]. It may even 
facilitate the incorporation of nitrogen [Young, 2005], which can practically extend devices operating to longer wavelengths. The experimental studies of bismuth's surfactant effect on dilute nitride began a couple of years ago, so up to now there are only a few reports on this topic in which its capability of smoothing surface and boosting $\mathrm{N}$ incorporation have been addressed [Tixier, 2003] [Young, 2005] [Cooke, 2006]. However, all of these results are limited to low N compositions, no more than $0.95 \%$. In this chapter, The investigation will be extended to higher $\mathrm{N}$ contents and present experimental results pertaining to the surface morphology and $\mathrm{N}$ incorporation while in the presence of Bi.

The heterojunction bipolar transistor (HBT) is a very important semiconductor device with applications including power amplifiers and high speed optical fibers. One concern is the high base-emitter voltage induced power dissipation which limits the number of transistors that can be fabricated in the integrated circuit [Welser, 2001]. The reduction of bandgap energy by introducing $\mathrm{N}$ into GaAs makes $\mathrm{GaAs}_{1-\mathrm{x}} \mathrm{N}_{\mathrm{x}}$ an attractive material to be used as the base layer of the HBT structure. The reduced energy gap which lowers the turn-on voltage required with respect to a desired collector current density also maximizes the efficiency and improves the overall performance of the device. The development of HBT integrated circuits (ICs) urges the investigation on $\operatorname{GaAs}_{1-\mathrm{x}} \mathrm{N}_{\mathrm{x}}$-based doping materials, with p-type $\mathrm{GaAs}_{1-\mathrm{x}} \mathrm{N}_{\mathrm{x}}$ needing attention due to its application in n-p-n HBTs as the base layer.

Beryllium and carbon are two suitable dopants compatible with the substrate temperature range for GaAs-based material growth. However, the difficulty to produce reliable carbon doping sources leads beryllium to be the more commonly used acceptor [Farrow, 1995b]. To date there have been few reports of Be-doped p-type $\mathrm{GaAs}_{1-\mathrm{x}} \mathrm{N}_{\mathrm{x}}$, and only a few for beryllium doped GaInAsN [Xin, 2000] [Li, 2001a] [Matsuura, 2004] [Fleck, 2001] [Xie, 2004]. A decrease of 
carrier concentration with increasing nitrogen content $[\mathrm{N}]$ has been observed in several reports, but the mechanism is still not clear. In addition, rapid thermal annealing (RTA) appeared to activate Be doping in some studies [Xin, 2000] [Li, 2001a], whereas a different phenomenon observed by another group seems to oppose this statement [Matsuura, 2004]. Apparently more work needs to be done to clarify the change of electrical properties as well as the mechanism behind the change. This chapter will include our study on Be-doped $\mathrm{GaAs}_{1-\mathrm{x}} \mathrm{N}_{\mathrm{x}}$ as well.

\subsection{Experimental description}

\subsubsection{Growth conditions}

All GaAs${ }_{1-\mathrm{x}} \mathrm{N}_{\mathrm{x}}$ samples were grown at $427^{\circ} \mathrm{C}$ on (100) semi-insulating GaAs substrates in the VG V80H MBE system equipped with an Oxford Applied Research (OAR) HD25 radio frequency (RF) plasma nitrogen source (Details can be found in chapter 3). As 4 was supplied by an EPI cracker cell with an operating temperature of $550^{\circ} \mathrm{C}$. Nitrogen incorporation was controlled by varying the growth rate $(0.3-0.9 \mu \mathrm{m})$ and changing the nitrogen partial pressure $\left(10^{-7}-10^{-6}\right.$ Torr $)$. A multi-layer sample, with each $\mathrm{GaAs}_{1-\mathrm{x}} \mathrm{N}_{\mathrm{x}}$ layer grown under a varied growth condition, was used to preliminarily determine $\mathrm{N}$ contents achieved from different combinations of growth conditions. A GaAs barrier layer was sandwiched between two $\operatorname{GaAs}_{1-\mathrm{x}} \mathrm{N}_{\mathrm{x}}$ layers to isolate and help discriminate growth conditions while also acting as a buffer layer favoring the following growth. The depth profile of SIMS measurement is shown in Fig 7.1 and $\mathrm{N}$ contents retrieved from SIMS are listed in Table 7.1. Numbers starting from 1 are assigned for each growth condition, with detailed information included in Table 7.1. In this study, $\mathrm{GaAs}_{1-\mathrm{x}} \mathrm{N}_{\mathrm{x}}$ samples were grown under an As/III BEP ratio ranging between 6 to 9. The $\mathrm{N}$ source was set with the partial pressure from $10^{-7}$ to $10^{-6}$ Torr, corresponding to $\sim 0.01$ to $0.1 \mathrm{sccm}$ based on the 


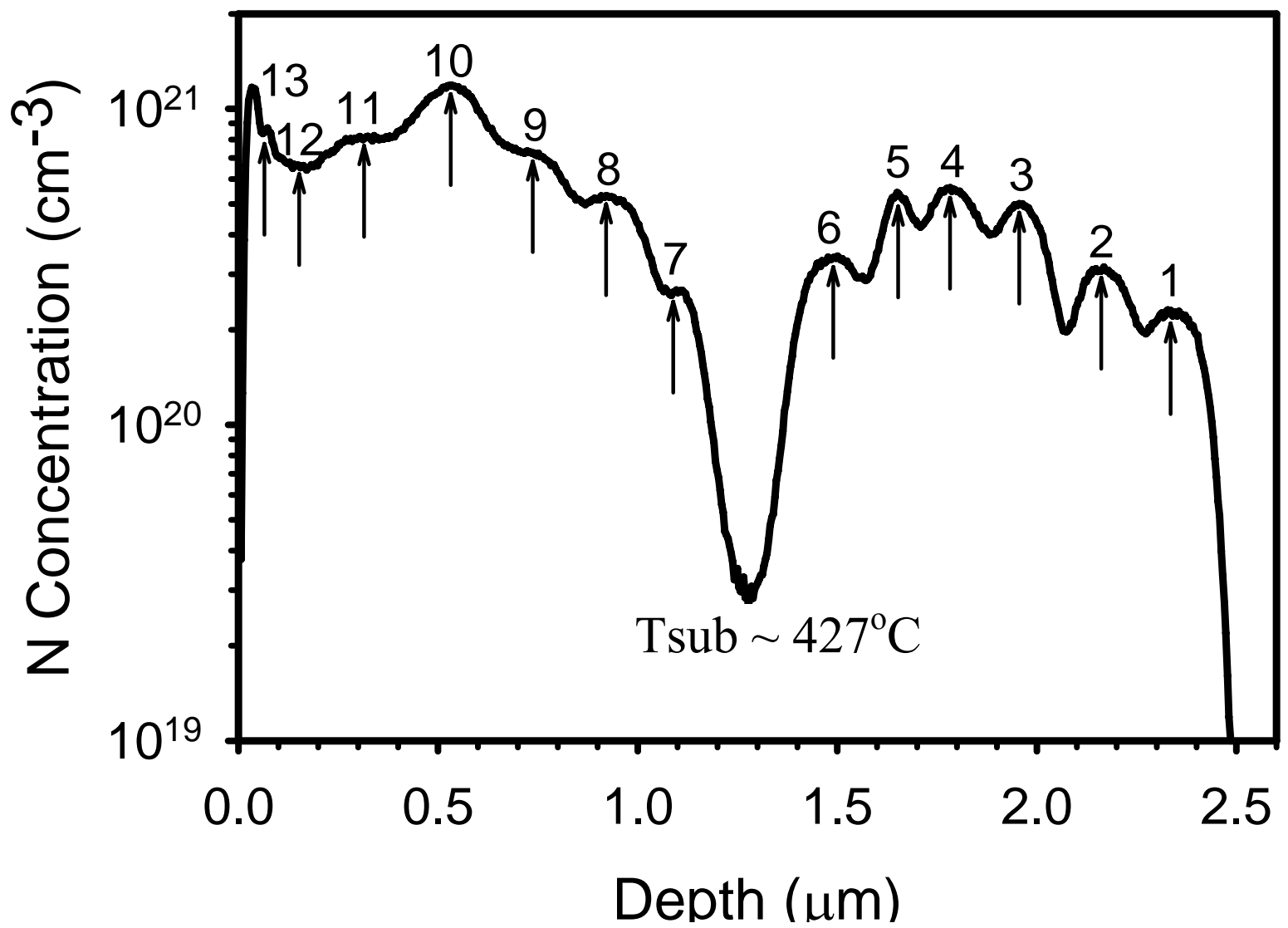

Fig 7.1 SIMS measurement of the multi-layer-sample under different growth conditions.

\begin{tabular}{|c|c|c|c|c|c|c|c|}
\hline$\#$ & $\begin{array}{c}\text { Gaflux } \\
\left(\mathbf{x 1 0}^{-7}\right)\end{array}$ & $\begin{array}{c}\text { As flux } \\
\left(\mathbf{x 1 0 ^ { - 6 }}\right)\end{array}$ & $\begin{array}{l}\text { N flux } \\
\left(\mathbf{x} 10^{-7}\right)\end{array}$ & $\begin{array}{c}\text { Plasma } \\
\text { Power }(\mathbf{W})\end{array}$ & $\begin{array}{l}\text { Growth } \\
\text { time (min) }\end{array}$ & $\begin{array}{c}\text { Barrier layer growing } \\
\text { time(min) }\end{array}$ & $\begin{array}{c}\text { N concentration } \\
(\%)\end{array}$ \\
\hline 1 & 5 & 5.8 & 1 & 100 & 20 & 5 & 1.04 \\
\hline 2 & 3.5 & 5.8 & 1 & 100 & 30 & 5 & 1.43 \\
\hline 3 & 3.5 & 5.8 & 10 & 100 & 30 & 5 & 2.26 \\
\hline 4 & 3.5 & 2.8 & 10 & 100 & 30 & 5 & 2.61 \\
\hline 5 & 5 & 2.8 & 10 & 100 & 20 & 5 & 2.52 \\
\hline 6 & 5 & 5.8 & 10 & 100 & 20 & 25 & 1.53 \\
\hline 7 & 5 & 5.8 & 10 & 100 & 10 & 5 & 1.20 \\
\hline 8 & 5 & 5.8 & 1 & 200 & 20 & 5 & 2.43 \\
\hline 9 & 3.5 & 5.8 & 1 & 200 & 30 & 5 & 3.33 \\
\hline 10 & 3.5 & 5.8 & 10 & 200 & 30 & 5 & 5.48 \\
\hline 11 & 5 & 5.8 & 1 & 300 & 20 & 5 & 3.71 \\
\hline 12 & 2 & 5.8 & 1 & 100 & 30 & 5 & 3.00 \\
\hline 13 & 2 & 5.0 & 10 & 100 & 30 & 5 & 3.98 \\
\hline
\end{tabular}

Table 7.1 N concentrations obtained from the multi-layer-sample. Each \# in the first column corresponds to one growth condition as numbered in Fig 6.1. 
pumping speed and conductance of the system, and the power from $100 \mathrm{~W}$ to $200 \mathrm{~W}$.

\subsubsection{Sample structures}

The same structures were used for both the undoped and Be-doped material with the only difference being thickness (Fig 7.2). The undoped structure had a $300 \mathrm{~nm}$ thick $\mathrm{GaAs}_{1-\mathrm{x}} \mathrm{N}_{\mathrm{x}}$ film on top of the $300 \mathrm{~nm}$ thick buffer layer, and the Be-doped samples were all grown on a 40nm thick buffer layer followed by a GaAs$s_{1-\mathrm{x}} \mathrm{N}_{\mathrm{x}}$ layer with a total thickness of $450 \mathrm{~nm}$.

\subsubsection{Beryllium incorporation}

Beryllium incorporation was ranged from $1 \times 10^{17} \mathrm{~cm}^{-3}$ to $2 \times 10^{19} \mathrm{~cm}^{-3}$ by adjusting the temperature of the Be thermal effusion cell. Beryllium flux is linearly proportional to its cell temperature, but not all incident Be atoms can account for the final Be concentration especially at high Be fluxes, because more beryllium diffuses with increasing flux. This increase of diffusion coefficient normally becomes much faster if [Be] is larger than $2 \times 10^{19} \mathrm{~cm}^{-3}$ [Farrow, 1995c]. For example, the diffusion coefficient at $900^{\circ} \mathrm{C}$ increased two orders of magnitude from

$5-10 \times 10^{-16} \mathrm{~cm}^{2} / \mathrm{sec}$ to $5-10 \times 10^{-14} \mathrm{~cm}^{2} / \mathrm{sec}$ after $[\mathrm{Be}]$ was increased to $3 \times 10^{19} \mathrm{~cm}^{-3}$ from $1.5 \times 10^{17}$ $\mathrm{cm}^{-3}$ [Farrow, 1995c]. In this study, the relationship between $[\mathrm{Be}]$ and Be temperature was experimentally determined under the growth temperature of $427^{\circ} \mathrm{C}$ as illustrated in Fig 7.3. Below $800^{\circ} \mathrm{C}$, the $\mathrm{Be}$ incorporation increases linearly with the temperature and then ramps up slower due to the increase in the diffusion coefficient. This increase in the diffusion coefficient limits the concentration of incorporated Be and will eventually lead to the saturation of $[\mathrm{Be}]$ at some point. Therefore, the maximum [Be] obtained is usually no more than $10^{20} \mathrm{~cm}^{-3}$. 


\section{GaAs $\mathrm{N} \sim 0.3 \mu \mathrm{m}$}

\section{GaAs buffer layer \\ Undoped $\sim 0.3 \mu \mathrm{m}$}

\section{GaAs substrate}

(100) SI

\section{GaAs $\mathrm{N} \sim 0.45 \mu \mathrm{m}$}

\section{GaAs buffer layer Undoped $\sim 0.04 \mu \mathrm{m}$}

GaAs substrate (100) SI

Fig 7.2 Sample structures for (a) undoped material, and (b) Be-doped material. 


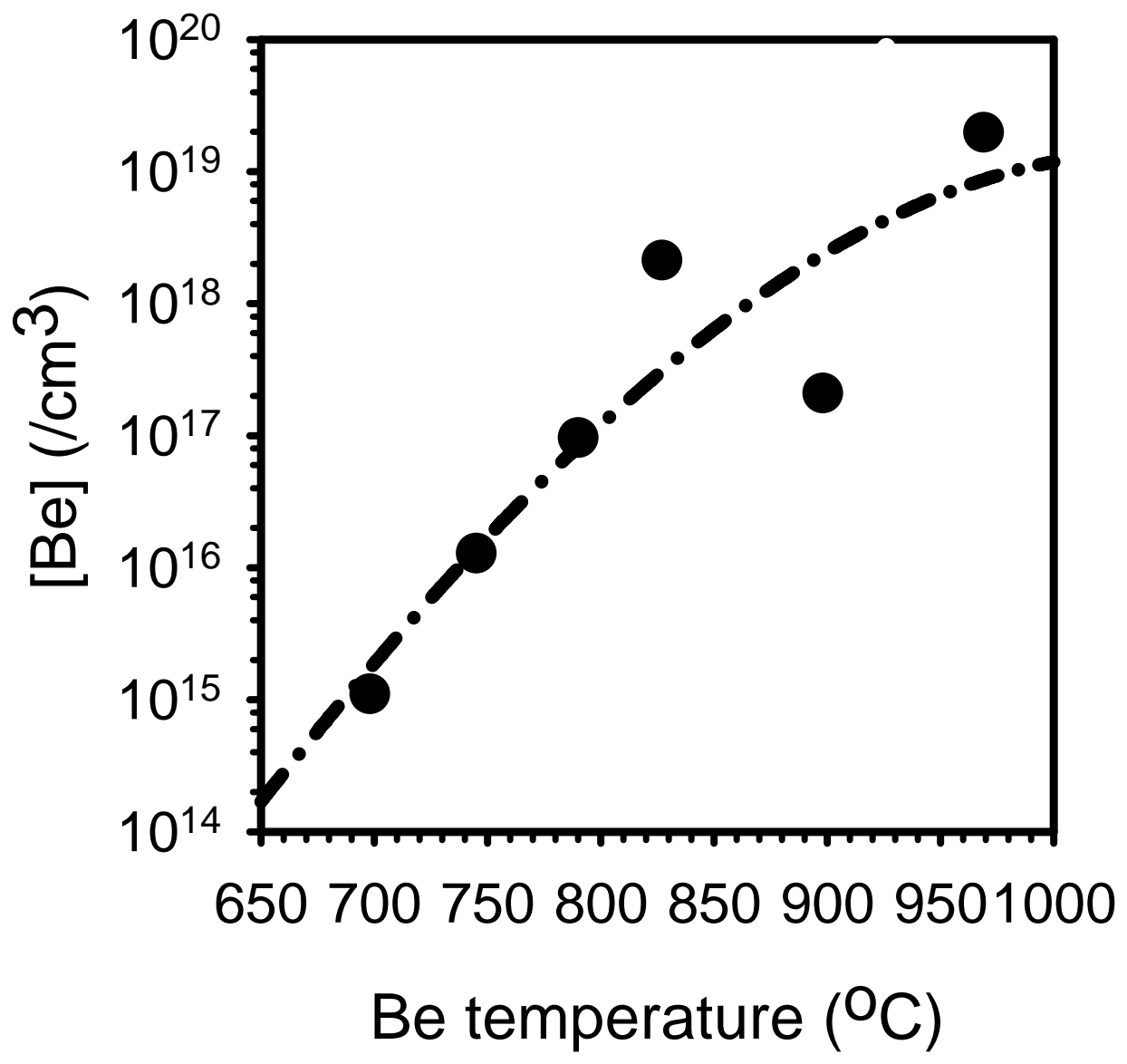

Fig 7.3 The concentration of incorporated Be vs. the temperature of $\mathrm{Be}$ effusion cell at growth temperature $427^{\circ} \mathrm{C}$. 


\subsubsection{Bi deposition}

RHEED is known to be highly informative when dealing with growth kinetics. By observing the RHEED pattern on GaAs (100), surface reconstruction was found to occur from an As stabilized $2 \times 4$ pattern to a Bi stabilized 1x3 pattern for a certain growth temperature if enough bismuth was supplied [Pillai, 2000]. This is a prerequisite to ensure Bi co-deposited growth functions as a surfactant. The result by Pillai et al. is illustrated in Fig 7.4 [Pillai, 2000], where an intermediate strip exists in between the $2 \times 4$ and $1 \times 3$ regions in which the transition occurs. In this work, the Bi flux was adjusted to be larger than that required to maintain a bismuthstabilized 1x3 surface reconstruction for all growths with $\mathrm{Bi}$. With a high enough $\mathrm{Bi}$ cell temperature applied, 1x3 RHEED patterns were obtained as shown in Fig 7.5 under the growth temperature of $427^{\circ} \mathrm{C}$.

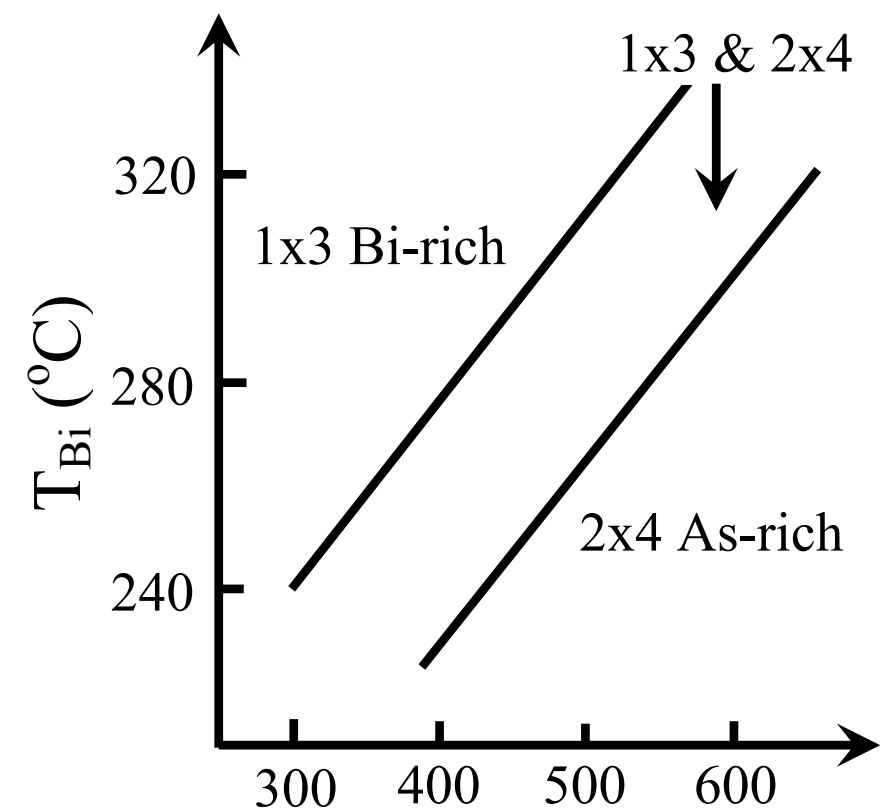

Fig 7.4 Surface phase diagram on GaAs (100) depending on substrate temperature and $\mathrm{Bi}$ cell temperature, observed by Pillai et al. in their MBE system.[Pillai, 2000]
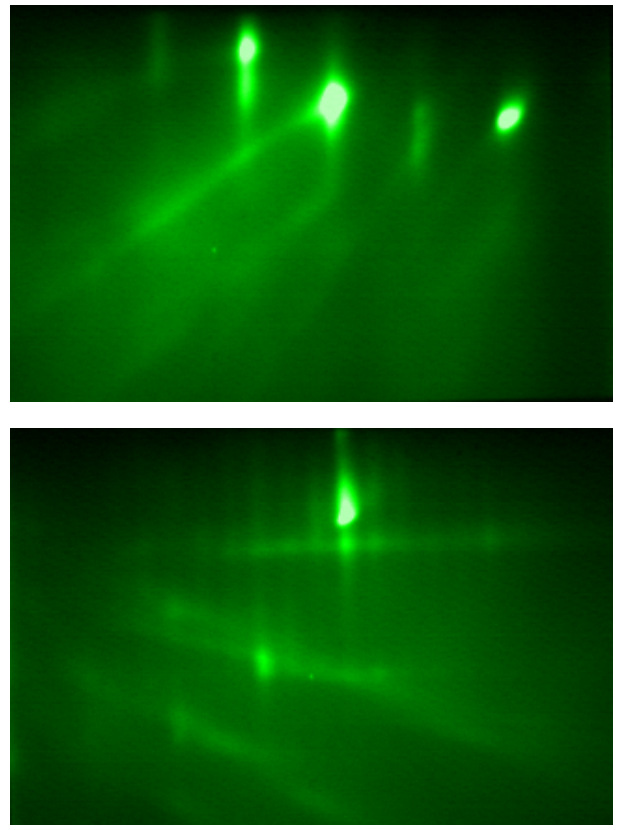

Fig $\quad 7.5 \quad \mathrm{Bi}$ stabilized $1 \times 3$ surface reconstruction at $\mathrm{T}_{\mathrm{s}} \sim 427^{\circ} \mathrm{C}$. The top is the $1 \mathrm{x}$ pattern, and the bottom is the $3 \mathrm{x}$ pattern. 


\subsubsection{Characterization}

Hall effect measurements were performed by the van der Pauw method with Pt or $\operatorname{In}(80 \%) / \mathrm{Zn}(20 \%)$ ohmic contacts forming on four corners of square sample pieces. Atomic force microscopy (AFM) measurements of the surface roughness were conducted with a VEECO multimode scanning probe microscope. A Renishaw Raman system was used for room temperature Raman scattering using the 514-nm line of an argon ion laser. Secondary ion mass spectrometry (SIMS) measurements were performed by either the Evans Analytic Group or QSPEC Technology utilizing previously developed standards.

\subsection{N concentration determined by Raman measurement}

The Raman shift of the GaN-like $\mathrm{LO}_{2}$ line has been shown to depend on $\mathrm{N}$ concentration with the relationship

$$
\omega=(468 \pm 1)+(1.97 \pm 0.1) x
$$

as determined by Prokofyeva et al. and Wagner et al. (Fig 7.6) [Prokofyeva, 1998] [Wagner, $2000]$ However the equation above was obtained with $[N] \leq 3.3 \%$, so the relationship may or may not be valid beyond this range.

SIMS measurements were peformed on selected $\mathrm{GaAs}_{1-\mathrm{x}} \mathrm{N}_{\mathrm{x}}$ samples in order to obtain exact N compositions. Fig 7.7 (a) shows SIMS results on several samples indicating the density of $\mathrm{N}$ to be $1.79 \times 10^{20}, 4.15 \times 10^{20}$ and $1.47 \times 10^{21}$ atoms $/ \mathrm{cm}^{3}$, corresponding to group $\mathrm{V}$ fractional $\mathrm{N}$ contents of $0.8 \%, 1.9 \%$ and $6.5 \%$ respectively. Raman spectra of $\mathrm{LO}_{2}$ phonon frequency for samples measured with SIMS are shown in Fig 7.7 (b), in which peak positions of the $\mathrm{LO}_{2}$ shift are labeled. By comparing absolute N concentrations determined using SIMS with Raman shift 


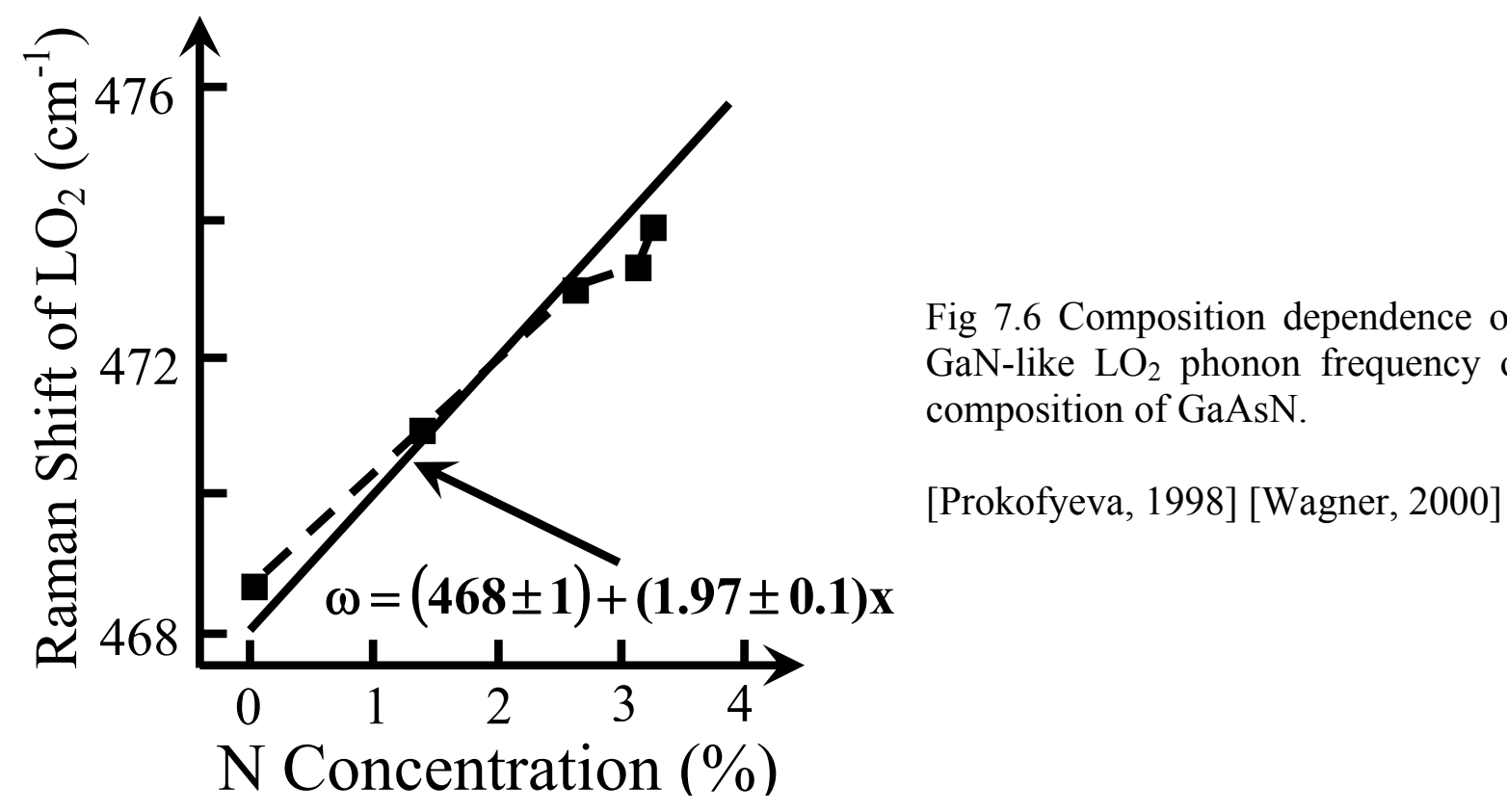

as shown in Fig 7.8, the relationship based on the linear fit to the data was determined to be

$$
\omega=468.3+1.91[\mathrm{~N}] \quad([\mathrm{N}] \text { is in } \%)
$$

This relationship is consistent with, but extending, the work of Prokofyeva et al. and Wagner et al. to $[\mathrm{N}]$ of about $\sim 6.5 \%$. Table 7.2 gives a comparison of $\mathrm{N}$ concentrations obtained by SIMS and Raman, also listing Raman $\mathrm{LO}_{2}$ phonon frequencies. The root mean square (RMS) error calculated from the difference (last column in Table 7.2) between the Raman estimation and SIMS measurement is $0.2 \%$, suggesting usefulness for estimating [N]. Therefore, Raman was used as a secondary method to estimate [N] for samples not investigated by SIMS.

The Raman shift for two samples which had the $[\mathrm{N}]$ concentration estimated using an $\mathrm{x}$ ray diffraction (XRD) measurement of lattice constant and Vegard's law are also shown in Fig 7.8 for comparison. Fig 7.9 shows XRD rocking curves of those two $\mathrm{GaAs}_{1-\mathrm{x}} \mathrm{N}_{\mathrm{x}}$ samples, from which the values for $\mathrm{x}$ were calculated to be $\sim 1.0 \%$ and $6.0 \%$ respectively by Vegard's law [Yu, 2005] 

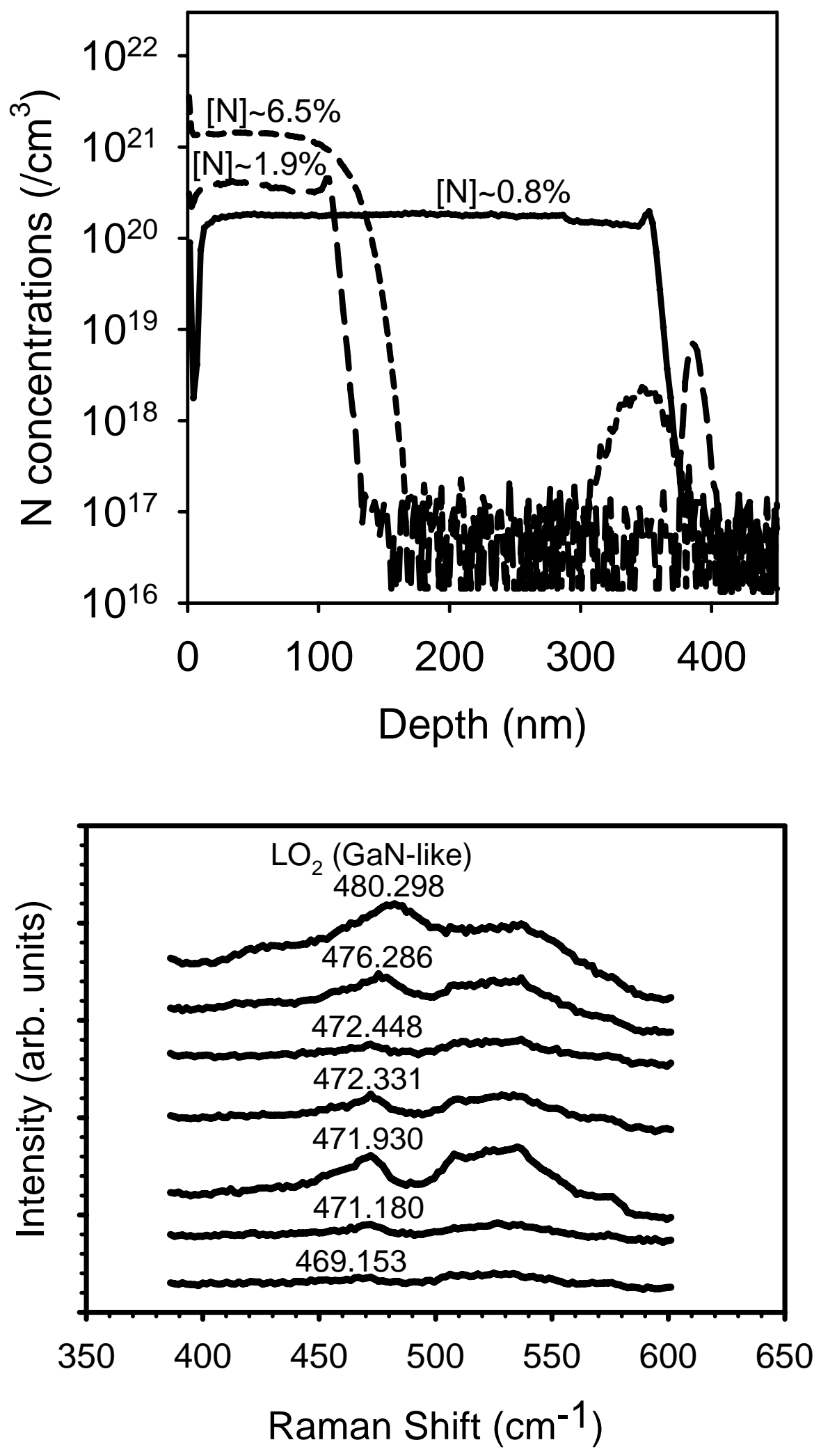

Fig 7.7 SIMS and Raman measurements to determine $\mathrm{N}$ contents of GaAsN samples. (a) $\mathrm{N}$ contents measured by SIMS. (b) Raman shift of the GaN-like $\mathrm{LO}_{2}$ phonon frequency. 


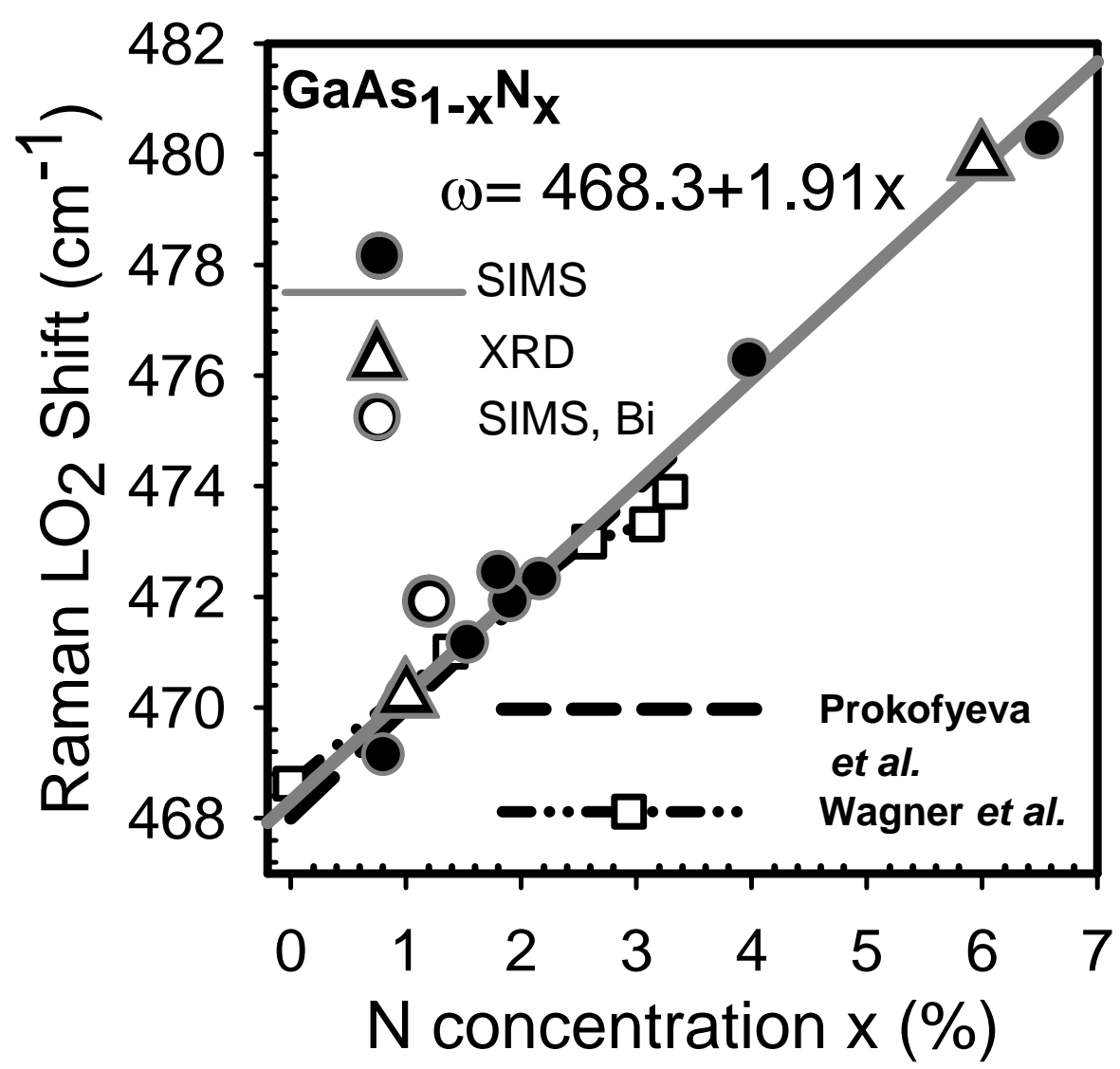

Fig 7.8 Raman shift of the $\mathrm{LO}_{2}$ phonon frequency vs. $\mathrm{N}$ content measured by SIMS and XRD. Also shown are comparisons to the relationship reported in Ref. [Prokofyeva, 1998] and [Wagner, 2000]. Results for a sample grown under Bi are shown, but were not included in obtaining the fit.

Table $7.2[\mathrm{~N}]$ measured by SIMS compared to $[\mathrm{N}]$ derived by Raman using Eq. (7.2).

\begin{tabular}{cccc}
\hline $\begin{array}{c}\text { Raman } \mathrm{LO}_{2} \\
\text { shift }\left(\mathrm{cm}^{-1}\right)\end{array}$ & $\begin{array}{c}\text { By Raman } \\
{[\mathrm{N}]_{\mathrm{R}}(\%)}\end{array}$ & $\begin{array}{c}\text { By SIMS } \\
{[\mathrm{N}]_{\mathrm{S}}(\%)}\end{array}$ & $\begin{array}{c}\mathrm{abs}\left([\mathrm{N}]_{\mathrm{s}}-[\mathrm{N}]_{\mathrm{R}}\right) \\
(\%)\end{array}$ \\
\hline & & & \\
469.153 & 0.446 & 0.800 & 0.354 \\
471.180 & 1.508 & 1.534 & 0.026 \\
476.286 & 4.182 & 3.977 & 0.205 \\
472.331 & 2.111 & 2.156 & 0.045 \\
480.298 & 6.284 & 6.520 & 0.236 \\
471.930 & 1.901 & 1.900 & 0.001 \\
472.448 & 2.172 & 1.800 & 0.372 \\
\hline \hline
\end{tabular}




$$
x=\frac{a-a_{G a A s}}{\Delta a_{N}}
$$

where $\alpha_{\mathrm{GaAs}}$ is the lattice constant of GaAs, and $a$ is the lattice constant of $\mathrm{GaAs}_{1-\mathrm{x}} \mathrm{N}_{\mathrm{x}}$ along the growth direction, which can be found by XRD measurements to be [Bisognin, 2004]

$$
a=a_{\text {GaAs }}\left(\frac{\Delta \theta}{\operatorname{tg}\left(\theta_{B r}\right)}+1\right)
$$

where $\triangle \theta$ is the measured angle between GaAs and $\mathrm{GaAs}_{1-\mathrm{x}} \mathrm{N}_{\mathrm{x}} \mathrm{XRD}$ rocking curve peaks, and $\theta_{\mathrm{Br}}$ is the Bragg angle, which can be determined by Bragg's law. $\triangle \boldsymbol{\alpha}_{\mathrm{N}}$ in Eq. (7.3) is the difference of lattice constant between GaN and GaAs expressed as [Bisognin, 2004]

$$
\Delta a_{N}=a_{\text {GaN }}-a_{\text {GaAs }}=-1.13 \AA
$$

$\mathrm{N}$ contents, determined by XRD and Raman measurement and listed in Table 7.3, indicate little difference which further confirms the validity of estimating [N] using Raman measurements. 


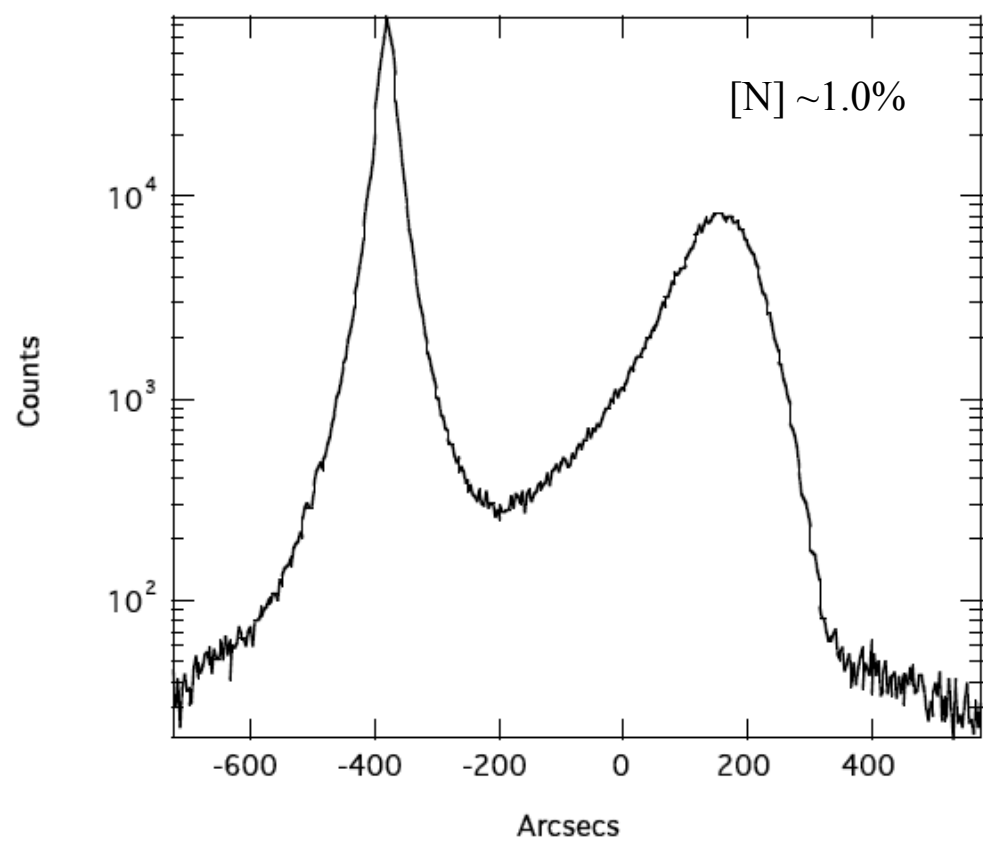

Fig 7.9 X-ray rocking curves of two $\mathrm{GaAs}_{1-\mathrm{x}} \mathrm{N}_{\mathrm{x}}$ samples with $\mathrm{x}=1.0 \%$

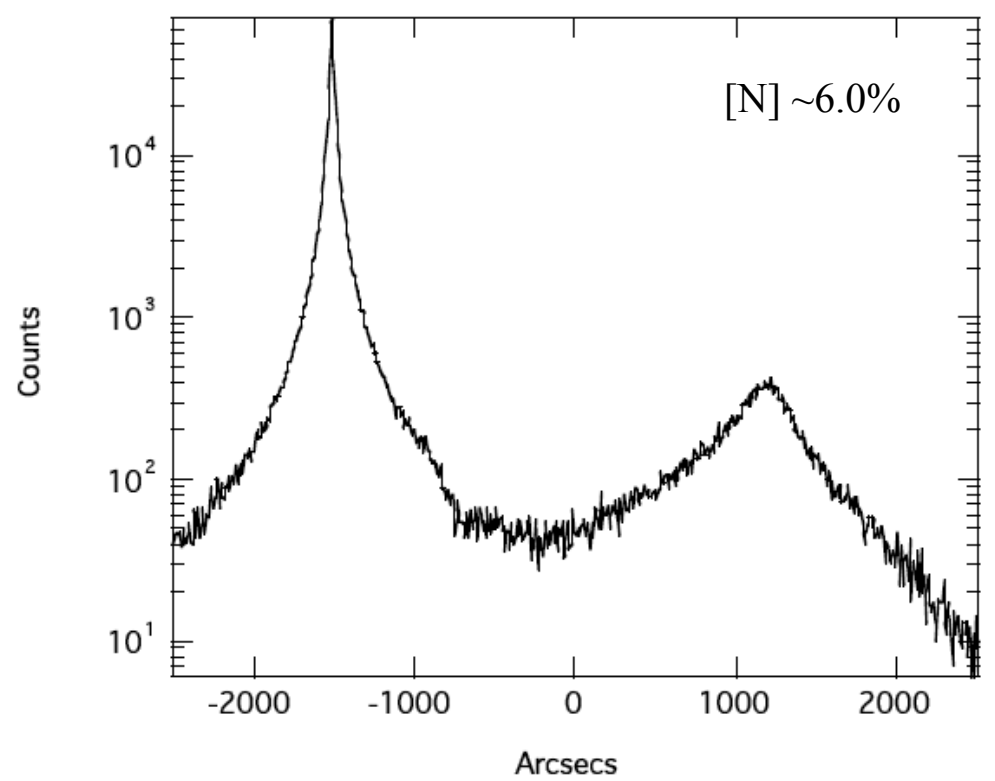

\begin{tabular}{ccccc}
\hline $\begin{array}{c}\text { Raman } \mathrm{LO}_{2} \\
\text { shift }\end{array}$ & $\begin{array}{c}\text { By Raman } \\
{[\mathrm{N}]_{\mathrm{R}}}\end{array}$ & $\begin{array}{c}\text { By XRD } \\
{[\mathrm{N}]_{\mathrm{X}}}\end{array}$ & $\begin{array}{c}{[\mathrm{N}]_{\mathrm{X}}-[\mathrm{N}]_{\mathrm{R}}} \\
(\%)\end{array}$ & $\begin{array}{c}\frac{\left|[N]_{X}-[N]_{R}\right|}{\left([N]_{X}+[N]_{R}\right) / 2} \\
(\%)\end{array}$ \\
\hline & $(\%)$ & $(\%)$ & $(\%)$ & 0.50 \\
470.220 & 1.005 & 1.0 & 0.005 & 1.31 \\
\hline 479.907 & 6.079 & 6.0 & 0.079 & \\
\hline \hline
\end{tabular}

Table $7.3[\mathrm{~N}]$ measured by XRD compared to [N] derived by Raman using Eq. (7.2). 


\subsection{Bismuth issues}

\subsubsection{Effect on growth conditions}

Using the RF source configuration, smooth surfaces (an RMS roughness $<1 \mathrm{~nm}$ ) were only achieved for $[\mathrm{N}]$ below $\sim 2$ to $2.5 \%$, depending on growth conditions. For example, as illustrated in Fig 7.10 (a), for the lowest achievable nitrogen flux condition ( $\mathrm{N}$ partial pressure of $10^{-7}$ Torr and $\mathrm{rf}$ power of $100 \mathrm{~W}$ ), growth rates were limited to above $0.2 \mu \mathrm{m} / \mathrm{h}$ (corresponding to [N] $\sim 2.5 \%$ ) in order to avoid RHEED patterns indicative of surface roughening. Growth under a Bi flux, however, allowed a much smaller growth rate under these conditions with the RHEED pattern remaining streaky until a growth rate of $0.06 \mu \mathrm{m} / \mathrm{h}$ was achieved, corresponding to [N] $\sim 3.5 \%$. Bi extends the useable growth conditions and produces smoother surfaces to a significantly higher group $\mathrm{V}$ fractional $\mathrm{N}$ content than without $\mathrm{Bi}$. The addition of $\mathrm{Bi}$ allowed $\sim 30 \%$ more nitrogen incorporation under these conditions while preserving the surface quality of the growing layer. RHEED patterns under growth rate $0.2 \mu \mathrm{m} / \mathrm{h}$ with and without $\mathrm{Bi}$ are also given in Fig 7.10 (b). In these patterns, the spotty pattern is associated with the rough Bi-free surface, while in comparison, the formation of Laue rings of the diffraction pattern under the same growth rate indicates the amelioration of surface smoothness with the presence of $\mathrm{Bi}$.

\subsubsection{Effect on surface morphology}

To further investigate the effect of $\mathrm{Bi}$, three pairs of $\mathrm{GaAs}_{1-\mathrm{x}} \mathrm{N}_{\mathrm{x}}$ samples were grown under conditions producing $\mathrm{N}$ composition of $0.8 \%, 1.9 \%$, and $6.5 \%$ (for growth without $\mathrm{Bi}$ ) as determined previously by SIMS. The only difference in growth conditions for each pair was the presence or absence of $\mathrm{Bi}$. 


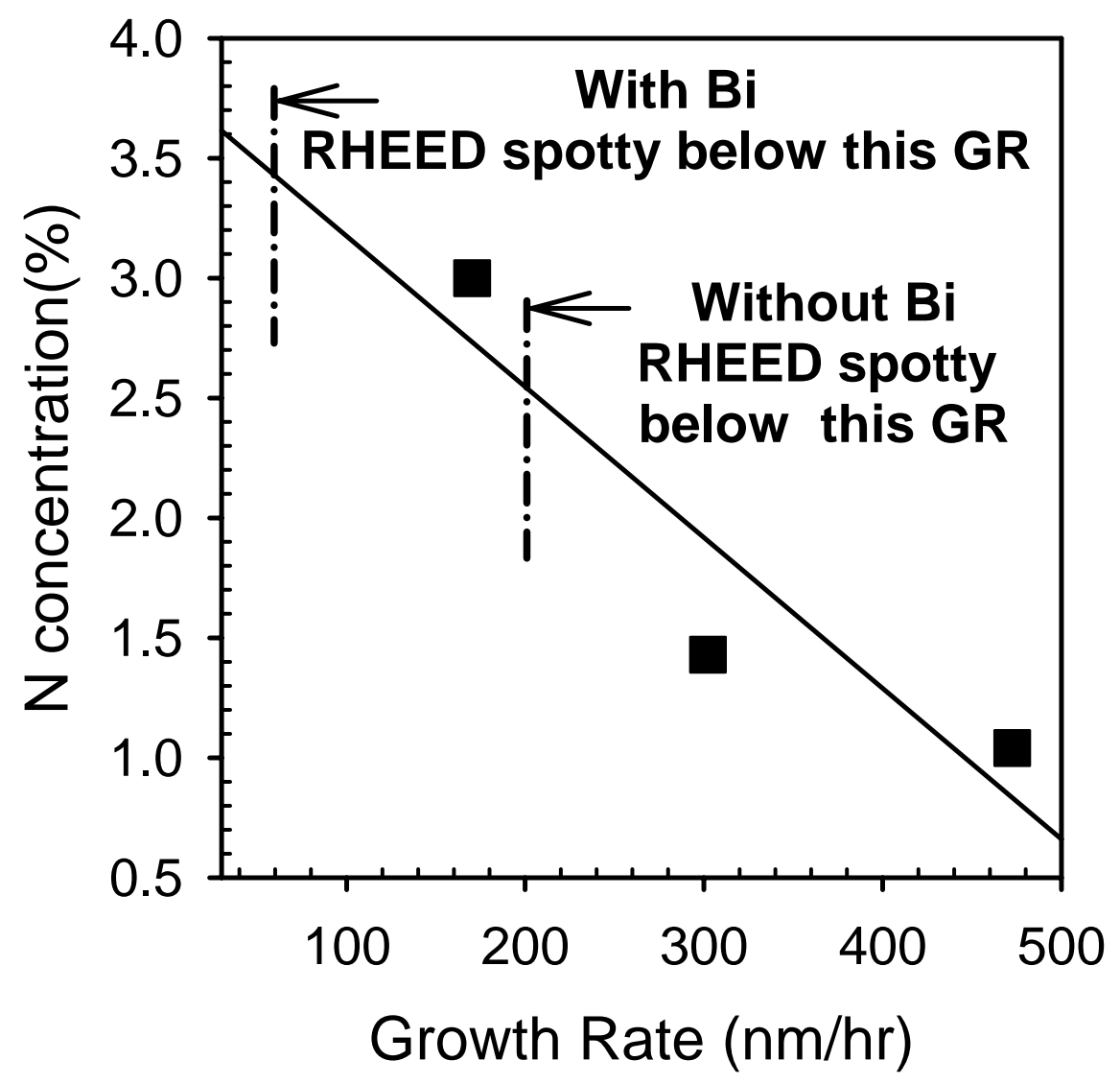

(a)
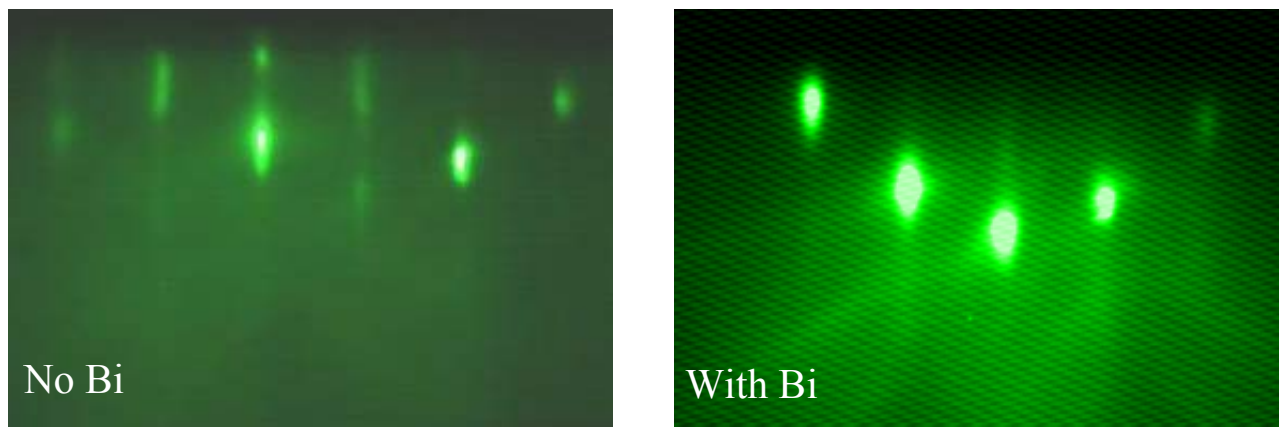

(b)

Fig 7.10 The extension of growth regime with the use of Bi determined by RHEED. (a) The dependence of $\mathrm{N}$ concentration on growth rate with changing the Ga beam flux only. Tsub $\sim 427^{\circ} \mathrm{C}$; N: $10^{-7}$ Torr, $100 \mathrm{~W}$; $\mathrm{As}_{4} \sim 3 \times 10^{-6}$ Torr. (b) Comparison of RHEED pattern with and without $\mathrm{Bi}$ at the growth rate of $200 \mathrm{~nm} / \mathrm{hr}$. 
The Raman shift of the one sample grown under Bi that was also measured using SIMS is included in Fig 7.8. AFM images of samples grown above are demonstrated in Fig 7.11, and the surface roughness derived by AFM is also listed in Table 7.4. As clearly illustrated from the graph and the table, the surface roughness increases as the active $\mathrm{N}$ species is increased if no $\mathrm{Bi}$ was involved. The existence of Bi, however, led to a significant decrease in surface roughness for higher $[\mathrm{N}]$, indicating that $\mathrm{Bi}$ acts to smooth the surface. However, Bi did not have much effect at lower $[\mathrm{N}]$ where smooth surfaces were readily obtainable. RHEED patterns observed during growths also indicated an improvement in surface smoothness obtained for higher $\mathrm{N}$ content with the addition of $\mathrm{Bi}$. As shown in Fig 7.12, for $[\mathrm{N}] \sim 1.9 \%$, the RHEED pattern without $\mathrm{Bi}$ was not as streaky as the one with $\mathrm{Bi}$, and for $[\mathrm{N}] \sim 6.5 \%$, the sample without $\mathrm{Bi}$ resulted in more spotty RHEED patterns.

Attempting to increase [N] by increasing the RF-source power alone always led to a RHEED pattern indicating increased surface roughness. Use of larger RF power actually decreased the maximum $[\mathrm{N}]$ possible for smooth epilayers. For example, increasing the power to 200W as indicated in Table I led to significant roughness in the $[\mathrm{N}] \sim 2.0 \%$ layer grown without $\mathrm{Bi}$ (in contrast to the use of a lower growth rate at lower power to achieve $[\mathrm{N}] \sim 2 \%$ ). A significant reduction in roughness was observed with the addition of $\mathrm{Bi}$. Bi allowed growth with reasonably smooth surfaces for $[\mathrm{N}]$ up to $6 \%$. 


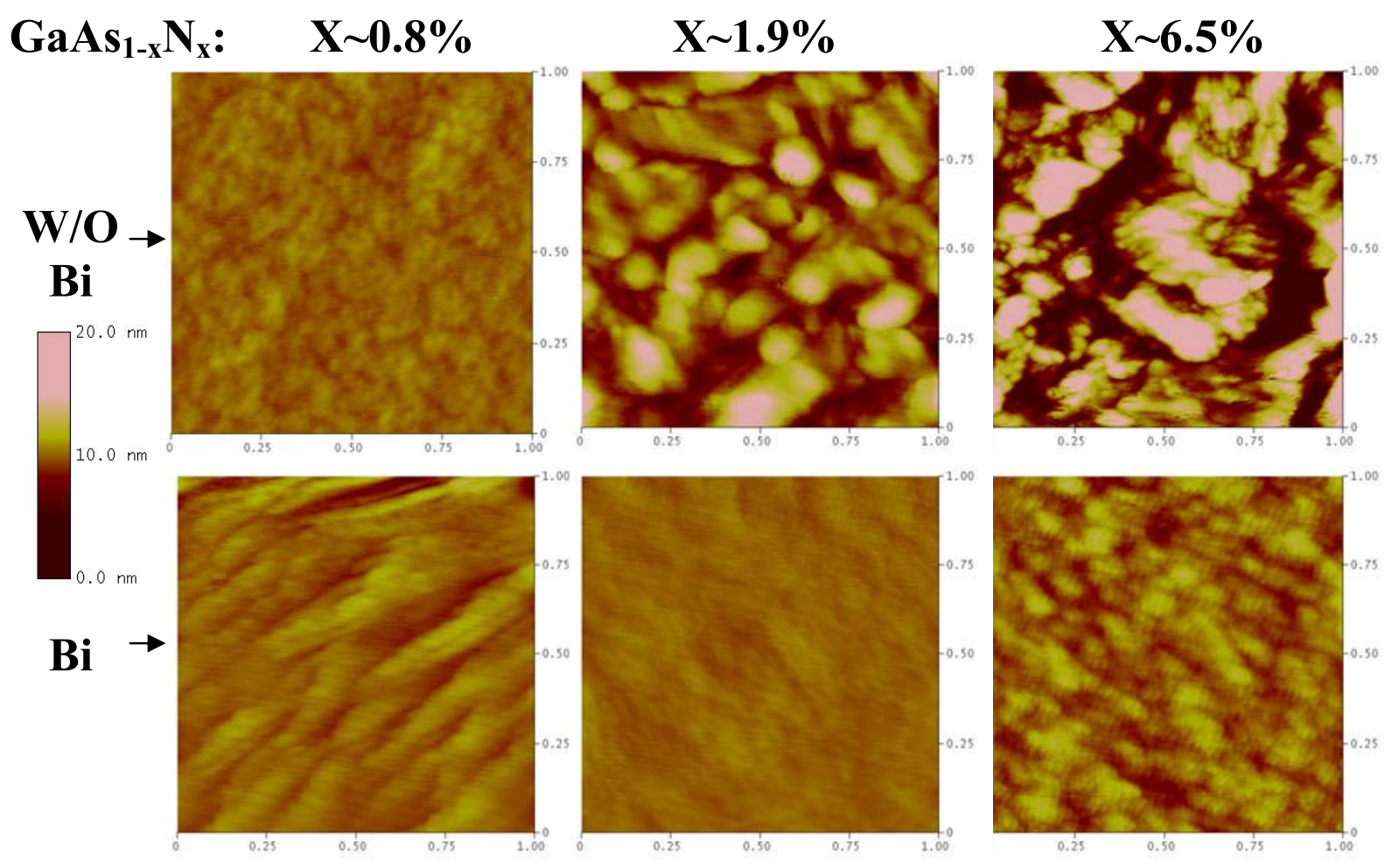

Fig 7.11 AFM images of $\mathrm{GaAs}_{1-\mathrm{x}} \mathrm{N}_{\mathrm{x}}$ grown with and without $\mathrm{Bi}$. Target $\mathrm{x}$ is $0.8 \%$, $1.9 \%$ and $6.5 \%$ respectively.

Table 7.4 Comparison of nitrogen concentration and surface roughness for GaAsN samples grown with and without Bi flux at WVU.

\begin{tabular}{|c|c|c|c|c|c|c|}
\hline \multicolumn{3}{|c|}{$\begin{array}{c}\text { Growth Conditions (rf power, } \mathrm{N} \\
\text { pressure, growth rate) }\end{array}$} & \multicolumn{2}{|c|}{$\begin{array}{l}\mathrm{N} \text { concentration estimated } \\
\text { by Raman } \mathrm{LO}_{2}(\%)\end{array}$} & \multicolumn{2}{|c|}{ AFM RMS roughness (nm) } \\
\hline Watts & Torr & $\mu \mathrm{m} /$ hour & w/o Bi & With Bi & w/o Bi & With Bi \\
\hline 100 & $10^{-7}$ & 0.45 & 0.4 & 0.8 & 0.41 & 0.57 \\
\hline 200 & $10^{-7}$ & 0.30 & 1.9 & 1.9 & 2.03 & 0.25 \\
\hline 200 & $10^{-6}$ & 0.30 & 6.2 & 6.1 & 4.06 & 0.88 \\
\hline
\end{tabular}


With Bi

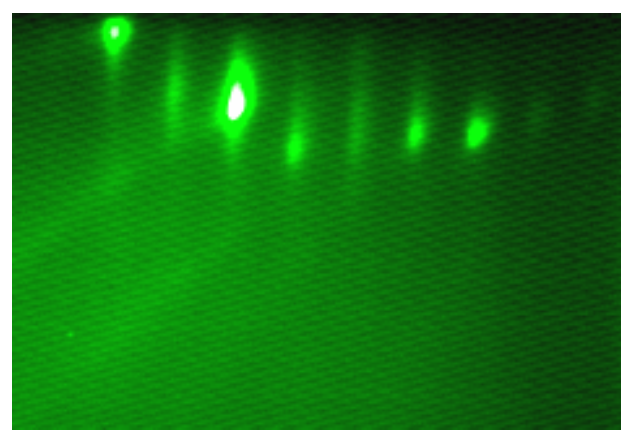

Without Bi
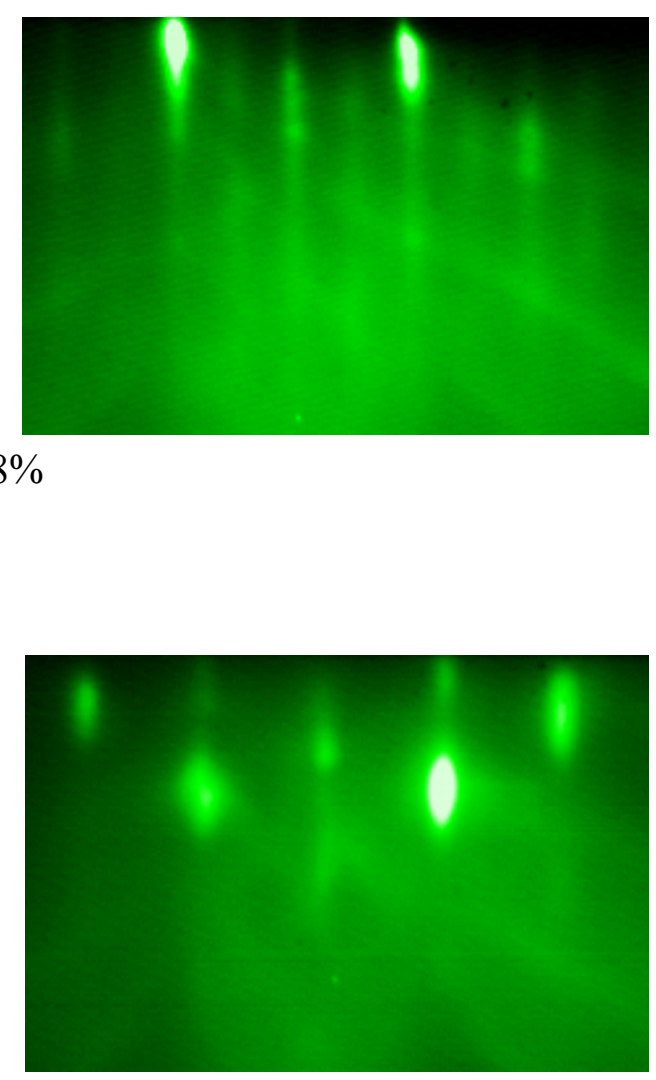

$\mathrm{X}=1.9 \%$

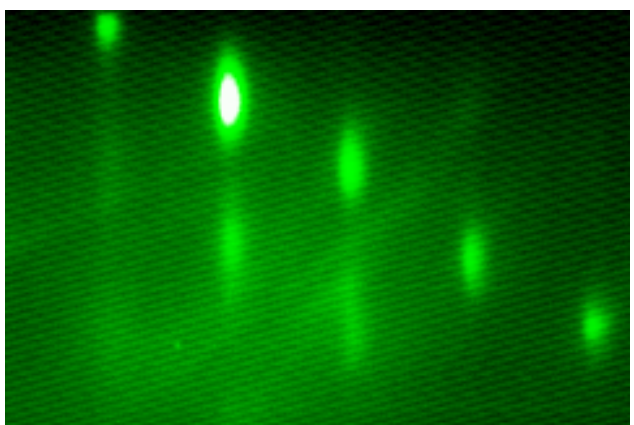

$\mathrm{X}=6.5 \%$

Fig 7.12 RHEED patterns of $\mathrm{GaAs}_{1-\mathrm{x}} \mathrm{N}_{\mathrm{x}}$ grown with and without Bi. Target $\mathrm{x}$ is $0.8 \%$, $1.9 \%$ and $6.5 \%$ respectively. 


\subsubsection{Effect on $\mathrm{N}$ incorporation}

Comparison of growths with and without $\mathrm{Bi}$ indicated little shift in the $\mathrm{N}$ concentration as

measured by Raman for higher [N], although for lower [N] there is about a $50 \%$ increase. The latter agrees with a previous study [Young, 2005] reporting an increase in nitrogen incorporation of up to $60 \%$ at low $[\mathrm{N}](<0.6 \%)$ with Bi flux (Fig 7.13). These results suggest that this effect is limited to low $[\mathrm{N}]$.

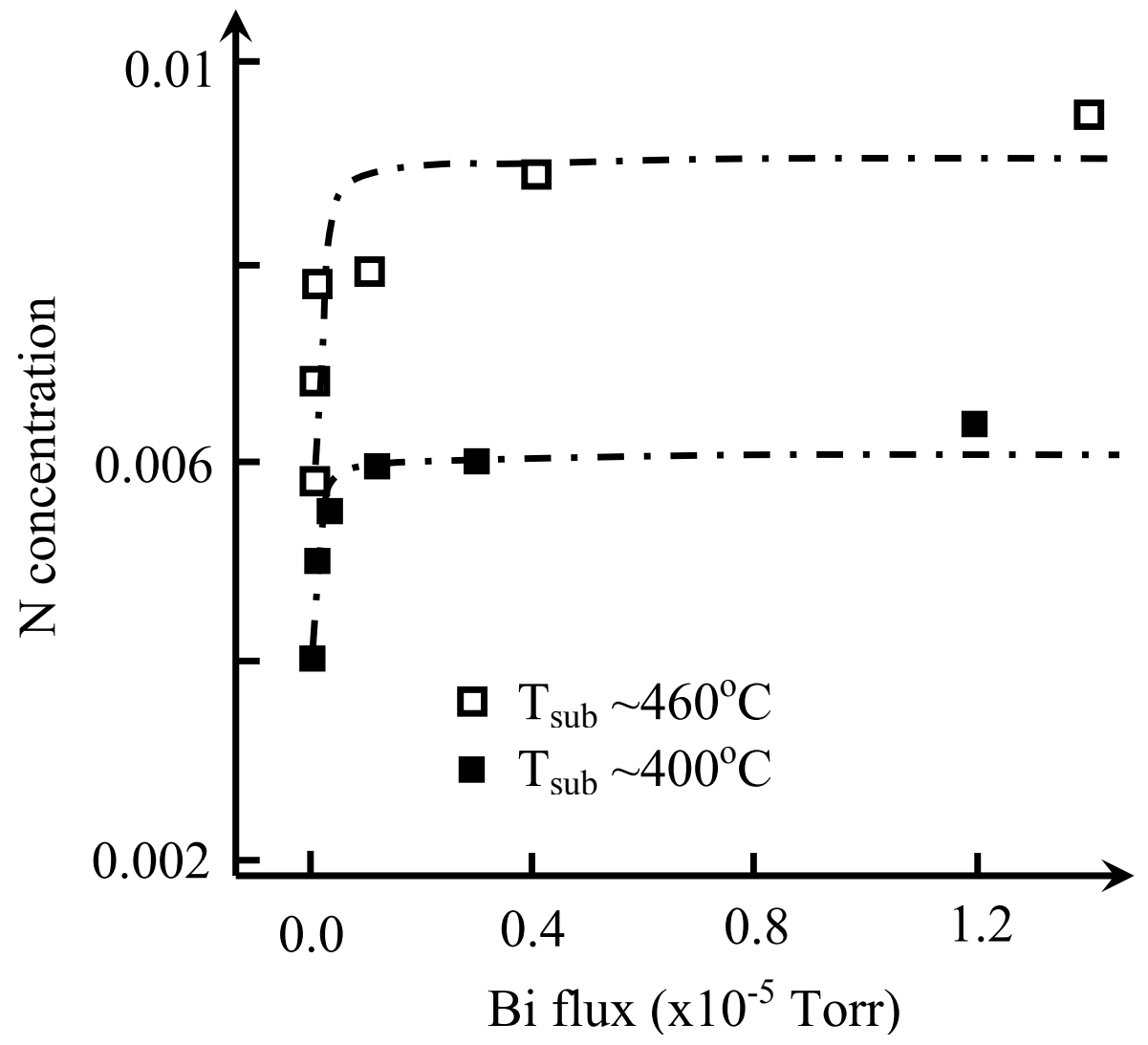

Fig 7.13 Diagram taken from Ref. [Young, 2005] showing N concentrations effected by $\mathrm{Bi}$ grown at $400^{\circ} \mathrm{C}$ and $460^{\circ} \mathrm{C}$. 


\subsection{Beryllium issues}

\subsubsection{Effects on $\mathrm{N}$ incorporation}

The use of Be was investigated for p-type doping. Prior to growing Be-doped $\operatorname{GaAs}_{1-\mathrm{x}} \mathrm{N}_{\mathrm{x}}$, resistivity measurements of unintentionally-doped $\mathrm{GaAs}_{1-\mathrm{x}} \mathrm{N}_{\mathrm{x}}$ grown on undoped, semi-insulating GaAs substrates indicated semi-insulating behavior, eliminating the possibility that factors other than Be impose influences on sample's electrical properties. SIMS measurements shown in Fig 7.14 on both Be-doped GaAs and $\mathrm{GaAs}_{1-\mathrm{x}} \mathrm{N}_{\mathrm{x}}$ samples grown using the same Be cell temperature $\left(969^{\circ} \mathrm{C}\right)$ indicated similar Be concentrations, $1.2 \times 10^{19} \mathrm{~cm}^{-3}$ and $9.6 \times 10^{18} \mathrm{~cm}^{-3}$, suggesting a reproducible Be flux and comparable incorporation. The p-type carrier concentration in GaAs, determined by Hall measurements, closely matched the SIMS determination of [Be]. For example, the GaAs sample mentioned above has the SIMS measured [Be] to be $1.2 \times 10^{19}$, and the Hall measured carrier concentration to be very close, $1.6 \times 10^{19}$. Thus the Hall measurement values were used to estimate [Be] for GaAs samples where SIMS was not performed.

A series of Be-doped $\mathrm{GaAs}_{1-\mathrm{x}} \mathrm{N}_{\mathrm{x}}$ samples were grown with nitrogen content $\mathrm{x}$ ranging from 0 to $6.5 \%$. For each composition, in addition to undoped samples, doped samples were grown under Be fluxes targeted to give concentrations ranging from $1 \times 10^{17}$ to $2 \times 10^{19} \mathrm{~cm}^{-3}$. Table 7.5 is a summary of Raman and Hall measurement results. Interestingly, [N] was found to increase with increasing $[\mathrm{Be}]$. Indeed, conditions giving a $[\mathrm{N}] \sim 0.8 \%$ in undoped samples resulted in $[\mathrm{N}] \sim 1.8 \%$ for the heavily doped $\mathrm{GaAs}_{1-\mathrm{x}} \mathrm{N}_{\mathrm{x}}$ sample. This increase in $[\mathrm{N}]$ was verified using SIMS (Fig 7.14), as was [Be]. An increase was observed in all more heavily Be doped samples investigated as shown in Fig 7.15, in which $\mathrm{N}$ contents determined by Raman measurement were shown with respect to 3 sets, totally 12 samples targeting 3 different $\mathrm{N}$ compositions and with varied Be fluxes applied for each set of them. One possible explanation 
for the rise of $[\mathrm{N}]$ might be that the presence of the dopant enhances nitrogen solubility. Xie et al. [Xie, 2004] also observed an increase in $[\mathrm{N}]$ in Be-doped GaInAsN at low $(\sim 1 \%) \mathrm{N}$ content, comparable to what observed in this study, and they attributed this to the high Be-N bond strength inhibiting the loss of $\mathrm{N}$ from the growth surface. Similar effects have been reported for $\mathrm{Cl}$ doping in $\mathrm{ZnMgSe}$, where bond strength differences (in this case between $\mathrm{Zn}-\mathrm{Cl}$ and $\mathrm{Mg}-\mathrm{Cl}$ ) significantly alter solubility and incorporation [VanMil, 2005]. This effect was seen up to [N] $\sim 6 \%$. It is interesting to note that $10^{19} \mathrm{~cm}^{-3} \mathrm{Be}$ atoms can apparently influence the extra incorporation of $10^{20} \mathrm{~cm}^{-3} \mathrm{~N}$ atoms.

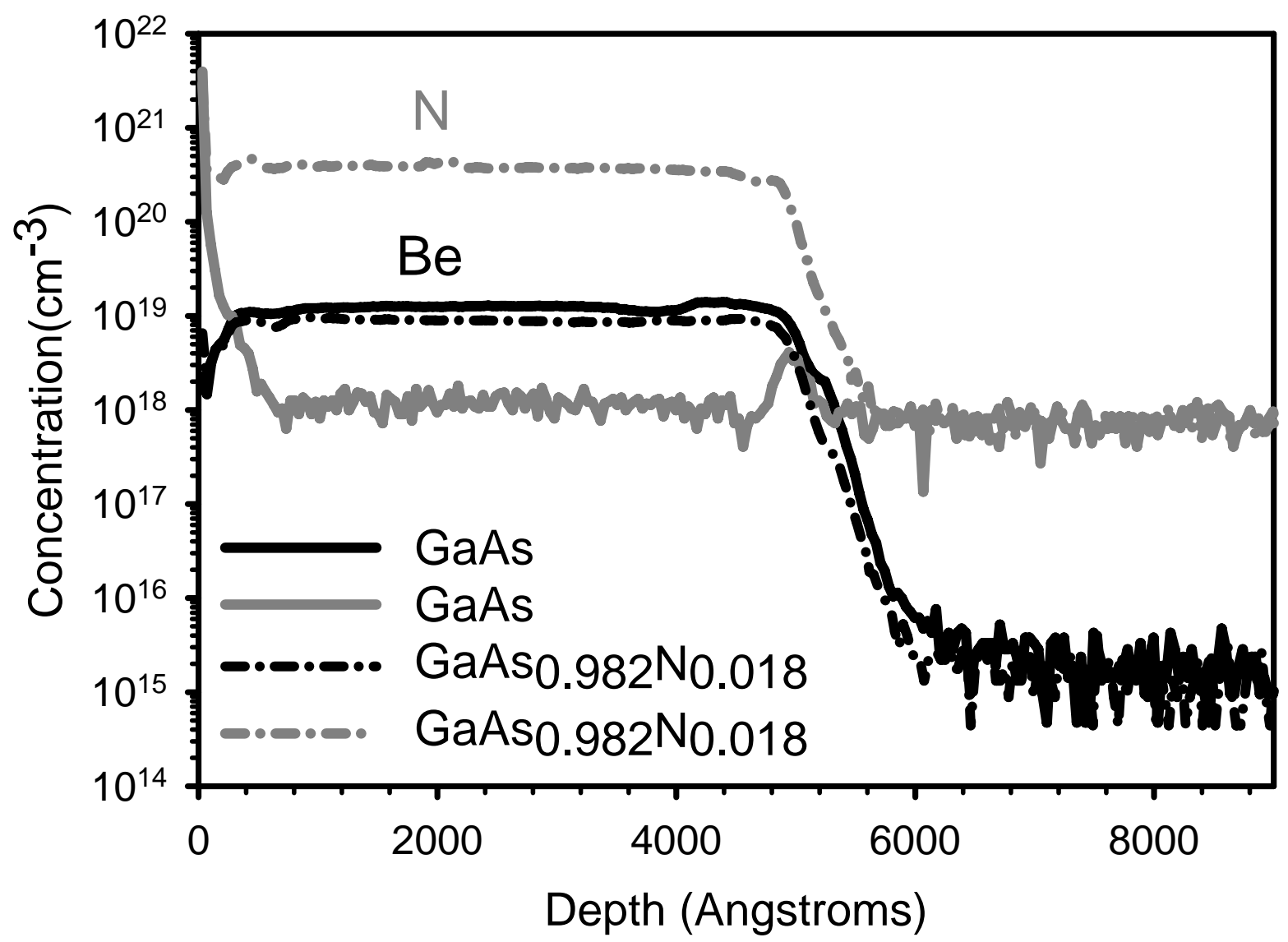

Fig 7.14 Be concentrations of Be-doped GaAs and GaAsN samples measured by SIMS measurement. For the GaAsN sample, $[\mathrm{N}]$ was determined to be $1.8 \%$. 


\begin{tabular}{|c|c|c|c|c|c|c|c|c|c|}
\hline \multirow{3}{*}[\mathrm{Be}]{} & \multicolumn{3}{|c|}{$\begin{array}{c}\text { N concentration estimated by } \\
\text { Raman } \mathrm{LO}_{2}(\%)\end{array}$} & \multicolumn{4}{|c|}{ Conducting or insulating } & \multicolumn{2}{|c|}{$\begin{array}{c}\text { Mobility } \\
\left(\mathrm{cm}^{2} /\left(\mathrm{V}^{*} \mathrm{~s}\right)\right)\end{array}$} \\
\hline & \multicolumn{3}{|c|}{ Target $\mathrm{N}$ concentration $(\%)$} & \multicolumn{4}{|c|}{ Target $\mathrm{N}$ concentration $(\%)$} & \multicolumn{2}{|c|}{$\begin{array}{c}\text { Target } \mathrm{N} \\
\text { concentration }(\%)\end{array}$} \\
\hline & 0.8 & 1.9 & 6.5 & 0.0 & 0.8 & 1.9 & 6.5 & 0.0 & 0.8 \\
\hline $1.984 \times 10^{19}$ & 1.997 & 3.978 & 6.639 & $\mathbf{C}$ & $\mathbf{C}$ & $\mathrm{I}$ & I & 80 & 52 \\
\hline $6.511 \times 10^{18}$ & 2.225 & 3.106 & 6.592 & $\mathbf{C}$ & $\mathbf{C}$ & $\mathrm{I}$ & I & 246 & 130 \\
\hline $2.137 \times 10^{18}$ & 1.413 & 2.052 & 5.113 & $\mathbf{C}$ & $\mathbf{C}$ & $\mathrm{I}$ & $\mathrm{I}$ & 141 & 231 \\
\hline
\end{tabular}

Table 7.5 N concentrations and conductivities of 3 series of Be-doped samples. 

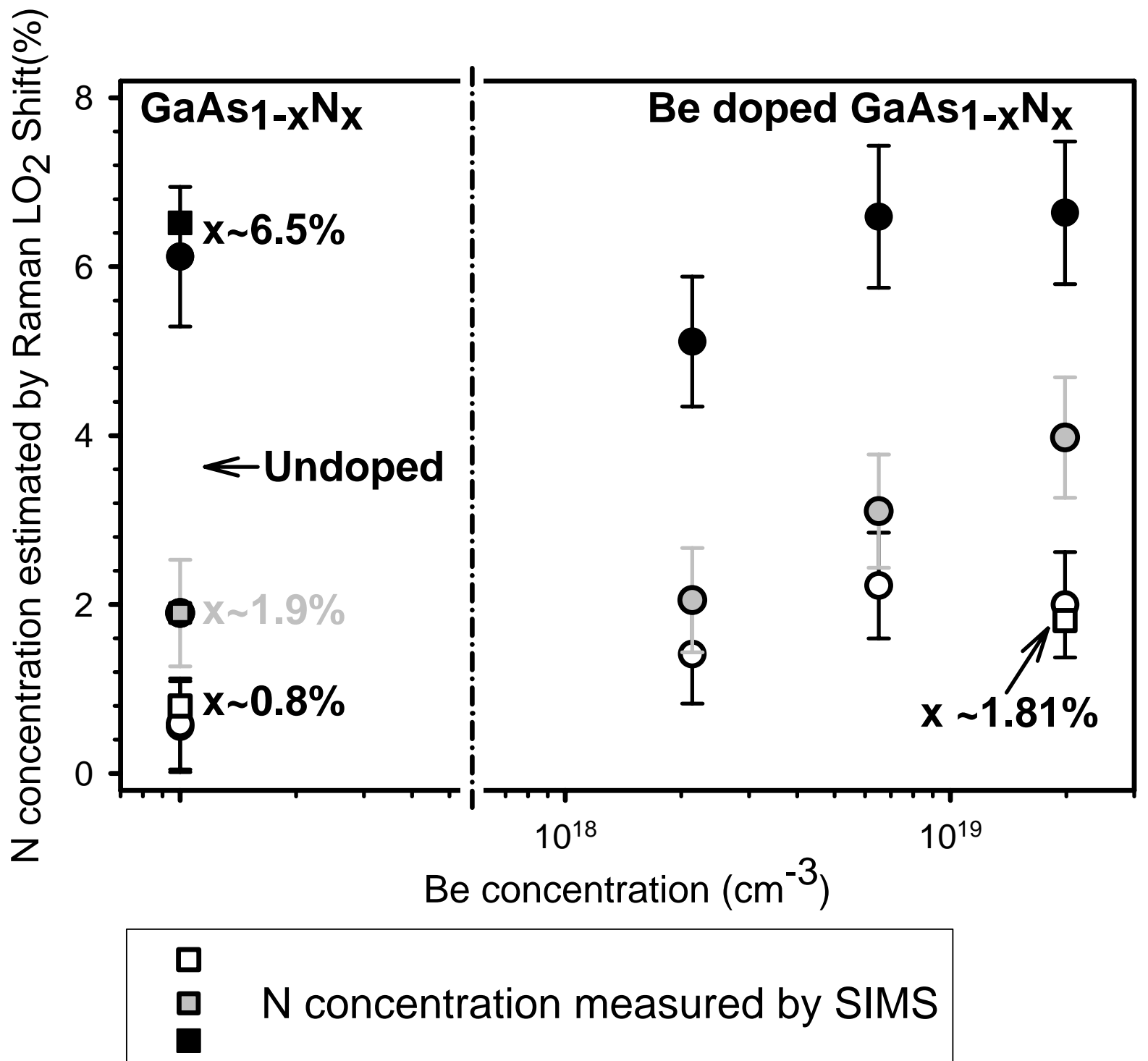

Fig 7.15 $\mathrm{N}$ concentrations of Be-doped $\mathrm{GaAs}_{1-\mathrm{x}} \mathrm{N}_{\mathrm{x}}$ compared to undoped samples determined by Raman measurement. Open circles, gray circles, and dark solid circles correspond to target $\mathrm{x}=0.8 \%, 1.9 \%$ and, $6.5 \%$ respectively. SIMS results are also shown as squares for those samples that had SIMS done on them. 


\subsubsection{Effects on conductivity}

As seen in Fig 7.16, which includes the above mentioned $\mathrm{GaAs}_{1-\mathrm{x}} \mathrm{N}_{\mathrm{x}}$ samples, Be-doped GaAs is highly conductive with carrier concentrations comparable to [Be]. Results from GaInAsN samples grown at NREL that had $[\mathrm{Be}] \sim 3-4 \times 10^{17} \mathrm{~cm}^{-3}$ were also added [Ptak, 2006]. For both sets of samples it can be seen that the carrier concentration drops significantly with increasing $[\mathrm{N}]$. All GaAs${ }_{1-\mathrm{x}} \mathrm{N}_{\mathrm{x}}$ samples with $[\mathrm{N}]$ greater than $3 \%$ grown at WVU were insulating at room temperature, even for the most heavily doped samples. While Matsuura et al. [Matsuura, 2004] suggested that $B e$ tends to have smaller incorporation efficiency in $\operatorname{GaAs}_{1-\mathrm{x}} \mathrm{N}_{\mathrm{x}}$ and GaInAsN, SIMS results obtained in this study indicate that $[\mathrm{Be}]$ is unchanged and thus the $\mathrm{Be}$ is either compensated or that the addition of $\mathrm{N}$ to GaAs significantly increases the activation energy of Be acceptors.

One possibility [Xin, 2000] [Li, 2001a] suggested by reports of Be-doped GaInAsN grown by GS-MBE using cracked $\mathrm{AsH}_{3}$, is that the decreased carrier concentration is due to the incorporation of hydrogen into GaInAsN, and the formation of H-N-Be complexes that passivate the dopants. RTA increased the carrier concentration in these studies presumably due to the depassivation of acceptors as a result of hydrogen dissociation. Another report attributed decreased conductivity to the increase of traps with adding more $\mathrm{N}$ [Fleck, 2001], but it should be noted that they also carried out their growth with GS-MBE. Based on the annealing conditions used by the two groups above, RTA were performed on samples at $750^{\circ} \mathrm{C}$ for 20 seconds under flowing $\mathrm{N}_{2}$, but did not observe a significant change in the carrier concentration. The primary effect of the RTA was to increase the surface roughness somewhat, possibly due to not having samples capped by GaAs. SIMS was performed on selected samples after RTA treatment. A small rise in near-surface $[\mathrm{N}]$ accompanied by a small drop in $[\mathrm{Be}]$ was observed but the bulk of 
the sample was comparable to the unannealed state. Fig 7.17 shows SIMS results of one Bedoped $\mathrm{GaAs}_{1-\mathrm{x}} \mathrm{N}_{\mathrm{x}}$ sample before and after annealing as an example. Our result agrees with Matsuura et al. [Matsuura, 2004], who also observed a lower carrier concentration for Be-doped $\operatorname{GaAs}_{1-\mathrm{x}} \mathrm{N}_{\mathrm{x}}$ and GaInAsN grown by MBE compared to that of GaAs, and did not see any change in the carrier concentration after RTA. Comparing to the apparently fully activated acceptors in GaInAsN grown by GS-MBE [Li, 2001a] after RTA at $750^{\circ} \mathrm{C}$, this suggests that different compensation and/or incorporation mechanisms may be occurring for material grown using solid source vs. gas source MBE.

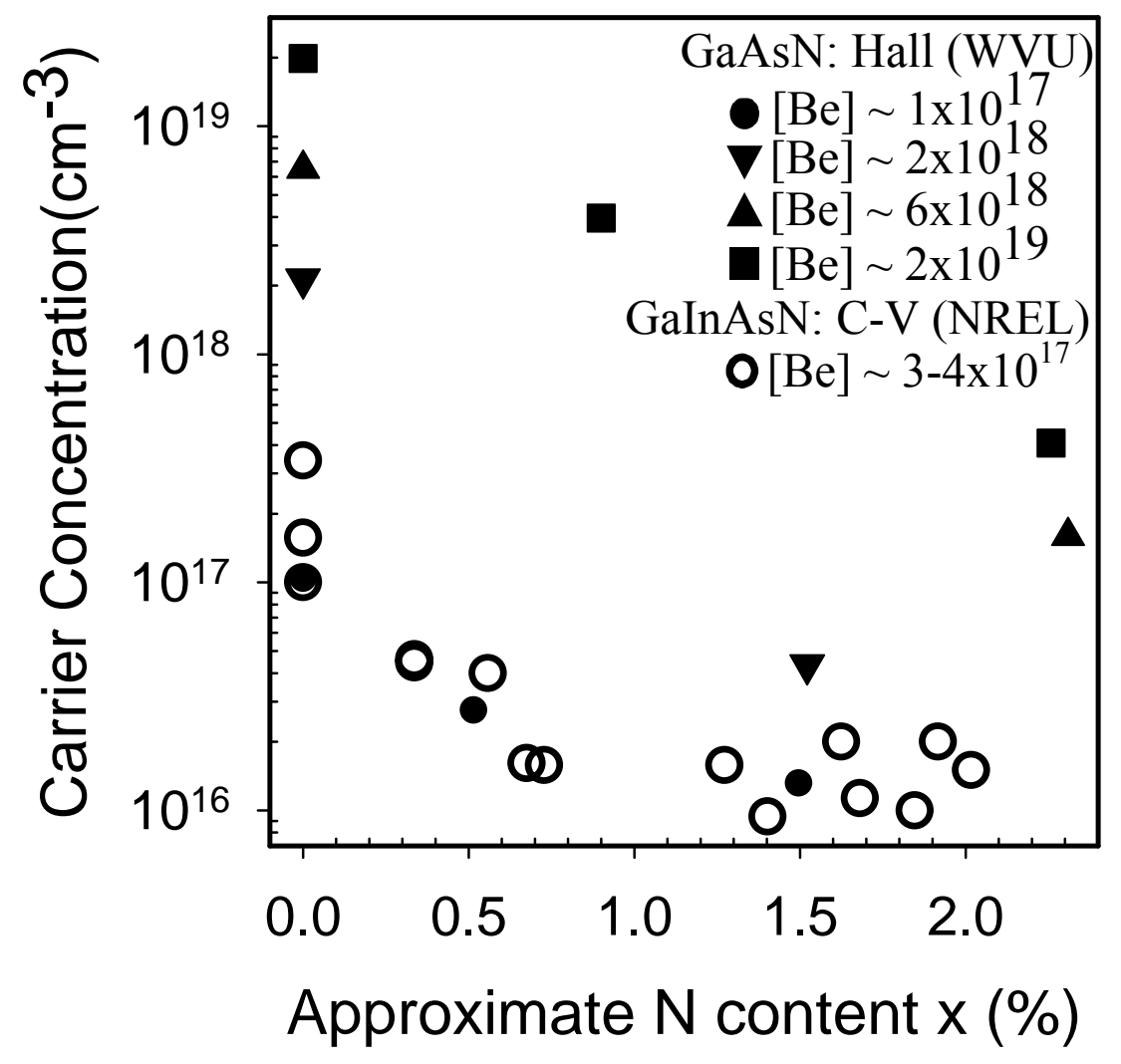

Fig 7.16 Dependence of room temperature carrier concentration on $\mathrm{N}$ content at different Be concentrations. Solid dots are GaAsN measured by Hall and open circles are GaInAsN measured by CV measurements. 


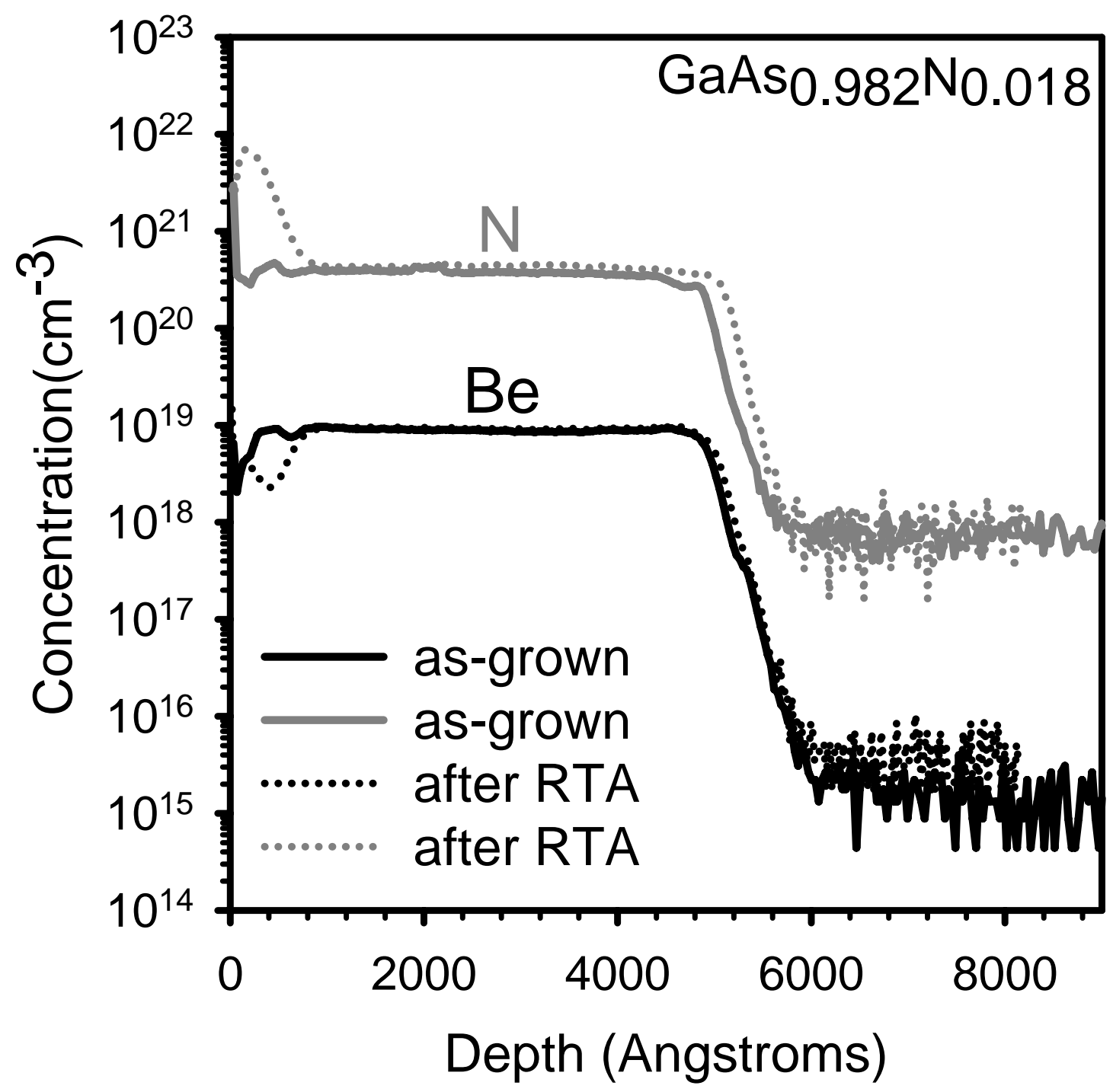

Fig 7.17 RTA was applied on Be-doped $\operatorname{GaAs}_{1-\mathrm{x}} \mathrm{N}_{\mathrm{x}}(\mathrm{x}=1.8 \%)$, and SIMS measurement was done to compare $\mathrm{N}$ and Be concentrations with those of the as-grown sample. Dark lines represent [Be], and gray lines correspond to $[\mathrm{N}]$. 
Compensation may not be the only mechanism present. Fig 7.18 shows the results of temperature dependent Hall measurements on three series of samples. Carrier concentrations and activation energies were sought by fitting to the charge balance equation expressed as [Ptak, 2001]

$$
P(T)=\frac{-P_{v} e^{\frac{-E_{a}}{K T}}}{2 g_{a}}-\frac{N_{d}}{2}+\sqrt{\frac{P_{v}{ }^{2} e^{\frac{-2 E_{a}}{K T}}}{4 g_{a}{ }^{2}}+\frac{N_{d}{ }^{2}}{4}+\frac{P_{v} N_{d} e^{\frac{-E_{a}}{K T}}}{2 g_{a}}+\frac{P_{v}\left(N_{a}-N_{d}\right) e^{\frac{-E_{a}}{K T}}}{g_{a}}}
$$

where $\mathrm{P}(\mathrm{T})$ is the measured carrier concentration depending on temperature, $\mathrm{P}_{v}$ is the near gap density of hole states, $E_{a}$ is the activation energy, $g_{a}$ is the degeneracy of the acceptor, $K$ is the Boltzmann constant, $\mathrm{N}_{\mathrm{d}}$ is the total donor density, and $\mathrm{N}_{\mathrm{a}}$ is the total acceptor density.

Hole concentrations of heavily doped GaAs and $\mathrm{GaAs}_{1-\mathrm{x}} \mathrm{N}_{\mathrm{x}}[\mathrm{N} \sim 0.8 \%]$ (Fig 7.18(a)) are almost constant with changing temperature, indicating degenerate conduction. Increasing $[\mathrm{N}]$ to $1.8 \%$ for the same $[\mathrm{Be}]$, however, led to a significant decrease in hole concentration with an apparent high activation energy. Fig 7.18(b) compares results obtained for $\operatorname{GaAs}_{1-\mathrm{x}} \mathrm{N}_{\mathrm{x}}$ and GaInAsN [Ptak, 2006] for similar [N] at lower [Be]. Again, the $[\mathrm{N}] \sim 0 \%$ case shows essentially full activation while increasing $[\mathrm{N}]$ leads to a significant decrease in activation. The hole concentration could be adequately explained for both GaAs and GaInAsN by assuming uncompensated material using the published Be activation energy of $28 \mathrm{meV}$ [Binggeli, 1991] [Shamirzaev, 2004]. Increasing [N] lead to both a decreased carrier concentration and an apparent increase in activation energy. Although attempts to fit the results to the charge balance equation suggest the activation energy was increased to $60-70 \mathrm{meV}$ for $[\mathrm{N}] \sim 1.5$ to $1.7 \%$ coupled with significant compensation, an adequate fit could not be obtained using a single acceptor. Preliminary studies using variable magnetic fields suggest that two types of acceptors may be present in these samples. 


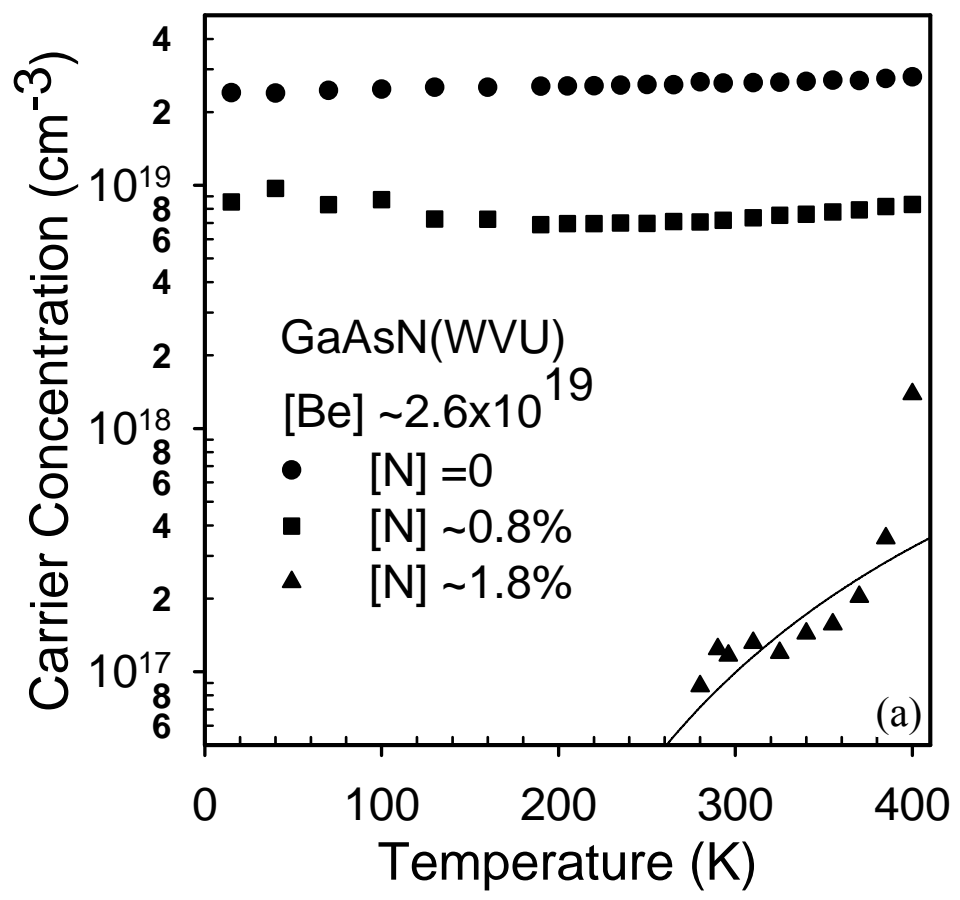

Fig 7.18 Temperature dependent Hall measurements. (a) Heavily doped $\mathrm{GaAs}_{1-\mathrm{x}} \mathrm{N}_{\mathrm{x}}$ with $\mathrm{x} \sim 0,0.8 \%$, and $1.8 \%$. (b) Lower doped GaAsN and GaInAsN with varied $\mathrm{N}$ concentrations.

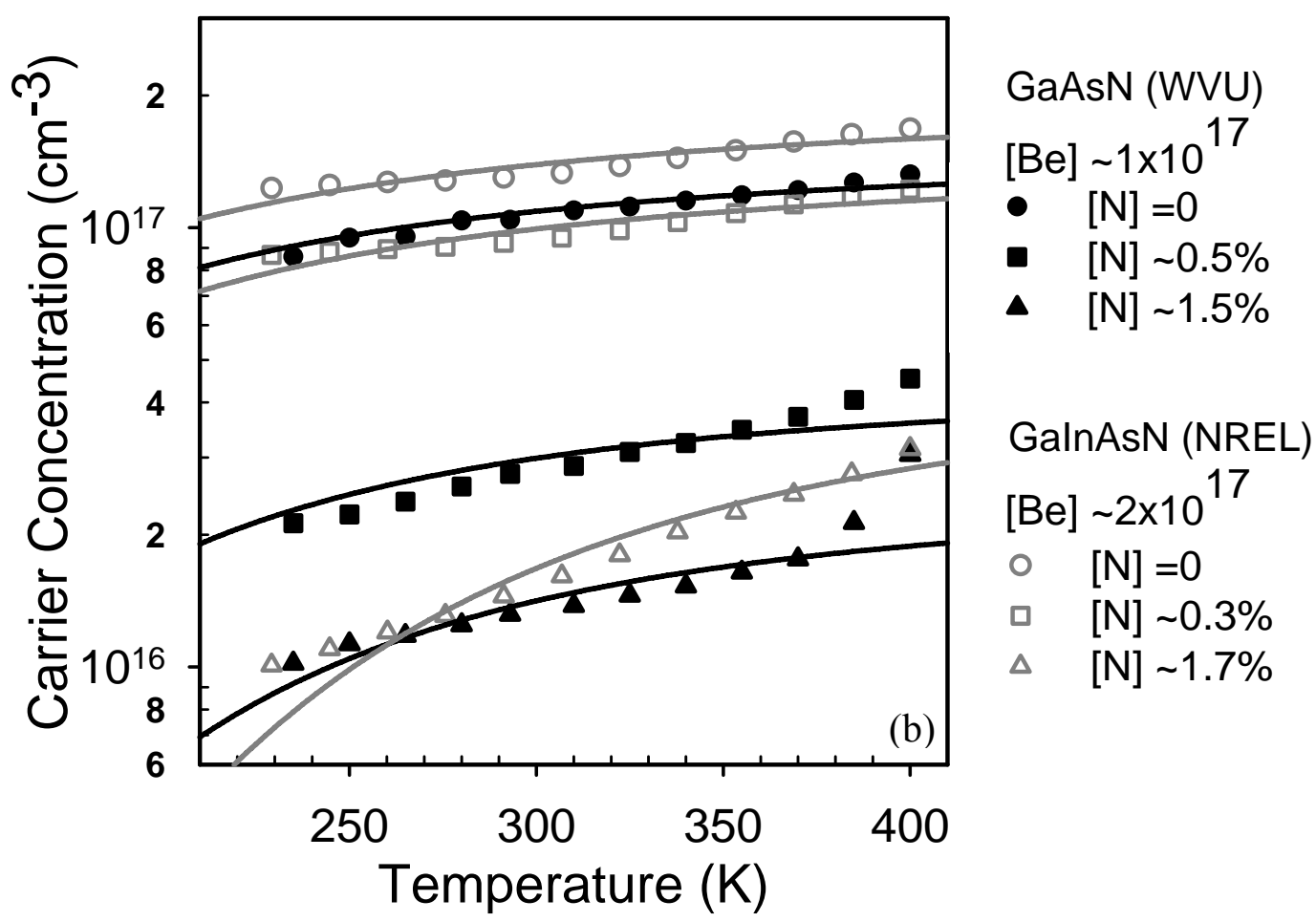


The same temperature dependent Hall measurement results are illustrated below using a $\log$ scale of carrier concentration as the $\mathrm{Y}$ axis and 1000/temperature as the $\mathrm{X}$ axis to allow for the easy determination of $\mathrm{Be}$ activation energies directly from the diagram.

Fig 7.19 Temperature dependent Hall measurements. (a) Heavily doped $\mathrm{GaAs}_{1-\mathrm{x}} \mathrm{N}_{\mathrm{x}}$ with $\mathrm{x} \sim 0,0.8 \%$, and $1.8 \%$. (b) Lower doped GaAsN and GaInAsN with varied $\mathrm{N}$ concentrations.
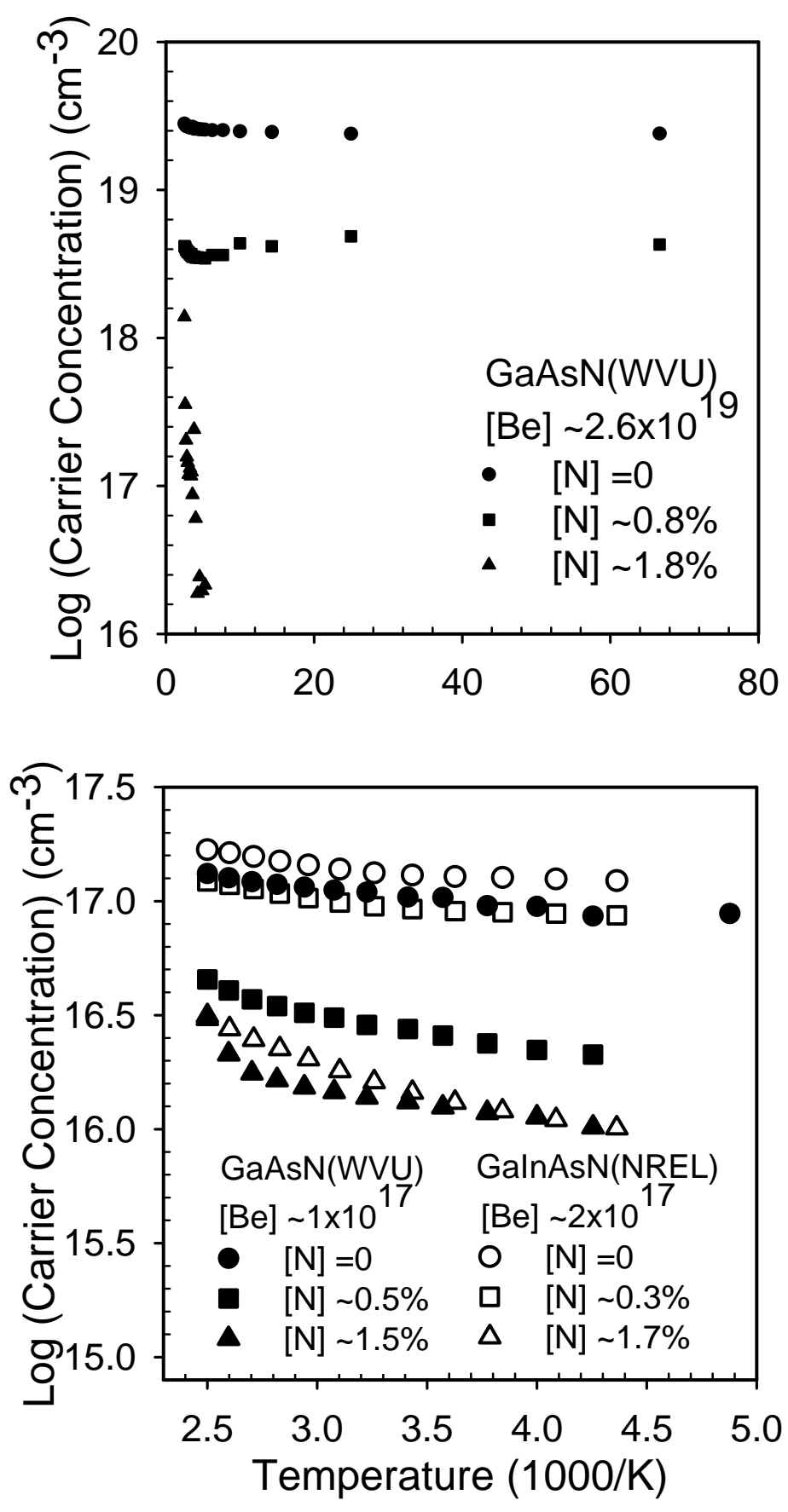


\subsubsection{Photoluminescence of Be-doped samples}

Photoluminescence measurements on a few selected Be-doped samples verified that luminescence is achievable. Fig 7.20 shows PL measured at $77 \mathrm{~K}$ with varied Be doping level of $2 \times 10^{19}, 2 \times 10^{18}$ and $10^{17} \mathrm{~cm}^{-3}$ respectively. PL of substrates which were used for growing these samples were also measured to make sure that PL signals obtained were not originated from the substrate underneath. With increasing the N concentration, the red-shift of PL emission energy is observed as anticipated due to the band gap bowing effect. N concentrations estimated from PL peak emission energy by applying Eq. (6.1) (Section 6.1.4) are in good agreement with [N] obtained by SIMS of Raman measurement for most of these samples as shown in Fig 7.20.

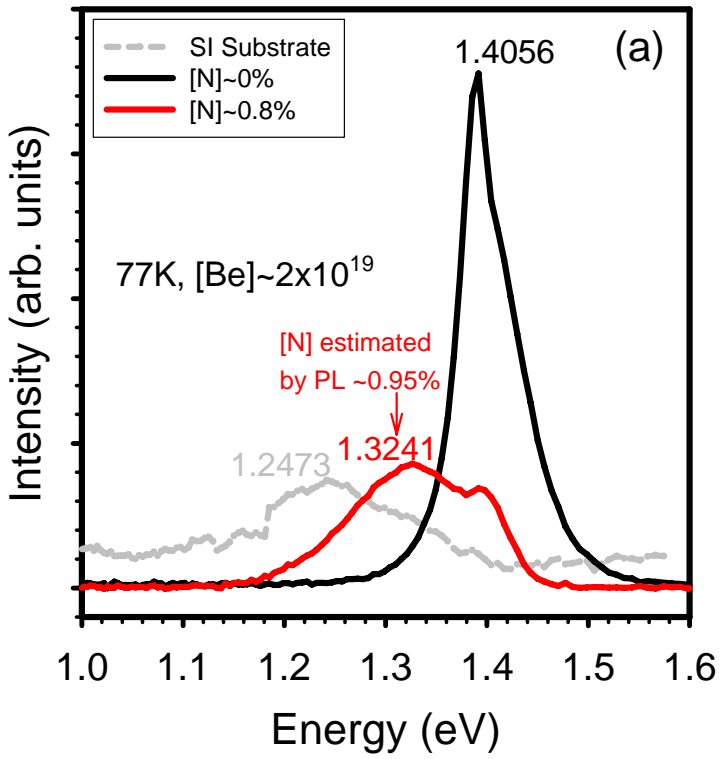

Fig 7.20 Photoluminescence of Be-doped GaAs or GaAsN samples with different carrier concentrations. [N] was also estimated by PL emission energy comparing to that measured by other methods. (a) $\mathrm{Be} \sim 2 \times 10^{19} \mathrm{~cm}^{-3}$; (b) $\mathrm{Be}$ $\sim 2 \times 10^{18} \mathrm{~cm}^{-3}$; (c) $\mathrm{Be} \sim 10^{17} \mathrm{~cm}^{-3}$.
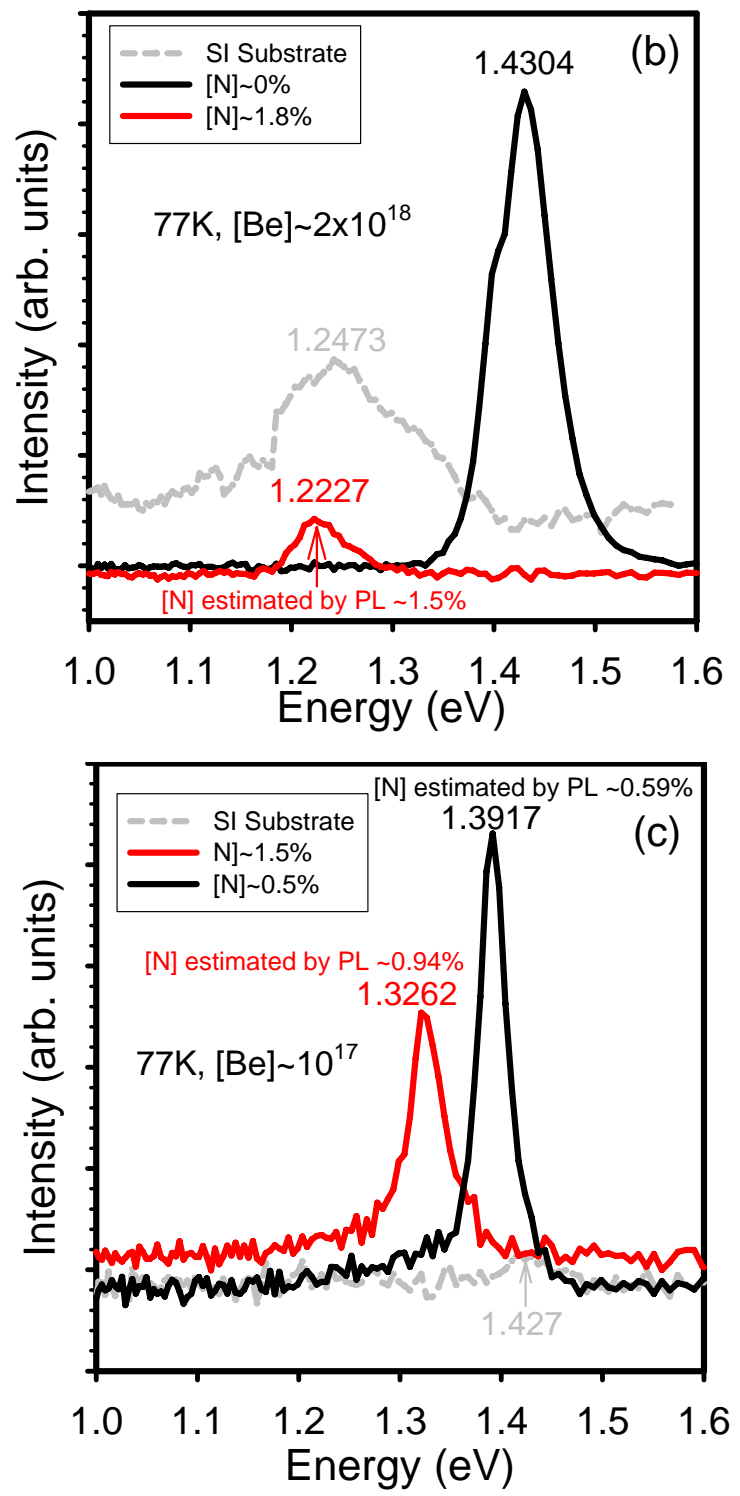


\subsection{Bismuth co-deposition on Be-doped $\operatorname{GaAs}_{1-\mathrm{x}} \mathrm{N}_{\mathrm{x}}$}

In order to assess if the presence of a $\mathrm{Bi}$ flux would improve the activation of $\mathrm{Be}$ in $\operatorname{GaAs}_{1-\mathrm{x}} \mathrm{N}_{\mathrm{x}}$, the Be-doped growths targeting $0.8 \%[\mathrm{~N}]$ were repeated under a $\mathrm{Bi}$ flux while maintaining a bismuth-stabilized 1x3 surface reconstruction. Resistivity measurements indicated the simultaneous presence of both $\mathrm{Bi}$ and $\mathrm{Be}$ resulted in insulating samples. For comparison, $\mathrm{Be}-$ doped GaAs grown under Bi gave a highly conductive film with a carrier concentration close to that of Be-doped GaAs grown under the same Be flux without Bi. This implies that nitrogen plays a key role leading to the decrease in conductivity, an effect perhaps enhanced by the presence of Bi. Table 7.6 is a comparison of Be-doped $\mathrm{GaAs}_{1-\mathrm{x}} \mathrm{N}_{\mathrm{x}}$ samples grown with and without Bi. Raman and AFM were done on the Be-doped, Bi co-deposited $\mathrm{GaAs}_{1-\mathrm{x}} \mathrm{N}_{\mathrm{x}}$ samples. Note that Be-doping of $\mathrm{GaAs}_{1-\mathrm{x}} \mathrm{N}_{\mathrm{x}}$ always led to rougher samples with the roughness increasing with Be concentration. Unlike the undoped case, the presence of a Bi flux did not improve the surface smoothness. Interestingly, in contrast to the Bi-free case, $[\mathrm{N}]$ decreased slightly with increasing $[\mathrm{Be}]$. Although at present the mechanism behind this is not clear, the decrease in $[\mathrm{N}]$ may help to explain the observed trend in RMS roughness. In addition, the excess $\mathrm{N}$ incorporation observed at this $[\mathrm{N}]$ for either $\mathrm{Bi}$ or Be was about the same as with both, indicating this is not an additive phenomenon. 
Table 7.6 Be doped $\mathrm{GaAs}_{1-\mathrm{x}} \mathrm{N}_{\mathrm{x}}$ with and w/o Bi (Target $\mathrm{N}$ concentration is $0.8 \%$ ).

\begin{tabular}{|c|c|c|c|c|c|c|c|c|}
\hline \multirow[t]{3}{*}{$\begin{array}{l}\text { Be concentration } \\
\left(\mathrm{cm}^{3}\right) \text { (estimate) }\end{array}$} & \multicolumn{2}{|c|}{$\begin{array}{c}\text { AFM RMS } \\
\text { roughness }(\mathrm{nm})\end{array}$} & \multicolumn{2}{|c|}{$\begin{array}{c}\text { Raman LO2 Shift } \\
(\mathrm{cm}-1)\end{array}$} & \multirow{2}{*}{\multicolumn{2}{|c|}{$\begin{array}{l}\text { N concentration } \\
\text { estimated by } \\
\text { Raman LO2 (\%) }\end{array}$}} & \multirow{2}{*}{\multicolumn{2}{|c|}{$\begin{array}{l}\text { Conducting or } \\
\text { insulating }\end{array}$}} \\
\hline & & & & & & & & \\
\hline & w/o Bi & With Bi & w/o Bi & With Bi & w/o Bi & $\overline{\text { With Bi }}$ & $\overline{\mathrm{w} / \mathrm{o} \mathrm{Bi}}$ & $\overline{\text { With Bi }}$ \\
\hline $1.984 \times 10^{19}$ & 0.854 & 0.77 & 472.45 & 471.73 & 1.997 & 1.797 & $\mathrm{C}$ & I \\
\hline $6.511 \times 10^{18}$ & 0.509 & 0.866 & 472.55 & 471.91 & 2.225 & 1.891 & $\mathrm{C}$ & $\mathbf{I}$ \\
\hline $2.137 \times 10^{18}$ & 0.447 & 1.199 & 471.0 & 472.71 & 1.413 & 2.312 & $\mathrm{C}$ & $\mathbf{I}$ \\
\hline
\end{tabular}




\subsection{Conclusions}

In summary, this study indicates that bismuth acts as a surfactant for growth of $\mathrm{GaAs}_{1-}$ ${ }_{x} \mathrm{~N}_{\mathrm{x}}$ and extends the range of $[\mathrm{N}]$ obtainable with smooth surfaces up to $6 \%$. Bi may increase $[\mathrm{N}]$ for low concentrations, but this effect is not observed for higher $[\mathrm{N}]$. A rise in $[\mathrm{N}]$ with heavy Be-doping was also observed for all samples, up to the relatively large $\mathrm{N}$ content of $\sim 6 \%$. The efficacy of Be-doping to produce p-type carrier concentrations decreased rapidly in both $\mathrm{GaAs}_{1}$ ${ }_{x} \mathrm{~N}_{\mathrm{x}}$ and GaInAsN with increasing [N]. Compensation is a likely possibility, but Hall effect measurements also suggest that the Be activation energy increases with increasing $[\mathrm{N}]$. Comparing Be-doped, Bi co-deposited GaAs and $\mathrm{GaAs}_{1-\mathrm{x}} \mathrm{N}_{\mathrm{x}}$ suggests that $\mathrm{N}$ (or $\mathrm{N}$ related complexes) is an important factor affecting the conductivity. Bi does not reduce the surface roughness of Be-doped samples, and actually may promote the formation of compensating complexes. 


\section{Chapter 8}

\section{Conclusions and Proposed Future Studies}

Results related to growth, annealing, surfactant effect and doping of $\mathrm{GaAs}_{1-\mathrm{x}} \mathrm{N}_{\mathrm{x}}$ were discussed in this work. Setup issues of the MBE system were also described.

The system was modified to accommodate growths of dilute nitrides. The modifications include a re-designed manifold, new cryo-pump, RHEED gun, mass spectrometer, plasma discharge tube and leak valve, stepper motor, beam flux monitor, water cooling and power supply, etc.

Two methods were used to calibrate the substrate. Combining results from pyrometer measurements and observing surface reconstruction while changing the substrate temperature, the relationship between the real and readout temperature was obtained.

The growth rate was also determined: Measuring the thickness of the film grown on a $\mathrm{SiO}_{2}$ patterned substrate gave a rough estimate of the growth rate. The growth rate could also be more easily and accurately determined through the RHEED oscillation, since each period corresponds to one monolayer growth.

The surface phase diagram was also ascertained for this MBE system. Growth temperatures and V/III BEP ratios associated with 2x4 RHEED patterns were found for normally used growth rates. Boundaries where surface reconstruction occurs were outlined.

Quantitative control of the N content was successfully established. Factors affecting N incorporation and their corresponding effects were investigated. $\mathrm{N}$ flow rate, power of the RFplasma, and growth rate were all found to have a large influence on $\mathrm{N}$ incorporation. 
A net red shift of PL emission peak intensity instead of the typical blue shift was observed for annealed $\mathrm{GaAs}_{1-\mathrm{x}} \mathrm{N}_{\mathrm{x}}$. This was accompanied by an increase of $\mathrm{N}$ content, suggesting As outdiffusion upon annealing, which has not been previously observed or reported.

Raman was found to be very effective to determine the $\mathrm{N}$ concentration by measuring the frequency shift of GaN-like peak. An empirical formula was retrieved from the comparison of $[\mathrm{N}]$ obtained by SIMS and Raman measurements, indicating a relationship between the Raman shift and $\mathrm{N}$ content. Relatively high $\mathrm{N}$ concentrations, up to $6.5 \%$, were achieved and fit the above mentioned as well.

The study of Bi assisted growths suggests the use of Bi largely extends the useable growth conditions by producing smoother surfaces to a significantly higher group $\mathrm{V}$ fractional $\mathrm{N}$ content than without Bi. As a surfactant, Bi smoothes the surface for higher $[\mathrm{N}], 1.9 \%$ and $6.5 \%$, but for lower $[\mathrm{N}], 0.8 \%$, the effect is not as obvious. Regarding to the $\mathrm{N}$ incorporation, its facilitation on $\mathrm{N}$ incorporation is only limited to low [N].

Be-doping effects were investigated. Hall measurement indicates the conductivity of Bedoped $\operatorname{GaAs}_{1-\mathrm{x}} \mathrm{N}_{\mathrm{x}}$ decreases with increasing $\mathrm{N}$ content. Possible causes of causing this phenomenon were discussed. Compensation might be responsible for this, but the temperature dependent Hall measurement illustrates that the alternation of activation energy may be another reason. SIMS and Raman results indicate that Be increases the $\mathrm{N}$ incorporation, which may be explained by the high Be-N bond strength that inhibits the loss of $\mathrm{N}$ from the growth surface.

The presence of both $\mathrm{Bi}$ and $\mathrm{Be}$ in GaAs led to highly conductive samples, while in comparison, their existence in $\operatorname{GaAs}_{1-\mathrm{x}} \mathrm{N}_{\mathrm{x}}$ resulted in insulating samples even for very low $[\mathrm{N}]$. N, therefore, may play a very important role imposing a large influence on the sample's conductivity. 
As a very promising material used primarily for long wavelength applications, future work needs to be done to further increase the $\mathrm{N}$ incorporation of $\mathrm{GaAs}_{1-\mathrm{x}} \mathrm{N}_{\mathrm{x}}$ while maintaining good surface morphology and optical properties. Doping studies may concentrate on overcoming the negative effect of $\mathrm{N}$ on material's conductivity. 


\section{References}

[Shockley, 1950] W. Shockley, in Electrons and Holes in Semiconductors, by Litton Educational Publishing Co., Inc., 1950.

[Fan, 2004] W. J. Fan, S. F. Yoon, W. K. Cheah, W. K. Loke, T. K. Ng, S. Z. Wang, R. Liu, and A. Wee, J. Cryst. Growth 268, 470 (2004).

[Serries, 2002] D. Serries, T. Geppert, P. Ganser, M. Maier, K. Kohler, N. herres, J. wagner, Appl. Phys. Lett. 80, 2448-2450 (2002).

[Wei, 1996] S. H. Wei, and A. Zunger, Phys. Rev. Lett. 76, 664 (1996).

[Bellaiche, 1996] L. Bellaiche, S. H. Wei, and A. Zunger, Phys. Rev. B. 54, 17568 (1996).

[Bi, 1997] W. G. Bi, and C. W. Tu, Appl. Phys. Lett. 70, 1608 (1997).

[Uesugi, 1999] Katsuhiro Uesugi, Nobuki Morooka, and Ikuo Suemune, Appl. Phys. Lett. 74, 1254 (1999).

[Ioffe, 2001] http://www.ioffe.rssi.ru/SVA/NSM/Semicond/GaAs/electric.html, Ioffe PhysicoTechnical Institute, copyright 1998-2001.

[Dispersion, 2005] http://www.fiber-optics.info/articles/dispersion.htm, 2005.

[Schnelder, 2007] K. S. Schnelder, http://www.telebyteusa.com/foprimer/foch2.htm, 2007.

[Cai, 2007] Introduction to InGaAsP Semiconductor Materials, ykuo.ncue.edu.tw/report/011Introduction\%20to\%20InGaAsP\%20Semiconductor\%20Materials.doc, (2007).

[Walukiewicz] W. Walukiewicz, New Semiconductors for High-Efficiency Solar Cells, Materials Sciences Division, Lawrence Berkeley National Laboratory, Berkeley, CA 94720

[Waferworld, 2007] www.waferworld.com, 2007.

[Kinsey, 2000a] G. S. Kinsey, D. W. Gotthold, A. L. Holmes, Jr., and J. C. Campbell, Appl. Phys. Lett. 77, 1543 (2000). 
[Kinsey, 2000b] G. S. Kinsey, D. W. Gotthold, A. L. Holmes, Jr., B. G. Steetman, and J. C. Campbell, Appl. Phys. Lett. 76, 2824 (2000).

[Chang, 2005] Y. A. Chang, H. C. Kuo, C. Y. Lu, Y. K. Kuo, and S. C. Wang, Semicond. Sci. Technol. 20, 601 (2005).

[Dutta, 1982] N. K. Dutta, J. Appl. Phys. 53, 7211 (1982).

[Miyamoto] T. Miyamoto, D. Schlenker, T. Kageyama, S. Makino, Y. Ikenaga, M. Kawaguchi, T. Kondo, E. Gouardes, Z. Chen, F. Koyama, and K. Iga, Excellent temperature haracteristics of GaIn(N)As lasers on GaAs, Quantum Nanoelectronics Research Center (QNERC), Tokyo Institute of Technology, Japan.

[Gotthold, 2001] D. Gotthold, S. Govindaraju, J. Reifsnider, G. Kinsey, J. Campbell, and A. Holmes, Jr. J. Vac. Sci. Technol. B 19, 1400 (2001).

[Kitatani, 1999] T. Kitatani, M. Kondow, T. Kikawa, Y. Yazawa, M. Okai, and K. Uomi, Jpn. J. Appl. Phys. 38, 5003 (1999).

[Shan, 1999] W. Shan, W. Walukiewicz, J. W. Ager III, E. E. Haller, J. F. Geisz, D. J. Friedman, J. M. Olson, and S. R. Kurtz, J. Appl. Phys. 86, 2349 (1999).

[Li, 2002] W. Li, J. Konttinen, T. Jouhti, C. S. Peng, E.-M. Pavelescu, M. Suominen, and M. Pessa, Advanced Nanomaterials and Nanodevices (IUMRS-ICEM 2002, Xi'an, China, 10-14 June 2002), p. 251 (2002).

[Postigo, 2002] P. A. Postigo, D. Golmayo, H. Gomez, D. Rodriguez, and M. L. Dotor, Jpn. J. Appl. Phys. 41, L565 (2002).

[Spruytte, 2002] S. Spruytte, M. C. Larson, J. S. Harris, and C. Coldren, United States Patent Application Publication, Pub No.: US 2002/0075920 A1, Pub Date: Jun. 20. 2002.

[Kondow, 2003] M. Kondow, and T. Kitatani, IEE Proc. Optoelectron. 150, 9 (2003). 
[Das] Mukunda B. Das, Optoelectronic Detectors and Receivers: Speed and Sensitivity Limits, Department of Electrical Engineering, and Electronic Materials and Processing Research Laboratory, The Pennsylvania State University, University Park, PA 16802.

[Luna, 2003] E. Luna, M. Hopkinson, J. M. Ulloa, A. Guzman, and E. Munoz, Appl. Phys. Lett. 83, 3111 (2003).

[Chang, 2000] P.C. Chang, A. G. Baca, N. Y. Li, M. Xie, H.Q. Hou, E. Armour, Appl. Phys. Lett. 76, 2262 (2000).

[Welser, 2001] R. E. Welser, P. M. DeLuca, C. R. Lutz, B. E. Landini, M. Chaplin, K. S. Stevens, T. L. Wolfsdorf-Brenner, R. J. Welty, P. M. Asbeck, A. Ikhlassi, J. C. Li, and R. L. Pierson, GaAs MANTECH, Inc. The International Conference on Compound Semiconductor anufacturing Technology 2001.

[Binggeli, 1991] N. Binggeli, and A. Baldereschi, Phys. Rev. B 43, 14734 (1991).

[Kressel, 1969] H. Kressel, and F. Z. Hawrylo, J. Appl. Phys. 41, 1865 (1969).

[Liu, 1992] B. D. Liu, T. H. Shieh, M. Y. Wu, T. C. Chang, S. C. Lee, and H. H. Lin, J. Appl. Phys. 72, 2767 (1992).

[Wiley, 1975] J. D. Wiley, R. K. Willardson, and A. C. Beer, Semiconductor and Semimetals, eds., Academic Press, N.Y., vol. 10, 1975, p. 91.

[Li, 2001] W. Li, M. Pessa, J. Toivonen, and H. Lipsanen, Phys. Rev. B 64, 113308 (2001).

[Matsuura, 2004] T. Matsuura, T. Miyamoto, S. Makino, M. Ohta, Y. Matsui, and F. Koyama, Jpn. J. Appl. Phys. 43, L433 (2004).

[Neugebauer, 1995] J. Neugebauer and C. G. Van de Walle, Phys. Rev. B 51, 10568 (1995).

[Tite, 2004] T. Tite, A. Chafi, J.P. Laurenti, O. Pages, D. Bormann and E. Tournie, IEE Proc.Optoelectron., 151, No. 5, 338 (2004). 
[Buyanova, 2000] I. A. Buyanova, G. Pozina, P. N. Hai, N. Q. Thinh, J. P. Bergman, W. M. Chen, H. P. Xin, and C. W. Tu, Appl. Phys. Lett. 77, 2325 (2000).

[Sun, 2005] H. D. Sun, S. Calvez, M. D. Dawson, J. A. Gupta, G. I. Sproule, X. Wu, and Z. R. Wasilewski, Appl. Phys. Lett. 87, 181908 (2005).

[Morooka, 1999] N. Morooka, K. Uesugi, and Ikuo Suemune, Jpn. J. Appl. Phys. 38, L1309 (1999).

[Massies, 1992] J. Massies, N. Grandjean, and V. H. Etgens, Appl. Phys. Lett. 61, 99 (1992).

[Pillai, 2000] M. R. Pillai, S. S. Kim, S. T. Ho, and S. A. Barnett, J. Vac. Sci. Technol. B 18, $1232(2000)$.

[Sakamoto, 1993] K. Sakamoto, K. Kyoya, K. Miki, H. Matsuhata, and T. Sakamoto, Jpn. J. Appl. Phys. 32, L204 (1993).

[Young, 2005] E. C. Young, S. Tixier, and T. Tiedje, J. Crystal Growth 279, 316 (2005).

[Xin, 2000] H. P. Xin, C. W. Tu, and M. Geva, J. Vac. Sci. Technol. B 18, 1476 (2000).

[Fleck, 2001] A. Fleck, B. J. Robinson, and D. A. Thompson, Appl. Phys. Lett. 78, 1694 (2001).

[Spruytte, 2001] S. G. Spruytte, C. W. Coldren, J. S. Harris, W. Wampler, P. Krispin, K. Ploog, and M. C. Larson, J. Appl. Phys. 89, 4401 (2001).

[Li, 2001b] W. Li, M. Pessa, T. Ahlgren, and J. Decker, Appl. Phys. Lett. 79, 1094 (2001).

[Loke, 2002] W. K. Loke, S. F. Yoon, S. Z. Wang, T. K. Ng, and W. J. Fan, J. Appl. Phys. 91, 4900 (2002).

[Veeco, 2005] 2005 Product Guide, MBE Componets, Veeco Instruments Inc. PP104-107.

[Fernández, 1992] R. Fernández, J. Cryst. Growth 116, 98 (1992). 
[Efunda, 2006] www.efunda.com, 2006.

[Spectrodyne, 2006] http://www.spectrodyne.com/DFP2000/tutorial.asp, Spectrodyne, Inc., 2006.

[Opyro, 2006] http://www.temperatures.com/opyro.html, 2006.

[Merchant, 2006] J. Merchant, "Infrared Temperature Measurement Theory and Application" from http://www.omega.com/pdf/temperature/Z/pdf/z063-066.pdf, Mikron Instrument Company, Inc., 2006.

[Omega] "Omegascope Infrared Pyrometer OS-2100 and OS-3000 Series Operator's Manual", Omega Engineering, Inc.

[Omega, 1989] Omegascope Infrared Pyrometer OS-2100 and OS-3000 Series Operator's Manual, Omega Engineering, Inc., 1989.

[Derby, 1986] J.J. Derby, and R.A. Brown, J. Crystal Growth 74, 605 (1986).

[Sabhapathy, 1989] P. Sabhapathy, and M.E. Salcudean, J. Crystal Growth 97, 125 (1989).

[Dupret, 1990] F. Dupret, P. Nicodeme, Y. Ryckmans, P. Wouters, and M.J. Crochet, Int. J. Heat Mass Transfer 33, 1849 (1990).

[SpringThorpe, 1987] A. J. SpringThorpe, S. J. Ingrey, B. Emmerstorfer, and P. Mandeville, Appl. Phys. Lett. 50, 77 (1987).

[Rumberg, 1995] J. Rumberg, J. T. Zettler, K. Stahrenberg, K. Ploska, W. Richter, L. Daweritz, P. Schutzendube, M. Wassermeiber, Surf. Sci. 337, 103 (1995).

[LaBella, 2001] V. P. LaBella, D. W. Bullock, C. Emery, Z. Ding, and P. M. Thibado, Appl. Phys. Lett. 79, 3065 (2001).

[Ohring, 1992] M. Ohring, The Material Science of Thin Films, Academic Press, New York, 1992. 
[Neave, 1981] J. H. Neave, B. A. Joyce, P. J. Dobson, and N. Norton, Appl. Phys. A31, 1 (1981).

[Joyce, 1988] B. A. Joyce, J. Zhang, J. H. Neave, and P. J. Dobson, Appl. Phys. A45, 255 (1988).

[Farrow, 1995a] R. F. C. Farrow, in Molecualr Beam Epitaxy Applications to Key materials, Noyes Publications, Park Ridge, New Jersey, 1995, pp. 139.

[Reason, 2004] M. Reason, H. A. McKay, W. Ye, S. Hanson, R. S. Goldman, and V. Rotberg, Appl. Phys. Lett. 85, 1692 (2004).

[Li, 2000] L. H. Li, Z. Pan, W. Zhang, Y. W. Lin, Z. Q. Zhou, and R. H. Wu, J. Appl. Phys. 87, 245 (2000).

[Zhang, 2003] X. Q. Zhang, S. Ganapathy, I. Suemune, H. Kumano and K. Uesugi, Appl. Phys. Lett. 83, 4524 (2003).

[Gannapathy, 2003] S. Gannapathy, X. Q. Zhang, I. Suemune, K. Uesugi, H. Kumano, B. J. Kim and T. Y. Seong, Jpn. J. of Appl. Phys., Part 1 42, 5598 (2003).

[Kouklin, 2003] N. Kouklin, H. Chik, J. Liang, M. Tzolov, J. M. Xu, J. B. Heroux, and W. I. Wang, J. Phys. D: Appl. Phys. 36, 2634 (2003).

[Kondow, 1994] M. Kondow, K. Uomi, K. Hosomi, and T. Mozume, Jpn. J. Appl. Phys. 33, L1056 (1994).

[Mintairov, 1997] A. M. Mintairov, P. A. Blagnov, V. G. Melehin, N. N. Faleev, J. L. Merz, Y. Qiu, S. A. Nikishin, and H. Temkin, Phys. Rev. B 56, 15836 (1997).

[Toivonen, 2000] J. Toivonen, T. Hakkarainen, M. Sopanen and H. Lipsanen, Journal of Crystal Growth 221, 456-460 (2000).

[Gwo, 2001] S. Gwo, S. Y. Huang and T.R. Yang, Phys. Rev. B 64, 113312 (2001).

[Frank, 1949] F.C. Frank, and J.H. Van der Merwe, Proc. R. Soc. London, Ser. A 198, 205 (1949). 
[Volmer, 1926] M. Volmer, and A. Weber, Z. Phys. Chem. (Munich) 119, 277 (1926).

[Stranski, 1938] I. N. Stranski, and L. Krastanow, Sitzungsber. Akad. Wiss. Wien, Math.Naturwiss. K1., Abt. 2B 146, 797 (1938).

[Grandjean, 1992] N. Grandjean, J. Massies, and V. H. Etgens, Phys. Rev. Lett. 69, 796 (1992).

[Snyder, 1993] C. W. Snyder, and B. G. Orr, Phys. Rev. Lett. 70, 1030 (1993).

[Yuen, 2006] H. B. Yuen, S. R. Bank, H. Bae, M. A. Wistey, and J. S. Harris, Jr., J. Appl. Phys. 99, 093504 (2006).

[Tixier, 2003] S. Tixier, M. Adamcyk, E. C. Young, J. H. Schmid, and T. Tiedje, J. Cryst. Growth 251, 449 (2003).

[Shurtleff, 2000] J. K. Shurtleff, R. T. Lee, and G. B. Stringfellow, 2000 IEEE International Symposium on Compound Semiconductors. Proceedings of the IEEE Twenty-Seventh International Symposium on Compound Semiconductors (Cat. No.00TH8498), 197 (2000).

[Fujita, 1990] K. Fujita, S. Fukatsu, H. Yaguchi, T. Igarashi, Y. Shiraki, and R. Ito, Jpn. J. Appl. Phys. 29, L1981 (1990).

[Trumbore, 1960] F. A. Trumbore, Bell Syst. Tech. J. 39, 205 (1960).

[Tixier, 2003] S. Tixier, M. Adamcyk, E. C. Young, J. H. Schmid, and T. Tiedje, J. Cryst. Growth 251, 449 (2003).

[Cooke, 2006] D. G. Cooke, F. A. Hegmann, E. C. Young, and T. Tiedje, Appl. Phys. Lett. 89, 122103 (2006).

[Farrow, 1995b] R. F. C. Farrow, in Molecualr Beam Epitaxy Applications to Key materials, Noyes Publications, Park Ridge, New Jersey, 1995, pp. 187.

[Xie, 2004] S. Y. Xie, S. F. Yoon, S. Z. Wang, Z. Z. Sun, P. Chen, and S. J. Chua, J. Cryst. Growth 260, 366 (2004). 
[Farrow, 1995c] R. F. C. Farrow, in Molecualr Beam Epitaxy Applications to Key materials, Noyes Publications, Park Ridge, New Jersey, 1995, pp. 188.

[Prokofyeva, 1998] T. Prokofyeva, T. Sauncy, M. Seon, M. Holtz, Y. Qiu, S. Nikishin, and H. Temkin, Appl. Phys. Lett. 73, 1409 (1998).

[Wagner, 2000] J. Wagner, K. Kohler, P. Ganser, and N. Herres, Appl. Phys. Lett. 77, 3592 (2000).

[Yu, 2005] A. Yu. Egorov, V. K. Kalevich, M. M. Afanasiev,a_A. Yu. Shiryaev, V. M. Ustinov, M. Ikezawa, and Y. Masumoto, J. Appl. Phys. 98, 013539 (2005).

[Bisognin, 2004] G. Bisognin, D. De Salvador, C. Mattevi, M. Berti, A. V. Drigo, G. Ciatto, L. Grenouillet, P. Duvaut, P. Gilet, and H. Mariette, J. Appl. Phys. 95, 48 (2004).

[VanMil, 2005] B. L. VanMil, R. P. Tompkins, K. Feng, C. H. Swartz, N. C. Giles, and T.H. Myers, J. Vac. Sci. Technol. B 23, 1814 (2005).

[Ptak, 2006] A. J. Ptak (NREL), private communications.

[Binggeli, 1991] N. Binggeli, and A. Baldereschi, Phys. Rev. B 43, 14734 (1991).

[Shamirzaev, 2004] T. S. Shamirzaev, K. S. Zhuravlev, J. Bak-Misiuk, A. Misiuk, J. Z. Domagala, and J. Adamczewska, Semiconductors 38, 277 (2004).

[Ptak, 2001] A. J. Ptak, 'Growth Kinetics and Doping of Gallium Nitride Grown by rf-Plasma Assisted Molecular Beam Epitaxy', dissertation submitted to the Eberly College of Arts and Sciences at West Virginia University, 2001. 